\title{
Religiöse
}

\section{Strategien der}

\author{
"machbaren"
}

\section{Gesellschaft}

Verwaltete Religion

und islamistische Utopie

in der Türkei 
Levent Tezcan

Religiöse Strategien der »machbaren « Gesellschaft 
Levent Tezcan (Dr. rer. soc.), geb. 1961 in der türkischen Kleinstadt Havza, hat Politikwissenschaft in Ankara und Soziologie in Bremen studiert. Er ist im Institut für interdisziplinäre Konflikt- und Gewaltforschung an der Universität Bielefeld tätig. 
Levent Tezcan

\section{Religiöse Strategien der »machbaren « Gesellschaft}

Verwaltete Religion und islamistische Utopie in der Türkei

[transcript $]$ 


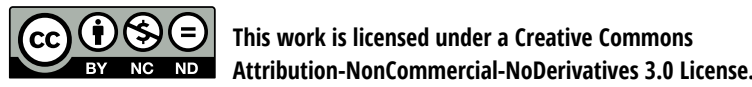

\section{Bibliografische Information Der Deutschen Bibliothek}

Die Deutsche Bibliothek verzeichnet diese Publikation in der Deutschen Nationalbibliografie; detaillierte bibliografische Angaben sind im Internet über http://dnb.ddb.de abrufbar.

(C) 2003 transcript Verlag, Bielefeld Lektorat \& Satz: Levent Tezcan Umschlaglayout: Kordula Röckenhaus, Bielefeld Umschlagfoto: Archiv transcript Verlag Druck: Majuskel Medienproduktion GmbH, Wetzlar ISBN 3-89942-106-X 


\section{INHAL T}

$\begin{array}{ll}\text { Vorwort } & 7\end{array}$

Einleitung $\quad 9$

I. Die verwaltete Religion des laizistischen Staates 21

1. Die ,säkularen“ Quellen der Moderne in der muslimischen Welt

2. Der makropolitische Kontext: Politische Rationalität und die moderne Staatlichkeit

2.1 Neue Akteure der Geschichte: Staat und Gesellschaft $\quad 34$

2.2 Die Staatsraison $\quad 36$

3. Transformationen an der Staatlichkeit 41

3.1 Ideen: Vom Mülk des Sultans zum Staat 41

3.2 Praktiken 53

3.3 Kontinuität und Bruch an der türkischen Staatlichkeit $\quad 55$

4. Türkische Laizität und das Amt für religiöse Angelegenheiten 61

4.1 Über die Geschichte des Amtes 62

4.2 Formen der Kooptation der Religion in den Staatsapparat $\quad 63$

4.2.1 Bestimmung der öffentlich zulässigen Religiosität 64

4.2.2 Gesellschaftspolitischer Auftrag des Amtes 71

4.2.3 Verwaltung der Gebetsanstalten $\quad 81$

4.3 Der Streit zwischen göttlichem und profanem Recht $\quad 88$

$\begin{array}{ll}4.4 \text { Religionspolitik und die Aleviten } & 94\end{array}$

4.4.1 Alevitische Selbstbeschreibungen $\quad 95$

4.4.2 Tücken der partikularistischen Anerkennung $\quad 98$

5. Resümee 1

II. Islam als Weltanschauung der ummatistischen Utopie 107

1. Ursprungsvisionen im Islam 109

1.1 Eschatologie ohne Roß und Reiter 111

1.2 Islamische Visionen von Rückkehr 113

2. Der Neomodernismus von Fazlur Rahman:

Die Suche nach islamischen Werten 
2.1 Die Einheit des Korans und die islamische

Weltanschauung

2.2 Realität als kritische Prüfungsinstanz 122

2.3 Werte, Diesseitigkeit und die Gesellschaftstechnik 123

3. Der Diskurs und sein zeitgeschichtlicher Kontext 128

3.1 Verschiebungen in der Trägerschaft des Islamismus $\quad 130$

3.2 Verschiebungen im globalen Feld 132

3.3 Die Konfliktlinien 137

4. Aspekte der islamistischen Modernitätskritik 139

4.1 Die Moderne als „totale Krise“

4.2 Kritik an der Fortschrittszeit 146

4.3 Modus der Anerkennung des Anderen: Benennen oder

Definieren?

4.4 Eine monotheistische Lektüre der Zeit 154

5. Das prophetische Medina im Gegensatz zum ,totalitären“ Nationalstaat der Moderne

5.1 Die Umma: Von der Gemeinschaft der Muslime zur

Gemeinschaft schlechthin

5.1.1 Die Prinzipien der Gemeinschaft 158

5.1.2 Die Umdeutung der Umma und ihre Friktionen $\quad 163$

5.2 Der Stachel des historischen Ereignisses, die Risse der

Konstruktion

5.2.1 Der umstrittene Status der Juden 165

5.2.2 Der intellektuelle Zwang zur Konsistenz 169

5.2.3 Wiederkehr der verdrängten Machtfrage:

Die Umma als muslimische Herrschaft

175

6. Übersetzungen der westlichen Konzepte

6.1 Der ,wahre Pluralismus“ des Islam,

die ,Zivilgesellschaft“ der apokalyptischen Reiter

6.2 Die islamistische Konzeption des „öffentlichen Glücks“ 187

7. Resümee 2

\section{Schlußfolgerungen und Ausblick}

1. Zusammenfassung der Ergebnisse

2. Ausblick: Kultur des Geständnisses, Kultur des Konventionalismus 


\section{VORWORT}

Dieses Buch ist eine leicht veränderte Version der Dissertation, die ich an der soziologischen Fakultät der Universität Bielefeld eingereicht habe. Die tragende Idee, daß der Islamismus wohl auf verschiedene Weise in die moderne Kulturproduktion verstrickt ist, war anfänglich noch revolutionär und anregend. Mittlerweile hat sich diese Idee zum wissenschaftlichen Glaubensbekenntnis entwickelt. Dadurch hat sie aber auch ihr kritisches Potential eingebüßt. Wie jeder wissenschaftliche Text sollte auch dieses Buch mit Kenntnis seiner geschichtlichen Einbindung gelesen werden. Daß ich mein Buch trotz dieses Wechsels des rezeptionsgeschichtlichen Kontexts ohne Akzentverschiebungen publiziere, liegt daran, daß es mir dort nicht einfach darum ging, auf eine affirmative Weise die Modernität des Islamismus zu zeigen. Dieser seit einiger Zeit grassierende Normalisierungsdiskurs liegt mir fern. Er ist genauso unhaltbar wie sein Gegenstück, nämlich der essentialistische Diskurs, der die Dimension des kulturübergreifenden Austausches nicht ernst nimmt. Statt dessen gilt es die produktive Spannung zwischen Eigensinn und wechselseitigen Austauschbeziehungen durchzuhalten.

Dank gebührt den Kollegen, die meine aufdringlichen Monologe unbeschwert über sich ergehen ließen. Prägend hat Georg Stauth auf die Ideen dieses Buches gewirkt, ganz abgesehen von seiner freundschaftlichen Betreuung, die er nicht nur in der Kairoer Bibliothek inmitten eigener Forschungsarbeit an den Tag legte, als er den zweifellos wertvolleren historischen Büchern eine frühere Version meiner Dissertation vorzog. Vor allem gilt mein Dank Zoltan Szankay, dessen kritische Gelassenheit mir stets eine weise Leitung ist. Schließlich fühle ich mich, wie am Ende üblich für derlei Vorworte, meiner Frau zum Dank verpflichtet. Auch in meinem Fall stimmt es tatsächlich, daß sie die eigentliche Leidtragende des ganzen Arbeitsprozesses war. Meine Kinder werden mir hoffentlich diese Zeit der Abwesenheit vergeben haben.

\section{Levent Tezcan}





\section{EINLEITUNG}

\section{Verwestlichung der Welt}

Wer heute über den Islam im allgemeinen und über die verschiedenen Konzeptualisierungsweisen, praktischen Ausgestaltungen, institutionellen und intellektuellen Verzweigungen des Islam, über die thematischen Gegenstände wie auch die Denkstrukturen der Muslime sprechen will, darf den geschichtlichen Kontext der Verwestlichung der Welt nicht ausblenden. Das ist die Ausgangsprämisse des vorliegenden Buches. Sie wird hier allerdings nicht einfach gesetzt. Die Berechtigung der Prämisse muß durch die Entfaltung der Argumentation im Verlaufe der Darstellung selbst nachgewiesen werden. Einstweilen möge der Hinweis auf die über zwei Jahrhunderte reichende Modernisierungsgeschichte der Türkei mit ihren ideellen und institutionellen Folgen, die auch in Bezug auf die islamische Religion nicht spurlos verlaufen sein dürfte, einen Vorschuß gewähren, um einen Berechtigungsschein für die Prämisse vorab auszustellen.

Ich möchte mich bei der Berücksichtigung der Verwestlichung der Welt von einer Denkfigur anregen lassen, die von Martin Heidegger in einem kurzen Text mit dem Titel „Die Zeit des Weltbildes“ (1950) entwickelt worden ist. Das Weltbild soll hier zunächst einmal als analytischer Begriff eingeführt werden. Mit ihm sollen Grundzüge eines Weltverhältnisses nachgezeichnet werden, welches sich auch der muslimischen Welt unausweichlich aufgezwungen hat, und zwar ganz gleich, ob über die affirmative Politik des Säkularismus, die Übernahme von Wissenschaften oder im negativen Modus der islamistischen Kritik der Moderne. Zudem wird es bereits in der wissenschaftlichen Literatur, wie gleich zu zeigen ist, zum Thema Islam gebraucht, um die Rekonstruktionen des „,islamischen Weltbildes“ zu ermitteln, ohne allerdings die mit ihm verbundene Bewandtnis zu reflektieren. Die Rede vom islamischen „Weltbild“ kann unter bestimmten Bedingungen durchaus übernommen werden. Es muß jedoch das Augenmerk auf die Geschichtlichkeit des Phänomens gerichtet werden, der für den Argumentationsverlauf eine wesentliche Bedeutung zukommt.

Heidegger zielt in seiner Abhandlung auf die radikale Differenz, 
die das neuzeitliche Weltverhältnis gegenüber den früheren auszeichnet.

„Doch warum fragen wir bei der Auslegung eines geschichtlichen Zeitalters nach dem Weltbild? Hat jedes Zeitalter der Geschichte sein Weltbild und zwar in der Weise, daß es sich jeweils um sein Weltbild bemüht? Oder ist es schon und nur die neuzeitliche Art des Vorstellens, nach dem Weltbild zu fragen?" (1950: 82)

Heidegger reserviert den Begriff nur für das neuzeitliche Denken, bringt es mit der Konstitution des aktivistischen Subjekts in einen wesentlichen Zusammenhang. Das „Bild“ im Weltbild meint dabei zunächst einmal den Sachverhalt, daß „die Sache selbst (so vor uns) steht [...], wie es mit ihr für uns steht" (ebd.). Damit ist aber nicht nur die Vorgestelltheit der Sache vor uns gemeint, „sondern daß es in all dem, was zu ihm gehört und in ihm zusammensteht, als System vor uns steht“ (ebd., Hervorhebung L.T). So gesehen ist ,im Mittelalter ein System unmöglich; denn dort ist allein die Ordnung der Entsprechungen wesentlich" (a.a.O.: 93).

Auf die leitende Frage „Was sind die wesentlichen Erscheinungen der Neuzeit?", läßt Heidegger in einem knapp gehaltenen, dafür aber sehr dichten Text einige Aspekte folgen, die konzeptionell für unser Vorgehen von erheblicher Bedeutung sind.

Als erstes macht Heidegger ein Wesenselement der Neuzeit in der Wissenschaft aus. Die Wissenschaft zeichnet sich durch die Art und Weise aus, daß sie als Forschung existiert. Als solche entwickelt sie notwendig Entwürfe, die zur Umgrenzung von Gegenstandsbezirken dienen. Ein jeder Gegenstandsbezirk wird durch Verfahren gesichert, die Regel und Gesetze aufstellen, welche wiederum mit Experimenten bestätigt oder widerlegt werden sollen. Festzuhalten an dieser Analytik der Wissenschaft ist, daß sie als Forschung sich die Natur und Geschichte nur als Gegenständliches vorstellen kann. „Natur und Geschichte werden zum Gegenstand des erklärenden Vorstellens. [...] Zur Wissenschaft als Forschung kommt es erst, wenn das Sein des Seienden in solcher Gegenständlichkeit gesucht wird.“ (1950: 80) Das wissenschaftliche Denken bestimmt somit den Hauptmodus der Wissensproduktion, mit dem überall gerechnet werden muß.

Eine weitere Erscheinung liegt darin, da $\beta$,das menschliche Tun [...] als Kultur aufgefaßt und vollzogen“" (Heidegger 1950: 69) wird. Diese Einsicht erweist sich zunächst einmal zum Verständnis der Dynamik und Ziele der Säkularisierungsbewegung als plausibel. Im Anschluß an diese Ausführungen werde ich auf die Funktionsweise dieser Kulturtechnik eingehen. Es soll dabei aufgezeigt werden, wie soziale Praktiken plötzlich unter den Bedingungen einer neuen Vorstellungswelt als Kultur in eine Systematik gebracht und auf ihre 
Funktionalität hin als Kultur erstrebt werden (so z.B. Religion, gebunden an die Staatsraison). Daher tritt denn auch die Rekonstruktion der Kultur im breiteren Sinne politisch auf: „Im Wesen der Kultur liegt es, als solche Pflege ihrerseits sich in die Pflege zu nehmen und so zur Kulturpolitik zu werden.“ (Heidegger 1950: 69)

$\mathrm{Zu}$ guter Letzt sei die Entgötterung als eine Erscheinungsform erwähnt, in der, so Heidegger, der metaphysische Grund der Neuzeit aufzuspüren sei. Dabei deute ,das Christentum seine Christlichkeit zu einer Weltanschauung (der christlichen Weltanschauung) um, macht sich so neuzeitgemäß“ (a.a.O.: 70, Hervorhebung L.T.). Denn, ,sobald die Welt zum Bilde wird, begreift sich die Grundhaltung des Menschen zum Seienden im ganzen als Weltanschauung bestimmt" (a.a.O.: 86).

Fassen wir die von Heidegger dargestellte Problematik zusammen: Die Weltbilder entstehen erst dadurch, daß die Welt (Natur und Geschichte) vom Menschen als Gegenstand in einer systemischen Gestalt vor-gestellt, also von ihm vor sich gestellt wird. Damit wird sie insgesamt dem herstellenden Zugriff des Menschen zur Verfügung gestellt, der sich anschickt, durch die Technik die Natur zu beherrschen, wie auch die Geschichte im Rückblick für sich nutzbar zu machen, was wiederum zur Kontrolle der Zukunft durch Voraussage und Planung führen soll. So gesehen, ist der Ausdruck modernes Weltbild ein Pleonasmus, wie die Ausdrücke das mittelalterliche oder antike Weltbild nicht mehr sein können als anachronistische Formulierungen.

Damit ist man nun auch bei der zentralen Thematik der Moderne, nämlich der Frage nach dem Subjekt, angelangt. Die Welt wird erst von dem Ort des Subjekts aus zum Bild. Und erst das Subjekt kann die Welt als sein zu bearbeitendes Objekt anschauen; mit anderen Worten, nur dem neuzeitlichen Subjekt kann eine Weltanschauung eignen. Mit dem Weltbild betritt das Subjekt die Bühne der Geschichte. So wird auch zum ersten Mal der Satz: „Geschichte ist machbar“ überhaupt denkbar.

Die von Sloterdijk den vormodernen Mentalitäten attestierte praktische Lebenserfahrung, „daß es immer anders kommt, als man denkt“ (1989: 21), verliert in der Zeit des Weltbildes ihren Wahrheitswert:

„Die Moderne als technopolitischer Komplex hat die alte Ökologie menschlicher Macht und Ohnmacht aus den Angeln gehoben. Beflügelt von einem geschichtemachenden Gemisch aus Optimismus und Aggressivität, hat sie die Herstellung einer Welt in Aussicht gestellt, in der es kommt, wie man denkt, weil man kann, was man will, und den Willen hat, zu lernen, was man noch nicht kann. Es ist der Wille zur Macht des Selberkönnens, der in moderner Zeit den Weltlauf laufen macht.“ (Ebd.: 22)

Dabei kommt es überhaupt nicht darauf an, ob sich dieser Wille empirisch so umsetzt, daß man eine zunehmende allgemeinere Kenntnis 
der Lebensbedingungen erwirbt, unter denen man steht. Entscheidend ist, wie Weber es knapp und prägnant formulierte, ,das Wissen oder der Glauben davon, daß man, wenn man es wollte, es jederzeit erfahren könnte, daß es also prinzipiell keine geheimnisvollen unberechenbaren Mächte gebe, die da hineinspielen, daß man vielmehr alle Dinge - im Prinzip - durch Berechnen beherrschen könne“ (1967: 17).

Die Zeit des Weltbildes, das ist die Bezeichnung für den seinsgeschichtlichen Hintergrund, dem sich auch die muslimischen Gesellschaften nicht ohne weiteres entziehen können. Der Einsatz dieser Denkfigur benötigt allerdings Erläuterungen, um ihre konzeptionelle Funktion genau anzugeben. Vorweg sei hier darauf hingewiesen, daß sich der Autor durchaus des modernitätskritischen Hintergrundes von Heideggers Ideen zum Weltbild bewußt ist. Dieser spielt in den folgenden Analysen keine Rolle. Es handelt sich hierbei weiterhin auch nicht um die Theorie der Moderne, die im Laufe der Darstellung auf die spezifischen Gegenstände der Untersuchung appliziert würde. Sowohl das moderne Denken als auch die modernen Gesellschaften sind dafür zu facettenreich, als daß man sie mit den hier angezeigten Erscheinungen erschöpfend analysieren und deren „Logik“ auf eine Formel bringen könnte. Von Interesse ist lediglich, auf die Grundzüge eines sich in der Neuzeit entwickelnden Verhältnisses zur Welt hinzuweisen, das vor allem in der Konzeption des modernen, aktivistischen Subjekts kulminiert. Das bringt über die Verwestlichungsprozesse auch für die nichtwestlichen Kulturen theoretische und praktische Folgen mit sich. Die Verwestlichung der Welt stellt hiermit die Kontextbedingungen auf, von denen die muslimischen Gesellschaften affiziert und transformiert werden (zu sozialen Transformationen in der muslimischen Welt durch die Modernisierung vgl. Lapidus 1988).

Wenn auch die Absicht der hier angestellten Überlegungen nicht darin besteht, das philosophische Konzept auf die Entwicklungen in der türkischen Gesellschaft anzuwenden, so bilden die Gedanken zum Weltbild ein Fundament, dessen Beschreibung mit gesellschaftstheoretischen Instrumenten vertieft und spezifisiert werden kann. Eine gesellschaftstheoretische Übersetzung der die Geschichtlichkeit berücksichtigenden Idee von Weltbild richtet das Augenmerk genau auf den Hauptgegenstand der Gesellschaftstheorie, nämlich auf die Gesellschaft als solche und hebt ihre Geschichtlichkeit hervor. In diesem Sinne ist die türkische Gesellschaft, von der diese Untersuchungen handeln, selber als ein geschichtliches Produkt zu verstehen. Sie hat sich unter dem Druck konstituiert, der von der schicksalhaften Begegnung mit dem modernen Westen ausging, und in ihre Konstitution sind die aus dem westlichen Bestand gewonnenen, ideellen und materiellen Instrumente wesentlich eingegangen, wobei die Auswirkungen 
dieser Instrumente, die Ausgestaltung des Prozesses, in der Interaktion mit den vorgefundenen Strukturen transformiert wurden. Die Etablierung einer säkularen politischen Ordnung und ihre rechtliche Ausgestaltung zeugen genauso von diesem Prozeß der Verwestlichung wie bereits die Suche nach den Grundlagen einer authentischen türkischen Kultur, welche im Zentrum der kulturpolitischen Anstrengungen der Modernisten stand. Nicht nur die Pflege der Kultur wird politisch, sondern bereits die Schaffung der nationalen Kultur geht aus einer politischen Sorge hervor.

Der dem Prozeß zugrundeliegende Mechanismus läßt sich mit einer genuin westlichen Vorstellung umschreiben, die ihren ideologischen Höhepunkt im Jakobinismus erlangte: Die „Vorstellung von der Gesellschaft als einem Objekt, das gemäß einer solchen Vision rundum erneuert werden kann. [...] Die Vorstellung, die die Gesellschaft zu einem Gegenstand der aktiven Konstruktion, vor allem des politischen Handelns des Menschen, macht“ (Eisenstadt 1998: 46). Diese Vision leitete denn auch das politische Handeln türkischer Modernisten, eine nationale Gesellschaft zu schaffen.

Mit dieser soziologischen These korrespondiert auch die von Foucault vorgenommene genealogische Analyse der modernen Macht, die sich ihrerseits von der Idee der Geschichtlichkeit von Gesellschaft in Bezug auf die hier wirksame politische Rationalität leiten läßt. Die Macht wird durch die moderne politische Rationalität strategisch, die sich nicht mehr auf die abschöpfenden Tätigkeiten (Steuer eintreiben, Soldaten einziehen) oder auf die negative Funktion von Lebenlassen oder Töten beschränkt. Als produktive Macht nimmt sie sich der Körper an. Sie wirkt über Disziplinartechniken und Bevölkerungspolitik als Biomacht auf die Körper ein, führt sie zur Gesellschaft zusammen, die sie erst durch diese Tätigkeit hervorbringt, und verwaltet sie mittels strategisch operierender Institutionen. Die Religion wird selber zum strategischen Instrument der Machtausübung, im türkischen Fall zudem eingespannt in die Herstellung einer modernen, säkular organisierten nationalstaatlich unterlegten Gesellschaft.

Andererseits verwickelt sich die politische Macht gerade durch den herstellenden Zugriff auf die Gesellschaft im allgemeinen und durch die Verwaltung der Religion im besonderen in ein strategisches Spiel, in dem sie an eben diese Gesellschaft Macht abtritt. Sie läßt sich auf ein strategisches Spiel ein, in dem sie mehr und mehr auf die Legitimitätsleistungen aus der Gesellschaft angewiesen wird. Mehr noch, sie durchtränkt die Gesellschaft durch eine zentralisierte und standardisierte Religion, die jetzt nun als gesellschaftliches Gut von den Gesellschaftsmitgliedern selbst in Anspruch genommen und als Gegenmacht gegen die säkularen Praktiken gewendet wird. Bestand die Funktion der verwalteten Religion darin, die Religion in die strategi- 
schen Ziele der Macht einzuspannen, so verkehren sich die Pole, so daß nunmehr die gesellschaftliche Organisation einem vereinheitlichten Religionsverständnis, der Religion als Weltanschauung, unterworfen wird. Die Bedingungen der Möglichkeit für ein islamistisches Gesellschaftsmodell liegen paradoxerweise in dem strategischen Einsatz der Religion, also darin, daß die Religion als Machtstrategie in Umlauf gebracht wird. Daher wäre die Entwicklung, die durch den Islamismus in Gang gekommen ist und sich durch die Idee eines alternativen islamischen Gesellschaftsmodells auszeichnet, ohne die erste, nämlich die ursprünglich säkulare Vorstellung von der Machbarkeit der Gesellschaft und ihre technisch-institutionelle Umsetzung, nicht möglich geworden.

Auf diesem theoretischen Hintergrund diskutieren die im Kapitel I zur verwalteten Religion des laizistischen Staates angestellten Reflexionen das eigentümliche Verhältnis von Religion und Politik auf der institutionellen Ebene, aber auch in unterschiedlichen diskursiven Ausarbeitungen. Die kemalistische Einbindung der Religion in den Nationalstaat wird folglich gemäß dem hier verfolgten Konzept, welches sich von der Bestimmung des authentischen Islam fernhält, nicht einfach als antiislamisch eingestuft. Vielmehr fördert die kemalistische Laizität diskursiv und institutionell eine bestimmte Form der islamischen Religiosität, während andere Formen (der organisierte Islam) im politischen Kampf disqualifiziert werden. Die Analyse erfolgt in diesem Kapitel am Beispiel der Diyanet, des türkischen Amtes für Religiöse Angelegenheiten. Dabei werden unterschiedliche Formen der Einbindung der Religion in den Verwaltungsapparat nachgezeichnet und die sich aus dieser Einbindung ergebenden Spannungen analysiert.

\section{Islamistische Reaktion}

Islamismus ist der Name für eine gewissermaßen durchaus heterogene Bewegung, in der sich ein Aufstand gegen die sozialen und politischen Folgen des Verwestlichungsprozesses im einzelnen und darüber hinaus gegen den Prozeß als solchen ankündigt. Mit dem Islamismus ist unmittelbar das politische Ziel verbunden, den Islam als öffentlichpolitische Norm einzuführen und anhand dieses Maßstabes alle gesellschaftlichen Bereiche einer Islamisierung zu unterziehen. Dabei werden nicht einfach verloren gegangene islamische Lebensformen wieder entdeckt, sondern bereits im Akt des Entdeckens nehmen die sogenannten islamischen Lebensformen ihre aktuelle Gestalt an. Offenkundig hat z.B. das uniformierte Aussehen islamistischer Frauen mehr 
mit unserer Zeit zu tun als mit einem vermeintlich authentischen Gebot.

Man könnte nun angesichts der radikalen Ablehnung der türkischen Moderne durch die Islamisten durchaus die Annahme pflegen, daß die Modernisierung der nichtwestlichen Gesellschaften in der Einführung institutioneller Formen auf einer oberflächlichen Ebene stecken geblieben sei, unterhalb deren jedoch das Unberührte, das Wesenhafte, das Lokale oder, mit einem aktuelleren Begriff ausgedrückt, das Authentische des Islam weiterhin währen und nur auf seine Stunde warten würden, um die übernommenen, wesensfremden Praktiken und Ideen wie die durch die republikanische Kleiderreform aufgezwungenen Kleidungsstücke abzuwerfen. Die als imitierte und wesensfremd unterstellte Trennung der staatlichen Politik von der Religion solle wieder, wie zu idealisierten glücklichen Zeiten der ersten Muslime, zugunsten einer Verschmelzung der Politik mit der Religion zurückgenommen und die ideale Gemeinschaft wieder errichtet werden. Dieser Annahme soll hier nicht gefolgt werden. Im Gegenteil, ich will mir die Sache etwas schwerer machen. Ausgangspunkt dabei ist die Idee, daß sich im Modus der Reaktion auf die Modernisierung, d.h. auf die Herstellung einer säkularen, nationalen Gesellschaft, folglich auch die islamistische Wiedererweckung bereits in den Kontext verstrickt.

Das Verhältnis des islamischen Revivalismus zur Moderne ist inzwischen nicht mehr ein unbetretenes Terrain (vgl. z.B. Tibi 1993; Büttner 1996; Marty/Appleby 1996; Stauth 2000). Dabei hat man mitlerweile von der simplen Gegenüberstellung Abschied genommen. Marty und Appleby schreiben in ihrem voluminösen Werk:

,[...] Diese Art der Einstellung trennt die Fundamentalisten von anderen Gläubigen, die ebenfalls über die Auswirkungen der Moderne besorgt sind und davor zurückschrecken, ihr unkritisch in die Arme zu fallen. Wenn Konservative sich von den Kräften einer säkularen Moderne bedroht fühlen, versuchen sie schlicht und einfach deren Einflüsse zu begrenzen. Orthodoxe Juden, die sich mit dem Modernismus konfrontiert sehen, versuchen ihn sich vom Leibe zu halten, indem sie sich in einen religiösen und kulturellen Kokon einspinnen; Traditionalisten wie zum Beispiel die Amish-Leute versuchen der Moderne zu entfliehen, indem sie sich von Pluralismus, Relativismus und anderen Versuchungen fernhalten. Fundamentalisten aber schlagen zurück." (Marty/Appleby 1996: 27, Hervorhebung im Original,)

Die Autoren machen mit ihrer zunächst schlicht anmutenden Bemerkung zum Zurückschlagen auf einen entscheidenden Punkt aufmerksam. Was nun alles an Elementen zum Bedeutungsspektrum des $\mathrm{Zu}$ rückschlagens gehört, das mehr als ein bloßes Reagieren sein soll, das wird von den Autoren deutlich, jedoch ohne auf die Konstitutionsbedingungen zureichend einzugehen, dargelegt. Darunter wird beispielsweise die Idee erwähnt, „das eigene Programm durchzusetzen“ 
(ebd.). Die im Fundamentalismus zum Ausdruck kommende Radikalität läßt sich noch weiter bestimmen als ,eine direkte und reflektierte Reaktion auf die Moderne“ (a.a.O: 19). Auf jeden Fall ist hier auf die Reflexion als Kulturtechnik hinzuweisen, deren praktische Formen bislang noch nicht ausreichend ausgeleuchtet worden sind. Ebenfalls gehört zu den Instrumenten, derer sich die Fundamentalisten ${ }^{1}$ bedienen, daß sie [...] die Grundsätze (konstruieren)“ (Marty/Appleby 1996: 31, Hervorhebung L.T.). Aufgrund solcher Kulturtechniken, die von den Autoren jedoch in ihrem Charakter nicht explizit analysiert werden, wird ,der Fundamentalismus des 20. Jh. in all seinen Manifestationen“ als „ein modernes Phänomen“ (Marty/Appleby 1996: 41) bezeichnet. Die vorliegende Studie greift die Hinweise auf Konstruktion, Reflexion und Programm auf, schließt sich auch an die These an, daß die Fundamentalisten ,sich bestimmter Denk- und Verhaltensmuster eben dieser Moderne bedienen“ (Marty/Appleby 1996: 28). Diese Thesen, die auf umfangreichen empirischen Fallstudien beruhen, sollten aber entgegen den Kurzschlüssen, denen viele Autoren selber erliegen, konsequent weiter gedacht werden. Vor allem muß das Bedeutungsumfeld des „Zurückschlagens“, sofern es in einen $\mathrm{Zu}$ sammenhang mit den Kategorien Konstruktion, Reflexion und Programm gehört, genauer berücksichtigt werden. In dieses Bedeutungsumfeld gehören unmittelbar Mobilisierung und Aktivismus, und sie führen genau ins Zentrum der Problematik, welche die Moderne durchzieht. Mit Mobilisierung ist jedoch hier mehr gemeint als eine Erscheinung, die sich anderen Erscheinungen der Moderne nur noch parasitär beigesellen würde. ${ }^{2}$ Mit Sloterdijk gesprochen, artikuliert sich darin die ,kinetische Utopie“ der Moderne (1989: 23).

Befremdlich wirkt - in diesem Licht betrachtet -, warum die Autoren trotz ihrer Sensibilität für die oben anführten islamistischen Spezifika unbekümmert in eine simple Dualität zwischen den Instrumenten und Werten der Moderne zurückfallen:

„Dennoch lehnen Fundamentalisten die in der Aufklärung wurzelnde Moderne nicht gänzlich ab. Sie schätzen viele ihrer Produkte - zügigen Trans-

1 Oder auch Islamisten; im folgenden werden beide Begriffe weitgehend identisch gebraucht.

2 Den Begriff der protestantischen Weltbeherrschung im Sinne von Weber kann man auch in dem Sinne deuten, daß die methodische Lebensführung auf die Welt derart einwirkt, daß ihre Ressourcen produktiv freigelegt werden. Das methodische Handeln in der Welt erfolgte doch gerade durch die Entwertung der Welt, deren Qualitäten gegenüber dann der Gläubige indifferent wurde, was die notwendige Bedingung für die Beherrschung derselben abgibt (vgl. auch Schluchter 1976: 274). 
port, Telekommunikation, Elektrizität, medizinische Versorgung -, aber sie sind gegenüber den Werten, die diese technologischen und wissenschaftlichen Wunder begleiten, mißtrauisch.“ (Marty/Appleby 1996: 24f)

Eine solche Reduzierung der Übernahme von Techniken auf die materiellen Technologien begibt sich folgerichtig der Möglichkeit, die Wirkungsweisen der übernommenen Kulturtechniken in nichtwestlichen Kulturen zu erkennen. Marty und Appleby nehmen daher die Sprengkraft ihrer eigenen Formulierung „Fundamentalisten aber schlagen zurück" nicht hinreichend wahr. Somit wird auch der Bedeutungsgehalt der These, ein anderes „Bild von der Welt“ zu machen, nicht ausgeschöpft.

„Vermöge dieser ,Show' wird jedoch eine Botschaft vermittelt: Es gibt noch einen anderen Weg, sich ein Bild von der Welt zu machen, das Schicksal der Menschen zu verstehen, Begeisterung zu entfachen, Hoffnungen und Talente des modernen Individuums fruchtbar zu erschließen.“ (Marty/Appleby 1996: 34, Hervorhebung L.T.) ${ }^{3}$

Gerade im und durch den Fundamentalismus dort, wo das säkulare Weltbild durch ein religiöses ersetzt werden soll, läßt sich das aktivistische Subjekt erst im islamischen Denken nieder. Erst dann macht es Sinn, von politischen Programmen zu sprechen, weil erst dann Gesellschaft als etwas klar Umrissenes in ihrer Objektivität denkbar wird und damit dem menschlichen Tun zur Verfügung gestellt wird. So sehen sich dann auch die muslimischen Intellektuellen, die auf die Einbindung der Religion in den säkularen Staat kritisch reagieren, ebenso mit der schicksalhaften Herausforderung konfrontiert, ein islamisches Gesellschaftsmodell zu konstruieren und gegebenenfalls dies durch eine islamische Revolution in die Tat umzusetzen. Hat einmal die Idee, daß die Gesellschaft machbar ist, um sich gegriffen und zudem noch ihre praktische Ausführung erfahren, so liegt es dann nahe, daß die Gesellschaft auch islamisch machbar sein müßte. Es tut der Sache nichts, wenn nun die Idee einer islamischen Revolution nicht länger aktuell bleibt, wie das an der islamistischen Bewegung in der Türkei in den 90er Jahren zu beobachten ist. An ihre Stelle kann eine „Gras-

3 Ähnlich konstatieren Jäggi/Krieger in ihrem Buch über „Fundamentalismus. Ein Phänomen der Gegenwart" die Existenz fundamentalistischer Weltbilder, und fügen sodann hinzu: „Weltbilder [...] tragen unvermeidlich ,religiöse' Züge.“ (1991: 189). Auch sie wollen mit dem Begriff „Weltbild“ eine vermeintlich universelle Tatsache hervorheben, sprechen aber im Grunde, ohne es zu problematisieren, eine sich bereits auch in der islamischen Kulturwelt vollziehende Transformation von historischer Bedeutung an. Auch sie gebrauchen den Begriff in einem ahistorischen Sinne, so daß jeder Zeit ein eigenes Weltbild eigne. 
wurzelstrategie" treten, mit der dem eigenen Bekunden nach die Gesellschaft, und nicht die staatliche Macht, nunmehr von unten her erobert werden soll.

Gegenstand der Analyse im Kapitel II ist hiermit Islam als eine ummatistische Utopie, deren Artikulationsformen am Beispiel eines konkreten Projektes verfolgt werden. Es soll erklärt werden, welche Transformationen sich im Islam durch den intellektuellen Diskurs von Islamisten ereignen. Die Analyse bewegt sich entlang einer islamischen Urvision, die allen Strömungen des Islam und allen Schichten muslimischer Gemeinde in unterschiedlicher Weise vorschwebt. Es ist die Rede von dem islamischen Goldenen Zeitalter, asr-i saadet, oder wörtlich übersetzt, dem Zeitalter der Glückseligkeit. Es handelt sich um eine spezifische Form des Rückgriffs auf das „Goldene Zeitalter“, um ein Mitte der 90er Jahre von einem kleinen Kreis islamistischer Intellektuelle in die Debatte aufgeworfenes Konstrukt, um das herum sich ein selbst für die islamistischen Kreise sehr ambivalenter Diskurs entfaltete.

Der Diskurs um die „Konvention (oder auch: den Vertrag) von Medina" beruft sich auf eine Urkunde des islamischen Propheten in der Stadt Medina, die zwischen den Migranten aus Mekka, den muslimischen und den heidnischen Arabern von Medina ausgehandelt wurde. Mit dieser Urkunde soll, so die islamistische Rekonstruktion, ein Gesellschaftsmodell Gestalt angenommen haben, wie der Islam es von seinem Wesen her verwirklicht sehen wolle. Die hoffnungslos verlorenen Menschen der Moderne könnten in der „Verfassung von Medina“ eine Alternative zur ,totalitären Moderne“ finden - eine Alternative, die nicht nur den Muslimen den Weg für ein gottgefälliges Leben zeige, sondern auch allen Menschen einen Ausweg aus der in der Moderne gipfelnde Verfallsgeschichte vorlege. Der Kern der um diesen Ursprungsmythos angestellten Überlegungen besteht in der Idee der Anerkennung unterschiedlicher Lebensformen, mit denen allerdings letztlich Religionsgemeinschaften (auch die Atheisten bildeten demnach eine Religionsgemeinschaft) gemeint sind. Propagiert wird also die Anerkennung differenter Religionsgemeinschaften, auf deren Basis sich erst eine gerechte Gesellschaft erheben könne.

Wiederholt sich nun in der Berufung auf die Anfänge des Islam, auf die Taten des Propheten und seiner Weggenossen, eine urislamische Art der Erneuerung, die über 1300 Jahre hinweg den wahren, in seiner Reinheit aufbewahrten Islam in der Gegenwart zur Geltung bringen will? Was bedeutet es, wenn die Muslime nunmehr ihr Recht, „Geschichte zu machen“ (Jäggi/Krieger 1991: 205) reklamieren? Meldet sich die authentische Stimme einer unterdrückten Kultur zu Wort, die das fremdkulturelle „Joch“ der Verwestlichung, Säkularisierung und Modernisierung abwerfen will, um der verschütteten Wahrheit 
des Urislam zur Geltung zu verhelfen? Oder hat nicht bereits hier schon eine radikale Transformation der Tradition stattgefunden, indem der Islam zum Kriegsgerüst einer weltgeschichtlichen Selbstbehauptung im kulturübergreifenden Austausch gemacht wird? Ganz im Sinne von Eisenstadt werde ich mich von dem Faktum nicht täuschen lassen, daß fundamentalistische Bewegungen der Gegenwart mit einer antimodernen Ideologie auftreten. Ich werde die Funktionsweise der aus der westlichen Moderne übernommenen Kulturtechniken, aber auch Ausflüsse moderner Denkstrukturen im islamistischen Diskurs aufzuweisen suchen. Von Interesse ist daher das islamistische Gegenstück, das gegen die säkulare „Machart“ der Gesellschaft ins Feld geführt wird.

Andererseits mißt Eisenstadt den in den jeweiligen Zivilisationen vorhandenen Urvisionen große Bedeutung bei, die in der kulturtechnischen Affinität der Fundamentalismen zur Moderne keineswegs verschwindet. Es ist letztlich dieses Spannungsverhältnis zwischen den etablierten Visionen des Islam und deren rekonstruktiven Bearbeitung durch den Islamismus, dem im zweiten Teil des vorliegenden Buches entlang eines intellektuellen Diskurses nachgegangen werden wird.

Kapitel III führt die Ergebnisse beider Kapitel zusammen. Dabei wird aber auch die Bedeutung einer Thematik betont, die hier nicht eigens in Angriff genommen werden konnte, da erst die theoretische Sensibilität dafür durch die hier angestellten Analysen vorbereitet werden mußte. Es handelt sich um den Zusammenhang zwischen den politischen Technologien und den Formen der Selbstkonstitution, einen Zusammenhang, den Foucault seinerseits erst in seiner dritten Schaffensperiode komplettieren konnte. Diese Thematik wird hier daher nur im Ausblick auf künftige Untersuchungen angerissen.

\section{Vorgehensweise}

Der materielle Gegenstand der hier unternommenen Untersuchungen ist das Verhältnis von Religion und Politik, welches jedoch in seiner Diskursivität betrachtet wird. Die institutionelle Ausgestaltung dieses Verhältnisses, sei es in der staatlichen Einbindung der Religion, sei es als eine durch den Islamismus entwickelte gesellschaftliche Alternative gegen die säkulare Ordnung, bildet nicht nur die Gerinnung diskursiver Auseinandersetzungen, sondern bleibt auch weiterhin als ein diskursiv umkämpftes Terrain. Diskurse werden hier als soziale Praktiken verstanden, denen eine performative Dimension innewohnt, welche sie über eine bloße Ansammlung von Ideen und Diskussionen erhebt. Als soziale Praktiken geben sie den Rahmen ab, in dem sich Identitäten konstituieren. Sofern gehen die folgenden Untersuchungen 
über eine Analyse politischer Ideen hinaus. Daher werden sie auch auf konkrete politische Entwicklungen bezogen.

Das Konzept enthält tatsächlich eine stark hervorgehobene geschichtliche Dimension. Mitunter mag der Eindruck genährt werden, $\mathrm{da} ß$ es sich um eine historische Studie handele. Gleichwohl ist der Charakter der Arbeit zutreffender umschrieben, wenn man die Bedeutung der geschichtlichen Ausführungen so versteht, daß sie weder einfach als Hintergrundsfolie noch Anschauungsmaterial dienen, auch nicht eine bestimmte historische Entwicklung soziologisch nachzeichnen. Sie liefern eher den Beleg für den konstitutiven Wert, den das Konzept der geschichtlichen Dimension zumißt. Dies kann auch nach dem Konzept des vorliegenden Buches nur so verstanden werden, weil sich die Bedeutung der Diskurse, verstanden als Praktiken, erst aus ihrem geschichtlichen Zusammenhang heraus erschließen. Es geht nicht um die abstrakten Grundzüge eines sozialen Phänomens, sondern um dessen geschichtliches Auftauchen, weswegen der praktische Aspekt systematisch berücksichtigt wird.

Der Text basiert auf zwei Fallstudien (die verwaltete Religion am Beispiel des Amtes für Religiöse Angelegenheiten und das islamistische Gesellschaftsmodell am Beispiel des Diskurses über Medina). Man kann sie selbstverständlich jeweils als in sich geschlossen lesen, wenngleich deren systematischer Bezug aufeinander nicht vergessen werden darf. Der Autor glaubt, daß jenseits der beanspruchten, letztlich vom kritischen Leser zu beurteilenden systematischen Erkenntnisgewinne bereits die Darstellung zweier in der deutschsprachigen Literatur zum Thema Islam bislang nicht bekannter Gegenstandbereiche eine Lücke zu schließen hilft.

\section{Zur Transkription:}

In der Regel wurde die türkische Schreibweise benutzt. Bei den Wörtern wie Scharia, Kalif, Hadith etc., die sich im Deutschen eingebürgert haben, wurde hingegen auf die türkische Schreibweise verzichtet. 


\section{DiE VERWALTETE RELIGION DES LAIZISTISCHEN STAATES}

Mit dem Begriff der ,verwalteten Religion“ wird eine bestimmte Erscheinungsform des Islam in der türkischen Gesellschaft bezeichnet. Der Begriff beschränkt sich auf das institutionelle Verhältnis zwischen Religion und staatlicher Politik. Es handelt sich hiermit um die Variante des Islam, die von der im Amt für Religiöse Angelegenheiten organisierten Orthodoxie repräsentiert, unter bestimmten Auflagen in den Staatsapparat eingebunden und hiermit kontrolliert und zugleich gefördert wird. Aus der in diesem Kapitel vorzunehmenden Analyse werden folglich andere organisatorische Erscheinungsformen des Islam wie die Partei (Refah und ihre Nachfolgeparteien) $)^{4}$ und Ordensgemeinschaften ausgeschlossen. Die in diesen Organisationen zum Tragen kommenden Strömungen politischer Islam und islamische Mystik fallen aus der Analyse heraus, obgleich sie sowohl ideell als auch personell gewissermaßen in die Orthodoxie hineinspielen.

Der analytische Wert des Begriffs weist allerdings über die Bedeutung der spezifischen Organisation der Orthodoxie hinaus. Dieser besteht vor allem darin, daß mit dem Gegenstand der „verwalteten Religion" eine Schnittstelle zwischen dem türkischen Modernisierungs- bzw. Säkularisierungsprozeß (d.h. Übernahme westlicher Ideen, Rationalitätsformen und Institutionen), der Kopplung des Übernommenen an die institutionellen Praktiken aus dem Traditionsbestand (,faktisch“ säkulare Quellen aus der osmanischen politischen Geschichte) und der Brechung/Übersetzung des Übernommenen (inhaltliche Religionspolitik des säkularen Staates) mit all ihren immanenten Problemen markiert wird. Unten wird zunächst einmal auf die historischen Praktiken und institutionellen Bestände eingegangen, welche bei der Errichtung der säkularen politischen Ordnung in der Türkei begünstigend gewirkt haben. Ohne die Berücksichtigung dieser historischen Bedingungen wird man die relativ erfolgreiche Etablierung der Säkularität in der türkischen Gesellschaft nicht würdigend erfassen können.

4 Ich verzichte auf eine Auflistung islamistischer Parteien, da sie infolge der zahlreichen Parteiverbote in der Türkei schnell wieder veraltet sein könnte, bevor dieses Buch erscheint. 


\section{Die ,säkularen" Quellen der Moderne in der muslimischen Welt}

Über den Islam hat sich mittlerweile eine große Menge an Wissen angesammelt. Wann das damit angezeigte Gebilde entstanden ist, in welchen geographischen Räumen es zu Hause und wo es noch verstreut anzutreffen ist, welche Praktiken, Gebote und Verbote Gläubige auf sich nehmen, all dies ist inzwischen in der kommunikativ zusammengerückten Welt nicht mehr unbekannt. ${ }^{5}$ Es fallen nun dabei bestimmte Stichworte, deren geläufige Bedeutung zumeist so selbstverständlich genommen wird, daß eine kritische Tiefenbohrung erst gar nicht in Erwägung gezogen wird. Die Einheit von Staat und Religion und die das gesamte Leben durchherrschende Macht des islamischen Gesetzes (Scharia) sind zwei solche, miteinander innerlich verbundene Annahmen, die bei einer sachkundigeren Analyse die an ihnen haftende Selbstverständlichkeit doch etwas einbüßen. Ich möchte einleitend zu dem vorliegenden Kapitel einen Streifzug in der islamischen Geschichte starten, um die diesen Sachverhalten zugesprochenen Selbstverständlichkeiten ein Stück aufzulockern. Zunächst soll also der historische Kontext erhellt werden, bevor man den Blick auf den Islam im zeitgenössischen Kontext, nämlich in Bezug auf den säkularen Nationalstaat, richtet.

Das Problem des religiösen Heils und der Herrschaft, das für die spätere islamische Geschichte - geltend selbst für die laizistische Türkei - von zentraler Bedeutung war, konnte sich zu Zeiten des islamischen Propheten selbstverständlich nicht stellen, da er gleichzeitig zwei Ämter als Gottes Gesandter und Herrscher des islamischen politischen Gebildes in sich verkörperte. Es handelt sich also um eine Eigenschaft der islamischen Religionsgeschichte, welche später die Vorstellung prämierte, im Islam (besser gesagt: in einer muslimischen Gesellschaft) sei eine säkulare Ordnung nicht denkbar.

Gleich mit dem Tod des Propheten tauchte die Frage auf, wie das durch ihn verkörperte Charisma auf Dauer gestellt werden könnte. Mit dem Zerfall der Einheit zweier Autoritäten in der politischen Figur des Gottesgesandten entstand auch zeitgleich die Urvision von dieser Einheit, die in der späteren Geschichte zwar nie mehr richtig ins Werk gesetzt werden konnte (vgl. Eisenstadt 1998: 26), jedoch als Orientierung auch nie wieder verschwand. Gegen den drohenden Verlust des

5 So gehörte es im Jahre 1996, um nur ein Beispiel anzuführen, zum Themenspektrum der Öffentlichkeit in der deutschen Stadt Duisburg, über den lautsprecherverstärkten muslimischen Gebetsruf zu streiten (vgl. mehrere Beiträge in Heitmeyer/Anhut (2000), darunter auch mein Text (Tezcan 2000). 
Charismas etablierten sich in der anschließenden geschichtlichen Entwicklung neben dem Koran das Imamat und die Sunna (Überlieferungen vom Propheten) als „Ersatzinstitutionen für das Prinzip der unmittelbaren Rechtleitung“" (Nagel 1975). Die Rezeptionsgeschichte und das Verhältnis dieser Institutionen zueinander spiegeln die ideologische Aufteilung der islamischen Landschaft wider.

Das Imamat hat sich als die genealogische Fortsetzung des prophetischen Charismas ins Zentrum des schiitischen Islam gesetzt. Demnach benötigt der Mensch die unmittelbare Rechtleitung durch einen Imam, der eine genealogische Bindung an den Propheten aufweist. Die für den schiitischen Islam entscheidende Heilswichtigkeit des Verhältnisses zwischen dem Herrscher (Imam) und den Beherrschten verlieh der schiitischen Opposition gegen die politische Herrschaft daher unvermeidlich chiliastische Züge, da ein gottgefälliges Leben nur unter der Herrschaft des legitimen Imams möglich sein konnte. Diese Gedanken fanden Ende des zweiten islamischen Jahrhundert durchaus Echo im Herrscherhaus der Abbasiden. Der Kalif alMamun (9. Jh.) strebte an, sich in die Kette der Propheten und Imame einzureihen. Auch al-Mamun geht bei der heilswichtigen Begründung seiner Herrschaft von dem islamischen Dogma aus, daß mit Muhammad die Offenbarung abgeschlossen ist. Der Herrscher übernimmt nun die Rechtleitung vom Propheten. Er braucht dadurch gleichzeitig für sein Handeln die Traditionarer (die Leute der Sunna) nicht, da er selber in einer heilswichtigen Verbindung zur göttlichen Botschaft steht. Al-Mamun erhob die „Erschaffenheit des Korans“ zum Dogma und rief eine Inquisition aus, vor der die Leute der Sunna sich dazu zu bekennen hatten. Aus diesem geschichtlich bedeutsamen Kampf sind allerdings letztlich die Sunniten, zumindest im Hinblick auf die Heilsverwaltung, siegreich hervorgegangen. Infolge dessen mußte der Herrscher seine Heilsbedeutung an die Traditionarer verlieren. Seine Aufgabe bestand folglich hauptsächlich darin, über das Gesetz zu wachen. Entsprechend verschob sich die Ebene, auf der sich das Heil einstellen sollte, von der herrschaftlichen Beziehung auf den Einzelmenschen.

„Sachwalter der Sunna sind nicht die Machthaber, sondern allein die Gelehrten, die das unschätzbare prophetische Erbe frei von allen Sachzwängen des Augenblicks sammeln, sichten und von Verfälschungen reinigen. Die Zuständigkeit für die Aufrechterhaltung der von Gott dem Menschen aufgetragenen Ordnungsprinzipien und die Befähigung für die Auslegung dieser Prinzipien sind nicht mehr in einer Hand vereinigt, sondern getrennt.“ (Nagel 1981a: 305)

Genau aus dieser Trennung, wobei in der Theorie die Gebundenheit des Herrschers an das Gesetz nie aufgegeben wurde, gewann die sun- 
nitische politische Theorie ihre Geschmeidigkeit, die dem Sunnitentum ermöglichte, unter jeder auch noch so religiös „verdorbenen“, allerdings letztlich doch noch muslimischen Herrschaft weiter zu bestehen. Sie konnte mit al-Mawardi versuchen (11. Jh.), angesichts der Machtlosigkeit des Kalifen gegenüber den Sultanen die faktische Herrschaft der letzteren doch religiös einzukleiden, indem sie ihre Herrschaft vom Kalif delegiert empfangen. Geschickt anpassen konnten sich die sunnitischen Theoretiker auch an die späteren Verhältnisse, als die „Theorie der Delegierung der Aufgaben zur Aufrechterhaltung der göttlichen Normen für die Verankerung des Sultanats in der gottgewollten Ordnung belanglos" wurde (Nagel a.a.O.: 438). Der Sultan stand nunmehr selber in einem unmittelbaren Verhältnis zu Gott ohne die kalifatische Vermittlung. Dank dieses eigentümlichen Verhältnisses zur politischen Macht konnte sich die sunnitische Orthodoxie sogar mit der dezidiert laizistischen Orientierung, wenn auch nicht ohne Probleme, letztlich doch arrangieren.

Eigentlich hatten einige führenden Gelehrten der seit Edward Saids Orientalism allzu sehr verschmähten Orientalistik (z.B. Goldziher, Becker, von Grunebaum) die Eigenart dieser Begriffe sowohl in Bezug auf die Entstehungs-, als auch auf die spätere Geschichte im unverkennbaren Gegensatz zu vorherrschenden populären Vorstellungen noch früher sehr deutlich nachgezeichnet. Für C. H. Becker wurde bereits anfangs ,,aus dem Einheitsstaat [...] das Ideal des Einheitsstaates" (1967: 21). Er spottete gar, indem er seinerseits auf die Bedeutung der geschichtlichen und historischen Umstände für das Verständnis des Islam verwies, ungeniert demjenigen, für den ,zur Erklärung der gegenwärtigen Tatsache der Koran und das Leben Muhammads genügen“; dem sei überhaupt nicht zu helfen (a.a.O.: 22). Solche Ideen, die wissenschaftlich nicht zu begründen seien, führt Becker seinerseits vornehmlich auf den Einfluß der islamischen Quellen zurück. Und sofern sich die Islamwissenschaftler von deren normativer Deutung leiten ließen, hätten sie keinen Sinn für die kulturrelevanten Differenzen zwischen Politik und Recht, Religion und Leben auch im Islam. Ein wenig auch als ironisch muß man wohl dann seine Bemerkung lesen: „Die Welt des Islam ist beherrscht von der Religion in Vergangenheit und Gegenwart - wenigstens in der Theorie“ (Becker 1967: 4, Hervorhebung L.T.).

„Erst in den letzten Jahrzehnten, jedenfalls erst lange nach Alfred von Kremers so verdienstlicher Kulturgeschichte, setzte die moderne Kritik ein. Allmählich rang sich die Forschung aus dem Bann der islamischen Tradition; wir lernten in Politik und Recht, in Religion und Leben, Theorie und Praxis unterscheiden. Wir sahen im Kampfe zwischen religiöser Forderung und Volkssitte die letztere siegen, wir erkannten im Ringen der Ideen die religiöse Färbung in unzähligen Fällen als reine literarische Form. Wir sa- 
hen das religiöse Recht sich entwickeln nicht an der Praxis, sondern im Gegensatz zu ihr, wir überzeugten uns schließlich, daß auch die Gründer des arabischen Weltreiches gar nicht ihre Religion propagierten, sondern nur die weltliche Herrschaft der Araber. Gibt uns das alles nicht zu denken? Sind gegenüber diesen Tatsachen unsere herkömmlichen Anschauungen von der Rolle, die die Religion im Islam als Konstituante spielt, nicht auBerordentlich reformbedürftig?" (Ebd.)

Anregungen zu einer solchen „Reform“ der wissenschaftlichen Betrachtung den Islam betreffender Themen will auch Muhammad Arkoun beisteuern. Dem populärwissenschaftlichen, aber auch vonseiten der Islamisten zur Programmatik erhobenen Gedanken, daß der Islam die Trennung zwischen dem Weltlichen und Geistlichen nicht kenne, spricht Arkoun keinen Realitätsgehalt zu. „Die faktische Trennung zwischen dem Geistlichen und Weltlichen ist“, so Arkoun, „ohne eine intellektuelle Anstrengung, sie zu ergründen, im Islam bereits vorhanden.“ (1995a: 51; teilweise ähnlich argumentiert Nagel 1981c)

Arkoun geht noch weiter, indem er den Begriff der Laizität schon in die Anfänge des Islam hinein verlagert und von dort aus durch die ganze bisherige Geschichte mehr oder weniger am Wirken sieht. Dabei verfehlt er kein einziges Mal, den Begriff stets auch mit dem Attribut „faktisch“ zu versehen. Denn gleichzeitig liegt ihm daran, genau diese Unklarheit, nämlich den Umstand zu unterstreichen, daß etwas faktisch tatsächlich wirkt, obgleich seine symbolische Realität in der Schwebe gelassen wird. Von der faktischen Realität verspricht sich wohl Arkoun in seinem innerislamischen (Be-)deutungskampf die empirische Begründung dafür, daß eine islamische Laizität nicht nur kein Widerspruch in sich sein muß, sondern auch nicht einfach als eine fremdkulturelle Erscheinung abzutun ist. Mit einer Reihe von Punkten, die dem Mainstream von Islamstudien verquer liegen, präsentiert Arkoun seine Programmatik, die darauf abstellt, den Islam neu $\mathrm{zu}$ besehen (hier werden nur diejenige, die das Thema Laizität betreffen, angeführt):

„1. Laizität ist im Koran und in der Erfahrung von Medina vorhanden.

2. Der umayyidische und der abbasidische Staat sind laizistisch; die ideologischen Theorien der Juristen haben die historische und politische Realität verdeckt. [...]

3. Die militärische Macht hat bei dem Kalifat, Sultanat und den späteren sogenannten islamischen Regimes von früh an eine führende Rolle gespielt.

4. Der Versuch, diese faktische Laizität zu rationalisieren und eine laizistische Haltung zu entwickeln, wurde von den Philosophen unternommen. [...]" (a.a.O.: 71)

Ich möchte hier Arkoun nur insofern folgen, als er die in der islamischen Geschichte durchaus vorhandene Differenz zwischen beiden 
Machtbereichen hervorhebt und die gemeinhin geteilte Idee von der Einheit beider nicht mitträgt. Gegen die Verlagerung der Laizität in die Geschichte sei hier jedoch Skepsis angemeldet, wenn auch der Hinweis auf ihre Faktizität den Einwand etwas milde stimmen läßt. ${ }^{6}$ In dem Kapitel (I.3) über die osmanische Politik wird noch zu zeigen sein, daß die faktische Trennung, die ja aufgrund der ausdifferenzierten Institutionalisierung gewissermaßen gar über die Faktizität hinausgeht, auch dort fortbesteht, wenn auch in Person des Kalifsultans in Grenzen gehalten wird. Der Konflikt verlagert sich dafür auf die unteren Ebenen des Machtapparates, wo die Ulema (Schriftgelehrten) und Militär- und Zivilbürokratie konkurrieren. Aber auch zwischen dem Sultan und der Klasse der Schriftgelehrten ist die Spannung, historisch variierend, durchaus festzustellen.

Eine ähnliche Doppeldeutigkeit, oder anders gesprochen, die in systematischer Hinsicht eventuell bedeutsame „Unklarheit“, das „Inder-Schwebe-Lassen", besteht auch bei der Frage nach dem islamischen Gesetz Scharia. Auch hier herrschten bei den bekannten Namen der Islamwissenschaft keine Illusionen über die Natur und Reichweite des islamischen Gesetzes: Diese war aus erklärlichen Gründen, die wir heute unter dem Begriff der Kontextualität erfassen würden, sehr gering. Der holländische Orientalist Snouck Hurgronje bemerkte bereits, wie Goldziher sich auch auf ihn beruft, daß ,das, was die Muhammadaner Al-Fikh nennen, nach Ablauf der patriarchalischen, noch ganz auf theokratischer Basis sich einrichtenden Epoche des Muhammadanischen Staates nicht eigentlich Muhammadanisches Recht, kein System [ist], das im Muhammadanischen Staate actuelle und praktische Geltung hatte“ (Goldziher 1968 [1889]: 354). Vielmehr handelt es sich beim islamischen Gesetz um eine „Pflichtenlehre von ganz idealem Charakter und theoretischer Bedeutung“ (ebd.; vgl. auch Schacht 1935). Unter der Wirkung der Bilder, die uns über die islamistischen Bewegungen von heute via Medien tagtäglich in die Wohnstuben gespült werden; angesichts der islamistischen Geschichtsklitterung, die uns die Scharia als ein positives Gesetz und zudem ein aus dem Gesetz emanierendes, islamisches Gesellschaftsmodel Glauben machen wollen; die selbstverständliche Rede von der Einheit von Politik und Religion im Islam; also kurzum, unter dem ohrenbetäubenden Lärm

6 Für İlber Ortaylı, einen bekannten türkischen Historiker, entscheidet sich die in der türkischen Debatte viel diskutierte Frage der Laizität dadurch, ob eine für alle Bürger gleichermaßen geltende Rechtsordnung herrscht oder die soziale Ordnung nach Religionsgemeinschaften gegliedert ist. In diesem Sinne war, so Ortaylı (1979), das Osmanische Reich zweifelsohne nicht laizistisch. 
vom ,islamischen Gesetz“ stimmen solche wissenschaftlichen Studien den Geist merklich heiter.

Der im heutigen Sinne unsystematische Charakter des islamischen Rechts, der von Weber (1972 [1922]) bereits in Bezug auf seine Konsequenzen für die Entwicklung der Rationalität reflektiert, von Schacht (1935) am Maßstab modernen, positiven Rechts gemessen worden ist, läßt sich ebenso an ihrer Entwicklung nachvollziehen. Die Rechtsentwicklung hat sich nicht an den idealen Vorstellungen der Gelehrten orientiert. ${ }^{8}$ Die rasante Ausdehnung des islamischen Herrschaftsgebiets ließ großen Bedarf an rechtlichen Bestimmungen aufkommen, der aber nicht mit den Bestimmungen aus dem Koran abzudecken war. In der praktischen Rechtspflege wurden daher Rechtstraditionen der eroberten Länder übernommen. ${ }^{9}$

7 Wenn man bei Goldziher liest, daß ,am Hofe des Prinzen Ibrahim b. al Mahdi [...] beim Weingelage über theologische Dinge disputiert (wird)“ (1968 [1889]: 355), dann ist das wohl eine Bestätigung der viel gerühmten Lebensbejahung in den muslimischen Gesellschaften, die noch große Geister wie Nietzsche begeistern konnte. Unschwer könnte man Parallelen aus der türkischen Gesellschaft finden, die an der Möglichkeit einer lebensbejahenden islamischen Religiosität und ihrer Toleranz auch in ihrer alltagsweltlichen Erscheinung wenig Zweifel aufkommen lassen. Dies alles droht durch die islamistische Hypostasierung religiöser Ideen, die zwischen Idee und Lebenspraxis eine fundamentalistische Konsistenz herstellt, weitgehend $\mathrm{zu}$ verschwinden. Mittlerweile wird dieser geschmeidige Umgang mit religiösen Geboten von den jungen Islamisten im Namen einer kompromisslosen Unterwerfung des Alltags unter die Idee als „Laxheit“ diffamiert (Beispiele in: Nökel 2002). Ein interessantes Konzept des „Volksislam“ hat Mihçıyazgan (1994a) vorgelegt.

8 Außerdem sei selbst unter den Schriftgelehrten eine Abneigung zur Vereinheitlichung der Lehrmeinungen festzustellen (vgl. Goldziher 1970). Goldziher bringt die Vorliebe zum Dissens und den Mangel eines dogmatischen Triebes im Islam in einen unmittelbaren Zusammenhang. Weber hingegen konnte diesbezüglich lediglich ein dogmatisches Heilsinteresse bei den Schriftgelehrten annehmen, alle Lebensbereiche in Bestimmungen des Gesetzes einzuzwängen (vgl. Weber 1972 [1922]: 474). Neuerdings wird diese Erkenntnis der alten Islamwissenschaft, nämlich die bis in die Reihen der Schriftgelehrten reichende Dissensfreude, unter den muslimischen Intellektuellen (nicht zuletzt als eine identitätspolitisch geschliffene Waffe in dem intellektuellen Wettrüsten) als Vorzug des Islam in dem Sinne reflektiert, daß der Text den Körper freigebe (Aktay 1997). Nicht nachzuvollziehen ist allerdings, daß Aktay aus dieser These auf eine intrinsische Notwendigkeit des Kalifats im Islam schließt.

9 Man kann dazu noch im Sinne der Weberschen Religionssoziologie, die u.a. auch auf die Beziehungen zwischen religiöser Ethik und sozialer Schicht abstellt, hinzufügen, daß sich der Kriegeradel, also Träger der 
„It was only natural that the legal, commercial, and administrative practices which prevailed in the conquered provinces should have survived under Islam, just as ancient Arab legal and commercial practices had survived, and should have been adopted by the Muslims as far as they were compatible with the demands of the new religious ideas." (Goldziher 1965: 886f; vgl. auch Goldziher 1968 [1889]: $363 f$ u. 1970 [1914]: 293ff)

Des weiteren steht es für Goldziher außer Frage, daß den „todte(n) Buchstaben" der theoretischen Gesetze, ersonnen in Studierstuben, gepflegt in den Herzen frommer Forscher, aber vernachlässigt und zurückgedrängt im Leben“, „die Sanction der Durchführung“ fehlte (Goldziher 1968 [1889]: 354). Im gleichen Sinne urteilt auch Becker, von dem bereits oben die Rede war.

„Nun erwuchs die Pflichtenlehre nicht auf dem Schlachtfeld, noch in der Staatskanzlei, sondern in der Gelehrtenstube. [...] Weder der Staat noch das Individuum konnten sich außer auf ganz bestimmten Gebieten an die Forderungen der islamischen Pflichtenlehre halten; sie ist zu ihrem größten Teil rein theoretische Spekulation, doch hat sie dadurch eine große Bedeutung, daß sie von allen Gläubigen in Bausch und Bogen als Ideal angesehen wird.“ (1967: 355)

Wem das Urteil nichtmuslimischer Orientalisten angesichts der angegriffenen Selbstverständlichkeit der Rede vom islamischen Gesetz suspekt erscheint, dem sei geraten, den Worten eines renommierten Muslims Gehör zu schenken, der übrigens nicht bloß theoretisch zum Thema gearbeitet, sondern auch an der Ausarbeitung eines modernen islamischen Rechts in Pakistan aktiv mitgewirkt hat. Fazlur Rahman schreibt zum islamischen Recht folgendes:

„In the still more important field of law [...], the Islamic legal system although in the main unsystematically linked with the Qur'an and the Sunna, was not of the sociomoral values of the Qur'an. In addition, from its very beginning, the legal literature of Islam has a ,bookish' smell in contradiction to the exigencies of everyday life: it is almost a purely theoretical effort. This effort is indeed vast and displays much originality, but strictly speaking it cannot be described as law - for, since it is basically concerned with morality, much of it is not enforceable in any court except that of the human conscience." (1982: 29)

Für Rahman steht es außer Frage, daß „Islamic Law, in fact, is not law in a modern sense“. Es ist ,a treasure of legal materials thrown up during long centuries of endless discussions, upon which modern Islamic legal systems can certainly be built, but only a part of which could

frühislamischen Religion, mit den theoretischen Grübeleien der Juristen schwerlich anfreundet (vgl. Weber 1972 [1922]: 288ff). 
ever be enforced in court" (Rahman 1982: 155). Das als Scharia bekannte islamische Gesetz hat sich eigentlich als Jurisprudenz (fikıh) entwickelt. Die islamische Jurisprudenz ging nicht aus einem bereits bestehenden Gesetz hervor, vielmehr brachte sie das Gesetz erst hervor (vgl. Goldziher 1965: 888). ${ }^{10}$ Sie hat nicht nur die reichhaltige Rechtsmaterie geschaffen, worauf oben mit Rahman verwiesen wurde, sondern darüber hinaus auch methodische Instrumente wie Analogieschluß (klyas), Konsensus (icma) entwickelt. Theoretisch war zwar Rechtsschöpfung nur Gott vorbehalten, aber faktisch vollzog sich die Rechtsschöpfung ungeachtet dieses Dogmas, wenn auch nur unter der Bezeichnung der „Rechtsfindung“. Selbst sie war nicht dem Richter (Kadi) gestattet, sondern ein Privileg der ,charismatischen Rechtspropheten" (Weber 1972 [1922]: 474), um einen Ausdruck von Weber zu verwenden - also der vier Rechtsschulen. ${ }^{11}$ Besonders relevant sind dabei die Folgen der Rechtsentwicklung. Eine entscheidende Folge ist, aus der Perspektive der modernen Rechtsentwicklung betrachtet, die Konfusion von profanem und göttlichem Recht. Weber ist der Ansicht, daß die islamische Jurisprudenz die Entwicklung des profanen Rechts erheblich behindert hat (vgl. Weber a.a.O.: 474f). Die Kehrseite der Durchdringung des profanen Gesetzes durch das religiöse erweist sich aber auch für dieses äußerst problematisch. Der Eingriff der Obrigkeit in religiöse Institutionen wurde dadurch erheblich erleichtert.

Schon sehr früh beobachtet man das Bestehen einer doppelten „Rechtsordnung“, die neben den Bestimmungen des religiösen Rechts Institutionen des profanen, ethnischen Gewohnheitsrechts enthält (Goldziher 1968 [1889] und 1970 [1914]). Sicher hatte sich das profane Recht zumindest legitimatorisch dem religiösen Recht zu unterwerfen, denn die „Leugnung seiner Verbindlichkeit ist Unglaube“ (Schacht 1935: 222; vgl. auch Esposito 1984: 22 und 30; Becker 1967: 358). Die praktische Handhabe zwang allerdings das religiöse Gesetz

10 Dazu auch Schacht (1965: 890): „The fikh is [...] the interpretation of a religious ideal not by legislators but by scholars, and the recognized handbooks of the several schools are not ,codes" in the Western meaning of the term."

11 Die rechtsprophetische Kraft gilt gemeinhin etwa seit dem 10. Jh. als erloschen oder in islamischer Terminologie ausgedrückt: „Das Tor der İçtihad ist geschlossen worden." Der islamische Modernismus wird dann im 20. Jahrhunderts ihre Energie daran setzen, das Tor aufzustoßen, um eine Neuinterpretation des Islam zu leisten. Die in der ersten Dekade des 20. Jh. bei Muhammad Abduh gipfelnde Forderung wird aber später ebenso bei den Fundamentalisten Anklang finden, die der Orthodoxie (wie z.B. auch der türkischen Diyanet) das Monopol der Authorität über Interpretation religiöser Texte streitig machen wollen. 
hauptsächlich in den Geltungsbereich des privaten Rechts. Die Scharia als Staatsrecht hingegen ist, im Gegensatz zur Vorstellung von heutigen, im Zeichen des modernen positiven Rechts aufgewachsenen Islamisten, eine ,reine Fiktion, und hat so überhaupt nicht existiert“ (Schacht 1935: 220). Der faktische Bedarf nach Institutionen des Gewohnheitsrechts und der Zwang des theoretischen Bekenntnisses zum religiösen Gesetz führte, so behauptet Goldziher, sehr früh zur Entstehung einer ausgeklügelten, überaus rechtsproduktiven Praxis, zur Erdichtung neuer Hadiths:

„Man bequemte die Doctrin den Anforderungen des im praktischen Leben Begründeten zuweilen an und fand - besser: man schuf - Rechtstitel, welche den Widerspruch der alltäglichen Vorgänge mit den traditionellen Doctrinen aufhoben. Man erdichtete Traditionen im Sinne der Erfordernisse des Lebens, und so wurde dieses traditionsgemäß." (Goldziher 1968 [1889]: 366)

Die Anpassung des islamischen Rechts an die praktischen Bedingungen steht bei Goldziher in einem systematischen Zusammenhang mit dem Mangel eines dogmatischen Triebes. Für ihn besteht ein geeigneter Nachweis ,auf dem Gebiete des Staatsrechts (Chalifat)“ (1970 [1914]: 303). Den Theologen blieb, „wo die Uniformierung nicht Resultat theoretischer Erwägungen, sondern zumeist das äußerer Gewalt und weltlichen Zwanges war, [...] hinterher ihre Theorie zu zimmern“ (ebd.) $)^{12}$.

Die geschichtliche Entwicklung der Rechtspraxis, die immer schon auch Hinweise auf die Macht der Schriftgelehrten (Ulema) enthält, hat im Osmanischen Reich zu einer deutlichen institutionellen Ausdifferenzierung des juristischen Apparates geführt. Es handelt sich nicht alleine um die bereits bei den Umayyiden und Abbasiden praktizierte doppelte Rechtspraxis (Gewohnheitsrecht und Scharia), sondern darüber hinaus um die in der islamischen Geschichte unvergleichlich weit vorangetriebene Einbindung der Ulema in den Staatsapparat. Die Auswirkungen dieses Umstands auf die spätere Säkularisierung werden nicht ausbleiben. Dazu bemerkt Rahman trefflich folgendes:

„This question of who should interpret law has been in Islamic societies because of the historical accident that the so called law (fiqh) has been the result of the work of private lawyers, while in the later medieval centuries governments - particularly the Ottoman government - had to promulgate

12 Im aktuellen islamistischen Diskurs der Türkei wird diese historische Entwicklung affirmativ gewendet und statt einer gezwungenen Anpassung an die geschaffene Realität als Produkt einer systematischen Bearbeitung islamfremder Rechts- und Denktraditionen gedeutet (vgl. Ali Bulaç 1994). 
laws on issues not covered by the Shari'a law. Although the state-made law basically sanctioned by certain general principles in the Shari'a law itself, nevertheless a dichotomy of the sources of law was unavoidable, and this process paved the way for the secularisation of law in several Muslim countries - most systematically in Turkey.“ (Rahman 1982: 156)

Die Frage nach dem Verhältnis von Staat und Gesellschaft in der Türkei war und bleibt ein bevorzugtes Thema wissenschaftlicher Analysen und politischer Diskurse. Während zumeist auf der konservativen bzw. nationalistischen Seite die Bedeutung des Staates für die türkische Nation affirmativ betont wird, gewinnt eine an der Idee der Zivilgesellschaft orientierte Kritik an der Omnipotenz des Staates immer mehr Raum (vgl. mehrere Beiträge in der Monatszeitschrift Birikim H. 106 und 107, 1998). ${ }^{13}$

Kaum ein anderer Wissenschaftler hat sich in seinen Studien für die Kontinuität und Brüche in der osmanisch-türkischen Geschichte so stark interessiert wie Serif Mardin. Mardin sieht beispielsweise im osmanischen Pragmatismus bezüglich unserer Thematik die Spuren einer relativen Laizität, wenn er anmerkt, daß ,,[...] auch der Kemalismus, der seine Quellen aus dem westlichen Positivismus bezog, Vorgänger bei den Osmanen hatte. Das waren der Pragmatismus der osmanischen Bürokratie und ihre relative Laizität.“ (1991: 141)

Die Kräfteverhältnisse waren dabei in der Reichsgeschichte überwiegend zugunsten der „weltlichen“ Macht, die sicherlich auch sakrale Legitimitätsansprüche geltend machte - weswegen auch Max Weber auf den cäsaropapistischen Charakter der osmanischen Herrschaft verwies (1972 [1922]: 690). Unterhalb des Sultans, der beide Autoritäten beanspruchte, existierte durchaus eine, wenn auch konjunkturell bedingt stets umstrittene, Hierarchie bzw. Konkurrenz (vgl. Mardin 1997: 356). Das höchste religiöse Amt, Şeyhülislam, besaß zwar einen Platz im Diwan (Imperial Council), aber, so Mardin, kei-

13 Die dominante Stellung des Staates fand übrigens auch bei prominenten Autoren Beachtung wie z.B. bei Gellner (1985). In seinen Studien über Nordafrika formuliert Gellner die nach seiner Auffassung für muslimische Gesellschaften typische Dichotomie von „schwacher Staat vs. starke Kultur", die er aus dem Zyklenmodell von Ibn Khaldun gewonnen hat. Die Schwäche des Staates rührt dabei daraus her, daß dem Herrscherstamm zwangsläufig die anfängliche Asabiyya (in etwa: Solidarität) abhanden kommt und folglich er ständig von anderen Stämmen bedroht wird, bis ein neuer Stamm mit nötigen Solidaritätsressourcen die Macht an sich reißt. Die osmanische Herrschaft konnte hingegen die Macht der Stämme durch die Institution von Militärsklaven brechen (kritisch dazu vgl. Çiğdem 1996). 
nerlei politische Befugnisse (Mardin 1991: 89). ${ }^{14}$ Die bereits in den arabischen Königreichen (Umayyiden und Abbasiden) vorhandene faktische Differenz zwischen weltlichen und religiösen Instanzen übertrug sich auch - verstärkt bei den Osmanen - unmittelbar in den Bereich der Juristerei. So waren im Osmanischen Reich beispielsweise die Ausdrücke Şer-i Hukuk (Scharia) und Örf-i Hukuk (Gewohnheitsrecht) relativ gut institutionalisiert. Das alttürkische Brauchtum, töre (auch yasa; arabisch: urf), und die altpersische Reichstradition begründeten im Grunde das Staatsrecht. Das „kodifizierte“ Osmanische Recht hat sich auch anfänglich entlang von kanun-name (urfi-laws; „Gesetzesbücher“, die von Sultans erlassen wurden) entwickelt.

„It can safely be said that the basic rules of the Kanun-i Osmani, traditional Ottoman law concerning the re'aya [die Untertanen, L.T.], took definite form as a result of fusion of Ottoman laws with pre-conquest practices and antedating the Conqueror's law-book which we know was proclaimed around 1453. The Conqueror's long and dynamic reign witnessed the issuance of a number of laws and statutes on specific matters, some of which seem to have been codified into the law." (Inalcık 1978, Kapitel VII, insb. S. 128)

In diesem ersten kanun-name, das vom Sultan Mehmed dem Eroberer (15. Jh.) stammt, besteht noch keine Referenz auf die Scharia. İnalcık berichtet, daß sich bereits im 16. Jh. ein Konflikt zwischen Scharia und Yasa (örf-i Hukuk) abzeichnet (vgl. auch De Bellefonds 1997). $\mathrm{Ab}$ dem 17. Jh. weicht kanun-name mehr und mehr adalet-name, die zur Klärung und Sanktionierung der kanun-names dienen soll. Damit erreicht das osmanische Recht gemäß seinem traditionalen Charakter seine Grenzen und erfährt keine weitere systematische Entwicklung. Andererseits muß diesbezüglich hinzugefügt werden, daß die Wende an der Kodifizierungstradition gleichzeitig mit einer stärkeren Betonung der Scharia einhergeht. Dazu schreibt İnalcık:

„If the Ottoman sultans ceased to publish new kanun-names and preferred to issue adalet-names, this must have been due principally to the fact that the şari'a began to be considered as the source of legislation even in matters that hitherto had been the subject of legislative activity on the part of the

14 Dagegen spricht Nagel vom Zuwachs der Macht der Ulema, der in der Glanzperiode des Reiches (15. Jh.) ansetzt: „Zwar war er [der Gelehrtenstand] nach außen hin dem Großwesir gleichgeordnet; wie dieser empfing er seine Ernennung aus der Hand des Sultans. Doch genoß der Scheich des Islams mehr Ansehen, und der Sultan war gehalten, ihm in regelmäßigen Abständen einen Höflichkeitsbesuch abzustatten.“ (1981b: 151). 
political power. From the first decades of the seventeenth centure on, the kanun-name-i Osmani, general Ottoman law, became increasingly overloaded with fetwas, the legal opinions of the şeyh ül-islam, based on religious authorities." (1978: 136)

Die Existenz der doppelten Rechtstradition läßt sich ebenso auch an einer zentralen Figur des osmanischen Staates, Kadl, studieren. Nach İnalc1k wissen wir, daß „local cadis were responsible for administering the kanun-i Osmani as well as the şari'a“" (İnalcık 1978: 134). Der Kadı scheint bei den Osmanen im Vergleich zu anderen islamischen Staaten der klassischen Zeit stärkere Verwaltungs- und richterliche Kompetenten zu besitzen (Ortayl1 1994: 28; vgl. auch 1979: 138). Sein Aufgabengebiet umfaßt Notardienste, Grundbucheintragungen, administrative Inspektionen, Preisbindung. Mit einer ganz spezifischen administrativen Aufgabe, nämlich der Überwachung und Kontrolle der Ordensgemeinschaften, damit sich diese nicht ordnungsstörend betätigen, scheint der spätosmanische Kadı der Diyanet der Republik insofern vorausgegangen zu sein, als er auch Wächter staatlich konformer Religiosität war. ${ }^{15}$ Jedoch gibt es einen wesentlichen Unterschied: Der osmanische Kadı gehörte zu der partikularen Rechtsschule der Hanafiten, während die Diyanet, eingebunden in den modernen Verwaltungsapparat, im Prinzip einen „unparteiischen“ Islam zu vertreten hat. Diese Differenz bleibt für die Verwaltung der Religion nicht folgenlos, da entsprechend der Logik der modernen Verwaltungsinstitutionen und der Funktionsweise der politischen Rationalität des modernen Staates neue Problemlagen auftauchen.

Was bedeutet es denn nun, den Islam im Kontext der modernen Türkei, im Blick auf die Idee von der Machbarkeit der Gesellschaft, zu betrachten? Die Verpflichtung auf den spezifischen Kontext besagt zunächst einmal in inhaltlicher Hinsicht schlicht einfach, daß man es immer schon mit einem historisch je spezifischen Islam zu tun hat. In arbeitstechnischer Hinsicht wird man dann nicht mehr allein von ei-

15 Als ein aufschlussreicher Beleg dafür, daß die alte Reichspraxis im $\mathrm{Zu}$ ge der administrativen Transformationen gleichzeitig verstärkt und transformiert wurde, ist der staatliche Zugriff auf die Derwischkloster (zu türkisch: tekke ve zaviyeler) zu betrachten, der gegen Ende des Reichs, 1918, durch eine Art Satzung erfolgte, die sowohl die interne Organisation als auch die Aufgaben der Derwischkloster festlegte (für den ins Neutürkische übersetzten Text der Verordnung vgl. Ceylan 1989: 214ff). Die Relevanz der Regelung wird deutlich vor allem, wenn man bedenkt, daß es sich bei diesen um die Organisationen des Volksislam handelt, die ehedem jenseits der in den Staatsapparat eingebundenen Orthodoxie operierten. 
nem wie auch immer gearteten Islam bzw. nicht allein von religiösen Fragen sprechen. Es wird statt dessen der Maxime Folge geleistet: Wer über den Islam heute spricht, der muß unentwegt auch über andere Dinge von heute sprechen. Ein Grundzug der türkischen Modernisierung besteht in den Auswirkungen der politischen Rationalität, die sich über die Globalisierung westlicher Ideen und Institutionen auch in der türkischen Gesellschaft beobachten lassen. Schicksalhaft bleibt somit der Kontext der modernen Gesellschaftlichkeit und des Nationalstaats maßgebend für die Konzeptualisierungen des Islam. Unten werden zunächst einmal die Spuren dieser politischen Rationalität aufgespürt und ihre Folgen und kulturellen Brechungen diskutiert.

\section{Der makropolitische Kontext: Politische Rationalität und die moderne Staatlichkeit}

\subsection{Neue Akteure der Geschichte: Staat und Gesellschaft}

Gesellschaft ist ein geschichtliches Produkt. Auf diese geradezu kategorische Aussage kann man die Gedanken von Michel Foucault zur politischen Rationalität zuspitzen. Der renommierte Autor bahnbrechender Studien zur Archäologie der Wissenschaften und zur Genealogie der Macht sowie der Selbsttechniken hat sich in seiner Spätphase dezidiert mit der den modernen Staat kennzeichnenden politischen Rationalität befaßt (1991; 1993b). Die dort entwickelten Ideen führen exakt in den Kern der Überlegungen, die den für die Konzeptualisierungs- und Institutionalisierungsweisen des Islam in der Türkei entscheidenden makropolitischen Kontext der modernen Staatlichkeit umreißen.

Versuchen wir erst diese Studien in das Gesamtwerk von Michel Foucault einzuordnen. Foucault selbst versteht sein Werk, das aus reichhaltigen Untersuchungen zum Themenkomplex Machtverhältnisse, Wissensformen und Selbsttechniken besteht, im Rückblick als eine Antwortsuche nach drei Grundfragen.

„Mit meinen Studien über Wahnsinn und Psychiatrie, Verbrechen und Strafe habe ich herauszufinden gesucht, wie wir unser Selbst auf indirekte Weise durch den Ausschluß Anderer - z. B. Krimineller, Irrer usw. konstituiert haben. [...] Meine gegenwärtige Arbeit befaßt sich mit der Frage: Wie haben wir auf direkte Weise unsere Identität geschaffen mit ethischen Selbsttechniken, die sich von der Antike bis in unsere Zeit entwickelt haben?“ (Foucault 1993b: 169)

Solange er sich dennoch im Problemkreis dieser beiden Fragen bewegte, konnte Foucault seine Mikrophysik der Macht mit der für die 
moderne Zeit so unübersehbaren Existenz des Staates nicht in einen systematischen Zusammenhang bringen. Wie sollen Analysen zum Staat in diesen Analyserahmen eingeflochten werden? ${ }^{16}$ Damit kommt Foucault zu einem dritten Forschungsfeld, in dem er sich bemüht, „zu ergründen, wie wir mittels einer politischen Technologie der Individuen dahin gelangt sind, uns selbst als Gesellschaft wahrzunehmen, als Teil eines sozialen Gebildes, einer Nation oder eines Staates.“ (Ebd.)

Eigentlich hatte Foucault bis dahin in seinen diversen Arbeiten immer wieder die These unterstrichen, daß sich die Macht keineswegs in ihrer negativen Funktion, Verbote aufzustellen, in Form von Abgaben Wert abzuschöpfen und schließlich Soldaten einzuziehen, erschöpfe. Diese negative Form der Macht ist in der Moderne selbstverständlich nicht verschwunden, dennoch bildet sie nicht mehr das Spezifikum der modernen Macht. So suchte Foucault nach neuen Formen der Macht, die durch ihre Art, daß sie auf den Körper einwirken und dadurch ihn abrichten, einen „produktiven“ Charakter aufweisen (1976a und 1976b; 1977). Mit der Analyse der Techniken des Selbst konnte er nun über den Aufweis der auf den Körper zielenden disziplinären Techniken und von Techniken der Ausschließung hinaus gelangen. Die Verknüpfung der Subjektivierungstechniken mit dem Staat sollte aber erst durch die Analyse der ,politischen Technologie der Individuen“" hergestellt werden.

Meine Reflexionen werden ihren Ausgang von der Frage Foucaults nehmen: „Wie (sind) wir mittels einer politischen Technologie der Individuen dahin gelangt [...], uns selbst als Gesellschaft wahrzunehmen, als Teil eines sozialen Gebildes, einer Nation oder eines Staates (1993b: 169).“ Dabei geht es nicht um eine allgemeine Theorie des modernen Staates, sondern lediglich um das Auftauchen einer bestimmten politischen Rationalität, die genealogisch zur Entstehung des modernen Zentralstaates gehört.

Die Frage enthält schon auch einen ersten Wink darauf, worin die Antwort besteht: Es ist nicht eine natürliche Tatsache, daß wir uns als Gesellschaft wahrnehmen. Man kann dabei sogar den Satz von Foucault in dem Sinne verstehen, daß sich auch Gesellschaft nicht von sich aus versteht; sie ist selber Ergebnis von spezifischen historischen Veränderungen. Daran zeichnet sich auch die Methode ab, die von Foucault verfolgt wird. Die in einer Gesellschaft gültigen Machtver-

16 Gordon weist auch auf diesen Wechsel hin: „In his lectures of 1978 und 1979 Foucault began to outline a move from the previous, ,microphysi$\mathrm{cal}^{6}$ orientation of his work, in terms of studies of particular, regional, individualising rationalities and power structures, towards a ,macrophysics', a study of the exercise of power at the scale of ,governmental rationality“."(Gordon 1987: 296) 
hältnisse lassen sich nicht einfach aus universalen Prinzipien (wie in der Vertragstheorie) ableiten. Man müsse sie eher mit einer historischen Ontologie, wie Foucault sie betrieb, analysieren, und zwar so, daß selbst die universalistischen Erklärungen in einen historischen Rahmen hineingestellt werden können.

Die Frage, der in diesem Teil nachgegangen wird, läßt sich im Lichte dieser Entscheidung folgendermaßen formulieren: Mit welcher Art von Veränderungen/Entwicklungen in den Beziehungen zwischen Individuen und Macht hängt die Entstehung eines solchen politischen Subjekts wie des (modernen) Staats ${ }^{17}$, der seine Legitimität, ohne auf kosmologische Komplizen angewiesen zu sein, auf sich selbst zurückführt, eine Gruppe von Menschen um gemeinsame Zugehörigkeiten herum organisiert, in alle Lebensbereiche ordnend eingreift und schließlich unter besonderen historischen Konstellationen der modernen Türkei so etwas wie eine „offizielle Ideologie“ hervorbringt? Wenn man die Frage Islam im Kontext der Moderne beantworten will, muß man sie in einen Analyserahmen einbetten, in dem es sich zunächst einmal um nicht mehr und nicht weniger handelt als um die Genealogie des modernen türkischen Staates. Denn dieser bildet nun mal den makropolitischen Kontext für den historischen Status der islamischen Religiosität, sowohl in ihrer institutionalisierten Form einer staatlich verwalteten Religion als auch in Reaktion auf diese Verwaltung.

\subsection{Die Staatsraison}

Die Analyse des modernen (westlichen) Staates erscheint bei Foucault als Ergebnis einer komplexen Verbindung von politischer und pastoraler Macht. Die Beziehung, die zwischen dem Pastorat und der Klientel hergestellt wird, verweist auf eine eigentümliche Verknüp-

17 In dieser Formulierung, in der Staat als Subjekt erscheint, liegt indes die Gefahr, Foucaults Denken mißzuverstehen. Denn für ihn ist der Staat im Grunde ,a composite reality and a mythicized abstraction, whose importance is a lot more limited than many of us think" (1991: 103). Foucaults Interesse gilt folglich weniger einer Staatstheorie, die auf Institutionen fokussiert, als der Analyse der Veränderungen an politischen Praktiken bzw. politischen Technologien (vgl. auch Gordon 1991: 4). Nichtsdestotrotz wird man hier, besonders im Kapitel I.4 über die türkische Religionsbehörde, von der Analyse der Praktiken auf die Institutionen überzugehen versuchen. Dabei wird das sich aus der Rede von dem Staat ergebende Problem diskutiert, indem durch ihre Dekonstruktion auf die diskursiven Praktiken unterhalb des institutionellen Funktionierens hingewiesen wird. 
fung von Wissen und Macht, die für die moderne politische Rationalität nicht ohne Folgen bleiben wird (Foucault 1993b; Rainbow/Dreyfus 1987; Gordon 1987; Lemke 1997). Der zivilisatorischen „Eigenlogik“ der mit der Hirtenmetapher arbeitenden Pastoraltechnik wird dabei ein besonderer Stellenwert zugemessen.

Die Aufgabe des Hirten ist es, die Herde ihrem Heil entgegen zu führen. Das Erreichen des Ziels hängt wesentlich davon ab, daß der einzelne Gläubige einer Verpflichtung zur Wahrheit unterworfen wird. Dem Hirten muß die Wahrheit uneingeschränkt erzählt werden, dies wird wiederum über die Institution des Geständnisses gewährleistet. Bereits hier deutet sich die Verknüpfung von Wahrheit mit Macht an, ist es doch nicht irgendein beliebiger Gesprächspartner, dem man sich seine Geheimnisse enthüllt, sondern eine Instanz, die über das Verfahren wacht und letztlich auch beurteilt. Die Individualisierung durch Diskursivierung, wie sie sich in diesem geschichtlichen, sozialen Kontext vollzieht, bedeutet zugleich Anbindung an ein weit ausgebautes Netz von äußerer Macht. Wie es bei der Pastoraltechnik angefangen hat, so wird die Anbindung an eine Machtinstanz in anderen sozialen Beziehungen fortgesetzt. Die Führung der Seelen mündet im Bereich der politischen Herrschaft ab dem 17. Jahrhundert allmählich in der Regierungstechnologie, darin liegt die zivilisatorische Eigenlogik der „Führung der Seelen“.

Der Übergang von der Führung der Seelen, die wesentlich unpolitisch war, zu einer politischen Rationalität geht mit dem Auftauchen einer neuen Fragestellung einher, für die es im vorangegangenen politischen Imaginären keinen Platz gab: Nach welchem Rationalitätstypus soll regiert werden? Für Foucault kündigt sich in der schlichten Antwort, die im 17. Jahrhundert gefunden wurde, ein radikaler Bruch sowohl mit der christlichen politischen Tradition als auch mit dem Denken von Machiavelli an (Foucault 1993b: 172ff). Es handelte sich für die Theoretiker der Staatsraison, wie dieser Rationalitätstypus damals bezeichnet worden ist, nicht mehr um die Frage nach der gerechten Regierung; ebensowenig wollten sie mit Machiavellis Denken in Verbindung gebracht werden, das seinerseits auf die Frage fokussierte, „was das Band zwischen dem Fürsten und dem Staat zu festigen vermag“ (Foucault 1993b: 172ff). In den Zielen der Regierungskunst, wie es die Theoretiker der Staatsraison verstanden haben wollten, zeichnet sich mehr und mehr die Herausbildung eines Staatsverständnisses ab, das man als selbstreferentiell auslegen kann. Dieser Staat entwickelt sich also allmählich weg vom Fürsten in Richtung einer Autonomie hin, so daß unter dem Ziel der Regierung immer weniger die Stärkung des Fürsten verstanden wird. Vielmehr ist es der Staat, dem jetzt die Regierung verpflichtet ist, um seine Macht wach- 
sen zu lassen. Damit kann auch die Frage beantwortet werden, was denn unter dem Begriff der Staatsraison zu verstehen ist.

Eine verschiedene Ausführungen Foucaults dazu zusammenfassende Definition kann wie folgt formuliert werden: Staatsraison ist das Wissen um die Ressourcen des Staates und über die Techniken, die in die Bereiche von Religion, Ökonomie, Kunst, Gesundheit bis hin zu Erziehung, kurzum alle Lebensbereiche, ordnend eingreifen sollen, um die Stärke des Staates zu erhöhen. Das wichtigste Instrument der Staatsraison, die Polizei, wie sie damals weit über die Sicherheitsfragen hinaus verstanden wurde, sollte die Ausführung dieser Aufgabe gewährleisten. Die gleiche Epoche wird auf epistemologischer Ebene Zeuge der inneren Verknüpfung von Macht und Wissen in Gestalt von Polizeiwissenschaft (vgl. Wagner 1995: 80). Der Staat, der sich nun der Bürde entledigt hat, das Gottes Reich auf Erden herzustellen, Gottes Schwert auf Erden zu sein, alle Staaten unter dem Banner des richtigen Glaubens zu vereinen etc., sieht sich nunmehr unter vielen anderen Staaten, deren Existenz er anerkennen muß, ständig zu beobachten und gegen sie zu konkurrieren hat.

Der Gegenstand der Staatsraison sind nicht mehr einfach Rechtssubjekte, die in einer rechtlichen Beziehung zu dem Souverän stehen, wie es noch das juridische Konzept der Macht vorsah; es sind nunmehr Individuen als lebendige, arbeitende und wirtschaftende Wesen. Entlang der Beispiele aus dem 1705 von N. Delamare für französische Staatsbeamten fertiggestellten Handbuch stellt Foucault die Lebensbereiche vor, um die sich die Polizei kümmern soll: Religion; Moral; Gesundheit; Versorgung; Wege, Straßen und städtische Bauten; öffentliche Sicherheit; freie Künste; Handel; Fabriken; Dienstleute und Fabrikarbeiter und schließlich die Armen. Somit taucht ein neues Objekt der Regierungspraxis auf, welche wiederum mit einer Technik verknüpft wird: Das „Objekt der Polizei ist das Leben“ (Foucault 1993b: 182).

Eine ähnliche Entwicklung ist in Deutschland zu beobachten. Die Krise des Ständegesellschaft im Spätmittelalter bringt eine immense Fülle von Ordnungsaufgaben hervor, die jetzt mehr und mehr Gegenstand neuer Staatlichkeit werden und zugleich zum Aufbau derselben beitragen. Hier füllen Polizeiordnungen mehr und mehr die durch die Auflösungserscheinungen der alten sozialen Bindungen entstandene Lücke. Der Historiker Hans Maier gibt den Umfang der Tätigkeit der Polizei folgendermaßen wieder:

„Von dem alten, vom Reich nie völlig gemeisterten Aufgaben der Friedenssicherung über die schwierigen Probleme der Regelung des Handels und Erwerbs bis hin zum persönlichen Bereich von Religion und Sitte erstreckte sich der Katalog der Ordnungsaufgaben. Dabei war es nicht so, daß der 
Staat, der diese Ordnungsprobleme lösen konnte, bereits vorhanden war [...].“(1966: 93)

$\mathrm{Da}$ die Staatsraison besonders in Frankreich und Deutschland zur Anwendung gekommen ist, besitzt besondere Relevanz für das Thema des vorliegenden Buches. Die modernen politischen Praktiken und Institutionen in der Türkei haben sich vorrangig an diesen beiden historischen Beispielen orientiert, während der angelsächsische Einfluß kaum Wirkung entfalten konnte. Die Bemühungen des Prinzen Sabahaddin, des ersten Vertreters eines Liberalismus, - Ende des 19. Jh. konnten kein positives Echo finden. Der reichhaltige Erfahrungsvorrat, den die Osmanen in Sachen der Reichsführung später dem säkularen Staat der Republik vermachtet haben, begünstigt die Übernahme der kontinentalen zentralstaatlichen Praktiken, während dadurch gleichzeitig die angelsächsische Politik kaum Resonanz findet. Die türkische Staatsraison hatte in einer bestimmten Hinsicht gute Startbedingungen, da der Staat, welcher die neuen Aufgaben übernehmen sollte, sich nicht erst aus dieser Tätigkeit entwickeln mußte. Das bereits bestehende osmanische Staatserbe mit dem dazugehörigen, hochentwickelten Organisationsgrad wirkte hier durchaus gewissermaßen begünstigend.

Die besondere Relevanz dieser Ausführungen besteht darin, daß nun die Beschäftigung der Regierung mit der Religion unter einem neuen Gesichtspunkt stattfindet. Der neuen politischen Rationalität geht es dabei, so Foucault, keineswegs um die rechte Lehre, sondern um die moralische Qualität des Lebens der Bürger. Schaut man sich analog dazu die Übernahme der Regierungstechnologien durch die Osmanen insbesondere in der zweiten Hälfte des 19. Jh. und ihre verstärkte Ausübung nach der Gründung der Republik an, so präsentiert sich dort eine ähnliche Entwicklung, wenn auch mit einigen, später zu explizierenden Unterschieden. Das Amt für Religiöse Angelegenheiten (Diyanet), welches, mit dem zunehmenden Ausgreifen der staatlichen Hand in das ganze Leben der Gesellschaft einhergehend, zur Transformierung des türkischen Islam aus unzähligen, lokal organiserten Glaubensrichtungen in einen einheitlichen religiösen Körper (sowohl institutionell als auch dogmatisch) unverkennbar beigetragen hat, verdankt seine spezifische institutionelle Existenz ebenfalls auch der Staatsraison, so wie sie in Deutschland und Frankreich entwickelt wurde. $^{18}$

$18 \mathrm{Da}$ indes die staatliche Religionspolitik keineswegs konfliktfrei verläuft, wird ebenfalls noch zu diskutieren sein. Die Ordnungsinteressen des Staates und die materialen Wertvorstellungen der ihres Amtes waltenden Geistlichen decken sich nicht immer und nicht nur, sie gefährden sich auch gegenseitig. Darüber hinaus, auch dieser bedeutsame Aspekt sei hier nur vorweg erwähnt, wird die diskursive Ausgestaltung 
In der französischen und deutschen Verwaltungspraxis kommt hiermit ein neues Machtkonzept zur Geltung, welches sich darin ausdrückt, daß sich die Macht nicht mehr auf eine Verfügungsgewalt über Töten und Lebenlassen beschränkt. Der neue Machttypus bringt zur gleichen Zeit seiner Entstehung in dem Begriff der Bevölkerung ein neues Objekt hervor, in das sie sich mit Techniken und für Ordnungsaufgaben einzugreifen berechtigt sieht. Ist es fortan schwierig geworden, vom Volk der Untertanen lediglich als einer Ressource für Abgaben und Rekruten zu sprechen; drängt sich nun die Bevölkerung als eine Größe auf, die aus lebenden, arbeitenden, wirtschaftenden Menschen besteht, dann ist zu konstatieren, daß der mit neuen Aufgaben bevollmächtigte Staat nicht alleine die Praktiken, Mentalität und Institutionen des alten Reichs modifiziert, sondern gleichzeitig Brüche mit der vorangehenden Staatlichkeit markiert. Das Verhältnis zwischen Staat und Bevölkerung basiert von nun an einerseits auf Disziplinartechniken, die in der Machtkonzeption Foucaults einen zentralen Platz einnehmen und für das Verständnis der Eindringung der staatlichen Macht in Mikrobereiche durch Einwirkung auf den mechanischen Körper von immenser Bedeutung sind; andererseits interveniert der Staat in das Leben der Bevölkerung durch Bevölkerungsplanung, Versicherungs- und Gesundheitsauflagen, Erziehungsauftrages und Beschäftigungsinstrumente. Beide Machttechniken, nämlich die Disziplinartechniken und Bevölkerungspolitik, faßt Foucault unter dem Begriff der Biomacht zusammen. Angesichts der Transformierungsprozesse, die sich auf der Ebene von Staat und Bevölkerung abspielen, liegt es nahe, daß unter den Bedingungen des modernen Staates mit seiner spezifischen Rationalität der religiöse Glaube in die strategischen Machtspiele eingespannt wird - in dieser Hinsicht ist es völlig einerlei, ob er in den Erziehungsanstalten des Staates unter bestimmter Zielvorgabe gelehrt wird oder in der Sprache einer sich religiös artikulierenden Opposition als eine alternative Ideologie für eine andere Gesellschaft und einen theokratischen Staat eingesetzt wird. Letztlich verwandelt er sich in eine Religion, in die sich die Spuren der modernen Rationalität eingeschrieben haben und die erst im Kontext der rationalen Bearbeitung der Bevölkerung adäquat zu verstehen ist. Im nächsten Kapitel werden solche Veränderungen in der türkisch-osmanischen Vorstellungswelt und Regierungspraxis diskutiert.

der türkischen Staatsraison unter der Wirkung der historischen Selbstverständlichkeiten starke inhaltliche Züge aufweisen (vgl. Kapitel I.4). 


\section{Transformationen an der Staatlichkeit}

\subsection{Ideen: Vom Mülk des Sultans zum Staat}

Die spezifische Verknüpfung, welche die in westlichen Gesellschaften funktionierende moderne Rationalität zwischen Macht und Wissen herstellte, blieb den Osmanischen Erneuerern im 19. Jahrhundert nicht verborgen. Bereits für Ali Suavi (1839-1878) lagen die „Grundlagen der Macht nicht auf der Scharia und Literatur, sondern auf Geographie, Wirtschaft und Moral“ (vgl. Ülken 1979: 79). Den Gedanken, die Macht auf weltliche Grundlagen zu verlegen, begleitete bei Suavi eine Selektion von unterschiedlichen Dimensionen der Religion. Der Koran und die Hadithe (Überlieferungen vom Propheten) könnten demnach nicht die weltlichen Angelegenheiten begründen; sie gäben lediglich für ibadet (Ritus) die Grundlage ab. Intendiert wird somit von ihm die Privatisierung der Religion; sie soll sich aus dem politischen Bereich zurückziehen und auf Moral beschränkt werden. Fortan erscheint die Religion, zumindest was ihre öffentliche Stellung anbelangt, mehr und mehr unter dem Gesichtspunkt ihrer Funktionalität im größeren Zusammenhang der Kultur (zur Religion als Kultur vgl. Luhmann 1996).

Im Grunde hatte sich schon vorher eine Entwicklung in der Frage Macht und Legitimität abgezeichnet, die sich von der Art und Weise, die für die klassische Epoche bezeichnend waren, mehr und mehr unterschied. Faruqhi (1989) hat bei der Darstellung der verschiedenen Legitimationspolitiken im Osmanischen Reich hervorgehoben, daß sich etwa die Bautätigkeiten und die Sicherung von Pilgerkarawanen besonders als effektive Legitimationsgrundlage hervortaten. Eine durchgehende und systematisierte Bezugnahme auf den Islam als Legitimationsquelle ist in dieser Zeit nicht zu beobachten. Außerdem fehlte ja auch dem Kalifentitel ,im Osmanischen Reich jeglicher greifbare Inhalt“ (Nagel 1981b: 176). „Es gab“, so fährt Nagel fort, „keine Herrscherideologie, keine religiös begründete Ordnungsvorstellung, die den Anspruch des Sultans auf das Kalifat gerechtfertigt hätte"(ebd.).

Erst im 19. Jh., dies besonders mit der oppositionellen, konstitutionalistischen Bewegung der Neoosmanen und zur Zeit des Sultans Abdülhamid II (1876-1908), dem die Begründung einer panislamistischen Politik zugeschrieben wird (vgl. Hülagü 1994; Türköne 1991), setzten Anfänge einer systematischen Reflexion über den Islam und islamische Lösungen für gesellschaftliche Probleme ein. Die systematische Bezugnahme auf den Islam als Machtinstrument für den sozialen Zusammenhalt und die ersten Zeichen seiner „Privatisierung“ gehören in den gleichen geschichtlichen Kontext, in dem die Religion 
prinzipiell unter dem Blickwinkel ihrer Funktionalität für die Politik betrachtet wird. Festzuhalten ist hier, daß die Beziehung der Souveränität zur Wissenschaft mit der Entstehung eines neuen Raumes zusammenhängt, in dem sich Ziel und Gegenstand der Macht verschieben. Es handelt sich bei diesem neuen Machttypus nicht mehr allein darum, Gehorsam der Untertanen (Reaya) zu gewährleisten und sie zu Leistungen wie Abgaben und Dienst an der Waffe zu zwingen. Aus den Untertanen soll eine Bevölkerung erwachsen, die man mit Hilfe wissenschaftlicher Praktiken und Techniken zur Stärkung des Staates nutzbar machen will. Inwiefern das Auftauchen eines solchen Machtkonzeptes tatsächlich voll zur Geltung gelangte, ob es völlig neu war oder nicht eher in mancherlei Hinsicht einige alte Vorstellungen und Praktiken übernommen hat, soll im Verlauf dieses Kapitels nach und nach aufgezeigt werden. Außerdem bleibt die Verknüpfung von Macht und Wissen zunächst einmal hypothetisch, als Utopie. Man muß dabei nicht sogleich vermuten, daß sie im türkischen Fall ähnlich der europäischen Entwicklung, wie sie z.B. von Foucault beschrieben wurde, voll zur Geltung kam. Warum man bezüglich dieser Thematik vorsichtig sein soll, wird im Kapitel III erhellt. Dort kann man sehen, daß sich die kulturspezifischen Formen der Selbstkonstitution die politischen Konzepte und das Funktionieren der übernommenen Institutionen (auch der Wissenschaft) durchkreuzen. Wenn man nämlich mit Foucault von einem wesentlichen Zusammenhang zwischen der politischen Technologie und den auf Geständnis basierenden Selbsttechniken ausgeht, wenn man also die Kontrolle der Individuen von außen mit den Techniken der ethischen Selbstkontrolle von innen verbindet, dann bietet sich Anlaß für die Annahme unterschiedlicher Entwicklungen in einer Kultur, in welcher der Aspekt der Selbstkontrolle anders (nämlich ohne Geständnis- bzw. Enthüllungspraktiken) konzipiert war. Im folgenden wird jedoch zunächst anhand zwei Texten auf die Veränderungen in der Vorstellungswelt der osmanischen Intellektuellen gegen Ende des 19. Jh. und Anfang des 20. Jh. eingegangen, wobei nicht vergessen werden darf, daß diese Veränderungen auf einer längeren Vorbereitungszeit basieren.

Yusuf Akçura (1879-1935) gilt als eine der Leitfiguren der Türkismus-Bewegung. Sicherlich gehörte er zu den politisch engagierten Intellektuellen, die entsprechend dem damaligen Zeitgeist die Grundlagen für den Nationalismus auf einer völkischen Linie anlegten. Wichtiger, oder zumindest genauso wichtig, ist dennoch, ohne den erstgenannten Gesichtspunkt aus den Augen zu verlieren, auf einen anderen Punkt hinzuweisen. In seinem 1904 abgefaßten Text $\ddot{U} c ̧$ Tarzı Siyaset (zu deutsch: Die drei Arten der Politik) deutet sich ein berechnender bzw. instrumenteller Umgang mit dem Regieren und der Iden- 
titätsbildung an, der in dieser Form einen Einschnitt im politischen Denken der Osmanen markiert. Akçura geht dort der für seine Zeit paradigmatischen Frage nach: „Welche von den Politikarten Moslemtum, Türkentum und Osmanentum sind nützlicher und praktikabler für den Osmanischen Staat?“ (1987 [1904]: 26) Die Analyse der Bedeutsamkeit, die Akçuras Überlegungen in Bezug auf das Auftauchen moderner politischer Rationalität auszeichnet, bedarf im Vorfeld einer Darstellung der drei Arten der Politik, wie sie von ihm konzipiert worden sind.

Die Anzeichen für die erste Politikart, das Osmanentum, macht Akçura bereits in den ersten Reformansätzen im ausgehenden 18. Jh. aus, bis es sich gegen Ende des 19. Jh. endgültig als unpraktisch erwies. Die Idee des Osmanentums strebe, beeinflußt von dem französischen Prinzip der Nation, das nach Akçuras Verständnis die Zusammengehörigkeit im individuellen Gewissen begründet, die Schaffung einer osmanischen Nation an, in der, wie es für die amerikanische Gesellschaft gelte, unterschiedliche Gruppen von Menschen ungeachtet ihrer Rasse und Religionszugehörigkeit gleichgestellt seien. Sultan Mahmud II (1808-1839), dem eine umfassende Reform des Militärwesens gelang, soll seine Vorstellung von seinem Volk folgendermaßen zum Ausdruck gebracht haben: „Ich will die religiöse Differenz meiner Untertanen nur in der Moschee, Synagoge und Kirche sehen.“ (zit. n. Akçura 1987 [1904]: 20)

Eine osmanische Nation würde für Akçuras Begriffe selbstverständlich den Interessen des osmanischen Staates zugute kommen, würden doch christliche, jüdische und muslimische Untertanen als gleichberechtigt zusammen für die Stärke des Staates sorgen. Jedoch scheitert die Politik einer osmanischen Nation am mangelnden Interesse muslimischer und christlicher Bevölkerungsteile. Mit dem Scheitern des Osmanismus tritt die islamische Politik als Alternative in Erscheinung. Alle Muslime sollen nunmehr, darin besteht das Ziel dieser auch als Panislamismus bezeichneten Politik, ungeachtet ihrer ethnischen Herkunft zusammengeführt werden - zunächst im osmanischen Lande, dann aber auch in der ganzen Welt. Akçura beschreibt, wie der in Europa als „roter Sultan“ bekannt gewordene Abdülhamid II (reg. 1876-1909 ) nunmehr seinen Titel Kalif in den Vordergrund rückt, der die religiös neutralen Bezeichnungen Sultan und Padischah verdrängte. Unter den diesbezüglichen Praktiken fallen die Islamisierung der Bildung, vermehrter Besuch von Geistlichen im Palast des Sultans und rapide Zunahme an Moschee- bzw. Derwischklosterbauten (tekke ve zaviyeler) auf. Gegenüber der starken Fundierung des Islamismus steht der Türkismus in politischer Hinsicht auf recht schwachen Füßen. Er bleibt zu Zeiten von Yusuf Akçura vielmehr eine akademische Bewegung. Der Türkismus unterscheidet sich nach Akçura von der 
französischen „Leichtigkeit“, die den Osmanismus bestimmt habe, deutlich dadurch, daß er sich am deutschen Prinzip der Nation orientiere, welches auf Kultur und Rasse ${ }^{19}$ beruhe. Die Abkehr vom Osmanismus und Zuwendung an den Türkismus erscheint nach Akçura als Werk von Akademikern, die vom deutschen System beeinflußt worden seien und sich gegenüber der französischen „Leichtigkeit“ durch ihre in „Ruhe, Beharrung und Forschung erworbene Wissenschaft“ (Akçura 1987 [1904]: 23) auszeichneten (zum deutschen Einfluß auf die türkische Modernisierung vgl. auch Ortaylı 1983 und Aydın 1998, insbes. S. 64).

Nachdem Akçura die verschiedenen Varianten aus dem seinerzeit aktuellen politischen Diskurs präsentiert hat, wirft er die Frage auf, welche nun die nützliche Politik für den osmanischen Staat sein soll. Allerdings besteht noch kein Grund zur Annahme, hierin stecke ein Novum in der osmanischen politischen Geschichte, solange die eigentlich entscheidende Frage von Akçura nicht in den Blick gelangt: „Vorher muß eine andere Frage geklärt werden: Worin bestehen die Interessen einer bestimmten Gesellschaft?“ (1987 [1904]: 25; Hervorhebung L.T.)

Sofern dies eine politische Frage sei, nehme sich die politische Wissenschaft ihrer an, wenngleich ihr Akçura gleichzeitig attestiert, daß sie noch keine Antwort auf die Frage gefunden habe. Während sie wissenschaftlich noch nicht entschieden sei, werde sie jedoch von Gesellschaften praktisch tagtäglich beantwortet. An dieser Stelle enthüllt sich schließlich der systematische Wert seiner zentralen Frage und der von ihm darauf gegebenen Antwort, die einen bereits in vielerlei Hinsicht faktisch vollzogenen Bruch innerhalb der osmanischen Staatlichkeit reflektiert. Es waren bisher Fürstenspiegel, die den Sultan mit nötigen Analogien, Weisheiten und genealogisch begründeten Empfehlungen versorgten. Und es ging bei politischen Angelegenheiten immer um die Frage, wie der Sultan sich am besten verhalten sollte bzw. wie die unterschiedlichen Teile des Staatsapparates arbeiten sollen. Auch kannte der osmanische Hof, analog zum Hofnarr, die Figur des Geistlichen/Lehrers, der den Sultan von Kind auf in Staatskünsten, Betragen und Wissenschaften belehrte. Nie konnte aber zuvor die Fra-

19 Die unbefangene Wiedergabe des Begriffs Rasse möge hier keinen Anstoß erregen. Man bedenke nur, daß das für den damaligen Sprachgebrauch völlig normal war. Heute würde man ebenso unbefangen von der Ethnie sprechen. Angemerkt sei auch, daß Akçuras Rassendiskurs noch sehr weit vom Rassismus entfernt ist. Denn sein Diskurs hat noch keinen Hauch von Hygenie, Säuberung und Überlegenheit, alles, was später den rassistischen Diskurs ausmachen wird. Für eine hervorragende Analyse des Rassendiskurses und seines Unterschiedes zu dem bzw. seiner Überleitung in den Rassismus siehe Foucault 1986. 
ge nach den „Interessen einer bestimmten Gesellschaft" gestellt werden, die überdies Gegenstand von wissenschaftlichen Überlegungen technischer Natur sein sollte. In diesem Lichte kann man die Bedeutung seiner eigenen Antwort besser erkennen: Jede Gesellschaft hat ein Interesse am Leben, d.h. am Machtgewinn und Machzuwachs (1987 [1904]: 26). Auffallend spricht Akçura auch in Bezug auf den Staat nicht vom Sultan oder vom Kalifen. Dieser scheint in seinem Gebrauch in keinem organischen Verhältnis zum Staat mehr zu stehen, auch wenn Akçura in seinem Text die Legitimität des Sultans nicht explizit in Frage stellt. Wie leicht zu verstehen, kann es sich hier nicht mehr bloß um den Sultan/Kalifen handeln, der auf seine Herrschaft bedacht ist, sondern um die neuen Subjekte der Geschichte (Staat und Gesellschaft). Selbst der Sultan ist, wenn auch nicht offengestanden, zu einem Stück in der großen Zweck-Mittel-Relation degradiert worden.

Der Staat befindet sich auch bei Akçura wie ähnlich bei den deutschen und französischen Theoretikern der Staatsraison inmitten eines Existenzkampfes der Gesellschaften. Erst in dem Vorstellungsraum von einem Existenzkampf führenden, vom Körper des Sultans abgelösten Staat einerseits ${ }^{20}$ und einer mit Techniken und Praktiken nach und nach zu entwickelnden Gesellschaft andererseits, taucht die Frage nach kollektiven Identitäten auf, mit denen die Unterstützung der Bevölkerung gewährleistet werden soll. Und schließlich in einem solchen Raum wird erst eine vom Körper des Herrschers abgelöste Debatte darüber vorstellbar, welches Mittel - Osmanismus, Türkismus oder Islamismus - richtig ist, um die Macht des Staates zu fördern. Akcuras Überlegungen, die in den Kontext eines sich herausbildenden neuen Konzepts von Staat und Herrschaft gehören, münden unter den Bedingungen der militärischen Bedrohung des Reiches von außen rasch ins Nachdenken über Mobilisierung und Zusammenhalt.

Hier fällt eine eigentümliche Ambivalenz an der Haltung von Akçura auf. Während er Nutzen und Nachtteile einer jeden Politikart für die Stärke des Staates mit der Manier eines Buchhalters gegeneinander ausrechnet und einen instrumentellen Umgang mit Identitäten an den Tag legt, nimmt er bezüglich der Frage, für welcher Gesellschaft

20 Das war dennoch, historisch gesehen, bis zur Verkündung der Republik im Jahre 1923 noch kein empirisch durchgehendes Faktum. Der Kopf des Sultans war zwar mehrmals angeschlagen worden, gerollt war er dennoch noch nicht. Die letzte Phase des Osmanischen Reichs wird somit durch das Spannungsverhältnis zwischen den weiteren institutionellen „Anschlägen“ auf den Sultan und seinen Versuchen, die eigene Herrschaft gegen die Autonomisierung des Staates zu entschärfen, gekennzeichnet sein. Sein Kopf wird schließlich mit der Republik endgültig fallen. 
Interessen wir uns einsetzen sollen, gleichzeitig eine dezisionistische Haltung ein. Wenn nämlich zwischen Gesellschaften, genauso wie bei allen lebendigen Seienden überall im Universum, ein ständiger Kampf tobt, was heißt, daß das Interesse jeder Gesellschaft in ihrer Fortexistenz besteht, wenn zudem der Nutzen für eine Gesellschaft meistens zum Nachtteil anderer Gesellschaften erlangt werden kann, dann stellt sich die Frage, warum Akçura sich für den Islam oder das Türkentum einsetzen soll, und „warum nicht für Slawen und Orthodoxen“ (1987 [1904]: 26), wie er es sich selber befragt. Seine Antwort auf dieses Gedankenspiel weist eine interessante zeitliche und inhaltliche Parallelität mit der berühmten These von Max Weber von dem Kampf um die letzten Werte auf, der deshalb besteht, weil die letzten Werte nicht wissenschaftlich entschieden werden können. Weber formulierte dies seinerseits folgendermaßen:

„Vorausgesetzt ist aber ferner: daß das, was bei wissenschaftlicher Arbeit herauskommt, wichtig im Sinn von, wissenswert sei. Und da stecken nun offenbar alle unsere Probleme darin. Denn diese Voraussetzung ist nicht wieder ihrerseits mit den Mitteln der Wissenschaft beweisbar. Sie läßt sich nur auf ihren letzten Sinn deuten, den man dann ablehnen oder annehmen muß, je nach der letzten Stellungnahme zum Leben.“ (Weber 1967 [1917/1919]: 22)

Als wollte nun Akçura 1904 das vorwegnehmen, was Weber 1919 in einem kurzen Beitrag über den modernen Nihilismus aussagte, antwortet er auf die Warum-Frage mit Verweis auf „unser Gefühl, das unsere Vernunft hat noch nicht durchleuchten können“ (Akçura 1987 [1904]: 26). Die Frage könne nicht logisch entschieden werden. Nur unser Gefühl sage uns, wofür wir uns einsetzen sollen. Daher ist es für Akçura klar, daß er sich für die Interessen des Islam und des Türkentums einsetzen solle, wobei er sich hier nicht mehr entscheiden kann, welches von beiden für den Staat besser ist. Blickt man von hier aus auf die Konzeption der politischen Technologie nach Foucault, so strahlt ein neues Licht auf eine Lücke zurück, die sich in seinen Überlegungen auftat. Foucault konzentrierte seinen Blick hauptsächlich auf den Aspekt der Individualisierung durch die Macht, während der Aspekt der kollektiven Identitäten kaum Beachtung fand. Die Codierung des Lebens durch die Biomacht geschieht aber neben den individualisierenden Techniken ebenso auch mittels kollektiver Identitäten (kritisch zu Foucault vgl. Keskin 1997: 40). Ja, man müßte die individualisierenden Techniken der Macht in einen wesentlichen $\mathrm{Zu}-$ sammenhang mit dem Auftauchen der kollektiven Identitäten setzen. Die entkörperte Macht des Staates, die zugleich die individuellen Körper produktiv erschließen, d.h. ihre materiellen Ressourcen mobilisieren will, bedarf anscheinend unabdingbar der inneren Mobilisie- 
rung dieser Individuen, um sie zur Stärke des Staates dienlich zu machen. Anhand des Textes von Akçura kann man also feststellen, wie die Vorstellung einer Identitätspolitik, wenn auch noch in nuce, aus dem Zusammenhang der Autonomisierung der politischen Macht entspringt. Ein Sultan in der klassischen Zeit brauchte keine Identitätspolitik, ein Nationalstaat hingegen codiert seine Bürger mit einer gemeinsamen Identität und ist angewiesen auf ihre identitätspolitische Mobilisierung. Selbst wenn der Anbruch der Staatsraison historisch gesehen noch keine relevante Verbindung zur kollektiven Codierung der Bürger aufgewiesen haben sollte, ist die Möglichkeit des Auftauchens kollektiver Identitäten bereits in seine Genese eingeschrieben.

Oben wurde bezüglich Akçuras Ambivalenz von seiner buchhalterischen Berechnung von Nutzen und Nachteilen verschiedener Politikarten gesprochen, die zu seiner auf Identität bezogenen Entscheidung in einem Spannungsverhältnis steht. Vielleicht rührt die Ambivalenz auch daher, daß Akçura in einem historischen Schnittpunkt steht, welcher zwei Bruchpunkte in der osmanischen Staatlichkeit miteinander verbindet. Während seine instrumentelle Redeweise vom selbstbezogenen Machtzuwachs als Ziel des Staates den ersten Bruch markiert, nämlich den Einbruch der Staatsraison, steht er auf der anderen Seite an der Schwelle zum Nationalstaat, in dem jetzt neben den Mitteln zur Förderung der staatlichen Macht auch die Identität des Staates auf die Tagesordnung rückt. In Bezug auf unseren thematischen Zusammenhang heißt das, zunächst einmal festzustellen, daß die Religion nunmehr als eine mögliche Identitätsgröße, und zwar nicht nur für die Herrschaftslegitimation, sondern auch für die aktive Mobilisierung der Bevölkerung, systematisch reflektiert und mit der Machtfrage gekoppelt wird. Auch die Islamisten, welche anders als Akçura, der ja noch starke Ambitionen auf den Türkismus hegte, die Identitätsdimension des Islam besonders hervorhoben, werden sich dieser Ambivalenz nicht gänzlich entziehen können, taucht doch auch bei ihnen Religion als (bester) Komplize des Zentralstaates auf. Erst mit einer neuen islamistischen Welle, die vor allem im Zuge der iranischen Revolution von 1979 in der zweiten Hälfte der 80er Jahre in der Türkei einsetzt - getragen u.a. von mit westlichen Ideen, vor allem mit der westlichen Zivilisationskritik, vertrauten Intellektuellen - wird das Verhältnis zwischen Staat und Religion grundsätzlich problematisiert. Erst spät wird also der Nationalstaat als ein ,westlicher Importartikel“ einer grundsätzlichen Kritik unterzogen, aus der jetzt „urislamische“ Modelle für ein politisches Gemeinwesen hervorgehen sollen, die den Islam als „ummatistische Utopie“ konstruieren (dazu im Kapitel II). Selbst diese sind aber bereits von den Strukturbedingungen des Nationalstaates „kontaminiert“, da die Religion als Ideologie der politischen und der Rechtsordnung erst durch die nationalstaatliche Rahmung der 
Gesellschaft denkbar wurde. Mehr noch, sie wurde als Machtfaktor und strategisch erst durch die modernen Institutionen (entstanden bereits in der letzten Phase des Osmanischen Reiches, endgültig etabliert in der Republik) in die Gesellschaft hineingestrahlt. Damit wurden zugleich die Bedingungen der Möglichkeit dafür vorbereitet, daß die Religion in der Gesellschaft als ein allgemeines Gut neu rezipiert und als Gegenmacht zur staatlichen Macht ins Felde geführt wurde. ${ }^{21}$

Am Beispiel von Akçura kann man also das Heraufkommen einer bestimmten Konzeptualisierung der Religion durch ihren strategischen Einsatz beobachten, wonach die Religion, ähnlich wie im europäischen Vorbild und aufgrund von dort übernommenen Ideen und Praktiken, unter dem Gesichtspunkt ihrer Funktionalität in Frage kommt. Die islamische Religion „kann“, so Akçura, „bei der Herausbildung der großen türkischen Nation ein wichtiger Faktor werden“" (1987 [1904]: 34). Damit der Islam den von ihm erwarteten Dienst erfolgreich erweisen kann, muß er sich allerdings, „wie das in letzter Zeit auch im Christentum ist, dahingehend verändern, daß er die Existenz der Nationen akzeptiert" (Ebd.) Akçuras nüchterner Blick registriert europäische Entwicklungen im Bereich der Religion exakt, wenn er auf Individualisierung und Privatisierung der Religion hinweist. Wenn er die Elemente moderner, europäischer Religiosität aufzählt, hat sich seine Intention dabei unmißverständlich in das Programm eingezeichnet, das darauf abzielt, die Religion für die Zwecke der „Rassen“ einzuspannen. In seinem hier ausführlich diskutierten Aufsatz kann sich jedoch Akçura nicht entscheiden, welche Politikart für den osmanischen Staat von Nutzen ist. Auf jeden Fall birgt jede von ihnen eigentümliche Probleme: die islamische Politik würde die Idee der Gleichheit der Bürger nicht vertragen, betrachtet doch der Islam die nichtmuslimischen Untertanen als nicht gleichberechtigt; der Türkismus würde zur Abspaltung muslimischer, jedoch nichttürkischer Völker vom Reich führen, es sei denn, es gelingt ihr ihre Assimilation in die türkische Identität. ${ }^{22}$ In seinem späteren Werk (1990 [1928]) erinnert er selber an seine damalige Unentschlossenheit, und sein Urteil

21 Damit ist der Einbezug eines generalisierten Religionsverständnisses auf die öffentliche Ordnung gemeint, die auch als solche erst im Entstehen begriffen war; es handelt sich um die Sorge um eine öffentliche Ordnung, die über die Wahrung des sittlichen Lebens im Viertel hinausgeht.

$22 \mathrm{Daß}$ dies nicht ganz gelungen ist und ja diese Politik sich längst in einer Sackgasse befindet und hauptsächlich über Gewalt aufrechterhalten wird, hat der jüngste Kurdenaufstand (Mitte 90er Jahre) unter Beweis gestellt. Um so selbstbewußter präsentiert der Islamismus das islamische Band als tauglich für die nationale Einheit. Die Verstrickungen zwischen Islam und nationaler Einheit scheinen weiterhin zu bestehen. 
fällt diesmal eindeutig für den Türkismus aus. Allein, seit fünf Jahren, Kalender schreiben mittlerweile das Jahr 1928, besteht die türkische Republik als historisches Faktum.

Wirkungsgeschichtlich betrachtet wird die Idee der Staatsraison in Akçuras Denken immer mehr zu einem Anhängsel seines Nationalismus ausarten. In der sich auf ihn berufenden, rechtsnationalistischen Tradition, aber auch in der darauf folgenden Staatspraxis wird das spannungsvolle Verhältnis zwischen Religion und Staat bzw. nationalen Interessen fortwirken, wenn auch dabei die Pole der Spannung konjunkturell unterschiedliche Gewichtungen erhalten werden. Konstant bleibt dennoch die historische Tatsache, daß das erst aus dem Zusammenhang des modernen Staates hervorgegangene funktionale Interesse an der Religion weiterhin den Kontext unterschiedlicher Konzeptualisierungsweisen des Islam umreißt. ${ }^{23}$

Die Bezugnahme auf Akçura im Hinblick auf die Anzeichen der Idee von Staatsraison soll hier nicht weiter ausgeführt werden. Es verdient ein anderer Name an dieser Stelle genauso viel Beachtung. Es ist von Ziya Gökalp (1876-1924) die Rede, der für eine soziologische Untersuchung nicht zuletzt aus dem Grunde interessant sein dürfte, daß er als erster in einer systematischen Art und Weise über die türkische Moderne und ihre politischen Implikationen soziologisch reflektiert hat.

23 Ein wichtiger Hinweis sollte hier nicht zurückbehalten werden. Es wurden im bisherigen Verlauf der Darstellung ausschließlich Akçuras Ideen diskutiert, die von ihm ausgelöste Diskussion wurde hingegen mit keinem Wort erwähnt. Dabei enthält die Kritik, die bspw. Ali Kemal (1987[1904]) an Akçuras Ideen übte, einen für unsere Fragestellung bedeutsamen Punkt. Hier kommt eine andere Regierungstechnologie zur Sprache, die jedoch weder in der osmanischen noch in der republikanischen Zeit eine besondere Beachtung gefunden hat. Ali Kemals Idee von dem Wohl des Staates und der Gesellschaft ist liberaler Herkunft. Nicht die Ideologien von osmanischer, islamischer oder türkischer Einheit sorgen nach Ali Kemal für das Wohl, sondern einzig und allein der Umstand, daß jeder Bürger in seinem Beruf arbeitet und Schaffungskraft beweist. Die Heilung einer Gesellschaft kann somit nur aus der ihrer einzelnen Bürger hervorgehen. Dieses Denken, das allein im Foucaultschen Sinne eine liberale Regierungstechnologie impliziert, hat aber bis auf einige Ausnahmen in der türkischen politischen Geschichte kaum Resonanz erfahren. Die kaum nennenswerte Rezeption der Ideen von Prinz Sabahattin (zweite Hälfte des 19. Jh.), der die Lösung für die Krise im privaten Unternehmertum und in der politischen Dezentralisierung suchte, führt uns wieder die Beliebtheit der Staatsraison und der darauf basierenden Ansätze in der türkischen Politik vor die Augen. 
Auch das Werk von Gökalp wird hier nicht in erster Linie im Hinblick auf die Rolle, die Gökalp bei der Konzeption des türkischen Nationalismus gespielt hat, gelesen werden. Gökalps Ideen wurden später teilweise zu Unrecht in den Dienst eines ethnischen Nationalismus eingespannt (ausführlich dazu: Parla 1989; Ülken 1998). Anders ausgedrückt, stimmt zumindest der Stellenwert nicht ganz, den die Rezeption seiner Rolle als Ideenvater des türkischen Nationalismus beigemessen hat, wenn man seine Leistungen bezüglich der Modernisierung und soziologischer Reflexionen über sie in Betracht zieht. Im folgenden werden zwei Aspekte seines Denkens hervorgehoben, die die im vorliegenden Kapitel behandelte Fragestellung unmittelbar betreffen.

Zunächst einmal war Gökalp der erste, der die Frage danach, auf welchen institutionellen Strukturen und Praktiken der Staat aufgebaut werden soll, entlang spezifischer Themen diskutiert hat. Sphären wie Sprache, Ökonomie, Kultur, Recht werden der ordnenden Hand des Staates zum ersten Mal im Rahmen einer Systematik anheimgestellt (1975 [1923]). ${ }^{24}$ Der Punkt Türkismus in der Sprache in seinem Programm gibt ein exzellentes Beispiel für die Funktionsweise der neuen Staatlichkeit. Die systematisierende und vereinheitlichende Funktion der Macht, sicherlich auf eine bereits von den Intellektuellen vollbrachte Leistung in Grammatik- und Wörterbüchern aufbauend, soll verschiedene Dialekte durch die wichtigste Institution dafür, die Schule, in eine einheitliche Sprache umformen, die überall in der Türkei gleichermaßen gesprochen werden wird. Es handelt sich also um ein Unternehmen, das im klassischen osmanischen Denken wie auch im politischen Imaginären der Osmanen nicht denkbar war. Entsprechend wird auch der Religion ein bestimmter Platz im Programm eingeräumt. Sie wird nunmehr auf ihre Funktion für die Moral hin konzeptualisiert, welche zwei Sphären, einerseits die auf der Wissenschaft basierende Zivilisation und andererseits die türkische Nationalkultur, zusammenkitten soll. Die aus der europäischen (ursprünglich: deutschen) Geistesgeschichte übernommene Unterscheidung zwischen Kultur und Zivilisation bezeugt Gökalps Skepsis gegenüber dem unter den türkischen Modernisten damals (und heute zum Teil auch weiterhin) weit verbreiteten Glauben an die Wissenschaft, die für den ersehnten zivilisatorischen Anschluß sorgen soll. Er antizipiert bereits sehr früh für die entstehende türkische Gesellschaft die Wertproblematik, die seit ihren Anfängen die Kulturproduktion der westlichen Moderne begleitet hat. Gökalp versprach sich durch die Unterschei-

24 Auch wenn Gökalp die Tätigkeit der Türkisten in erster Linie als ein Kulturprogramm betrachtete, mit dem das Volk erzogen werden soll, steht der Adressat seines Programms des Türkismus eindeutig fest. Es ist der Staat. 
dung zwischen Kultur und Zivilisation im Bereich der Kultur Potentiale ausmachen zu können, die durch die Religion eine moralische Imprägnierung bekommen und dem Nihilismus der Zivilisation entgegenwirken sollen. ${ }^{25}$

Der zweite wichtige Punkt, der Gökalp seine Besonderheit verleiht, führt über die oben dargestellten Reflexionen über einzelne Bereiche hinaus. Er nimmt sich nämlich des Sozialen als Gegenstand einer systematischen Programmatik an und analysiert es mit den Instrumenten der Soziologie. Die osmanische Gesellschaft konnte für ihn keine funktionstüchtige Integration aufweisen, in der die einzelnen Teile miteinander in einem harmonischen Zusammenhang stünden. Den politischen Revolutionen der Tanzimat und Meşrutiyet (1839 und 1856) soll daher eine soziale Revolution folgen. „Das neue Leben“ und „die neuen Werte“ - Resultate der sozialen Revolution -, die eine gesellschaftliche Integration herbeiführen sollen, müßten erst noch geschaffen werden. Dafür bedürfe es der Soziologie, die das Wissen über das Volk zur Verfügung stellen soll (vgl. Ülken 1998: 305).

Damit steht Ziya Gökalp im Grunde auf der Tradition der wissenschaftlich flankierten Rationalität, die sich über praktische Verfügungen nach und nach im gesellschaftlichen Leben durchzusetzen begonnen hatte. Zwar hatten Osmanische Sultane schon immer Gelehrten als Berater auf ihrer Seite gehabt. Dennoch blieb diese Verbindung zwischen Macht und Wissen im Vergleich zu der auch Gökalp infolge der kulturübergreifenden Einflüsse vorschwebenden Funktion, die die Humanwissenschaften in der westlichen Moderne übten, eher äußerlich. Gökalps Interesse für das Wissen über das Volk (bspw. für die Hervorhebung der gesellschaftlichen Bedeutung der Kindererziehung, 1975 [1923]: 315) zeugen von der Transformation, die sich hier im

25 Erwähnenswert ist übrigens bei seiner Bezugnahme auf die zentralasiatischen Wurzeln der türkischen Kultur nicht so sehr der historische Wahrheitsgehalt seiner Thesen, der an einigen Punkten sehr leicht widerlegbar ist. Viel wichtiger scheint mir die Motivation dieser Suche zu sein. Gökalp stand nämlich wie viele seiner Zeitgenossen vor dem Problem, wie denn moderne Thematiken - Gleichstellung der Geschlechter, Etablierung einer republikanischen Staatsordnung, Demokratiefrage in der türkischen Gesellschaft - in einem Interpretationsrahmen eingeführt werden könnten, der nicht lediglich auf dem Technikglauben und der Vorstellung des nach seinen Interessen jagenden Individuums basieren sollte, weil das seiner Ansicht nach auch nicht erfolgen könnte. Vor allem bei der Geschlechterfrage stellte sich ein im Buchstaben geronnener Gott als das größte Hindernis in den Weg. So enthüllte sich ihm die vorislamische, „urtürkische“ Gesellschaft in Zentralasien als eine solche, in der Frauen hohes Ansehen genossen, öffentliche Aufgaben wahrnahmen und leitende Ämter bekleideten. 
Denken abzeichnet - deren technische Umsetzung bleibt allerdings eine andere Frage, über die man auch nach mehreren Jahrzehnten mit gutem Grund streiten könnte. Die im Volke gespeicherten unendlichen Ressourcen für die Macht sollen mit den Mitteln der Wissenschaft erschlossen werden. Wissenschaft wird zu einem strategischen Hilfsmittel zwecks Schaffung einer national integrierten Gesellschaft.

Genauso wie bei Akçura, ebenso auch später in der offiziellen Ideologie der laizistischen Republik, wird die Religion in die Sphäre einer Moral verschoben, die von Fikıh (Jurisprudenz) und Politik gereinigt werden soll (vgl. Parla 1989: 80). Man kann bei Gökalp einen Vertreter des islamischen Modernismus erblicken, welcher die innere Rationalität der Religion weitgehend unberührt beläßt (kennzeichnend für den islamischen Modernismus), während sein Hauptinteresse dem Versuch gilt, die Religion auf die neuen sozialen und politischen Umstände anzupassen. Selbst seiner Vorliebe für tasavvuf, den mystischen Islam, lag hauptsächlich der solidarische Effekt zugrunde (ebd.), den die Mystik auf die Menschen ausstrahlt. Für Gökalp konnte sich die Möglichkeit der Nationswerdung nur durch den Austritt aus der Umma ergeben. Nicht nur die Idee einer säkularen Republik wurde von ihm mit vorbereitet. Mit Ideen bezüglich einzelner Praktiken mit protestantischem Anklang wie z. B. der Forderung, daß der islamische Ritus vom Arabischen abgelöst und in der Sprache des türkischen Volkes abgehalten werden soll, hat er auch den immer noch nicht abgeschlossenen Streitfragen sein Denken aufgeprägt. In den letzten Jahren tauchte bspw. die ursprünglich von ihm stammende Forderung nach türkischsprachigem Gebetsruf wieder verstärkt in der öffentlichen Debatte auf.

Die Ideen, die hier exemplarisch an Akçura und Gökalp vorgestellt worden sind, beziehen ihre Relevanz zweifellos nicht zuletzt aus ihrer Wirkungsgeschichte. Freilich sind beide Autoren die wichtigsten Referenzpunkte des späteren radikalen Nationalismus (vor allem durch die MHP - Nationalistische Aktionspartei, die sogenannten Grauen Wölfe). Obgleich die auf Moral beschränkte Rolle der Religion in der politischen Rezeption immer mehr aufgegeben wurde (bedeutsam genug für die nichtintendierten Folgen des strategischen Einsatzes von Religion), bleibt die Spannung zwischen Religion und nationaler Identität letztlich auch bei den späteren Nationalisten ungelöst. Nur die Idee der Verwestlichung, die beiden Autoren offensichtlich eigen war, schwächt sich im späteren radikalen Nationalismus deutlich ab. In den 80er Jahren wird der Versuch einer neuen Verknüpfung von Religion und nationaler Identität, nicht ohne erhebliche Unterstützung der Militärjunta von 1980, in einer intellektuellen Bewegung gebündelt, die unter der Bezeichnung „Türkisch-Islamische Synthese“ firmiert. Zur gleichen Zeit wird die „Privatisierung“ der Religion immer mehr zu- 
rückgenommen, während der andere Zug in den Werken beider Autoren, vor allem bei Akçura, nämlich der Beitrag der Religion zur nationalen Identität, eine Aufwertung erfährt. Die stärkste Reaktion auf die Indienstnahme der Religion durch den Nationalstaat wird aber die islamistische intelligentia zeigen, indem das ganze Nationskonzept und der darin der Religion zugewiesene Platz in Frage gestellt wird. Das wird der Gegenstand vom Kapitel II sein. Bis dahin liegt allerdings noch ein langer Weg vor uns, der aus mehreren Etappen besteht. Zunächst wird die Frage nach der modernen Staatlichkeit in der Türkei und dem Platz der Religion weiter behandelt. Unten wird die bereits erfolgte Darstellung zweier Schlüsselfiguren der türkischen Nationalstaatsidee durch einen kurzen Exkurs auf die Verwaltungsgeschichte gestützt, um die Übergänge im Verständnis der Staatlichkeit auch auf einer praktischen Ebene nachzuzeichnen.

\subsection{Praktiken}

Solche Verschiebungen im Denken können, das ist die den folgenden Überlegungen zugrundeliegende Idee, nicht isoliert von den praktischen Regelungen gedacht werden. Man kann bereits die ersten Anzeichen eines Übergangs von den negativen Machttechniken zu den produktiven, oder zumindest das Auftauchen einer neuen Rationalität, schon vor den hier dargestellten wissenschaftlichen Reflexionen konstatieren. Die Brutstätte der Modernisierungspraktiken in der Türkei liegt konkurrenzlos in der Militärreform. Man kann sie allerdings auch in ganz anderen Bereichen, die in der Forschung wenig Aufmerksamkeit gefunden haben, aufspüren. Tekeli und Ilkin haben ihre Analyse des Bruches, der sich bei dem Verständnis und der Praxis der „Bebauung“ ereignete, zwar nicht unter dem Titel „,politische Rationalität“ gefaßt, dennoch lassen sich ihre Überlegungen mühelos unter dieser Thematik subsumieren.

Entsprechend dem negativen Machtkonzept der osmanischen Zeit vor der Einführung moderner Praktiken wurde unter Bebauung (imar) zweierlei verstanden: In der einen Dimension wurde sie mit dem Begriff şenlendirmek (Beleben, Aufblühen, Aufheitern, Aufmuntern etc.) wiedergegeben. Das Ziel der Belebenspraktiken bestand schlicht und ergreifend darin, zum einen die Agrarproduktion zu steigern, zum anderen die Sicherheit für Handelswege zu gewährleisten. Es sollten damit Zunahme an Abgaben erzielt und gemäß dem osmanischen Pfründensystem neue menschliche Quellen für Rekrutierung erschlossen werden. Die zweite Dimension der Bebauung meint wiederum lediglich, die Städte im Land des Sultans (Mülk) mit Bauten wie Brücken, Badehäusern, Straßen usw. auszustatten. „Es existiert noch kei- 
ne Referenz auf das Wohl der Bevölkerung“" (Tekeli/Ilkin 1990: 162; Hervorhebung L.T.), wie wir sie im Denken von Akçura hingegen, mitunter als Reflexion der praktischen Entwicklung, sehr wohl antreffen konnten.

Der Wendepunkt im Hinblick auf das Verständnis von Macht läßt sich symptomatisch auf das Jahr der Erneuerungen von 1839 (Gülhane Hatt-i Humayun) datieren. Bedeutsam ist, daß in diesem Dekret sowohl Regelungen für rechtliche Sicherungen als auch eine Reihe von Regelungen zur Bevölkerungsthematik zu finden sind.

So erscheinen beispielsweise als Aufgaben des Amtes für öffentliche Arbeiten (Meclis-i Umur-u Nafia) u.a. die Instandhaltung der Schulen und Bekämpfung der Fehlgeburten (Tekeli/Illkin 1990: 163). Läßt sich die eine Seite der Medaille durch das Auftauchen einer Bevölkerung als Gegenstand des Regierungshandelns darstellen, so findet die Kehrseite ihren Ausdruck in der Transformierung des Staates angesichts einer völlig neuartigen Aufgabenstellung. In diese Zeit fällt folglich auch, zumindest in richtungsweisenden Ansätzen, die Umbildung der bürokratischen Organisation, deren Handeln jetzt unter dem Stichwort der „Wahrung des Allgemeinwohls“ legitimiert wird.

Die Genealogie des türkischen Staates, bevor er sich noch diese explizite Bezeichnung durch die Republikgründung verliehen hat, läßt sich noch unter anderen Bereichen verfolgen. Die Techniken der politischen Rationalität setzten vor allem im Bildungs- und, wie bereits angedeutet, Militärwesen ein, die einer grundlegenden Umstrukturierung unterzogen wurden und dadurch eine Wesensänderung erfuhren. Bis zu der Reformierung des alten Bildungswesens wurden Schulen mittels Spenden unterhalten. Die Gründung der ersten Grundschulen geht nach Mardin (1992: 173) auf das Jahr 1847 zurück. In den Schulen wurde die Kommunikationsform der Bildung nach und nach von der personalen Beziehung zwischen dem Lehrer und seinen Schülern auf die Basis von Büchern gelegt. Bei der Bildung durch Bücher, die das Denken in abstrakten Schemata fördern sollte, handelte es sich, so Mardin, immer weniger darum, Gottes Willen zu entsprechen, als vielmehr an einem abstrakten zivilisatorischen Fortschritt zu hängen. ${ }^{26}$

26 Gleichwohl bleibt die Frage, inwieweit sich das Ethos eines versachlichten Schulunterrichts auch mit seinen praktischen Folgen durchgehend durchsetzen konnte, oder ob nicht die eher formell vollzogene Versachlichung durch die alten Unterrichtsformen und -ideale eingeholt (wie z. B. Auswendiglernen faktisch als Grundmuster der Wissensvermittlung) wurden, ein sehr spannendes Forschungsthema. Der Autor der vorliegenden Arbeit kann zumindest biographisch bis in die 60er (Grundschule), 70er (Mittelschule und Gymnasium) und 80er Jahre (Universität) das Fortwirken alter Muster in der Wissensvermittlung bezeugen. 
Auch die innermilitärischen Verhältnisse werden durch die preußischen Disziplinartechniken einer nachhaltigen Transformierung unterzogen. Vor allem fällt hier auf, daß die Repräsentation der Offiziersschicht immer mehr durch Kleidung und Körperdisziplin unterstrichen wurde, womit sich diese entschieden von den einfachen Soldaten absetzte (Mardin 1992: 213). Diese Tradition der Modernisierung in der und durch die Armee wird eine Art säkularisiertes ,Sendungsbewußtsein" stiften, mit dem die Militärs bis zum heutigen Tage immer zur Wahrung des Staates, ob gegen die Linke oder den Islamismus, in das politische Geschehen aktiv eingreifen.

Selbstverständlich gibt es zahlreiche Beispiele für die Transformationen. Die bisher erwähnten dürften wohl genügen, die praktischen Folgen der modernen politischen Rationalität in der türkischen Gesellschaft aufzuspüren. Wichtig bleibt hier, in welchem Zusammenhang die Stellung der Religion zu der Menge der Transformationen steht. In der Fortsetzung der reformerischen Regelungen von 1839 finden wir im Jahre 1856 eine Entwicklung hin zur legitimatorischen Abkoppelung der Regierungsmacht von der religiösen Zugehörigkeit. Das bedeutet keineswegs, daß dadurch die Bedeutung der islamischen Religion zurückgefahren wurde. Statt dessen entwickelt sich ein anderer Umgang mit der Religion, ihr Stellenwert verändert sich, und zwar in der Richtung, wie es später in den Überlegungen von Akcura und Gökalp ihre theoretische Reflexion erfuhr, nämlich als ein strategischer Faktor zur Herstellung einer organisch integrierten Gesellschaft bzw. zu der dem gleichen Ziel untergeordneten Schaffung einer nationalen Volkskultur, für deren moralischen „Kitt““ die Religion zuständig sein soll. Bevor wir nun diese Überlegungen am Beispiel der Diyanet empirisch erweitern, soll auf die Frage von Kontinuität und Bruch an der türkischen Staatlichkeit eingegangen werden, wobei die Art von Einheitsverständnis im Zentrum der Überlegungen steht.

\subsection{Kontinuität und Bruch an der türkischen Staatlichkeit}

Die Geschichtsschreibung und die darauf beruhende ideologische Selbstbeschreibung des Mainstream-Laizismus markieren die ersten Reformansätze aus dem 18. und 19. Jahrhundert, aber vor allem die Gründung der Republik als den Anfangspunkt der darauf folgenden Geschichte der Türkei. Demnach dient die Idee vom Bruch mit der Osmanischen Geschichte als das Grundkonstituens der neuen Türkei. Diese Idee hat über lange Zeit die offizielle Geschichtsschreibung beherrscht. Nicht zuletzt bewegen sich die islamistischen Kritiker des türkischen Laizismus ebenfalls entlang der Vorstellung vom Bruch, spezifischer gesagt: von einem illegitimen Bruch. Nun häufen sich in 
den letzten Jahren immer mehr Anzeichen für eine paradigmatische Verschiebung. Vor allem im wissenschaftlichen Diskurs über nationale Identität, demokratische Frage, türkische Modernisierung und Laizismus - allesamt Themen, die miteinander eng verwoben sind wird die Idee eines totalen Bruches zugunsten einer zumindest damit einhergehenden Kontinuität gemildert, wenn nicht gar teilweise von ihr Abschied genommen wird (vgl. auch Tapper 1993: 10). Die These von der Kontinuität zwischen dem Osmanischen Reich und der türkischen Republik konzentriert sich vorrangig auf die Punkte Staatsverständnis, Einheit von Religion und Staat bzw. die staatliche Kontrolle der Religion und das Verhältnis zwischen Zentrum und Peripherie. Neben in der politischen Theorie beheimateten Arbeiten (z.B. Köker 1996) fallen Analysen auf, die aus einer soziologischen Perspektive heraus die Kontinuitäten auf einer tieferen und breiteren Ebene aufzuspüren und diese im politischen Verhalten und in der Funktionsweise moderner Institutionen von dort aus aufzuschlüsseln suchen (z.B. Öğün 1995).

Die Idee, die der Trennung bzw. der Asymmetrie zwischen religiösen und politischen Instanzen (und wie gesehen auch im rechtlichen Bereich) zugrunde lag, wird in einigen wissenschaftlichen Studien einmütig als der „Fortbestand des Staates“ (zu türkisch: Devletin bekası, vgl. Mardin 1991: 94) definiert. ${ }^{27}$ Aktuelle Untersuchungen versuchen Kontinuität und Bruch zusammenzudenken, wenn auch mit einigen Problemen. So funktioniert bspw. die „Idee von der Einheit des Staates“ im Hinblick auf die Legitimationsfrage, wie das bei Köker konzipiert wird. In seinem Konzept wird das Schwergewicht nicht darauf gelegt, mit welchem Inhalt die Einheitsidee ausgefüllt wird, sondern es genügt ihm, auf die Tatsache hinzuweisen, daß sie (die Einheitsidee) auch nach der inhaltlichen Veränderung der Legitimation beibehalten wird. Daher wird nach Köker die „,klassische Idee der

27 Die Bedeutung des osmanischen Staats hat wohl ehemals europäische Geister beeindruckt. Der Italiener Boccalini (1556-1613) sah in der damaligen Türkei die Verwirklichung der Staatsraison (Meinecke 1963: 101). Selbst wenn man von seinen auf Türken projizierten Wunschgedanken absieht, bleibt noch ein wahrer Kern seiner Beobachtungen, die sich von der nüchternen militärischen Maschinerie und dem politischen Apparat begeistert zeigen. In der gleichen Tradition stand Campanella (1568) - , der ,sich dabei wie Boccalini [...] von dem Anblicke des diabolischen Rationalismus (fesseln) ließ, der in dem türkischen Staats- und Heerwesen waltete“ (a.a.O.: 123). Im Gegensatz zu diesem begeisterten, natürlich auch mit Abscheu vermischten Interesse erzeugen die Türken bei Rousset (1686-1762) nur noch das Gefühl einer niedergehenden Macht, deren Armeen keine Disziplin und Regel kennen. 
Einheit von Religion und Staat durch die Einheit von Nation und Staat im Kemalismus ersetzt" (1996: 157). Köker hat nun Recht, wenn er entgegen dem Mainstream-Kemalismus, der mit der Betonung des Wechsels der Souveränitätsinhaber (statt Sultan jetzt die Nation) den Bruch lediglich auf der Gegenstandsebene festmachen will, die Kontinuität an Mustern der Wahrnehmung verortet. Auf der These der fortbestehenden Muster insistierend, ist es ihm dann möglich, auf die strukturelle Analogie zwischen der osmanischen Verweisung auf islamisch gedeutete Transzendenz und dem kemalistischen, positivistischen Scientismus hinzuweisen, der ebenfalls eine Art transzendenten Verweis enthalte (ebd.). Dennoch gesteht Köker auch, daß die Fortexistenz von Mustern mit neuen Inhalten keineswegs dahingehend darf verstanden werden, als sei der Kemalismus ,eine bloße Wiederholung des Alten unter neuen (modernen) Bedingungen“ (a.a.O.: 158). Dabei betont er den aufklärerischen Fortschrittsgedanken, an dem sich der Kemalismus orientiert. ${ }^{28}$ Meiner Ansicht nach verdient ein anderer Punkt, dem, obwohl der in seiner Argumentation durchaus vorkommt, eher der Status eines Zusatzes zugemessen wird, eine systematische Beachtung. Köker schreibt:

„Die Betonung der Idee von der ,Einheit des Staates“ wurde zwar beibehalten, doch wurde dabei dem Staat eine zusätzliche Aufgabe auferlegt. Diese Aufgabe entspricht dem Ziel des ,modernen Staates', die privaten und soziokulturellen Räume zu durchdringen und auf diese Weise die Gesellschaft zu ordnen." (Ebd.)

Hier stellt sich allerdings die Frage, ob es sich dabei lediglich um das Hinzukommen einer neuen Aufgabe für den Staat im Rahmen einer dann nämlich als gleichbleibend anzunehmenden Staatlichkeit handelt. Der Schlüssel zu einer Antwort liegt in der Konzeption der Einheitsidee selbst. Wir müssen nämlich unterscheiden zwischen dem Einheitsverständnis, d.h. auch den Praktiken und Mitteln der Einheit in der klassischen osmanischen Zeit vor der allmählichen Einführung neuer politischer Regelungen einerseits und denen des modernisierten Apparates andererseits. Hier kann man einen Hinweis von Foucault auf die Differenz zwischen dem feudalen und dem modernen Staat zu Hilfe nehmen. Demnach zeichnet sich die feudale Macht, die grund-

28 Die Differenz zwischen einer außerweltlichen Transzendenz und dem quasi als eine Art Transzendenzfunktion enthaltenden Fortschritt ist, was ihre Funktionsweise anbelangt, von immenser Bedeutung, darf daher nicht einfach in einer Analogie verwischt werden, sosehr die zweite ihre Wurzeln in der christlichen Heilsgeschichte haben mag. Zur Kontinuität und den Differenzen/Brüchen zwischen christlicher Heilsgeschichte und der Zeit des Fortschritts siehe Marramao 1989. 
sätzlich eine negative, also abschöpfende, war, durch die Ambivalenz aus, daß sie absolut und doch schwach zugleich war und merkwürdigerweise aber ihr Funktionieren genau dieser Ambivalenz verdankte. In Entsprechung zu den schwach entwickelten Kommunikations- und Transportmöglichkeiten, die vormoderne Gesellschaften kennzeichnen, war es nicht möglich, eine flächendeckende Kontrolle zu praktizieren, die vereinheitlichend gewirkt hätte. In diesem Fall bedeutet die Einheitsidee hauptsächlich, über die Ressourcen der beherrschten Länder zu verfügen. Auch waren alle Lebensbereiche umfassend und produktiv bearbeitende Regelungen und Institutionen noch nicht denkbar. Hier fehlten generalisierende, abstrakte Regeln, die für das Funktionieren moderner Institutionen typisch sind.

In einigen, neueren Arbeiten über den Islam in der osmanischen Ordnung wird die Beziehung zwischen Sozialstruktur und religiösem Glauben jenseits von pauschalen Erklärungen auf eine produktive Art und Weise reflektiert. Über das soziale Band, das der Islam stiftete, schreibt Öğün:

„Das islamische Band besaß bei den Osmanen die Funktion, verstreute Gemeinschaften zu versammeln. Dennoch soll man diese Funktion des Islam nicht überschätzen. Die vereinheitlichende Funktion des Islam zeigte sich eher auf der Ebene lokaler Gemeinschaften und in einem symbolischen Rahmen. Dieser Umstand hängt zum größten Teil mit dem primitiven Entwicklungsgrad von Transport- und Kommunikationstechnologien zusammen. Im stillen Tempo des traditionellen Lebens ist das , universelle' Band, das der Islam unter den Gläubigen stiftete, Gegenstand einer beschränkten Erfahrung.“"(1995: 22)

In diesem Sinne trifft die These von Mardin, daß das Osmanische Reich nicht über ein ,zentrales Wertesystem“ (1991: 91) verfügte, vollkommen zu. ${ }^{29}$ Die ersten Ansätze der Idee von einem allgemeinen

29 Im Zusammenhang mit „Weltbild“ führt Heidegger die „Vorstellung des Wertes“ als ein weiteres Element des neuzeitlichen Weltverhältnisses an: „Gleich wesentlich wie das System ist für die neuzeitliche Auslegung des Seienden die Vorstellung des Wertes. Erst wo das Seiende zum Gegenstand des Vorstellens geworden ist, geht das Seiende in gewisser Weise des Seins verlustig. Dieser Verlust wird unklar und unsicher genug gespürt und entsprechend schnell dadurch ersetzt, daß man dem Gegenstand und dem so ausgelegten Seienden einen Wert zuspricht und überhaupt das Seiende nach Werten bemißt und die Werte selbst zum Ziel alles Tuns und Treibens macht. Da dieses sich als Kultur begreift, werden die Werte zu Kulturwerten und diese dann überhaupt zum Ausdruck der höchsten Ziele des Schaffens im Dienste der Selbstsicherung des Menschen als Subjectum. Von da ist es nur noch ein Schritt, um die Werte selbst zu Gegenständen an sich zu machen. 
Wertesystems zeichnen sich durch die Konfrontation mit der westlichen Moderne ab, gleich ob die Verarbeitung der Konfrontation dabei ablehnend oder übernehmend motiviert war. In diesem Zusammenhang ist dann auch die Entstehung des Islamismus zu verstehen, also der politischen Strömung, die den Islam als eine Einheit stiftende Ideologie konstruierte. Die moderne Wertgeneralisierung, die ihren politischen Ausdruck ebenfalls in modernen Ideologien findet, bezog auch den Islam in ihren Bannkreis ein, indem der Islam den Wandel „,von einer sozialen Kategorie zu einer politischen Kategorie, mit anderen Worten von einem heterogenen, lockeren präideologischen Band (nun) durch den Islamismus zu einem politisch-gesellschaftlichen Standard" (Öğün 1995: 22) machte.

Das Nichtvorhandensein der Idee von einem einheitlichen Wertesystem kann man ebenfalls für die Ulema geltend machen. Hätte man hier nicht am ehesten denken können, daß die Ulema mit ihren nicht zuletzt durch die Einbindung in den zentralistisch organisierten Reichsapparat ermöglichten, vordergründig exzellenten Ausgangsbedingungen selbstverständlich imstande sein müßte, ein Wertesystem $\mathrm{zu}$ etablieren? $\mathrm{Da}$ dies der gesamten klassischen Orthodoxie nicht gelungen ist, wirft ihr z. B. Rahman systematisch vor. Der Grund dafür liegt allerdings, weit entfernt von persönlichen Unzulänglichkeiten, lediglich darin, daß die Ulema den Koran nicht als eine Einheit verstanden und folglich keine Methodologie entwickelt habe, eine historische Analyse des Korans vorzunehmen, um die dahinter stekkenden allgemeinen Werte zu Tage zu fördern.

„The Bane of later medieval Islam, as we shall presently see, was that what was regulative, namely, God, was made the exclusive object of experience and this, instead of men's seeking values from this experience, the experience became the end in itself." (Rahman 1982: 14)

Eine ausführliche Interpretation des Werkes von Rahman wird in Kapitel II.2 im Hinblick darauf vorgenommen, seinen die Gesellschafts-

Der Wert ist die Vergegenständlichung der Bedürfnisziele des vorstellenden Sicheinrichtens in der Welt als dem Bild.“ (1950: 93f)

Obwohl der Sozialanthropologe Louis Dumont den Wertbegriff nicht in dieser geschichtlichen Spezifizität betrachtet, kontrastiert er den modernen Wertbegriff, der erst durch die Trennung zwischen Sein und Sollen möglich geworden ist, mit dem nichtmodernen, in soziale Tatsachen eingebetteten Wertbegriff: „Um wissenschaftliche Erkenntnis zu ermöglichen, hat man [...] die Bestimmung des Seins dergestalt verändert, daß man daraus gerade die Dimension der Werte eliminierte. (1991: 260) Dies führte folglich dazu, daß man ,die Werte von den Ideen und generell von den Tatsachen" trennte (ebd.). 
konstitution systematisch in das Zentrum des islamischen Denkens einführenden Neomodernismus auf die Funktion eines nichtintendierten Übergangs zum islamischen Fundamentalismus hin zu befragen. Dort wird man sich auf die Funktion seiner zentralen Begriffe Einheit des Korans, islamische Werte, Koranische Weltanschauung, action in this world u.a. - ihren modernen Kontext aufzeigend - konzentrieren, um sein programmatisches Ziel, nämlich eine innere Rationalisierung des Gesetzes, zu diskutieren. An dieser Stelle sei auf ihn als Zeuge dafür verwiesen, daß die innere Rationalisierung des islamischen Gesetzes durch die Orthodoxie, durch die ganze klassische Geschichte fehlte. Dasselbe ist nun aber auch, mit einiger Vorsicht, auch für die Institution der türkischen Orthodoxie, der Diyanet, zu behaupten. Hierin besteht auch die relativ beständige Allianz zwischen der laizistischen Religionspolitik und der Orthodoxie. In wieweit läßt sich aber die Orthodoxie auf das Spiel der Staatsraison bzw. auf die strategischen Ziele des modernen türkischen Staates ein, wo bricht die Allianz auf, wie wird die Dissens politisch bearbeitet? Diese Fragen werden im folgenden behandelt. Vorher soll jedoch das bisher Gesagte kurz zusammengefaßt werden.

In Folge der im bisherigen Verlauf der Argumentation vorgenommenen theoretischen Bezugnahmen, - sei es das „Heideggersche“ Weltbild, seien es die Jakobinischen Komponenten der modernen Gesellschaften (Eisenstadt), oder sei es auch Foucaults politische Technologie der Individuen -, erscheint es plausibel, die Frage nach dem Islam in der modernen Türkei nicht allein aus der islamischen bzw. aus der Staatstradition orientalischer Länder selbst zu erklären. Weder die sogenannte offizielle Ideologie mit ihren unterschiedlichen Varianten, vom stark laizistischen Kemalismus hin zu der sich auf die Religion explizit berufenden konservativen Variante desselben, noch die oppositionellen Bewegungen werden völlig von jenseits der modernen Staatlichkeit her sprechen können. Auch die religiöse Opposition (allen voran ihre ehemalige politische Vertreterin Refah Partei) wird an den Grundstrukturen dieser Staatlichkeit nicht viel zu rütteln versuchen; vielmehr wird sie sich mit einem riesigen Apparat konfrontiert sehen, den sie nun islamisch einzubinden und für sich zu nutzen trachten wird. Befürworter wie auch Gegner einer mit Republik bzw. Laizismus wie auch immer versöhnten islamischen Religion werden ihre Vorstellungen von Religion immer im Kontext der Auswirkungen des Vereinheitlichungsprozesses formulieren. Der Staat schafft dabei zum einen die Bedingungen für die Religion als öffentliche Norm, auch 
wenn er dies selber nicht praktiziert. Zum anderen bildet er im Gegenzug das Zentrum des religiösen Begehrens. ${ }^{30}$

\section{Türkische Laizität und das Amt für Religiöse Angelegenheiten}

Im Kapitel I.3 wurde in Bezug auf das Verhältnis zwischen Staat und Religion zwei Wurzeln des Umgangs mit der Religionsfrage herausgearbeitet: Die klassische Obhut des osmanischen Herrschers über die Hierokratie, die sich ursprünglich aus der weltlichen Macht der osmanischen Kriegerdynastie speiste, findet durch die Funktion des Sultans als Kalif eine zusätzliche Verstärkung, so daß sie die Orthodoxie zusätzlich daran hinderte, ein Gegengewicht aufzubauen. Jedoch ist hier noch nicht von einer zur Technik ausgearbeiteten Staatsraison zu sprechen. Es fehlte dafür der institutionelle Rahmen, d.h. die praktische Ablösung der Souveränität vom Körper des Souveräns und die konstitutive Einbeziehung der Bevölkerung in die Prozesse der Legitimationsbeschaffung.

Selbstverständlich kam es auch dort zu Unstimmigkeiten und Spannungen zwischen der Hierokratie und dem Herrscher. Nie konnten sie sich aber zu einem grundsätzlichen Konflikt entwickeln. Der Konflikt konnte nur im Modus von Einflußnahme und Palastintrigen ausgetragen werden, und nie in Form öffentlich politischer Auseinandersetzungen oder als Rechtsstreit. Zum Gegenstand politischer Auseinandersetzungen konnte das Verhältnis von Religion und Staat erst parallel zur Institutionalisierung der Staatsraison als politischer Technologie werden. Die Gründung der Diyanet (Amt für Religiöse Angelegenheiten) kann man auch daher nicht eine Wiederauflage des alten Şeyhülislams betrachten, obwohl die bestehende Tradition in der neuen Form des Verhältnisses begünstigend weitergewirkt haben dürfte.

30 Selbst die mystische Tradition beraubt sich dabei teilweise in ihrer Wiederbelebung unter den Bedingungen des modernen Staates ihrer ureigenen mystischen Bedeutung, der Erfahrung der inneren Dimension. Die religiöse Reaktion der mystischen Ordensgemeinschaften auf einen die Religion kontrollierenden Staat, der sich wiederum nicht religiös definiert, artikuliert sich denn auch in einem „eingeengten, starren Formalismus" (Öğün 1995 : 190). In der typischen Trilogie islamischer Mystik, nämlich Seriat (Scharia, das äußerliche Gesetz), Tarikat (Weg, auch Ordensgemeinschaft) und Hakikat (Wahrheit) wird denn von nun an der Aspekt der Scharia besonders stark hervorgehoben. Damit erklärt sich wohl auch ein Stück, warum die heutigen mystischen Gemeinschaften sehr starke orthodoxe Züge tragen und sich weitgehend politisch engagieren. 


\section{1 Über die Geschichte des Amtes}

Die Gründung eines Verwaltungsamtes für die Regelung religiöser Angelegenheiten findet ihren Platz in einer Reihe historisch bedeutsamer Entscheidungen, die den politischen Neubeginn in Gestalt der türkischen Republik markieren, wobei sie andererseits auf eine Reihe von Transformationen zurückgehen. Im Grundgesetz des Revolutionsparlaments von 1921 wurden mit der Bestimmung „Alle Souveränität geht vom Volke aus“ auch die Weichen für die institutionelle Zukunft des Islam gestellt. Damit war denn auch der Weg vorgezeichnet, der von der Abschaffung des Sultanats (1922) und des zuvor politisch entmachteten Kalifats (1924) zu einer neuen Institutionalisierung der Religionsbürokratie führte. Mit dem Gesetz zur Abschaffung des Ministeriums für Scharia- und Stiftungsangelegenheiten und der Abschaffung des Ministeriums für Militärangelegenheiten (1924) wurde der Existenz des für die Religion im osmanischen Staat zuständigen Amtes des Şeyhülislam ein Ende bereitet und die neu ins Leben gerufene Direktion für Religionsangelegenheiten (Diyanet İşleri Reisliği) wurde mit dessen Aufgaben betraut, wobei erheblich der vormaligen Kompetenzen gestutzt. Damit sollten, so muß man jedenfalls die Intention des Republikgründers M. K. Atatürk bei der Gesetzinitiative deuten, zwei potentiell mächtigen Institutionen im neuen Staat Schranken gesetzt werden. Die Rechnung ging im Falle der Armee gar nicht auf, während die Macht der Diyanet, von konjunkturellen Schwankungen abhängig, kontrolliert werden konnte. Während nämlich das der Diyanet vorausgegangene Amt des Şeyhülislam auf Ministeriumsebene angesiedelt war und eigene Schulen unterhalten durfte, um nur ein Beispiel zu geben, mußte sich das neue Amt mit dem Status eines Unterstaatssekretariats begnügen und durfte (zumindest am Anfang) lediglich das in der Zentrale beschäftigte Personal befehligen. In der Begründung des Gesetzes wird auf den politischen Bezug hingewiesen, den es in der darauf folgenden Geschichte im Umgang mit Religion auf der staatlichen und öffentlichen Ebene stets zu vermeiden gelte. Die politische Betätigung der Armee und Religion „bringt Probleme mit sich. Diese Tatsache wird von allen zivilisierten Nationen und Regierungen als Grundsatz anerkannt“. (in: Uluçay 1998: 16f.)

Die Struktur und die dem Amt zugestandenen Befugnisse haben sich selbstverständlich unter dem Einfluß politischer Veränderungen stets gewandelt. Vor allem hat das Amt von dem 1946 vollzogenen Übergang in ein Mehrparteiensystem erheblich profitiert. Auf eine ausführliche Darstellung der Amtgeschichte kann hier verzichtet werden. Denn der mit der Existenz des Amtes gegebene strukturelle Konflikt, der ja im Grunde die vorliegende Studie interessiert, hat sich in ihren Grundzügen auch durch die verschiedenen politisch ausgelösten 
Verschiebungen hindurch erhalten. Im Grunde ist die geschichtliche Dimension bereits in der Einbindung der Religionsangelegenheiten in einen institutionellen Rahmen, nämlich durch die Kooptierung der Hierokratie in den nationalstaatlichen Apparat, enthalten. Gleichwohl muß die Geschichte der Akzentverschiebungen auch innerhalb des gegebenen historischen Zeitrahmens an den entsprechenden Stellen berücksichtigt werden. Nicht zuletzt gebietet es uns die Verpflichtung auf die Foucaultsche Art des Fragens, selbst die institutionellen Strukturen als machtumkämpfte, diskursiv ausgestaltete Gebilden zu betrachten. Auf welche Art und Weise erfolgt nun, das ist die folgende Überlegungen leitende Frage, die Kooptierung der ehedem als Ulema bezeichneten, bereits im Osmanischen Reich staatlich eingebundenen Religionsbürokratie in den laizistischen Staat; was sind die soziologisch relevanten Grundzüge dieser Kooptation?

\subsection{Formen der Kooptation der Religion in den Staatsapparat}

Artikel 1 des „Gesetzes zu Gründung und Aufgaben des Amtes für Religiöse Angelegenheiten“ von 1961 bestimmt die Aufgaben der Einrichtung folgendermaßen: „Durchführung der den Glauben [iti$\mathrm{kad}$, den Ritus [ibadet] und die Ethik/Moral [ahlak] ${ }^{31}$ betreffenden Angelegenheiten der islamischen Religion und Aufklärung der Gesellschaft in Sachen Religion sowie die Verwaltung der Gebetsanstalten." (Diyanet 1997: 3)

Ausgehend von dieser Aufgabenbeschreibung, die in der geschichtlichen Entwicklung des Amtes mit der Einführung der Ethik/Moral über die anfängliche Beschränkung auf den Glauben und den Ritus hinausgegangen ist, lassen sich die Formen der staatlichen Verwaltung der Religion unter drei Punkten analysieren:

- Bestimmung der öffentlich zulässigen Religiosität (Sachgebiete der Tätigkeit des Amtes)

31 Das Wort ahlak läßt sich aus dem hier relevanten Gebrauchszusammenhang der Orthodoxie heraus nicht eindeutig einem von den beiden Begriffen zuordnen. Es bezeichnet die individuelle Haltung und die zu vermittelnden moralischen Werte zugleich, ohne daß sie sich voneinander ausdifferenziert haben. Sittlichkeit wird damit ebenfalls mit angesprochen. Dies dürfte über eine bloße Schwierigkeit der Übersetzung hinaus reichen. In der praktischen Aufklärungstätigkeit des Amtes artikuliert sich, wie unten zu zeigen ist, diese Diffusion. 
- Gesellschaftspolitischer Auftrag des Amtes (Religiöse Aufklärung)

- Technische Dienstleistungen (Verwaltung der Gebetsanstalten).

\subsubsection{Bestimmung der öffentlich zulässigen Religiosität}

Der spezifische Zugriff des modernen türkischen Staates auf die Religion erfolgt, das ist hier entscheidend, bereits auf eine formale Art und Weise, bevor noch materiale Wertinteressen in Anschlag gebracht werden; also bevor sich die Frage stellt, welche Inhalte denn den wahren Glauben ausdrücken, welche Riten verbindlich oder zeitgemäß, welche ethisch-moralischen Werte vermittelt werden sollen, welche hingegen als Mißbrauch oder Pervertierung der Religion eingestuft werden sollten. Demnach bestimmt der Staat die Sachgebiete der Religiosität, auf die sich das Amt bei seiner Tätigkeit zu beschränken hat. Damit werden die Formen der öffentlich zulässigen Religion im vorhinein festgelegt. Nach dem aktuellen Stand besteht die islamische Religion aus ibadet (Ritus), itikat (Glauben) und ahlak (Ethik/Moral). Allerdings darf man diese Unterscheidung nicht einfach aus einer bestimmten Sachlogik ableiten. Man muß die Praxis der formalen Bestimmung zulässiger Bestandteile der Religion in ihrer Geschichtlichkeit betrachten, die deren diskursive Umkämpftheit unterstreicht.

In dem von der Verfassung von 1924 vorgezeichneten rechtlichen Rahmen hatte sich das Amt lediglich auf die Glauben und Ritus betreffenden Angelegenheiten zu beschränken, von der Ethik/Moral als Bestandteil der zulässigen Religion war noch keine Rede. Diese Beschränkung entsprach dem Geist des radikalen Laizismus, so wie er zu Beginn der türkischen Republik bestand. Religion sollte damit eine innere Angelegenheit jedes Einzelnen sein. Die Idee einer islamischen Reformation war tatsächlich für die Modernisten der „heroischen“ Phase der Republik, nämlich der Einparteienära (1923-1946), offenkundig. Die geistigen Quellen der islamischen Reformation wurden am Beispiel der Ideen von Yusuf Akçura und Ziya Gökalp ausführlich diskutiert (Kapitel I.3.1). ${ }^{32}$ Die Politik, die öffentliche Erscheinung der Religion auf rituelle Praktiken zu beschränken, erforderte andererseits flankierende Maßnahmen, die dafür zu sorgen hatten, die politische Artikulation der Religion zu den die Grundfesten des Regimes tangie-

32 Bei der Entscheidung, daß der bis dahin arabisch gehaltene Gebetsruf (ezan) in der aufgeklärten nationalen Republik nunmehr auf türkisch erschallte, kann man beispielsweise den unzweifelhaften Einfluß der in Versform vorgetragenen Ideen von Gökalp erblicken, wonach er die Heimat des Türken dort verortet, wo der ezan auf türkisch gerufen wird. 
renden Fragen zu untersagen. Dazu gehört u.a. auch die Degradierung der Stellung des Amtes in der institutionellen Hierarchie: Es durfte nicht mehr, wie bspw. der spätosmanische Şeyhülislam, ein Kabinettsmitglied sein, sondern lediglich eine Einheit im Verwaltungsstab. Die politischen Motive der rechtlichen Regelung, die die öffentlich zulässige Religiosität auf die Bereiche von Glauben und Ritus beschränkte, liegen auf der Hand. Der jungen Republik geht es angesichts der noch lebendigen Gefahr einer Umkehrung des Prozesses um Bestandssicherung der Republik. Denn die innerhalb kürzester Zeit beschlossenen radikalen Reformen, nicht zuletzt die Abschaffung des Kalifats, hatten selbst unter den engsten Vertrauten von Mustafa Kemal (Atatürk), die ja zum Revolutionskader gehörten, oppositionelle Regungen heraufbeschworen. Es kam also angesichts der politischen Umstände zunächst einmal darauf an, daß der Staat die Religion nicht aus der Hand geben wollte, d.h. sie weiterhin unter Kontrolle behielt und sie im Gegenzug im Gewissen der Individuen als Privatangelegenheit einrichtete bzw. beließ, damit sie im ,von Wissenschaft und Vernunft geleiteten Kampf um den Anschluß an die zeitgenössische Zivilisation" nicht im Wege stehe. Mehr wollte die Republik von der Religion offenbar nicht wissen. Die Alltagsreligiosität, die konventionalistisch praktiziert wurde, ist dabei kaum tangiert worden. Man kann gar behaupten, daß sich eine Art Allianz zwischen der laizistischen Skepsis gegen die organisierte Religion und überhaupt gegen den politischen Gebrauch der Religion einerseits und der konventionellen Religionspflege im Alltag andererseits einstellte, was für die relativ erfolgreiche Institutionalisierung einer säkularen politischen Ordnung jedenfalls nicht ohne Bedeutung gewesen ist. Unterstützt wird die staatliche Aufsicht über die Religion zudem mit der in der Alltagskultur weit verbreiteten Sorge um die Religion, daß man sie nicht für politische Zwecke benutzen darf.

Die Republik konnte sich allerdings auch deshalb noch vollauf auf diese minimalistische Religionspolitik verlassen, weil im Lande ein Einparteienregime herrschte. Die Einleitung des Mehrparteiensystems (1946), wodurch religiöse Bedürfnisse der parteipolitischen Konkurrenz freigegeben wurden, führte erst zur diskursiven Aufwertung von Religion als öffentlicher Angelegenheit und zur Auflockerung der strikten Durchführung laizistischer Ziele der Republik. ${ }^{33}$ Die sich in

33 Dies meint keineswegs, daß sich die Republik einer religiösen Begründung ihrer Existenz völlig enthalten hätte. Im Gegenteil, hätte die ungemein geschichtsträchtige Tat, nämlich die Abschaffung des jahrhundertealten, mit Islam fast identisch gewordenen Kalifats, vielleicht ohne die durch und durch religiöse Rede des damaligen Justizministers, Seyyid Bey, der selber durch die Schulen der Ulema durchgegangen war und als Juraprofessor das Amt des Dekans der theologischen Fa- 
der Gesellschaft formierenden religiösen Forderungen fanden ihren Niederschlag in der staatlichen Regelung der Religionsangelegenheiten.

Mit dem 1946 eingeleiteten Mehrparteiensystem griff nun, wie bereits gesagt, die Bevölkerung, vor allem die damals mächtige Provinz, in die politischen Prozesse aktiv ein. Das von der republikanischen Klasse durchgeführte social engineering mußte nun aufgrund der politischen Konkurrenz aufgelockert werden. Bereits vor dem Machtwechsel, der durch die Wahlen 1950 stattfinden sollte, nämlich im Jahre 1947, beschloß die republikanische Volkspartei des Einparteiensystems, religiöse Kurse einzurichten, in denen die Geistlichen ausgebildet werden sollten. Auf der anderen Seite trat die Türkei ab 1950 wiederum in eine umfassende Industrialisierung und Verstädterung ein, was die ländlichen Strukturen für kapitalistische Wirtschaft öffnete und die Bevölkerungsschichten aus ihren subsistenzwirtschaftlich bedingten sozialen Beziehungen herausriß. In diesem Kontext kam, entgegen den modernisierungstheoretischen Erwartungen vom Niedergang der Religion, der Prozeß in Gang, daß Religion für Teile der

kultät bekleidete, nicht vollzogen werden können. Diese religiöse Würdigung einer laizistischen Republik in einem islamischen Land hat man allerdings in der wissenschaftlichen Literatur kaum wahrgenommen. Anscheinend entspricht sie den Authentizitätserwartungen nicht. Unten sei ein Auszug aus der Parlamentsrede des Seyyid Bey (3. März 1924) wiedergegeben: „Delegierung erfolgt manchmal absolut, manchmal beschränkt. Denn wenn jemand sich einen Vertreter sucht, nach Belieben seine Geschäfte auf ihn überträgt und ihm freie Hand gibt, das ist die absolute Delegierung. Nach Belieben kann er aber auch den Handlungen des Repräsentanten Bedingungen auferlegen, das ist beschränkte Delegation. [...] Dies gilt nun auch für das Kalifat. Wählt die Nation den Kalifen als absolut, dann gilt die absolute Regierung. Wenn sie will, kann die Nation aber auch die Handlungen des Kalifs unter Vorbehalt stellen. Das gibt die begrenzte Regierung. Die sogenannte konstitutionelle Regierung ist eine solche. Wenn nun die Nation niemandem ihre Vertretung überträgt, also keinen Kalifen, keinen Imam wählt, dann kann es kein Kalifat geben. Dann gibt es eine Republik. Was steht dem im Wege? Daß die Nation beansprucht, ihre Sache selber auszuüben; wenn sie sagt, warum lasse ich mich durch jemand anderes dazu nötigen, wieso dürfte das nicht gelten? Die Nation kündigt also an, ich erledige meine Sache selbst, und nur wenn ich hilflos bin, dann delegiere ich es einem Kalifen oder Imam. Jetzt aber, Gott sei dank, bin ich nicht hilflos, bin nunmehr mündig. Ich brauche keinen Vertreter. Ich werde meine Geschäfte durch die für Nationen nützlichste Regierungsart, nämlich Republik und qua Beratung erledigen. Wer kann nun etwas dagegen einwenden? Niemand! Denn das Recht gehört dem Volk." (Kara 1987: 207f, Hervorhebung im Original) 
entwurzelten oder nunmehr erschlossenen ländlichen Bevölkerung bei der Knüpfung neuer sozialer Beziehungen wichtig wurde. In dieser Zeit etablierte sich denn auch die konservative, wirtschaftsliberale „demokratische Partei“ als die Stimme der religiösen Forderungen. Während ihrer erst 1960 mit einem Militärputsch beendeten Regierungszeit hatte sie die Religionsbürokratie erheblich ausgebaut. In der Verfassung von 1961 wurde die Diyanet später als Teil des allgemeinen Verwaltungsapparates aufgeführt (Art. 154). Die Veränderung des Aufgabenspektrums trat aber erst mit dem Gesetz von 1965 in Kraft. Religion wurde nunmehr zu einem gesellschaftspolitisch relevanten Thema in dem demokratischen Machtkampf. Erst unter diesen Bedingungen entwickelte sich der Bedarf nach der Modifizierung der Aufgabenbereiche der Diyanet. Das Gesetz von 1965 führte einen dritten Bereich in die Aufgaben des Amtes ein, indem nunmehr neben Glauben und Ritus auch die Ethik/Moral (ahlak) unter den Zielen der staatlichen Verwaltung der Religion subsumiert wurde. Damit wurde die anfängliche Kontrollidee ein Stück in Richtung einer religiös gestützten Staatsideologie hin erweitert. Die Verwaltung der Religion begnügte sich demnach nicht mehr damit, die Bedingungen für eine private Religionspflege bereitzustellen und zu verhindern, daß der Islam von regimekritischen Ordensgemeinschaften als eine anti-laizistische Ideologie artikuliert wird. Die politischen Veränderungen im Lande, die mit einer Zunahme der Bedeutung der Religion in der Politik einhergehen, haben sich folglich in der Gesetzgebung niedergeschlagen und damit der Verwaltung der Religion neue Dimensionen verliehen.

An der Einführung der ethisch-moralischen Zuständigkeiten der Religionsbehörde kann man eine Bedeutungsverschiebung in der Ausübung der Staatsraison feststellen. Sie will sich fortan die ideologische Zurichtung der Bürger immer mehr zunutze machen, der Islam soll dabei das ethisch-moralische Rüstzeug liefern. Ich werde später darauf eigens eingehen, mit welchen Problemen die religiös begründete Moralpolitik des laizistischen Staates verbunden ist und daß außerdem dies über die von Foucault eindringlich analysierte Anwendung der Staatsraison hinausgeht, indem hier nicht mehr nur die „moralische Qualität des Lebens der Bürger" auf der Tagesordnung steht, sondern darüber hinaus die „rechte“ Lehre, d.h. die „Rechtleitung“, den Bürgern staatlich beigebracht wird.

Die zusätzlich dem Amt zugeschlagene Aufgabe steht nun in einem Zusammenhang, in dem denn auch alsbald die organisatorische Lage der Diyanet aufgebessert wird (z.B. gesicherter Status des Personals). Gleichwohl bleiben diese Veränderungen innerhalb des laizistischen Rahmens der Republik, auch wenn dieser erheblich ,großzügiger" interpretiert wird als je zuvor. Der funktionale Zugriff des Staa- 
tes auf die Religion bleibt somit trotz der weitreichenden materialen Erweiterungen paradigmatisch.

Infolge der Verschiebungen an politischen Kräfteverhältnissen, die sich vor allem ab Mitte der 80er mit dem Erstarken des Islamismus ereignet hatten, wurde selbst die Beschränkung auf drei Bereiche in Frage gestellt, da darin immer noch der ,wahre“ Islam nicht zu seiner Entfaltung finde. Der sich jetzt offensiver zu Wort meldende Islamismus, welcher in der (inzwischen verbotenen) Refah-Partei ihr parlamentarisches Sprachrohr gefunden hat, verlangt nun einen vierten Aspekt bei der Bestimmung der islamischen Religiosität: Muamelat (,zivilrechtliche", vertragliche Beziehungen), die, im Falle ihrer Einbeziehung, den ganzen Apparat der Jurisprudenz (fikıh) in Gang setzen würde. Dort wird dann nun auch mit einem weiteren Aspekt der islamischen Religiosität, ukubat (Bestrafung) aufgewartet. In den Haushaltsdebatten brachte das der Sprecher der Refah-Fraktion zum Ausdruck:

„Gleich kommen wir zur Sache: Die islamische Religion besteht nicht nur aus Glauben, Ritus und Ethik/Moral. Es hätte der Umfang breiter gezogen, der Diyanet die Aufgabe gegeben werden sollen, über alle Aspekte des Islam, der die Totalität des Lebens umfaßt, Aufklärung zu betreiben. Hier besteht ein Mangel. Wenn das so wäre (die Totalität des Islam berücksichtigt worden wäre, L.T.), könnte nicht jeder beliebige über diese erhabene Religion schwatzen und könnten auch diejenigen, die keinen Schimmer Ahnung von Islam haben, ihre Besserwisserei nicht betreiben.“ (Ebd.) (TBMM-Bulleten 1997: 392; Hervorhebung L.T.)

So eignet den hier gemeinten Sachgebieten der in der Jurisprudenz vorgesehenen praktischen Regelungen (muamelat und ukubat), anders als den drei anderen Aufgabenbereichen, zumindest implizit, ein hoch konflikthafter Status in der türkischen staatlichen Praxis. Überhaupt bildete z. B. muamelat einen prominenten Streitpunkt für den islamischen Modernismus des 20. Jh., von dem aus eine den modernen Zeiten zuträgliche Interpretation des Islam entfaltet werden sollte. Für Muhammad Abduh (gest. 1905) und Rashid Rida (gest. 1935) hatten nur die allgemeinen Prinzipien der muamelat ihren Ursprung in der Offenbarung (vgl. Bernand 1987). Im selben Geist bemühten sich später auch Iqbal (gest. 1938), Ali Abd al-Razik (gest. 1965) und AlAschmawi um die Trennung zwischen für immer gültigen Prinzipien (z.B. ibadet) und historisch bedingten, praktischen Bestimmungen des Islam (muamelat). Einer der aktuellsten Vertreter dieses islamischen Modernismus in der Türkei, Yasar Nuri Öztürk (u.a. 1995, Teil II; 1997: 46-98), wandelt auf dem Pfad des selben Geistes, wenn er, übrigens bei expliziter Berufung auf die Tradition von Abduh und Iqbal, den Islam vor der islamistischen Einspannung in die Politik zu wahren 
sucht und die Rückkehr zum „Islam im Koran“ in der Befreiung von den (traditionsbedingten) Bestimmungen der Jurisprudenz als solcher propagiert. Dabei hatte die Übernahme westlicher Gesetze nach den Tanzimat-Reformen praktisch und der explizite Laizismus der Republik das Problem der muamelat zudem auch prinzipiell behoben.

Nun stellt sich hier die Frage, wie neutral denn diese von uns so genannte „formale“ Bestimmung der öffentlich zulässiger Religiosität tatsächlich ist. Läßt denn die staatliche Beschränkung religiöser Sachgebiete tatsächlich so, wie der laizistische Diskurs es konzipierte, den „ursprünglichen“, durch politischen Mißbrauch nicht verdorbenen Islam hervortreten? Aus diskurstheoretischer Sicht ist hierzu zu konstatieren, daß jede Definition, auch und gerade eine solche, die sich möglichst auf die äußerliche Bestimmung der Sachgebiete beschränken will, notwendigerweise ein bestimmtes Verständnis der Religion präferiert, während sie andere Konzeptionen der Religion als unwahr (od. mißbräuchlich) ausschließt. Über die theoretischen wie politischen Implikationen dieser These muß man gründlich nachdenken. Man muß das vor allem in solchen Zeiten tun, wo im Namen der postmodern inspirierten populären Forderung nach der Anerkennung des Anderen einem sich als unparteiisch gerierenden Liberalismus vorgeworfen wird, er würde mit seiner scheinbaren Neutralität ihre kulturellen Wurzeln verdecken und den Anderen so raffiniert letztlich doch ihrer Herrschaft unterwerfen. Tatsächlich begegnen sich aber die Kulturen (im Grunde genommen: die im Namen von Kulturen Sprechenden) nie in irgendeiner reinen Form, sondern immer schon in einer spezifischen diskursiven Ausgestaltung. Jede diskursive Position ist aber darauf angelegt, eine bestimmte Bedeutung zu fixieren, was ihre unvermeidlich die anderen Definitionen partiell oder total ausschließende Praxis ausmacht. Es gibt also jenseits dieser eingreifenden, mitkonstituierenden Definitionen keinen reinen, m.a.W. außerdiskursiven, authentischen Islam, den wir so herausschälen könnten, wie er jenseits aller diskursiven Konstruktionen in Wirklichkeit existierte. Auch die konservative Kritik bzw. die islamistische Ablehnung der staatlichen Festlegung der innerhalb des Staatsapparates zulässigen Religion ist nichts anderes als eine andere, ebenfalls spezifische Ausformung des Islamverständnisses.

Das Problem besteht also nicht darin, daß auch die sogenannte neutrale Bestimmung letztlich eine bestimmte Konzeptualisierung mit transportiert. Die türkische Praxis der Laizität geriet vielmehr dadurch in eine grundsätzliche Schwierigkeit, daß zwecks der Verwaltung der Religion einem mächtigen Apparat in der staatlichen Organisation Platz eingeräumt wurde. Damit ist nicht notwendigerweise gesagt, daß die staatliche Verwaltung der Religion auf alle Fälle aufgegeben werden müßte. Denn unterhalb der verwalteten Religion wartet nicht der 
Freigeist der religiösen Ordensgemeinschaften oder islamistischen Intellektuellen auf, welche neuerdings sogar als wesentliche Bestandteile der Civil Society von Toleranzhändlern auf dem politischen Markt feilgeboten werden (dazu vgl. die Kapitel II.5. u. 6 dieses Buches). Die Ordnungsinteressen eines säkularen Staates haben nun einmal, und das nicht nur mit einer muslimischen Bevölkerung, vielerorts dazu geführt, Strukturen für das Verhältnis des Staates zur Religion zu schaffen, die der Befriedigung religiöser Bedürfnisse seiner Bürger dienen sollen. Allein das Problem besteht hierbei darin, daß der zur Verwaltung der Religion geschaffene Apparat, jedenfalls wenn er so mächtig ist wie die türkische Diyanet (vgl. unten im Unterkapitel I.4.2.3, Verwaltung der Gebetsanstalten), gleichzeitig die Bedingungen bereitstellt, die eine zentral gesteuerte religiöse Durchdringung der Gesellschaft ermöglichen. Tatsächlich taucht die Rede von der „Totalität des Islam“, von der systematischen Einheit unterschiedlicher Sachgebiete der Religiosität durch die Existenz eines Staatsapparates immer öfter auf, der mit der dazu befähigenden Infrastruktur in alle Lebensbereiche eingreift und (auch für die Religion) standardisierend wirkt. Die Totalität der politischen Rationalität läßt also Bedingungen hervortreten, unter denen auch der Islam als Totalität gedacht und zur öffentlichen Norm der politischen Ordnung gemacht werden kann (zum Islam als öffentliche bzw. Metanorm vgl. Salvatore 1998).

Solange nun die Verwaltung der Religion in einer religiösen Kultur stattfindet, in der sich das göttliche und das profane Gesetz auseinander entwickelt haben, so daß das erste das zweite freigegeben hat (oder auch dessen Geltungsbereich anerkennt); solange sich die Staatsraison konsequent der materialen Bestimmung der Religion enthält ${ }^{34}$; und nicht zuletzt solange sie von einer politischen Kultur getragen wird, in der die Säkularität verwurzelt ist, solange wird man dann nicht von einem spannungsgeladenen Problem sprechen müssen. Allerdings treffen diese Bedingungen kaum oder nur teilweise auf die türkischen Verhältnisse zu. Die Diyanet geht ihren auf einen Verfassungsauftrag zurückgehenden, gesetzlich bestimmten Aufgaben sehr wohl im Sinne der Verbreitung partikularer Inhalte nach. Noch inter-

34 Arkoun formuliert in seinem Vergleich zwischen dem französischen Vorbild der türkischen Laizität diesen Unterschied folgendermaßen: „Der partikulare Fall der Laizität in Frankreich scheint, als Atatürk die Religionsausübung unter staatliche Kontrolle stellen wollte, in der Türkei nachgeahmt worden zu sein. Das französische Innenministerium ist gleichzeitig Ministerium für Andachtsübungen. Kultische Handlungen werden in ihrer öffentlichen Ausübung kontrolliert, jedoch in religiöser Hinsicht nicht verwaltet.“ (1995b: 21) Arkoun meint hiermit aber auch, daß die türkische Praxis über das französische Vorbild hinausgeht, daß also die Verwaltung hier auch in religiöser Hinsicht stattfindet. 
essanter wird es, wenn man vor die Augen führt, daß dies auch in der rechtlichen Konzeption inzwischen so angelegt ist.

\section{2. 2 Gesellschaftspolitischer Auftrag des Amtes}

Der gesellschaftspolitische Auftrag, der eigentlich nicht von Anfang an zu den Aufgaben des Amtes gehörte und erst mit dem Gesetz von 1965 eingeführt wurde, ist, ganz allgemein ausgedrückt, religiöse Aufklärung. Mit ihm wurde ein weiterer Meilenstein auf dem Weg dahin gelegt, die Staatsraison von der formalen Bestimmung in die materiale hin auszuweiten. Auch wenn im Begriff Aufklärung seine europäische Herkunft noch mitklingt, wäre man richtig beraten, ihn mit Vorsicht in dieser Richtung zu interpretieren. Es haften nämlich dem Begriff mitunter ganz andere Selbstverständlichkeiten als die aus der europäischen Aufklärung bekannten. Im Kontext der Diyanet vermischen sich nämlich die Ideen aus der populären Aufklärungstradition, die in dieser Form hauptsächlich von der Sozialdemokratie und teils auch von der konservativen bürgerlichen Mitte getragen wird, und dem vormodernen, religiösen Wissenschaftsverständnis derart, daß schlußendlich die religiösen Konnotationen im Verständnis der Aufklärung stärker nachhallen. Nach dem Aufklärungsverständnis der Ersteren soll das Amt einen wissenschaftlich aufgeklärten Islam verbreiten, der sich selbstredend am Prinzip der Laizität zu orientieren hat. Die wissenschaftlich geläuterte Religion führt demnach automatisch dazu, den wahren Kern des Islam von den „mißbräuchlichen“ Zusätzen zu bereinigen. Die türkische Modernisierung enthielt eigentlich schon von Anbeginn den Impetus der „heilsspendenden“ Wissenschaft. Zugleich wurde aber Islam, trotz einer durchaus vorhandenen Religionskritik, selten völlig aufgegeben, statt dessen erhoffte man sich durch diesen wissenschaftlich aufgeklärten Islam die Bestätigung der Zivilisationsziele. ${ }^{35}$

Auf der anderen Seite konnte die Orthodoxie, bzw. auch die religiös artikulierte Opposition, bereitwillig das Idiom vom wissenschaft-

35 Eine exklusiv auf Wissenschaftlichkeit begründete, religiöse Aufklärung würde natürlich der Aufklärung im Kantischen Sinne widersprechen. Kant wollte, im Gegensatz zu türkischen Laizisten und aber auch einer traditionsreichen europäischen Interpretation der Aufklärung, keineswegs die Religion unter die Herrschaft der Wissenschaft stellen, sondern gerade durch das Aufzeigen der Grenzen der Wissenschaft für den Glauben Platz schaffen (so z. B. im Vorwort zur Kritik der reinen Vernunft). Für die systematische Ausarbeitung einer solchen Kant-Interpretation vgl. Bielefeldt 2001. Die vorliegende Dissertationsarbeit möchte einer szientistisch verengten Aufklärung keine Folge leisten. 
lich geläuterten Glauben übernehmen, wobei hier andere Elemente wirksam waren. Immer wieder wurde vorgetragen, daß der Islam den für das Christentum typischen Konflikt zwischen Vernunft und Glauben nicht kenne. Die These hatte Konsequenzen in zwei Richtungen:

Zum einen wurde mit ihr eine laizistische Praxis als nicht zum Islam passend gänzlich abgelehnt, da sie ja aus einer anderen historischen Erfahrung hervorgegangen sei (zuerst von Said Halim Paşa 1913 [1997]; jüngst wird dies von den islamistischen Intellektuellen emsig vorgebracht). Wichtig ist allerdings, darauf wird unablässig insistiert, daß sich die Vernunft vom Gesetz leiten lasse. „Der Verfallsprozeß ${ }^{\prime \prime}$, der nach dieser Geschichtsbetrachtung im 18. Jh. einsetzte, durchlief die Tanzimat- (1839) und Islahat-Dekrete (1856) [Reformdekrete, L.T.], die erste Konstitution (1876), die zweite Konstitution (1908) und gelangte mit der Republik vollends zu einem Gottes Gesetze leugnenden Höhepunkt. „Der neue Staat wurde“, so Pamak (ein Vertreter dieser verfallsgeschichtlichen Bewertung der türkischen Modernisierung), ,über das neue Regime, welches den Westen, die Kultur und Institutionen, das Rechtssystem des Westens angenommen, die Vernunft und den menschlichen Willen vergöttlicht, d.h. sich auf den Laizismus gründet, mit einer antiislamischen Identität errichtet.“(M. Pamak, in Uluçay 1998: 473)

Zum anderen wurde die Kompatibilität beider als so „selbstverständlich“ hingestellt, daß sich eine besondere Konzeptualisierung des Laizismus als politisches Prinzip erübrige, da der Islam bereits eine Vernunftreligion sei. Indem die Orthodoxie den „wahren“ Islam mit Hilfe der „Wissenschaft“ verbreitet, kommt sie, so funktioniert die Argumentation, ihrem Auftrag der religiösen Aufklärung nach. Dazu sagt der derzeit amtierende Vorsitzende der Diyanet, Mehmet Nuri Yilmaz folgendes:

„Im Koran ist nichts zu finden, was der Technologie widerspricht. Der Koran steht nicht im Widerstreit mit Wissenschaft und Technik. Im Gegenteil, der Koran fördert wissenschaftliche Suche, das Lernen. Er erzählt von Gott, Mensch und Universum. Unter Universum fallen natürlich auch sämtliche technologische Erfindungen. [...] Laizität konnte sich bei uns nicht so recht bemerkbar machen. Denn unsere Religion räumt Glaubens- und Gewissensfreiheit breiten Platz ein. In der osmanischen Zeit gab es keine Laizität, davor auch nicht. Sie gab es auch in der Zeit des Propheten nicht. Gleichwohl existierte Religions- und Gewissensfreiheit. Das heißt, Laizität gab es als Wort nicht, dagegen Religions- und Gewissensfreiheit. ,Jeder ist frei in seinem Glauben und Gewissen.' Jeder kann seine Religion aus freiem Willen wählen. Andersgläubige zu unterdrücken, sie mit Gewalt zu behandeln, wird von der Religion untersagt. Weder diejenigen, die sich für Laizität aussprechen, noch die Gegner der Laizität wissen recht, was sie ist. Der Islam hat keine Probleme mit der Laizität.“ (Tageszeitung Hürriyet vom 12. September 1994) 
Nun, aus diesen für die Diyanet typischen Formulierungen weiß man nicht so recht, was die Position der Diyanet ist. Wenn sich der Orthodoxie keine grundsätzlichen Probleme stellen, die soweit gingen, daß ihr Verhältnis zu den Erscheinungen der Moderne im allgemeinen und $\mathrm{zu}$ einem laizistischen System im besonderen die innere Rationalität der Heilslehre dadurch tangierte, dann liegt diese Haltung zunächst einmal in der bekannten Reaktion der islamischen Orthodoxie auf die Moderne, die darin besteht, die neuen, politisch durchgesetzten Konzepte zu vereinnahmen, anders ausgedrückt: zu erobern, ohne ihren Kern systematisch zu durchdringen. ${ }^{36}$ In dieser Hinsicht ähnelt die Orthodoxie dem islamischen Modernismus, geht allerdings bei der Anpassung der Religion an die modernen Bedingungen nicht so weit und ist nicht so entschieden wie dieser. Das wird auch durch die selbstverständlich nicht konfliktfreie Zwangsallianz zwischen der laizistischen Elite und der Orthodoxie gefördert, welche zur Durchsetzung der Laizität etwas, wenn auch zwiespältig, beigetragen hat. ${ }^{37}$ Nun, nicht eine genuin islamische Begründung der Laizität ist hier symptomatisch, sondern, daß überhaupt keine Begründungsarbeit geleistet wird. Auf der anderen Seite konnte die Orthodoxie diese Haltung des Durchwurschteln, des In-der-Schwebe-Lassens, nämlich etwas zu sagen, es doch nicht ganz genau so zu meinen, deshalb auch innerhalb eines laizistischen Staates erfolgreich praktizieren, weil in den unterschiedlichen Schattierungen des politischen Willens ebenfalls die Erwartungen auf eine material gehaltene Aufklärung zirkulierten. Dies hängt erheblich mit der Rolle zusammen, die die Religion im Rahmen der

36 Die Durchdringung der Begriffe könnte man dann, will man im Rahmen der Weberschen Begrifflichkeit bleiben, im Gegenzug "beherrschen" nennen. Dieser hier zaghaft gehaltene Anklang an die Webersche Begrifflichkeit von Weltbeherrschung (protestantische Ethik) und Welteroberung (islamische Ethik) ist wert, systematisch diskutiert zu werden, wenn auch dies hier nicht zu leisten ist.

37 Gleichzeitig gibt es jede Menge von Belegen, die auf eine eindeutig antilaizistische Haltung des Amtes hindeuten. So z. B. steht in einem von der Diyanet vertriebenen Kalender auf dem Blatt vom 23/24 Oktober 1979: „Um als Muslim zu gelten, muß man Dschihad betreiben.“ Dort wird dann gefragt, mit welchen materiellen und geistigen Waffen man gegen die laizistischen Reformen wie Schließung der Heiligtümer, Abschaffung des islamischen Kalenders etc. gekämpft habe. Auf dem Blatt vom 13. Juni 1979 wird gar offenkundig das Kalifat als ein heiliges Vermächtnis an die türkische Nation gepriesen (Tarhanli 1993: 93). Angesichts noch weiterer Beispiele dieser Art (ebd.) erhält nicht nur die Formulierung der „religiösen Aufklärung“ ganz andere Dimensionen, sondern auch das ganze Dilemma einer staatlichen Religionspolitik im Dienste der laizistischen Republik wird noch einmal deutlich. 
nationalstaatlichen Ordnung spielen soll. Die von der Orthodoxie angestrebte „religiöse Aufklärung“ meint im Grunde, der Bevölkerung die orthodoxe Lesart beizubringen, und nicht eine Aufklärung in dem Sinne, die Grundsätze eines mündigen Umgangs mit religiösen Fragen zu vermitteln. Letzteres ist „selbstverständlich“ und entspricht auch den Vorstellungen der Politiker mit einigen Ausnahmen vollkommen, auch wenn hier die Vorstellungen je nach der politischen Couleur in Nuancen voneinander abweichen mögen.

Es irritiert so denn auch kaum einen, wenn die „religiöse Aufklärung" fließend in die Aufgabe übergeht, die nationale Identität und Einheit sowie den sozialen Frieden zu wahren. Sie kommt nicht nur in zahlreichen politischen Stellungnahmen vor, sondern ist bereits in die Bestimmungen des formalen Rechts in Gestalt von Erwartungen materialer Art eingelassen. Bis zum Gründungsgesetz von 1965 waren die Aufgaben vornehmlich in technischer Hinsicht bestimmt. Der Artikel 5e des Gesetzes von 1965 beauftragt hingegen das Amt zusätzlich damit, „die Religion betreffende Publikation im Inland wie im Ausland beobachten, sie zu bewerten und Grundsätze für eine wissenschaftliche Auseinandersetzung mit negativen Publikationen auszuarbeiten“ (Diyanet 1987). Die Verschiebung von einer technischen hin zu einer inhaltlichen Sprache, welche die Neutralität des laizistischen Staates mehr und mehr durchdringen wird, artikuliert die Verbindung der religiösen Aufklärung mit den nationalen Zielen im Artikel 7.2c völlig unverhüllt. Eine Unterabteilung im Amt soll demnach Regelungen treffen, die die „Loyalität der muslimischen Bürger zu den nationalen Zielen pflegen und den Mißbrauch der Glaubensdifferenzen verhindern" sollen [gemeint sind selbstverständlich lediglich die innerislamischen Differenzen und dies auch aus der sunnitischen Perspektive, wie noch zu zeigen ist]. Allein schon in rechtlicher Hinsicht wird hiermit ersichtlich, daß die Staatsraison zwar weiterhin als die entscheidende politische Technik gepflegt wird; sie wird aber immer mehr von einer, wenn auch von vornherein schwer haltbaren, immer schon etwas inhaltlich durchsetzten Neutralität hin zu einer freimütig angestrebten, partikularen Bestimmung der Religionspolitik verschoben. Die innere Verknüpfung der verwalteten Religion mit nationalpolitischen Zielen deutet einen folgenreichen Wechsel von der ausschließlich auf Religionskontrolle abgestellten Politik zur aktiven Inanspruchnahme der Religion an. Auf dem Hintergrund der bürgerkriegsähnlichen politischen Entwicklungen in den 70er Jahren wird der Trendwechsel in der von der Militärjunta von 1980 in Auftrag gegebenen Verfassung gar festgeschrieben - sowohl ein Niederschlag des vorangegangenen Prozesses in der Gesetzgebung als auch ein Katalysator für eine beschleunigte Fortsetzung desselben. 
„Artikel 136) Das in der allgemeinen Verwaltung aufgeführte Amt für Religiöse Angelegenheiten erfüllt gemäß den Prinzipien der Laizität und unabhängig von sämtlichen politischen Richtungen und Meinungen bleibend, sowie die Solidarität und den Erhalt der nationalen Einheit als Ziel erachtend, ihre im Gesetz näher zu bestimmenden Aufgaben, die Gesellschaft über die Religion aufzuklären und die Gebetsanstalten zu verwalten.“

Die Verfassung unterstreicht zudem nicht nur die Bedeutung des Amtes für die Wahrung der nationalen Einheit, die ja vor dem Militärputsch tatsächlich bedroht war und deren drohender Zusammenbruch als historische Erfahrung in die höchste Schrift des Staates eingraviert wurde. Sie schreibt denn auch im Zuge der institutionellen Aufwertung der Religion den Religionsunterricht in den Schulen als Pflichtfach vor (Art. 24); eine auf der höchsten Ebene festgesetzte Regelung, welche den Machtzuwachs der Diyanet beträchtlich vorangetrieben haben dürfte. Warum sie zur Stärkung der Diyanet dient, konstatiert Davut Dursun, die Regelung bejahend, die Folgen des staatlichen Einsatzes der Religion zutreffend:

„Zwar ist bei dieser Auflage die Religionsbürokratie nicht unmittelbar die Ansprechpartnerin, sondern das Kultusministerium. Die Regelung hat aber sehr wohl zur Zunahme der Anzahl der den mit der Religionsbürokratie gleiche Ideale teilenden Lehrern beigetragen, weil man theologischer Bildung für diese Lehrer bedarf. Dadurch wurde auch die Verbreitung des religiösen Denkens gefördert. Es sollte der mittelbare Einfluß der Verfassungsregelung auf die Entwicklung religiös orientierter politischer Bewegungen und Ideen angemerkt werden." (Dursun 1992: 207)

Die ausgerechnet von der kemalistischen Militärjunta geförderte Religionspolitik mit ihrem rechtlichen Ausfluß, die, ordnungspolitisch motiviert, im Islam ein moralisches „Gegengift“ zum Kommunismus sah, ist somit ein Faktor, der zu Verschiebungen in der politischen Kultur beigetragen hat. ${ }^{39}$

38 Man kann sich dann auch den möglichen Bedeutungs-, d.h. Machtzuwachs der Religionsbürokratie unter den Bedingungen des modernen Zentralstaates vorstellen, falls die Diyanet, wie vor einiger Zeit immer stärker gefordert wurde, einen autonomen Status erhalten sollte, wobei ihr zusätzlich auch die direkte Verwaltung der Predigerschulen übertragen würde - dieser Prozeß ist jedoch durch den unmittelbaren Eingriff der Militärs am 28. Februar 1998 vorerst gestoppt worden.

39 Die Folgen des erstarkenden Islamismus für die verwaltete Religion dürften sich denn auch im politischen Diskurs bemerkbar machen. Seit den 90er Jahren können die islamistischen Strömungen einen enormen Zuwachs nachweisen. Dabei greifen die innertürkischen Faktoren und die Auswirkungen weltpolitischer Entwicklungen derart ineinander, daß es folglich nahezu unmöglich wird, sie weiterhin als separate Fak- 
Die Haushaltsdebatten über das der Diyanet zugebilligte Finanzvolumen aus dem Jahre 1997 z. B. sind sehr geeignet dafür, die gesellschaftspolitisch an die Verwaltung der Religion geknüpften Erwartungen aufzuspüren. Die parteipolitischen Differenzen scheinen auf der grundsätzlichen Ebene, auf der die Rolle und der Zweck der Religion bestimmt werden, eine geringe Rolle zu spielen. Nahezu durchweg bei fast allen Reden steht der Beitrag der islamischen Religion zur „nationalen Einheit und Solidarität" an der vordersten Stelle. Der Sprecher der Demokratischen Partei der Türkei (Demokratik Türkiye Partisi, DTP) aus der bürgerlichen Mitte, Mehmet Korkmaz, formuliert die Grundsatzerklärung seiner Partei zur Diyanet in der Haushaltsdebatte vom 19.12.1997 in diesem Geiste verbleibend folgendermaßen.

„Gemäß den Prinzipien der Laizität und unabhängig von sämtlichen politischen Richtungen und Meinungen bleibend, sowie die Solidarität und den Erhalt der nationalen Einheit als Ziel erachtend, erfüllt die Diyanet ihre Aufgaben, die Gesellschaft über die Religion aufzuklären und die Gebetsanstalten zu verwalten, weiterhin gebührend. [...] Der gläubige Mensch hat als Mitglied der Gesellschaft auf der einen Seite Erfordernissen seines Glaubens zu entsprechen, sich auf der anderen Seite gemäß den Regeln der Gesellschaft, in der er lebt, zu verhalten. Damit die religiösen Angelegenheiten gemäß dem religiösen Glauben und den religiösen Prinzipien verrichtet, die Religion als ein moralischer Bereich für die Gesellschaft ermöglicht, die Religion vor Fanatismus und Aberglauben geschützt, und die religiösen Dienste durch kompetente und befugte Personen geleistet werden, ist die Bedeutung der Verankerung der Diyanet im Staatsapparat und Zuweisung von Finanzmitteln für ihre Leistungen offenkundig." (TBMMBulleten 1997: 375)

Der Sprecher der konservativ-liberalen Regierungspartei ANAP, Esat Bütün, akzentuiert noch klarer, was alles von der Religion erwartet bzw. warum u.a. auf sie gesetzt werden soll. Man kann es auch andersherum formulieren: Welche Begründungen für die staatliche Religionspolitik begünstigt der politische Diskurs? Nach Bütün z.B. gehört ,die Diyanet im Hinblick auf die moralische Unterstützung und die freiwilligen Beiträge, welche die erste Bedingung für die Schaf-

toren zu betrachten. Erwähnt werden sollen hier die Verwicklungen, die sich zwischen den Auswirkungen der postmodernen Diskurse einerseits, welche den laizistischen Fortschrittsideal erheblich abgeschwächt haben, und der Einbeziehung der entwurzelten Schichten in die Politik andererseits anbahnen, welche durch die gravierenden ökonomischen Umwälzungen aus ihren sozialen Zusammenhängen in die Großstädte getrieben wurden. In dieser sozialen und intellektuellen Atmosphäre gelang es dem Islamismus mit seinen unterschiedlichen Spielarten, die Einwanderer der Großstädte anzusprechen (vgl. Seufert 1997b) und sich als eine öffentlich relevante Stimme zu etablieren. 
fung des sozialen Friedens und der Herstellung des öffentlichen Lebens sind, zu den unverzichtbaren Institutionen.“ (a.a.O.: 382)

An die Beteuerung der sozialen und politischen Funktion der Religion schließt sich eine von beiden sozialdemokratischen Parteien, Partei der demokratischen Linken (Demokratik Sol Parti, DSP), problemlos an. Hier wird natürlich die zusätzliche Ausstattung der Geistlichen mit Kenntnissen der modernen Wissenschaft hervorgehoben, damit die Religion nicht als Aberglaube und als etwas Beängstigendes verstanden werde und ihre wahre Identität erlange (a.a.O.: 423). Der Parteiführer Bülent Ecevit, mehrmaliger Premier der türkischen Republik, bestätigt die Haltung seiner Partei, die tatsächlich in erster Linie von Staats wegen motiviert war. In seiner Stellungnahme spiegelt sich wohl die der staatlichen Religionspolitik inhärente, vielleicht gar nicht mehr auflösbare Spannung wider:

„Manche Kreise fordern, die Diyanet abzuschaffen. Theoretisch mögen sie Recht haben. Die praktische Realität entspricht dem aber nicht immer. Wie die letzten Ereignisse [gemeint sind vermutlich die Ausschreitungen wegen der Überfälle auf Aleviten] gezeigt haben, wäre der Platz nur denjenigen überlassen, die Glaubensmißbrauch betreiben, gäbe es nicht die Diyanet, die sich ihrer Mission bewußt ist.“ (in: Uluçay 1998: 259)

Das Problem besteht natürlich in dieser Schärfe nur für die streng laizistische Position, die zwar theoretisch am liebsten auf die Beihilfe der Geistlichen verzichten würde, sich aber praktisch zu einer Religionspolitik auch mit stark inhaltlichen Elementen gezwungen sieht, da sonst die Religion in die Hände der staatlich nicht zu kontrollierenden, regimefeindlichen Kräfte fallen werde. Solche Bedenken reduzieren sich andererseits in den Augen der Politiker aus der konservativen Mitte erheblich. Hier wird die Verkündung der „rechten“ Lehre mit den nationalen Zielen bedenkenlos verknüpft. Die Wahrung des sozialen Friedens und der öffentlichen Ordnung bedarf auch hier ,moralischer Unterstützung und freiwilligen Beitrags" seitens der Bürger, wobei der Diyanet, so z.B. der Sprecher der bürgerlichen ANAP, ein besonderes Verdienst zukomme. Des weiteren spricht er dem Amt auch das Verdienst zu, die nationale Einheit mit zu garantieren, deren Grundlagen im Islam lägen:

„Zur Vermittlung des Islam, der richtigen Religion, müßte die Diyanet, so bin ich überzeugt, noch größere Aufgaben übernehmen. [...] Jeder Beitrag, den wir bei dieser Sache leisten, wird zugleich der nationalen Einheit und Eintracht der Türkei zugute kommen; denn die Quelle unserer nationalen Einheit und Eintracht entspringt einzig und allein aus unserer erhabenen Religion und Nation.“ (TBMM-Bulleten 1997: 383).

Das Amt hat die ihm überantwortete Ordnungsaufgabe unmißver- 
ständlich wahrgenommen. Die historisch bedingte Brisanz einer möglichen Verbindung zwischen Religion und Politik, die sehr schnell die Frage nach der Legitimation des Staates (göttlich oder weltlich) nach sich zieht, hatte die türkischen Verfassungsgeber bereits früh zu der Maßnahme veranlaßt, für die Beamten des Amtes ein Politikverbot zu verhängen, und zwar nicht nur während des Dienstes, sondern auch außerhalb der dienstlichen Zeit und Zusammenhänge. Bemerkenswert ist es, daß sich das Amt, vor allem dann, wenn es um hohe ,nationale Interessen" ging, daran nicht halten mußte; noch erstaunlicher ist eigentlich, daß dieses Engagement kaum öffentlichen Protest auslöst. Der Vorsitzende der Diyanet konnte z.B. nach der Verschleppung des PKK-Führers Öcalan in die Türkei ohne rechtliche Konsequenzen oder irgendeine Kritik an seine Muftis die Anweisung geben, ,in den Gemeinden über Öcalans Untaten zu berichten, damit man daraus Lehren zieht" (Hürriyet vom 19.02.1999). Die an diesem Beispiel bezeugte Loyalität des sunnitischen Islam gegenüber dem Herrscher kommt in einem anderen Statement von ihm noch deutlicher zum Ausdruck. Der Vorsitzende befindet zwar, daß Öcalan vor der Hinrichtung auf seinen Wunsch ein Geistlicher zur Verfügung gestellt werden solle. Gleichzeitig erklärt er aber, daß ,das Totengebet von jemandem, der sich gegen den Staat auflehnt, nicht abgehalten werden darf" (Zaman 02.06.1999). Anzumerken ist auch, daß diese Position, nämlich die Weigerung des Totengebets für einen Staatsfeind, in der Tradition der Orthodoxie abgedeckt ist. Auffallend ist nun dabei, daß nicht die Glaubensüberzeugung dafür, ob die Zeremonie abgehalten werden darf, ausschlaggebend ist, was ja für die Praxis eines Amtes naheliegen müßte, sondern das Fehlgehen gegenüber dem Staat. Dank seiner faktischen Sonderstellung beeilt sich der Vorsitzende der Diyanet anläßlich der Ausschreitungen des kurdischen Neujahrfestes (Newruz; türk.. Nevruz), das vom Parlament prompt zu einem ursprünglich türkischen, nationalen Feiertag erklärt wurde, die türkische Herkunft des Festes zu unterstreichen, ganz in der Manier eines nationalistischen Politikers (vgl. Hürriyet, 18. März 1999).

Damit legitimiert das Amt seine Existenz gegenüber den (besonders in den 90er Jahren) laut gewordenen Stimmen, welche die Abschaffung der Institution fordern, durch unmittelbare Verknüpfung der dogmatischen Tätigkeit mit der Pflege der politischen Einheit. Für den Vorsitzenden besteht kein Zweifel daran, daß die vom Amt behütete Einheit des religiösen Dogmas gleichzeitig einen Garant für die Einheit der Nation bildet. (Hürriyet, 12. September 1994). ${ }^{40}$ Die ruhmrei-

40 Das vom Vorsitzenden dafür zwecks Abschreckung eingebrachte Beispiel handelt von den Moscheegemeinden türkischer Migranten in Deutschland, die in der Tat - im Unterschied zu den Moscheen in der Türkei - nicht zuletzt aufgrund des deutschen Vereinsrechts um ideolo- 
che Geschichte des Islam lasse sich denn auch nur so erklären. Denn die religiöse Autorität sei schon immer innerhalb des Staatsapparates etabliert gewesen. Diese Aussage trifft M. N. Yllmaz auf dem von der alevitischen Stiftung CEM in Istanbul am 26/27 März 1996 veranstalteten internationalen Symposium zur Restrukturierung der religiösen Dienste. Das Symposium ist historisch gesehen bereits ein Novum (vgl. Uluçay 1998: 278). ${ }^{41}$ Selbst diejenigen (gemeint sind u.a. Aleviten), die darüber klagen, von den auf den sunnitischen Islam zugeschnittenen Diensten der Diyanet nicht zu profitieren, zögen, so Yılmaz, unbemerkt Nutzen aus der Existenz der Diyanet: Die Dienstleistungen der Diyanet richten sich demnach an alle. Und zwar ganz gleich, so fährt Yılmaz fort, „ob sie davon profitieren oder nicht, das ist eine andere Frage. Dennoch profitieren davon doch alle, wenn auch unbemerkt. Herrscht in einem Land Aufrichtigkeit, ehrlicher Handel, Liebe und Respekt, Religion spielt dabei eine Rolle. Es sind unsere Geistlichen, die dafür sorgen“" (in: Uluçay 1998: 214).

In der Person des Vorsitzenden präsentiert sich das Amt zu Recht seiner Macht bewußt. Er weiß natürlich, daß er dabei nicht nur auf die Unterstützung durch die Politiker zählen muß. Ein Urteil des Verfassungsgerichts hatte schon früh die ,historisch und gesellschaftlich bedingte Notwendigkeit" religiöser Dienste durch den laizistischen Staat unterstrichen - und das bringen die Amtsvertreter stets in Anschlag. Das oberste Gericht hatte 1972 die Klage der Partei der Eintracht (Birlik Partisi), die lautete, daß die Ausübung religiöser Dienste durch

gische Ziele herum, quasi als „Sekten“, organisiert sind. Der Vorsitzende der Diyanet erzählt: „Ich habe es mit meinen eigenen Augen gesehen. In einer Stadt in Deutschland haben sie einen Raum mit Ziegelsteinen getrennt; auf der einen Seite betet eine Gemeinde, auf der anderen Seite eine andere. Obwohl sie alle türkischen Staatsbürger sind, gehen sie nicht in die Moschee, in die Gebetsräume der anderen. Moscheen sind solchermaßen gespalten. Die Muslime sind gespalten. Wir wollen nicht, daß die Türkei in die gleiche Situation hinein rutscht. Sonst nimmt die Glaubenseintracht Schaden dadurch, unsere religiöse und nationale Einheit löst sich auf. Religion würde dann für bestimmte Interessen instrumentalisiert. In der Türkei würde Chaos herrschen.“ (Hürriyet, 12.09.1994)

41 So weitgehend auch die Technik der Staatsraison von einer bekenntnisorientierten Religionspolitik korrumpiert worden sein mag, funktioniert sie doch weiterhin und ein solches Symposium ist ein Beleg dafür, weil die Diyanet, die Vertreterin des sunnitischen Islam, nicht mehr gemäß ihrer Tradition die alevitische Heterodoxie zu verteufeln wagt, sondern die legitime Existenz der Aleviten öffentlich eingesteht, wenn sie auch dabei gleichzeitig nicht anders kann als die Anerkennung ausschließlich partikularistisch zu formulieren. Das funktioniert nur dadurch, daß die alevitische Besonderheit stillschweigend übergangen wird. 
den Staat dem Prinzip der Laizität widerspreche, mit folgender Begründung abgelehnt:

„Das Amt für religiöse Angelegenheiten ist keine religiöse Organisation. Es ist nach dem Artikel 154 der Verfassung als eine innerhalb der allgemeinen Verwaltung aufgeführte administrative Organisation und das Personal dieser Organisation hat [...] den Beamtenstatus. Da dieser Umstand auf eine Verfassungsbestimmung zurückgeht, kann von einem Verstoß gegen den Artikel 117 der Verfassung keine Rede sein.

Zweifellos ist die Tatsache, daß das Amt für religiöse Angelegenheiten in der Verfassung aufgeführt wird und sein Personal als Beamte gilt, Ergebnis verschiedener historischer Gründe, Realität und landesspezifischer Umstände sowie Notwendigkeiten.

[...] Demnach läßt sich die Aufführung des Amtes für religiöse Angelegenheiten in der Verfassung auf folgende Notwendigkeit und Gründe zurückführen: staatliche Religionskontrolle ausüben; in religiösen Angelegenheiten tätiges Personal ausbilden; dem religiösen Fanatismus vorbeugen; dafür sorgen, daß Religion zu einer geistigen Disziplin wird und somit die türkische Nation an den Stand der modernen Zivilisation gelangt; außerdem Personal, Gotteshäuser und andere religiösen Bedürfnisse in unserem mehrheitlich von den Muslimen bewohnten Land befriedigen und für ihre Pflege sorgen. [...]

Aus diesen Gründen bedeutet die staatliche Hilfe in diesen Bereichen und der Beamtenstatus des Personals des Amtes für religiöse Angelegenheiten keineswegs, daß der Staat Religionsangelegenheiten praktiziert, sondern daß man eine angemessene Lösung aus den landesspezifischen Umständen hervorgegangenen Bedürfnisses findet." (Hervorhebung L.T.)

Das Verfassungsgericht ist ohne Zweifel gewillt, den Aspekt der „landesspezifischen Gründe" lediglich auf die technische Durchführung bestimmter Dienstleistungen zu beschränken. Tatsächlich unterminiert denn auch eine solche Regelung nicht notwendigerweise sogleich das säkulare Recht. Gleichwohl muß man bedenken, daß sich die religiöse Aufklärung, von deren Ausübung ja das Gericht ausgeht, auf alle Fälle den gesetzlich vorgezeichneten, und vom Gericht dementsprechend angenommenen Rahmen sprengt, ja eigentlich völlig anderes bedeutet. Und man muß es sich klar machen, daß dies keine zufällige, oder akzidentielle Erscheinung, sondern wesentlicher Bestandteil der Praxis der Orthodoxie ist.

Sicher betreibt die Orthodoxie den Islam nicht notwendigerweise als Ideologie eines alternativen Gesellschaftsmodells. Sie wird jedoch andererseits aufgrund der auf sie gesetzten Erwartungen geradezu durch politische Ideen und materielle Ausstattung dazu ermuntert, den gesellschaftlichen Halt auf religiösen Grundlagen zu festigen und dabei auch für die Legitimationsaufgaben aufzukommen. Von dort aus ist folglich der Weg hin zu einer expliziten religiösen Ordnungsideo- 
logie nicht mehr weit. Die Relevanz der Sache wird besonders deutlich, wenn man sich das Ausmaß der gigantischen Organisation vor die Augen führt. Somit möchte ich auf den dritten Aspekt der staatlichen Kooptation der Religion überleiten: Verwaltung der Gebetsanstalten. Unter diesem Aspekt wird man ebenfalls sowohl die strukturell angelegten als auch politisch bedingten Verflechtungen hervorheben müssen. Das heißt auch, daß wir noch einmal, jedoch unter einem anderen Aspekt, an die Probleme herangehen, die sich aus der doppelten Lage des Amtes ergeben: ein religiöses Amt mit materialen Aufgaben, dessen Tätigkeit verfassungsrechtlich über die technische Dienstleistung nicht hinausgehen darf und zugleich politisch zur Stärkung des Staates dienen soll, indem es die Gesellschaft ethisch-moralisch imprägnieren soll.

\subsubsection{Verwaltung der Gebetsanstalten}

Die Diyanet hat sich im Laufe ihrer Geschichte zu einer weit verzweigten Organisation entwickelt, die vom staatlichen Haushalt einen ansehnlichen Beitrag zur Erledigung ihrer Aufgaben bezieht. Die tabellarische Darstellung (Tabelle 1, S. 82) bestätigt das. Die den Anteil einiger Ministerien übertreffende Summe, die der Religionsbürokratie aus dem Haushalt zugewiesen wird, kann man als einen aufschlußreichen Indikator für die Bedeutung verstehen, die dem Amt innerhalb des politischen Systems beigemessen wird.

Die Zahl des zugewiesenen Personals, die im Jahre 1994 schon auf ca. 88.544 anwuchs (Uluçay 1998: 385), unterstreicht die Relevanz, aber auch, wie später zu zeigen ist, die Brisanz der Verwaltung der Religion. In Tabelle 2 (S. 82) wird ein Überblick über den zahlenmäBigen Verlauf der Personalentwicklung der Diyanet gegeben. Die Zahl des Personals stieg auch nach 1980 kontinuierlich an. Sie belief sich im Jahre 1987, zusammen mit dem Auslandspersonal, auf 78.832 (Diyanet 1987: 53). Als das Amt ins Leben gerufen wurde, hatte die Republik die dem Şeyhülislam, dem Vorgänger der Diyanet aus der spätosmanischen Epoche, zugestandenen Befugnisse weitgehend gestutzt. Eigene Schulen, Gerichte, Ordensgemeinschaften und Stiftungen (eine essentielle Institution in der osmanischen Ordnung) wurden dem Machtbereich der Diyanet entzogen. Die Verwaltung des Moscheepersonals (sowohl zahlenmäßig die stärkste als auch wegen der Bevölkerungsnähe der Angestellten eine sehr wichtige Gruppe) wurde zudem dem Direktorium des Stiftungswesen übergeben (Gesetzänderung vom 4. Januar 1932). Außerdem beschloß die Regierung am 25. Dezember 1932 einen Erlaß, mit dem Kriterien dafür eingeführt wurden, was als Moschee gelten durfte. Sämtliche Moscheen und Bethäu- 
RELIGIÖSE STRATEGIEN DER ,MACHBAREN“ GESELLSCHAFT

Tabelle 1: Haushaltsgesetz für das Finanzjahr 1998

\begin{tabular}{|l|r|}
\hline Posten & Summe (in Million TL) \\
\hline Verteidigungsministerium & 1.390 .263 .200 \\
\hline Kultusministerium & 1.243 .108 .000 \\
\hline Gesundheitsministerium & 390.961 .701 \\
\hline Polizeipräsidium & 338.693 .250 \\
\hline Gendarmerie & 226.239 .800 \\
\hline Justizministerium & 121.833 .944 \\
\hline Ministerpräsidium & 112.777 .621 \\
\hline Amt für Religiöse Angelegenheiten & 96.646 .050 \\
\hline Innenministerium & 84.463 .700 \\
\hline Ministerium für Landwirtschaft & 84.427 .603 \\
\hline Ministerium für Bau- und öffentliche Arbeiten & 60.998 .006 \\
\hline Parlament & 51.722 .296 \\
\hline Kulturministerium & 47.301 .500 \\
\hline Verkehrsministerium & 31.495 .000 \\
\hline Industrie- und Handelsministerium & 22.741 .405 \\
\hline Forstministerium & 21.975 .000 \\
\hline Ministerium für Arbeit und Sozialversicherung & 15.708 .000 \\
\hline Ministerium für Energie & 17.584 .000 \\
\hline Tourismusministerium & 14.046 .500 \\
\hline Umweltministerium & 8.770 .8250 \\
\hline Gesamt & 14.789 .000 .000 \\
\hline
\end{tabular}

Quelle: Uluçay 1998: 273 (Gesetzbulletin am 27.12.1997/23213).

\section{Tabelle 2: Personalentwicklung}

\begin{tabular}{|l|r|r|r|}
\hline Jahr & Religiöse Dienste & Sonstiges & Gesamt \\
\hline 1927 & 1343 & 5829 & 7172 \\
\hline 1940 & 948 & 154 & 1102 \\
\hline 1950 & 1158 & 4681 & 5839 \\
\hline 1960 & 2954 & 10881 & 13835 \\
\hline 1970 & 28557 & 2592 & 31149 \\
\hline 1980 & 49820 & 3458 & 53278 \\
\hline
\end{tabular}

Quelle: Diyanet 1987: 46-52 
ser in der Türkei wurden anschließend gezählt, und diejenigen, die die Kriterien nicht erfüllten, wurden geschlossen. Damit erklärt sich denn auch der in der Tabelle ersichtliche rapide Rückgang der Personalzahl zwischen 1927 und 1940. Dies war ein bedeutsamer Akt in der türkischen Geschichte der staatlichen Einbindung der Religion, der später von der konservativen wie auch islamistischen Seite so interpretiert wurde, daß jetzt auch noch die Moscheen dichtgemacht worden seien. Allerdings erfuhr das Amtpersonal nach der Einführung des Mehrparteiensystems (1946) eine gewisse Aufwertung, die schon von der ehedem alleine als rechtmäßig geltenden Einheitspartei in ihren letzten Regierungsjahren (1947), offenkundig aufgrund der politischen Konkurrenz um die Wählergunst, vorgenommen wurde. Die alte Regierung wies am 23 März 1950 kurz vor den Wahlen, die sie übrigens mit immensen Stimmeinbussen verlor, mit einem Gesetz das Moscheepersonal wieder der Diyanet zu, und zwar jetzt zusätzlich mit Gehalt versorgt (vgl. Diyanet 1987: 65). Dadurch erlangte die Diyanet ihre Bevölkerungsnähe wieder (vgl. Tabelle 2). Seit den 50er Jahren findet infolge der Einführung der Mehrparteiensystems ein nahezu kontinuierlicher Anstieg des Personals statt.

Nach den Angaben der Diyanet zählte die Türkei im Jahre 1995 insgesamt ca. 70.000 Moscheen (davon 18.000 in Provinzstädten, ca. 5.000 in Kreisstädten und ca. 47.000 in Dörfern), die, mit Ausnahme von etwa 8.000, allesamt dem Amt für Religiöse Angelegenheiten unterstehen (Uluçay 1998: 377). Die Brisanz, die der Religionspolitik des laizistischen Staats innewohnt, wird angesichts des das ganze Land durchziehenden Netzes der Diyanet in Bezug auf die Kontrolle der Moscheen noch einmal deutlich. Weder der Staat als Institution mit seiner laizistischen Grundorientierung noch die politischen Kräfte, die eine inhaltliche, bekenntnisorientierte Religionspolitik betreiben, wollen von der geballten Macht des Apparates absehen. Würde der Staat dieses Instrument aus der Hand geben, mit dem er entweder bestimmte Botschaften über die Moscheen an die Bevölkerung heranbringen will oder lediglich in kontrolltechnischer Hinsicht den Bereich der praktischen Religionsausübung absteckt und somit den regimefeindlichen Kräften die Entfaltungsbasis entziehen will, dann würde die aus staatlicher Sicht ,unkontrollierte“ Religion hineinströmen. Das wäre außerdem auch für die Orthodoxie nicht akzeptabel. Denn dafür, daß sie ihrem Gründungszweck entspricht, eine zumindest offensichtlich subversive Politik aus den Moscheen fernzuhalten, wird sie mit dem Monopol öffentlicher Religion belohnt. Sie bringt deshalb auch immer wieder selbstbewußt ihre Funktion in Anschlag, die darin bestehe, den innerislamischen Spaltungen vorzubeugen, die gleichzeitig sowohl der Nation als auch der Religion drohten - ja, es gehe im Grunde um ein und dieselbe Gefahr. Der Vorsitzende des Amtes ant- 
wortete auf die in der Öffentlichkeit verbreitete Kritik, in den Moscheen fänden politische Aktivitäten statt, wie folgt:

„Was den Sachverhalt, Politik in den Moscheen zu betreiben, betrifft: Niemand darf sich anmaßen, die Weltanschauung des Islam abzulehnen. [...] Wir besitzen einen Glauben, der die Religion nicht zwischen Diesseits und Jenseits trennt. Der Islam hat Politik und wird sie haben. Wir versuchen aber, klarzumachen, daß es nicht richtig ist, den Islam als Mittel der Tagespolitik zu benutzen. Wir wehren uns dagegen, das Wort ,siyaset ${ }^{\star}$ [Politik] in einen parteipolitischen Rahmen zu setzen. Wir zweifeln nicht im geringsten daran, daß jeder vernünftige Mensch, der sich für die islamische Brüderlichkeit ausspricht, unsere Sorge teilt. Unsere Moscheen sind unsere Einheit und Eintracht symbolisierende Orte, in denen unsere Menschen, welcher Anschauung und welcher Gruppe auch immer, Schulter an Schulter in der Reihe beten. In diesen gesegneten Plätzen die Ideen bestimmter politischer Parteien zu gestatten und andere Menschen auszuschließen, ist nicht zu akzeptieren. Wir müssen uns immer wieder der tiefen Bedeutung dessen vergewissern, daß man in Einheit und Eintracht betet. Der Grund für unser Politikverbot in Moscheen liegt darin, Muslime einheitlich und zusammen zu halten, die doch jeder auch noch versucht, zu spalten, auseinanderzubringen." (in: Uluçay 1998: 379f)

Moscheen sind wahrscheinlich seit jeher höchst sensible Orte. Nachdem der Islamismus ab Mitte der 80er, insbesondere verstärkt in den 90er Jahren die politische Bühne betreten hatte, kamen die Moscheen erst recht als begehrte Objekte in Frage. ${ }^{42}$ Es ist dabei selbst der Diyanet bzw. ihren Angestellten immer wieder vorgeworfen worden, in den Moscheen regimefeindliche Propaganda zu betreiben. Ein Beispiel unter vielen anderen, so behauptete beispielsweise der Verein des kemalistischen Denkens am 10.03.1993, daß ,in den Moscheen Feindseligkeit gegen Atatürk geschürt werde“ (Uluçay 1998: 378). Angesichts des bei allem formellen Bekenntnis zum laizistischen Staat letztlich doch gespaltenen Verhältnisses der Diyanet sind solche Tendenzen sicherlich zu erwarten. Andererseits ist es genau so gut denkbar, daß die Diyanet nicht die volle Kontrolle über die weit verzweigte Organisation ausüben kann. Denn die Ordensgemeinschaften, die, mittlerweile mit Wirtschaftsunternehmen und eigenen Massenmedien ausgestattet, über enorme finanzielle und personelle Mitteln verfügen, operieren ebenfalls in den Moscheen. Teilweise weigern sie sich sogar offen, ihre Moschee der Kontrolle durch die Diyanet zu unterstellen. Aus den Kreisen der Diyanet wird hin und wieder verlautbart, daß die Kontrollaufgabe bei etwa 8400 Moscheen nicht vollständig erfüllt

42 Nach den Beschlüssen des Ministerrats, die, wie gleich unten noch zu zeigen ist, auf den Druck der Militärs zurückgehen, wurden später jegliche Demonstrationen und Kundgebungen im Umkreis von $100 \mathrm{Me}-$ tern der Moscheen untersagt (Hürriyet 24. März 1998). 
werden könne (Uluçay 1998: 96). Ob nun die laizismuskritische Tätigkeit selbst von den Beamten der Diyanet betrieben wird, ob sich Teile des Personals wider die Anweisungen aus der Zentrale regimefeindlich betätigen oder auch ob sich bereits eine Anzahl von Moscheen überhaupt der Kontrolle der Diyanet entzieht, dies alles zeugt von einer zunehmenden Politisierung der Moscheen in der zweiten Hälfte der 90er Jahre. Unter diesen Bedingungen sah sich ein anderes Machtzentrum im Staate berufen, in den Prozeß einzugreifen. Gemeint ist die Armee, der ja Atatürk neben der Religionsbürokratie schon in der Gründung der Republik die Möglichkeit nehmen wollte, sich aktiv in das politische Geschehen einzubringen.

Mit den Militärs kommt nun eine weitere Dimension der staatlichen Verwaltung der Religion ins Spiel, die darin besteht, daß sich zumindest Teile des Staates nicht ganz auf das demokratische „Spiel“ verlassen wollen, da gerade dadurch die politische Bedeutung der Religion nicht selten enorm wuchs und u.U. eine Gefahr für die Republik selbst sein könnte. Die Militärs hatten die islamistische Entwicklung über Jahre hinweg mit Besorgnis und Sorgfalt beobachtet. Anders als zuvor, als sie bereits mehrere Male (1960, 1971 und 1982) mit Panzern das politische Geschäft übernahmen, haben sie allerdings diesmal nicht geputscht (28. Februar 1997). Oder, wie man es in der türkischen Literatur bezeichnete - auch etwas wegen des modischen Geschmacks des Begriffs -, sie haben den ersten ,postmodernen Putsch“ ins Werk gesetzt. Innerhalb des Generalstabs wurde ein Arbeitskreis eingerichtet, mit Namen Batı Calışma Gurubu (Arbeitskreis West), um wohl auch die Richtung der Republik gen Westen noch einmal zu unterstreichen. Diese Gruppe sollte nun alle als islamistisch zu bezeichnenden Aktivitäten, Organisationen, Unternehmen, Medien Politiker dokumentieren, publik machen und die Öffentlichkeit gegen sie sensibilisieren. Nachdem die Militärs mit ihren Befunden einen überaus wirksamen öffentlichen Diskurs in Gang gesetzt haben, sind sie sodann dazu übergegangen, auch auf die Politik Druck auszuüben. Infolge dessen kamen die sogenannten Beschlüsse des Nationalen Sicherheitskomitees vom 28. Februar 1997 zustande, die später unter der Regierung von Mesut Yilmaz in ein Aktionsprogramm, irticaya karşı mücadele (der „Kampf gegen Fanatismus“) aufgenommen wurden.

Die Beschlüsse an sich sind exemplarisch, um die überaus umkämpfte Praxis der staatlichen Kontrolle der Religion in der Türkei mit all ihren Implikationen zu studieren. Ich begrenze mich hier nur auf den die Diyanet betreffenden Aspekt des Sachverhalts. Anhand der Stellung, die das Amt innerhalb dieser politisch sehr folgenreichen Beschlüsse einnimmt, läßt sich noch einmal das Dilemma der staatlichen Religionspolitik veranschaulichen. Das Dilemma besteht, das sei in Erinnerung gerufen, darin, daß der Staat entsprechend der Staatsrai- 
son ein weitgespanntes Netz der Religionsbürokratie aufbaut, das genau den Prämissen derselben zuwider arbeitet, oder zumindest die Tendenzen in dieser Richtung verstärkt. Dasselbe Dilemma tritt in den besagten Beschlüssen offensichtlich zutage, wenn auf der einen Seite Maßnahmen empfohlen werden, die auch die Diyanet in kritischer Absicht betreffen, auf der anderen Seite aber die Diyanet in den „Kampf gegen den Fanatismus“ einbezogen wird. Beide Punkte bedürfen einer Erläuterung.

1) Der wichtigste Punkt der Beschlüsse, welcher sodann auch im Zentrum des Regierungsprogramms stand, ist die Umstrukturierung der Imam Hatip Okulları, der Predigerschulen, die man als die wichtigste Säule der Religionsbürokratie betrachten kann. 1993 waren in 417 Schulen der Sekundarstufe und 391 Schulen der Primärstufe 448.992 Schüler eingeschrieben (Uluçay 1998: 217). Nach den Zahlen von 1995 hatten 68 \% des Diyanetpersonals den Abschluß einer Predigerschule. Man kann auch von denen mit Hochschulabschluß (15\%) mit ziemlicher Wahrscheinlichkeit annehmen, daß sie (zumindest die meisten von ihnen) ebenfalls die Predigerschule absolviert haben. Demnach sind nur die restlichen (8\% mit Grundschulabschluß u. $9 \%$ aus regulären Mittelschulen und Gymnasien) nicht in den Genuß der Ausbildung in Predigerschulen gekommen (Uluçay 1998: 49). Mit den Beschlüssen der Regierung wurde nun die Schulpflicht auf 8 Jahre angehoben, was praktisch bedeutet, daß die Primärstufen der Predigerschulen künftig wegfallen, weil die Schüler nicht mehr nach den ersten vorgeschriebenen 5 Jahren der Grundschule auf die Predigerschulen wechseln können. Erst auf der Sekundarstufe kann man also eine Ausbildung als Prediger anfangen. In dieser Regelung, gegen welche die Islamisten und Teile der Konservativen prompt landesweit mobil gemacht haben (vgl. Hürriyet vom 2. April 1997), drückt sich offenkundig ein Mißtrauen eines (sicherlich mächtigeren Teils) des Staatsapparates, nämlich der Militärs, gegenüber einem anderen Teil, nämlich der Religionsbürokratie, aus. Die staatlichen Predigerschulen, aus denen dann das spätere Personal der Diyanet hervorgeht, sind somit in den Verdacht geraten, gegen eben diese laizistische Republik zu agieren. Die Diyanet merkt selbstverständlich, daß ihre Machtbasis durch die Beschlüsse ins Wanken gerät, da sie ja zudem auch als Institution von der Stimmung profitierte, die die wachsende Zahl der Absolventen von Predigerschulen im Lande mit verbreitete. Über die Publikationen der Diyanet Işleri Vakfi (Diyanet-Stiftung), die zur Fi- 
nanzierung der Tätigkeiten der Diyanet wesentlich beiträgt, ${ }^{43}$ wird kritisch registriert, daß das neue Schulgesetz die Predigerschulen schwäche und die Attraktivität der Religionsausbildung beeinträchtige (Hürriyet vom 25. März 1998). Der Stiftung, und mittelbar auch dem Amt, wurde in den Berichten des Arbeitskreises West vorgeworfen, in islamistischen Finanzgruppen mit Kapitalanteilen beteiligt zu sein (ebd.). Selbst der höchste Repräsentant der Republik sah sich aufgrund der Brisanz der Sache veranlaßt, tätig zu werden. Der Staatspräsident Süleyman Demirel beauftragte die Diyanet (sic.!) aufgrund der publik gewordenen Vorwürfe, die Stiftung zu beaufsichtigen (ebd.). Damit gehen wir auf den zweiten Punkt über.

2) Führen also die von den Militärs durchgedrückten Maßnahmen einerseits dazu, die Macht der Religionsbürokratie zu schwächen, werden andererseits im Rahmen derselben weitere Regelungen getroffen, bei denen man für den Erfolg des Aktionsprogramms voll auf die Diyanet setzt. Nur im nachgewiesenen Bedarfsfall darf eine Moschee gebaut werden, und die unter dieser Auflage zu errichtenden Moscheen müssen vom zuständigen Mufti (Diyanets Vertreter in Provinz- und Kreisstädten) begutachtet bzw. zugelassen werden. Mit der darauf folgenden, am 31.7.1998 verabschiedeten Gesetzesänderung (Gesetzesbulletin vom 2.8.1998) wird die absolute Kontrollmacht der Diyanet über die Verwaltung der Moscheen offiziell besiegelt. Ähnlich werden der Diyanet später die privaten Schulen der Gemeinde von Fethullah Gülen überschrieben. ${ }^{44}$

Auch hier taucht das besagte Dilemma der staatlichen Religionspolitik (Verwaltung der Religion einerseits und religiöse „Rechtleitung" andererseits) wieder einmal auf. Im folgenden soll die Darstellung mit zusätzlichem empirischem Material analysiert werden.

43 Obwohl die Stiftung in rechtlicher Hinsicht mit Diyanet nichts zu tun hat, ist sie auf der personellen Ebene faktisch mit der Organisation der Diyanet verwachsen (vgl. Dursun 1992: 209).

44 Die Gülen-Gemeinde ist eine Abspaltung des Naksi-Ordens. Gülen selbst wurde lange Zeit gegen die islamistische Refah Partei als Vertreter eines regimetreuen Islam von verschiedenen politischen Lagern, aber auch von staatlichen Stellen hofiert, bis die Staatsraison ihn auch wegen laizismusfeindlicher Umtriebe belangte (vgl. Hürriyet vom 19. 07.1999; zu den mit Gülen verbundenen Erwartungen von seiten der Politik vgl. Laçiner 1995a u. 1995b). 


\subsection{Der Streit zwischen göttlichem und profanem Recht}

Die praktischen Spannungen zwischen einer partikularen staatlichen Instanz (Diyanet) und den auf dem substantiellen Boden des Säkularismusideals stehenden, allgemeinen Ordnungsinteressen des Staates gehen auf einen strukturellen Konflikt zurück. Es ist die Rede vom allgemeinen Konflikt zwischen dem profanen und dem göttlichen Gesetz. Nehmen wir einen, zwar gesamtgesellschaftlich in praktischer Hinsicht wenig relevanten, aber in rechtlicher Hinsicht ziemlich krassen Fall. Es handelt sich um die Verbrennung der Leichen unter bestimmten Bedingungen. Auf vermehrte Anfragen seitens der Bürger, die eine Zulassung der Verbrennung der Leichen forderten, hatte die Istanbuler Oberstadtverwaltung das Thema in die Öffentlichkeit gebracht. Die Diyanet reagierte umgehend mit einer Fatwa-ähnlichen Erklärung $^{45}$ auf die Bestimmung aus dem Gesundheitsgesetz, die in bestimmten Fällen eine Verbrennung der Leichen vorsieht. Das Gutachten der Diyanet fällt kompromißlos aus. Demnach ist ,nach islamischen Bestimmungen das Verbrennen der Leichen nicht gestattet. Selbst die Leiche eines Nichtmuslims darf nicht verbrannt werden. [...] Daß das (Verbrennen) im Gesetz vorgesehen ist, ändert nichts an der Sache." (Tarhanlı 1993: 92)

Die massive Intervention der Diyanet gegen die erwähnte Bestimmung des Gesundheitsgesetzes zwang schließlich die Kommune dazu, von ihrem Vorhaben abzusehen. In diesem überaus symptomatischen Konflikt treten drei Probleme hervor: Erstens setzt sich die Diyanet als Verwaltungseinheit, die laut Gesetz mit technischen Dienstleistungen in Sachen Religion betraut ist, über ein Gesetz hinweg, ja sie widersetzt sich explizit den Bestimmungen eines Gesetzes. Zweitens will dieses Verwaltungsamt, also die Diyanet, allen Bürgern seine eigenen materialen Wertvorstellungen auferlegen, obwohl seine Befugnis bei der technischen Ausführung bestimmter Aufgaben liegt und nicht bei der inhaltlichen Bestimmung der Gesamtheit der Lebensführung. Schließlich wird damit die bereits in der Idee der Staatsraison angelegte Rechtsgleichheit verletzt, gemäß der die andersgläubigen Bürger

45 Diyanet produziert jedes Jahr Hunderte von Fatwas, religiösen Gutachten. Sie haben jedoch keine Rechtswirkung, sondern fungieren lediglich als ethische Anleitungen für den Alltag der Muslime. Die Praxis bereitet solange kein Problem, als das Prinzip der Laizität weiterhin die Grundlage der Rechtsordnung bestimmt. Mit dem Wegfallen dieses Prinzips würden aber die Fatwas aufgrund der Strukturen des Nationalstaates eine ganz andere Funktion und Macht erhalten, die ihnen in dieser Form noch nie zukam, auch nicht in der langen osmanischen Geschichte. 
des Staates, auch die Atheisten, vor der Übernahme islamischer Wertvorstellungen wider ihren Willen geschützt werden müßten. ${ }^{46}$

Die Erfassung der religiösen Dienste als Verwaltungsakt schreibt der Diyanet vor, daß sie wie alle anderen Verwaltungsdienste nach dem Gleichheitsprinzip verrichtet werden. Die Ausgaben der Verwaltung für den öffentlichen Dienst werden ja auch unter den Bedingungen eines modernen Staates von allen Bürgern, die ungeachtet ihrer religiösen Zugehörigkeit vor dem Gesetz gleichgestellt sind, durch Steuerleistungen getragen. Der von der Verwaltung geleistete öffentliche Dienst muß daher unumgänglich dem Kriterium formaler Rationalität entsprechen. Genau das wurde aber in dem angeführten Fall in Frage gestellt. Die Frage, ob für den laizistischen Staat religiöse Leistungen als öffentlicher Dienst in Frage kommen dürfen, ist indessen im juristischen Diskurs der Türkei nicht unumstritten (siehe dazu Tarhanlı 1993: 100f). Tarhanlı ist bspw. der Meinung, daß die Rege-

$46 \mathrm{Da}$ dies nicht ein bloßes rechtspraktisches Problem ist, sondern die ganze politische Kultur, ja darüber hinaus die ganze Soziokultur in der Türkei betrifft, muß an dieser Stelle erwähnt werden. Damit ist zugleich auch die strukturell angelegte Inkonsequenz der Laizität des türkischen Staates erklärt. Bürger werden in erster Linie, trotz der erklärten Freihaltung der staatlichen Praxis von religiösen Kriterien, als Muslime behandelt. Aus eigener Erfahrung weiß der Autor, daß z.B. bei einer Volkszählung der Interviewer alle Antworten der Befragten gewissenhaft eintrug, bloß bei der Frage nach der Religionszugehörigkeit eigenmächtig Islam in die entsprechende Zeile schrieb. Die Widerrede eines der Befragten hatte ihn ziemlich irritiert. Die gibt es nämlich in der Regel nicht, es sei denn, es handelt sich um die im Vertrag von Lausanne (1923) anerkannten nichtmuslimischen Religionsgemeinschaften.

Die Tatsache wiederum, daß Atheisten überhaupt nicht berücksichtigt werden, läßt sich nur aus der religiösen Tradition der türkischen Gesellschaft und ihrer selbstverständlichen Fortführung im Staatsapparat erklären. Ein genaues Verständnis dieses Phänomens verlangt kultursoziologische Analysen, wobei die Berücksichtigung islamischer Spezifizitäten ebenfalls in das Zentrum einer solchen Studie gehört. Wenn man dies kurz erläutern soll, sei zum einen auf die Tatsache hingewiesen, daß aufgrund der Abwesenheit kirchenähnlicher Strukturen ein Austreten aus dem Glauben institutionell nicht vollzogen werden, daher auch schwer festgestellt werden kann. Zum anderen wird die Apostasie nach dem islamischen Gesezt theoretisch mit Todesstrafe geahndet, was in der islamischen Geschichte jedoch dazu geführt hat, daß mit dem Vorwurf der Apostasie sehr zurückhaltend umgegangen wurde. Auch wenn die Apostasie im laizistischen Staat auf der institutionellen Ebene keinen Bestand mehr hat, kann man durchaus weiterhin ihre praktische Verankerung in der Soziokultur annehmen. 
lung nicht zwangsläufig dem Prinzip der Laizität widerspreche, da es sich hier um ein „kollektives Bedürfnis“ (ebd.) handle (vgl. auch das Urteil des Verfassungsgerichtes dazu, hier besprochen im vorangegangenen Kapitel I.4.2.2, unter Gesellschaftspolitischer Auftrag). Entscheidend sei dabei allein die Art der Leistung, und sie sei nur als Verrichtung eines technischen Dienstes vertretbar. Die Beamten des Staates sind also verpflichtet, ihre Dienste technisch zu verrichten und dürfen dabei keine substantiell gebundene Position bevorzugen, da diese zwangsläufig andere inhaltlichen Positionen benachteiligen würde, was dem Gleichheitsprinzip widerspräche. Der in der Sache begründete Streit bricht allerdings dann unvermeidlich aus, wenn sich die Behörde auf Grund ihrer gesetzlich bestimmten Aufgabe, nämlich Bürger über Religion aufzuklären, konsequent auf die göttliche, immer schon partikularistisch ausgefüllte Bestimmung beruft. Wenn sie es indes nicht tut, verliert sie auf der anderen Seite ihre Besonderheit, reduziert sich nämlich auf irgendeine beliebige Verwaltungseinheit. Könnte sie dann überhaupt ihrem Auftrag ,religiöser Aufklärung“, so wie sie von der Orthodoxie verstanden wird, gerecht werden, wenn sie irgendeine bürokratische Einrichtung wäre?

Das sich darin äußernde Problem ist von weitergehender Reichweite. Verläßt man die rechtspraktische Ebene, betrifft das Problem in rechtssoziologischer Hinsicht das Verhältnis von profanem und theologischem Recht, das unter den Bedingungen der modernen Gesellschaft besondere Schärfe erhält, sich aber bereits für die vormoderne Gesellschaft als konfliktträchtig erwiesen hatte. Es handelt sich um die Frage, wie das religiöse Gesetz über die Politik den Staatsapparat beeinflußt und die profanen Regelungen dazu zu zwingen versucht, sich in ein religiös legitimes Verhältnis zu ihm zu bringen. Dabei ist, was die Genese der Spannung betrifft, anzumerken, daß sie aufgrund einer historischen Entwicklung möglich geworden ist und vorerst noch bestehen zu bleiben scheint. Ich meine damit die Konzeptualisierung der religiösen Transzendenz, die Eisenstadt in Anlehnung an Jaspers auf einen Bruch in den alten Kulturen zurückführt.

Der Konflikt zwischen dem weltlichen und dem göttlichen Gesetz, dem wir bereits in der frühislamischen Periode begegnet und über das Osmanische Reich bis in die laizistische Republik hin nachgegangen sind, tauchte demnach zum ersten Mal durch einen Bruch in den Herrschaftsstrukturen der alten Hochkulturen auf. Dieser Bruch datiert in Jaspers Version grob vom 8. Jh. v. Chr. bis zum 2. Jh. v. Chr. (1955: 14), oder in Eisenstadts Version bis zum ersten nachchristlichen Jh. Ich will hier die unterschiedlichen Dimensionen dieses Bruchs nicht in vollem Umfang wiedergeben. Mit der Fokussierung auf die Transzendenz, die das Ende des Gottkönigs einläutet, ist dem Zweck des vorliegenden Buches genüge getan, da genau daraus die Vorstellung ent- 
springt, daß das Gesetz von woanders abzuleiten ist als vom weltlichen Herrscher. Diese Entwicklung vollzog sich, mit dem Schwerpunkt in der genannten Zeitspanne liegend, in mehreren Kulturen der Welt - im biblischen Israel, im klassischen Griechenland, im Frühchristentum, im Persien Zarathustras, im China der frühen Kaiserzeit und in den hinduistischen und buddhistischen Kulturen. Hierzu gehört auch die Entstehung des Islam, obwohl er zeitlich betrachtet erst nach der eigentlichen Achsenzeit auftaucht. Shmuel Eisenstadt hat das Jaspersche Konzept zur Grundlage seiner vergleichenden Zivilisationsforschung gemacht. Die Relevanz der Achsenzeitproblematik liegt in der historischen Innovation, also in der „Konzeptualisierung und Institutionalisierung einer grundlegenden Spannung zwischen der transzendentalen und der weltlichen Ordnung" (Eisenstadt 1987: 10). Dies konnte nur durch eine neue geistige Elite geleistet werden, die sich vom Gottkönig ablöste, eigene Rekrutierungsmechanismen und schließlich Visionen entwickelte, an deren Maßstab die weltliche Ordnung bewertet wurde (a.a.O.: 19): Die jüdischen Propheten und Priester, die griechischen Philosophen und Sophisten, die chinesischen Literaten, die hinduistischen Brahmanen, die buddhistischen Sangha und die islamische Ulema waren Erscheinungsformen dieser Elite neuer Art. Aus dem Gottkönig (wie bspw. dem altägyptischen Pharao), der irdische wie kosmische Ordnung verkörperte, wurde ein weltlicher Herrscher, von dem man jetzt gegenüber einer höheren Ordnung Rechenschaft abverlangen konnte. Damit waren folglich die Möglichkeiten für die Absetzung des Herrschers und für die Protestbewegungen gegeben. Mit der Institutionalisierung der Kluft ergibt sich umgekehrt die Möglichkeit für Versuche, sie überwinden zu wollen. Gleichzeitig festigt sich unvermeidlich das Bewußtsein von der Unvollkommenheit jeder Lösung der Spannung, das zum „Anwachsen der Reflexivität“ und zur „Vielfalt der Visionen“ (a.a.O.: 21) führt (vgl. auch Jaspers 1955: 15). Eine letzte, gravierende Veränderung tritt folglich in der Spannung zwischen dem Zentrum und Peripherie bzw. der großen und der kleinen Tradition in Erscheinung (vgl. Eisenstadt 1987: 17).

Kehren wir, diese Überlegungen bedenkend, zu unserem Ausgangspunkt zurück. Jetzt wird deutlich, warum die Diyanet, so eng sie auch in den Staatsapparat eingebunden sein mag, als geistige Klasse nicht völlig darauf verzichten kann, das Gesetz im Streitfall aus der Transzendenz zu holen. Da sich das göttliche Recht in der islamischen Tradition aus dem weltlichen nicht löste bzw. das weltliche Recht 
nicht freigab ${ }^{47}$; da zudem im Islam keine autonome, kirchliche Institution entstanden ist, verlagern sich die, von moderner Rationalität her betrachtet, bestehende Konfusion der beiden Autoritäten und der Konflikt zwischen ihnen in den Staatsapparat hinein (vgl. auch Eisenstadt 1992: 156). Die türkische Orthodoxie kann diese Spannung bis zu einem relativ hohen Grad aushalten, nicht zuletzt deshalb, weil sie mit ihrer sunnitischen Tradition zur Loyalität gegenüber der Obrigkeit prädestiniert ist. Sie wird zudem im Gegenzug dafür reichlich belohnt, indem sie mit der Verwaltung der religiösen Anstalten betraut und mit dem Privileg, alleiniger legitimer Ansprechpartner für religiöse Angelegenheiten zu sein, ausgestattet wird. So kann sie auch in ihrer jahrhundertealten Rivalität mit der „,kleinen Tradition“, mit dem stark magische Elemente tragenden Volksislam, ihre Macht ausweiten zumal sie sich jetzt partiell, äußerlich angeknüpft an den modernistischen Diskurs - auf die Vernunft im Kampf gegen den Aberglauben beruft. Im Gegenzug wird die Legitimationslast, die auf den Schultern der Diyanet gegenüber dem religiösen Gesetz lastet, weil sie sich dem weltlichen Gesetz unterwirft, auf der Ebene der politischen Diskurse und folglich auf der Ebene der staatlichen Praxis erheblich erleichtert. Denn anders als auf der Ebene der rechtlichen Bestimmung der Säkularität spielt die Religion im politischen Diskurs der Türkei explizit eine erhebliche Rolle, so daß die inhaltliche Ausrichtung der Arbeit der Diyanet weitgehend auf die politische Unterstützung zählen kann. Oben wurden dazu einige Beispiele (z.B. aus der Haushaltsdebatte von 1997) angeführt, die alle die Tätigkeit des Amtes unter dem Gesichtspunkt beschworen, daß sie darin bestehe, „die“ richtige Religion zu lehren. Kaum ein Politiker schien auch an der Tätigkeit des säkularen Staates, die richtige Religion zu vermitteln, Anstoß genommen zu haben. ${ }^{48}$ Die in der Einrichtung eines religiösen Amtes eingebaute

47 Das ist sicher einer der Gründe dafür, warum der türkische Laizismus, besonders in seiner heroischen Phase, in der Behandlung der Religion in ihrer öffentlichen Wirksamkeit so radikal vorging.

48 Bei Tarhanli sind etliche Beispiele für eine solche Haltung zu finden. Ein besonders interessantes wird hier zitiert, weil es zeigt, wie tief dieses Faktum in der politischen Kultur der Türkei verwurzelt ist. Es handelt sich um einen Wortbeitrag aus den Reihen der im Grunde streng laizistischen Sozialdemokratischen Partei des Volkes in den Haushaltsdebatten von 1989: „Unser Land hat seinen Beitritt in die Europäische Union angemeldet. Wenn wir beigetreten sind, dann werden wir nicht nur in der Wirtschaft, sondern auch in Hinblick auf die Religion bei der Verteidigung der islamischen Religion gegenüber der christlichen Welt Probleme mit diesem Kader haben. Wir erfahren in letzter Zeit aus der Presse, daß in unserem Land christliche Missionare, die aus Europa kommen, unsere Religion spalten und die für unsere Auffassung un- 
Spannung zwischen dem theologischen und dem profanen Gesetz zeigt ihre volle Brisanz genau an dieser Stelle. Denn die richtige Religion muß immer einer partikularen Überzeugung verpflichtet sein, die zwangsläufig andere partikulare Glaubensrichtungen ausschließen wird. Aus der Sicht einer religiösen Autorität wäre nun ein solcher Einwand belanglos. Selbstverständlich existiert für sie ein einziger Islam, wenn er auch noch nicht von allen gleichermaßen korrekt verstanden werde. Genau darum brauche man eben die Gelehrten, deren Aufgabe darin bestehe, das Verständnis des einen, richtigen Islam zu vermitteln. Deshalb reagiert auch die Diyanet sehr aufgeregt, wenn sie auf ihre partikulare Lehre, den sunnitischen Islam, angesprochen wird. Unübersehbar problematisch gestaltet sich die Bindung des säkularen Staates an einen religiösen Partikularismus in der Praxis.

Was passiert nun mit den anderen Glaubensrichtungen? Inwiefern werden sie von der staatlichen, glaubensbezogenen Praxis tangiert, inwiefern wird ihre Stellung im politischen Diskurs reflektiert? Diese Fragen führen nochmals zurück zu den Problemen der Staatsraison bzw. der verwalteten Religion. Das strukturelle Problem der staatlichen Verwaltung der Religion wurde schließlich nicht infolge der juristischen Dispute zu einem öffentlich relevanten Thema. Vielmehr trug erstens die Verschärfung der Auseinandersetzungen um eine islamistische Gefahr dazu bei, daß die der staatlichen Religionspolitik entgegengebrachte Aufmerksamkeit wuchs, da Religion zum zentralen Gegenstand politischer Auseinandersetzungen avancierte; zweitens meldeten die Aleviten zum ersten Mal als gleichgestellte, steuerzahlende Bürger öffentliche Ansprüche an, die zur Problematisierung der partikularistischen Tätigkeit und Identität der Diyanet führten. Beide stehen im wesentlichen Zusammenhang mit dem Umstand, daß Religion zur Grundlage von Gesellschaftstechnik wurde. Ob sie dann zur Bekämpfung der Laizität eingesetzt wird (Islamismus - teilweise vertreten auch innerhalb der Orthodoxie (vgl. Seufert 1999) -, oder zu deren Verteidigung wie bei den Aleviten, ist dann in diesem Zusammenhang nur noch sekundär. Im folgenden wird der Politik der Diyanet in Bezug auf die alevitische Herausforderung nachgegangen.

wahre Religion verbreiten wollen, indem sie Adressen unserer in Europa lebenden Arbeiter feststellen, ihnen über Kirchen Hilfeleistungen erbringen und christliches Propaganda betreiben." (TBMM-Bulletin, Nr. 299, zit. n. Tarhanl 1993: 100). Tarhanli berichtet im weiteren, das muß aber auch vermerkt werden, daß der damalige Präsident der Diyanet darin eine marktwirtschaftliche Konkurrenzsituation sehe. Diese Haltung hat sich allerdings bisher nicht durchgesetzt. 


\subsection{Religionspolitik und die Aleviten}

Das Problem der Integration der Aleviten ist ein genuin modernes Problem. Die Frage stellte sich nämlich als solche in der „Logik“ der osmanischen Ordnung nicht. Es existierten nicht nur keine Konzepte gesamtgesellschaftlicher Integration. Die soziale Ordnung war nicht nur im Verhältnis zwischen Herrscher und Untertanen hierarchisch aufgebaut, sondern auch unter den Religionsgemeinschaften, die allerdings parallel zu dieser externen Ungleichheit weitgehende interne Regulierungsautonomie genossen. Der Hof griff nicht in die inneren Angelegenheiten der Gemeinschaften ein. Wenn man den Begriff der Integration trotzdem verwenden will, dann wäre damit hauptsächlich die Ordnungsfrage betroffen, die besagte, daß Ruhe und Frieden im Lande herrschen sollte, die sogenannte pax ottomana. Diesem Bild auf der Ebene der Gemeinschaften entspricht genau die partikulare Gebundenheit der Spitze der politischen Ordnung, also des Sultans. Unter diesen Bedingungen konnte sich die oben beschriebene Spannung zwischen der inhaltlichen Religionspolitik und der technischen Ausrichtung staatlicher Dienstleistungen nicht entwickeln. Der durchaus vorhandene, jedoch nicht explizite Konflikt zwischen profanem und göttlichem Recht konnte auch nicht dieses Resultat hervorbringen, da er 1) formell durch die Verknüpfung der weltlichen und religiösen Autorität im Körper des Kalifen/Sultans wieder entschärft wurde, 2) der Staat in das soziale Leben nicht produktiv eingriff, 3) das soziale Leben sich weitgehend in abgeschlossenen Gemeinschaften abspielte und wenig über Märkte miteinander verknüpft war, 4) eine systematische, praktische Rechtsentwicklung nicht stattfand und 5) keine moderne Bürokratie bestand. Diese Bedingungen tauchen in der osmanischen Ordnung erst nach und nach im Zuge der Modernisierung auf. Die Behandlung der Minderheiten ließ sich daher in der klassischen Phase der Osmanen nicht als einklagbares Recht konzipieren. Die weitgehende Toleranz war dort auch eher ein Zeichen der, neben dem ordnungspolitischen Pragmatismus, material durch islamische Toleranzvorstellungen untermauerten Güte der osmanischen Herrschaft, und nicht ein qua Bürgerstatus zustehender Anspruch, der ja als solche nicht einmal für die Muslime bestand. Es ging bei diesem Umgang mit dem Anderen um den Platz in der sozialen Hierarchie. Während die material bestimmte Behandlung des Anderen den monotheistischen Religionsgemeinschaften weitgehenden Schutz und Spielraum gewährleistete, ereilte die Aleviten genau aus demselben „Prinzip“ Ausschluß und gar Verfolgung. Solange jedoch Religion kein Gegenstand einer politischen Technologie war, die mittels Staatsapparates für die moralische Präparierung der Bevölkerung eingesetzt wurde, blieb die Art und Weise des Ausschlusses vornehmlich auf Verfolgung be- 
schränkt. Erst unter den neuen Bedingungen, daß die Aleviten qua Bürgerstatus integriert wurden und selber als politische Subjekte mit öffentlichen Ansprüchen auftraten, mußte die Orthodoxie als Teil eines säkularen Verwaltungsapparates von der expliziten Ausschließung der „Ketzer“ absehen und über neue Formen des Machterhalts nachdenken. Zuvor sollen jedoch einige Informationen über Aleviten gegeben werden.

\subsubsection{Alevitische Selbstbeschreibungen}

Das Alevitentum bezeichnet eine unter den anatolischen Türken verbreitete heterodoxe Glaubensrichtung innerhalb des Islams. Ursprünglich entstanden als eine Spielart des Schiitentums, hat sich das anatolische Alevitentum von ihrem „Ursprung“ stark ,entfernt“, oder um eine treffendere Formulierung zu gebrauchen, weitgehend vorislamische kulturelle Elemente beibehalten und sie in einer islamischen Sprache neu artikuliert. ${ }^{49}$ Es wäre falsch, wenn man die Verfolgung bzw. Diskriminierung der Aleviten mit rein religiösen Gründen erklären wollte. Richtiger liegt man, wenn man den Schnittpunkt zwischen religiösen Differenzen und Ordnungsfragen als Erklärungsgrundlage heranzieht. In diesem Sinne kann man auf zwei Punkte aufmerksam machen, die Aufschluß über den Ausschluß und die Verfolgung der Aleviten geben.

Das Alevitentum wurde anfänglich hauptsächlich von nomadierenden turkmenischen und kurdischen Stämmen übernommen, die wegen seiner Ordnungsinteressen dem osmanischen Hof ein Dorn im Auge waren. Sie waren im Hinblick auf Abgabenschöpfung und Rekrutierung von Soldaten nicht kontrollierbar. Der Konflikt zwischen dem sunnitischen Hof und den alevitischen Stämmen gewann auch eine militärische Dimension, sofern die religiöse Zusammengehörigkeit

49 Reflexionen über das ständige Wechselspiel zwischen Monotheismus und Polytheismus, ihre wechselseitige Durchdringung würden den Rahmen des vorliegenden Buches sprengen. Dabei schießen polytheistische Momente, nicht beschränkt auf die alevitische Heterodoxie, auch im sunnitischen Islam unaustilgbar immer wieder hervor. Die mit hoher Achtung verbundene Existenz der Heiligen in der islamischen Kultur ist ein Indiz polytheistischer Durchbrüche (vgl. Gellner 1985; Stauth 2001). Als Momente, in denen der strenge Monotheismus aufgebrochen wird, zu lesen wären auch Feste wie Hochzeit- und Beschneidungszeremonien mit immer ins Extase zu driften drohenden Tanzeinlagen und exzessivem Alkoholkonsum, welche von der Orthodoxie und den Strenggläubigen höchstens geduldet, ja von einigen islamistischen Gruppen gar als unislamisch verworfen werden. 
zwischen den Aleviten und dem damals größten Gegner der Osmanen im Orient, dem persischen Königreich, in den Augen der Osmanischen Herrscher einen Unsicherheitsfaktor bildete, zumal die alevitischen Stämme tatsächlich exakt das Grenzgebiet zwischen dem persischen und osmanischen Land bewohnten. Auf dem Höhepunkt des Konfliktes zwischen dem persischen Schah und dem Osmanischen Reich, im 16. Jh., nahm auch die brutale Verfolgung mit Massakern, wie sie seinerzeit der Sultan Yildirim Bayazid auf seinem Kriegszug gegen Persien (Anfang des 16. Jh.) unternahm, ihren historischen Anfang (vgl. Glassen 1979; van Bruinessen 1996; Kehl-Bodrogi 1996)

Diese sozialen und politischen Bedingungen waren also sehr geeignet, sich mit einem religiösen Konflikt zu verbinden. Die anderen Glaubensrichtungen entgegengebrachte Toleranz schlug hier in eine Verfolgung um. Dagegen gab es kein diskursives Mittel, das den Anspruch der Aleviten auf Toleranz hätte rechtfertigen können. Nur ein vitales Ordnungsinteresse des Sultans hätte, wenn ein Konjunktiv hier erlaubt sein kann, die Anerkennung der Aleviten als islamische Gemeinschaft ermöglicht, was aber wiederum einen Konflikt zwischen ihm und der Orthodoxie bedeutet hätte. ${ }^{50}$

Unter den Bedingungen der Republik verändert sich die Situation der Aleviten in der Praxis zunächst wenig, dagegen im Prinzip sehr. Die Einstellung staatlicher Verfolgung und die Ablösung der Ämterverteilung von der Glaubenszugehörigkeit bedeuten sicherlich bereits eine gravierende Veränderung in der Situation der Aleviten auch in praktischer Hinsicht. Doch waren die Aleviten lange Zeit durch die Republikgeschichte hindurch öffentlich inexistent. ${ }^{51}$ Erst ab Mitte der

50 Indessen wäre hier vielleicht eine Einschränkung vonnöten. Die osmanische Behandlung, ja Verfolgung der Aleviten, schloß andererseits nicht den paradoxen Umstand aus, daß die alevitischen Ordensgemeinschaften (wie z. B. Bektasis) selbst im Herrschaftsapparat, bspw. in der Armee, weit verbreitet waren. Man sieht hier, daß der osmanische Pragmatismus es nicht zuläßt, die materielle Ordnung aus einem Prinzip abzuleiten.

51 Auch bei der Ämterverteilung, so lautet es jedenfalls nach einem weit bekannten anonymen Volkswissen, sorgte die staatliche Autorität, zumindest in der wichtigsten Institution des türkischen Staates, nämlich in der Armee, dafür, daß die alevitischen Offiziere in ihrer Karrierebahn von den höheren Stabsposten ferngehalten würden. Dies dürfte sich jedoch angesichts der zunehmenden islamistischen Gefahr in den letzten Jahrzehnten gelockert haben. Als unglaublich übertrieben muß jedoch die aktuelle islamistische Anspielung auf Syrien zurückgewiesen werden, wo eine alevitische Militärelite über die sunnitische Mehrheit herrscht. Damit wird nämlich implizit behauptet, daß der Kampf der Armee gegen den Islamismus von den alevitischen Offizieren dirigiert werde. 
80er Jahre konnten die Aleviten ihre öffentliche Existenz mutig demonstrieren und sie auch in institutionelle Formen eingießen.

Das Alevitentum wird in verschiedenen politischen Diskursen, freilich mit sehr unterschiedlichen Konnotationen, artikuliert und damit unterschiedlich rekonstruiert. Das macht eine Standortbestimmung des Alevitentums heute besonders schwierig. Sie scheint selbst unter den Aleviten, ja im Grunde vor allem und gerade dort, ziemlich unübersichtlich zu sein. Nichtsdestotrotz würde der Versuch, einen Überblick zu skizzieren, folgendes Bild ergeben: Auf der einen Seite steht die mittelständische Elite, deren Politik darauf zielt, innerhalb der laizistischen Ordnung die alevitische Gemeinschaft als eine moderne, freiheitliche Variante des Islam zu vertreten. Diese Gruppe ist es auch, die den Mainstream des Alevitentums ausmacht. Sie kann ohne große Schwierigkeiten auf die bestehenden, über Jahrhunderte hinweg im Untergrund gepflegten Strukturen aufbauen und verspricht diesen, die bis dato verweigerte Anerkennung zu ermöglichen. Von ihr geht keine radikale Opposition gegen das politische System aus. Sie ist auch die treibende Kraft für die Politik, daß die Aleviten genauso vom Staat alimentiert werden sollen wie die Sunniten qua Diyanet.

Ihr gegenüber steht die Haltung ehemaliger Marxisten. Besonders diese „Konvertiten“, welche nach dem Absterben alter politischer Identitäten schnellstens ihre neue Identität im ethno-religiösen „Heim“ gefunden haben, bemühen sich sehr, das Alevitentum jenseits des Islam als eine Lebensphilosophie zu definieren. Nur so können sie sich nämlich des Eindrucks eines totalen Bruchs in ihrer individuellen Biographie erwehren. Der kommunistische Atheismus wird jetzt in die alevitische Lebensphilosophie, nicht selten mit schamanistischen (weil vorislamisch türkischen) Elementen versehen, hinüber gerettet und der kommunistische Kampf gegen die Unterdrückung wird als Emanzipationsideal in den Widerstand der Aleviten übersetzt (für eine Übersicht auf politisch vorgenommene Definitionen des Alevitentums durch Aleviten vgl. Öz 1996).

Mit ihrem öffentlichen Auftreten haben nun die Aleviten den in der Anlage der Republik als Prinzip vorhandenen Bürgerstatus für sich reaktiviert. Daraus ergaben sich folgerichtig - das ist einmalig in ihrer Geschichte - Ansprüche auf die Dienste des Staates. Man kann sich jetzt unschwer vorstellen, daß diese Entwicklung, wenn auch noch nicht in ihrem praktischen Ausmaß voll entfaltet, eine immense Herausforderung für die bisherige Politik der staatlichen Verwaltung der Religion bedeutet. Während die sunnitische Orthodoxie ihre substantiellen Vorstellungen durch staatliche Mittel in Geltung bringen konnte, ohne daß die in der Sache der Verwaltung der Religion liegenden Probleme dramatisch auftraten, tritt die genannte Spannung 
durch die öffentliche Präsenz der Aleviten vollauf zu Tage. Sie war zwar auch bei der Behandlung anderer Religionsgemeinschaften angelegt. Doch konnte sie sowohl aufgrund der mittlerweile verschwindend geringen Zahl dieser Minderheiten (wie z.B. der griechisch-orthodoxen Kirche oder der armenischen Kirche) als auch aufgrund von deren vertraglich geregelten Minderheitenstatus nicht den Rang eines Politikums erreichen. Erst nachdem die Aleviten eine politische Größe bilden und als Bürger den Staatsapparat in Anspruch genommen haben, ist die partikularistische Dienstleistung der Diyanet nicht mehr umstandlos weiter zu betreiben. ${ }^{52}$ Diesem Konflikt soll unten etwas näher nachgegangen werden.

\subsubsection{Tücken der partikularistischen Anerkennung}

Im öffentlichen Diskurs über die Aleviten dominiert bei der Frage ihrer institutionellen Einbindung eine ganz eigentümliche Inklusion. Es wird geradezu pathetisch beschworen, daß zwischen Aleviten und Sunniten keine Unterscheidung gemacht werde. Ferner wird jedwedem Versuch, Aufmerksamkeit auf die Differenz und die Nichtbeachtung des Alevitentums bei der Verrichtung staatlicher Dienste zu lenken, ganz in gewohnter Manier türkischer politischer Kultur Verschwörung attestiert; Absichten werden vermutet, es gehe um nichts anderes als Haß und Zwietracht in der Bevölkerung zu säen. Der Fraktionssprecher der damaligen Regierungspartei ANAP (von 1997), Esat Bütün, wiederholt in seiner Rede während der Parlamentsdebatten zum Haushalt des Finanzjahres 1998 die gesellschaftliche Paranoia in ihrer typischsten Form, und zwar so, daß dabei auch die selbstverständliche Ausschließung der Aleviten gerade durch den vordergründigen Einschließungsakt auch in diesen Zeilen noch einmal zur Sprache kommt. Die Essenz des folgenden, knapp gehaltenen Zitats durchzieht die politischen Selbstverständlichkeiten wie auch, das ist für un-

52 Man kann diese Entwicklung auch analog zu der These von Andreas Wimmer (1995) interpretieren, welche besagt, daß die ethnischen Identitäten keineswegs archaische Relikte seien, die die Moderne schlußendlich abtragen würde. Stattdessen werden sie durch den Einbezug der Legitimation auf das Staatsvolk durch den modernen Staat geradezu provoziert, was dann zum Auftauchen des Konflikts darüber führe, welche ethnische Gemeinschaft nun diesen Apparat jetzt legitimatorisch, d.h. auch praktisch, besitzen wird. Wenn also, anders formuliert, die moderne Gesellschaft auf die Bestimmung der letzten Werte verzichtet, indem der Staat sich einer substantiellen Glaubenszugehörigkeit im Prinzip enthält, dann entbrennt der Kampf darum, sich als legitimer Nutznießer staatlicher Dienste einzuklagen, vollauf. 
seren Zusammenhang von besonderer Bedeutung, die Haltung der Diyanet.

„Daher ist das die schlimmste Übeltat, die man diesem Land antun kann, wenn man so tut, als gäbe es ein Problem zwischen Aleviten und Sunniten, oder wenn man die Cemhäuser [Gebetsanstalten der Aleviten, L. T] gegen die Moscheen ausspielt, als seien die Aleviten keine Muslime und beteten sie nicht in der Moschee." (TBMM-Bulletin 1997: 382)

Seine Rede hatte der Fraktionsvorsitzende mit dem Hinweis darauf begonnen, daß „die sozialen, kulturellen, politischen und moralischen Probleme, die wir heute durchleben“ im Grunde aus der „bislang immer noch nicht richtig angepackten religiösen Frage" rührten. Man habe der Bevölkerung die richtige Religion nicht beigebracht. Die Debatte um den Haushalt der Diyanet müsse sich daher in diesem Rahmen bewegen. Sodann hebt er an, eine Reihe der anatolischen Heiligen aufzuzählen, die auch den Aleviten sehr viel bedeuten, ja besonders Hacı Bektaş Veli, der zwar nicht ausschließlich, so doch weitgehend mit Alevitentum identifiziert wird. Was würde es nun bedeuten, wenn Cemhäuser den gleichen Status erwürben, wenn sie also fortan vor dem säkularen Gesetz als Gebetsanstalt einer Religionsgemeinschaft neben der Moschee gleich gelten sollten? Dem weiteren Wortlaut des Beitrags ist es zu entnehmen: Es bedeute Spaltung des Volkes, der islamischen Gemeinde, der Nation, des Landes (a.a.O.: 385). Wie bereits oben gesehen, greifen auch hier Nation und die islamische Gemeinde, Religion und Staat ineinander. Es wird aus einer partikularen Perspektive bestimmt, daß ,die Moscheen Gebetsräume für alle Muslime sind“; da nun „die Aleviten Muslime sind“, gilt das auch für sie. Solange die Aleviten der gleichen Meinung sind, wird es keine Probleme geben, und tatsächlich besuchen Aleviten in bestimmten Regionen Moscheen. Gleichwohl ist es ein offenes Geheimnis, daß die Aleviten in der Regel und mehrheitlich die Moscheen nicht betreten. Religionsgeschichtlich wird diese Entscheidung darauf zurückgeführt, daß der Kalif Ali, für die Aleviten der rechtmäßige Nachfolger des Propheten, in einer Moschee umgebracht worden ist. Was auch immer der historische Grund gewesen sein mag, Fakt ist, daß die Aleviten ihre kulturellen und religiösen Praktiken in den Cemhäusern durchführen und dies auch seit ihrer öffentlichen Präsenz ganz offen vertreten. In dieser neuen Situation werden die Sunniten in ihrer Selbstverständlichkeit verunsichert. Jetzt müssen sie die Aleviten (und zwar nicht als einzelne Menschen, sondern in ihrem spezifischen Glauben) als legitime Bewohner des Landes im öffentlichen Raum anerkennen. Damit tun sich weite Teile des Sunnitentums sehr schwer. Das bislang fast unproblematische Funktionieren religiöser Dienstleistungen aus staatlicher Hand hapert angesichts der Herausforderung, die von der legi- 
timen öffentlichen Präsenz jahrhundertlang verfolgter Überzeugungen ausgeht. Die Diyanet steht zuvörderst im Zugzwang, nicht zuletzt deshalb, weil sie jetzt mit der Forderung konfrontiert wird, sich völlig umzuorganisieren, wenn nicht gar ihr rechtlicher Status aufgrund ihrer mit dem formalen Recht nicht verträglichen Arbeitsweise radikal in Frage gestellt wird. Das Amt hat sich daher immer wieder öffentlich zu Wort gemeldet bzw. wurde aus etlichen Anlässen dazu aufgefordert, eine Haltung gegenüber den Forderungen der Aleviten zu bestimmen, die, wenn man von der radikalen Variante der Forderungen absieht, auf eine eigene Abteilung innerhalb der Diyanet abzielen. Es geht hier natürlich vor allem um die existentielle Frage nach der Vormachtstellung der sunnitischen Ulema innerhalb der Religionsverwaltung. Aber hier steht auch nichts Geringeres zur Debatte als eine nicht zu ignorierende Herausforderung an die selbstverständliche politische Kultur, die sich unter den Bedingungen eines säkularen Zentralstaates weiterhin ausschließlich mit einer partikularistischen Haltung behaupten konnte. Jetzt müssen die sunnitische Orthodoxie und ihre Vertreter die Erfahrung der eigenen Kontingenz bewältigen. Damit ist die sich aufdrängende Erfahrung gemeint, daß die Rede vom „wahren“ Islam letztlich vielleicht doch von der jeweiligen Perspektive abhängt, und daß man selber auch lediglich aus einer bestimmten Perspektive heraus den Islam betrachtet. Bis jetzt hat sich die Orthodoxie mit einer solchen Erfahrung nicht im geringsten angefreundet. Die Diyanet denkt dabei vollkommen in Übereinstimmung mit den Politikern aus den konservativ bürgerlichen Parteien, von den islamistischen ganz zu schweigen.

Dem Präsidenten der Diyanet stehen aufgrund des Doppelgesichtes des Amtes im Prinzip zwei diskursive Möglichkeiten zur Verfügung. Er kann auf die Forderungen als Mitglied des Verwaltungsapparates reagieren, indem er von seinen inhaltlichen Vorstellungen vom „richtigen" Islam absieht und den Aleviten Platz innerhalb des Amtes einräumt. Dabei muß er selbstverständlich auf seine religiösen Ideen nicht verzichten, sondern sie nur zurückstellen. Um diesen Diskurs zu führen, ist es übrigens nicht zwangsläufig, daß man aus der formalen Beamtenrationalität heraus handelt. Man könnte auch aus substantiellen Vorstellungen heraus die legitime Vertretung anderer religiöser Interpretationen mindestens ,dulden“.

Nichts von all dem ist in den Stellungnahmen des Amtes zu spüren. Statt dessen beharrt die Diyanet auf der zweiten diskursiven Möglichkeit, die darin besteht, die Identität beider Gruppen zu betonen, das man aber leider aufgrund falscher Informationen, Vorurteile oder auch hinterhältiger Umtriebe dunkler Mächte bisher nicht so recht habe zur Geltung bringen können. Aus einer solchen, den eigenen Stand nicht relativierenden, d.h. totalen, Perspektive kann dann die Aner- 
kennung der Aleviten nur durch deren Angleichung an das Eigene erfolgen. Die folgenden Stellungnahmen, die ausnahmslos gute Vorsätze vorspielen, sollte man mit diesen Voraussetzungen im Hinterkopf lesen.

„Also dürfen wir nie Feindseligkeiten gegeneinander betreiben. Es gibt keine Differenz zwischen uns. Der heilige Ali ist ein uns allen gemeinsamer Wert. Ali zu lieben, gehört zum Glauben. Das Drama von Kerbela [wo Alis Sohn, Imam Hüseyin von den Soldaten des umayyidischen Kalifs Yezid im Jahre 680 umgebracht wurde, L.T.] ist eine Wunde, die in uns allen blutet. Die Pflicht, für Ehl-i Beyt [die Familie, Nachkommen des Propheten, denen nach dem schiitischen, d.h. auch alevitischen Glauben das Amt des Imams (Kalifen) zusteht, L.T.] zu beten, sie zu respektieren, ist uns allen aufgetragen.“(Uluçay 1998: 285)

Was diese inhaltliche Nähe, die genealogische Bindung der Aleviten, an der man für sich genommen nicht unbedingt etwas aussetzen muß, praktisch bedeutet, wird aber noch einmal deutlich, wenn man die Erklärungen des Präsidenten der Diyanet zu expliziten Fragen nach der Repräsentation der Aleviten im Amt und nach den Cemhäusern heranzieht.

„Seit der Zeit des Propheten beten Menschen in Moscheen. Sind denn an die eine Milliarde Menschen dumm? Das Cemhaus ist nicht adäquat zur Moschee. Wir haben nichts gegen ihre Cemhäuser; soweit ich weiß, sind sie so etwas wie Dergah [Derwischkloster]. [...] Was soll der Alevit vertreten? Im Cemhaus führt er Cemandacht. Ich betrachte das Alevitentum als eine Ordensgemeinschaft. Die Ordensgemeinschaften werden in der Diyanet nicht vertreten." (in: Uluçay 1998: 435)

Interessant ist hier die Strategie, daß die alevitischen Cemhäuser in einen diskursiven Zusammenhang mit den Ordensgemeinschaften gebracht werden. Diese sind nämlich seit der Gründung der Republik offiziell verboten. Damit wird quasi die laizistische Politik gegen die Forderung der Aleviten in Anschlag gebracht, die eigentlich als eine der zuverlässigsten Säulen der Laizität gelten. Der Präsident zeigt indessen Verständnis für den Abstand, den die Aleviten zu der etablierten Religion pflegen. Dies sei, so fährt er fort, nur historisch zu erklären. Der Staat, die religiösen Gelehrten, alle hätten die Aleviten vernachlässigt; sie seien auch in den Moscheen des öfteren diskriminiert worden. Das müsse jetzt ein Ende haben. Dafür müßten aber auch die Aleviten etwas tun: „Wenn sie sich von der mündlichen Kultur hin zu der literatischen [schriftlichen] Kultur wenden, dann verschwinden solche Probleme“. (Ebd.) Die These, warum eine solche Wendung, sprich: die Sunnitisierung des Alevitentums, die bestehenden Probleme beheben würde, hört sich vom Diskurs der Diyanet aus sehr 
plausibel an. Die Diyanet tut dem eigenen Anspruch nach - das Amt behauptet es zweifellos aufrichtig - nichts anderes als die Menschen zu der „wahren“ Form des Islam einzuladen. In einem Gespräch mit alevitischen Vertretern spannt der Diyanetinspektor Abdülkadir Sezgin den Bogen der „Aufklärungsdienste“ so weit, daß die staatlich abgesicherte Missionsarbeit unverhüllt zur Sprache kommt; bloß auch hier wird sie im Namen der „unparteiischen“ Aufklärungsarbeit erledigt.

„In dieser Gesellschaft wird kein Unterschied zwischen Muslim, Christ, Jude, oder gläubig, ungläubig gemacht. Es ist gestattet, allen Mitgliedern der Gesellschaft Dienste in Fragen des Islam zu erweisen, die Glauben, Ritus und Moral betreffen, und sie darüber aufzuklären; ja, nicht nur den Muslimen, sondern allen, aus denen sich die Gesellschaft zusammensetzt; Die Diyanet hat den Auftrag, ohne zwischen Ehrenhaften, Ehrlosen, Guten, Bösen, Gläubigen, Ungläubigen zu unterscheiden, jeden über diese drei Aspekte des Islam aufzuklären; um zu zeigen, das ist das Moslemtum.“ (in: Uluçay 1998: 493)

Es ist ein staatliches Gebot, es bürdet angesichts der vorherrschenden moralisch-politischen Kultur jedem die Pflicht auf, Menschen gleichzubehandeln. Man kann dazu auch noch das genuin islamische Gebot als verstärkenden Effekt hinzuziehen, das einen absoluten Egalitarismus in die Gemeinschaft der Muslime (aber eben der Muslime) führt. Auf jeden Fall hat jeder, der öffentlich agiert, und vor allem ein Staatsbeamter im Prinzip Rücksicht auf das Gleichheitsprinzip zu nehmen. Der Inspekteur handelt vollauf überzeugt nach dem diesem Prinzip der Gleichheit, der Islam muß allen Menschen ungeachtet ihres persönlichen Charakters oder jeweiligen Glaubens nahegebracht werden. Sie sollen die Wahrheit über den Islam erfahren. Man könnte auch sagen: Gleichheit vor der staatlich legitimierten Missionsarbeit. Hier wird das religiöse Gesetz mit seiner partikularistischen Zielsetzung und der Funktionsweise, daß sie keine Universalisierung über die islamische Gemeinschaft hinaus hervorbringen kann, auf die Ebene moderner Institutionen erhoben. Die Wertgeneralisierung kann daher nicht in der Weise zustandekommen, wie sie sich für die modernen Institutionen eignet, zu denen die Diyanet aufgrund ihrer gesetzlichen Anlage zählen soll. ${ }^{53}$ Was nicht nur in der Aussage des besagten In-

53 Talcott Parsons schloß diesbezüglich kategorisch die Möglichkeit aus, daß so imposante Systeme wie das Talmudische Gesetz und der traditionelle Islam eine solche moderne Wertgeneralisierung hervorbringen könnten. Denn "es fehlt ihnen der Allgemeinheitsgrad, den Max Weber als formale Rationalität bezeichnete" (1975: 48). Die Überlegung, daß die Wertgeneralisierung der formalen Rationalität kulturell nicht voraussetzungslos, d.h. selber partikularistischer Herkunft ist, wird jedoch 
spekteurs zur Sprache kommt, sondern überhaupt die Anlage und Funktionsweise eines der größten Ämter des türkischen, aber auch darüber hinaus die Einstellung der Politiker auszeichnet, ist dann nur noch die Simulation der Logik, nach der moderne Institutionen arbeiten: Man nutzt dankbar die Vorteile der formalen Wertgeneralisierung $\mathrm{zu}$ Legitimationszwecken der eigenen ungebrochen partikularistischen Tätigkeit. Selbst diese gravierend oberflächliche „universalistische“ Rhetorik wird allerdings kaum einen Atemzug lang durchgehalten. Rasch schlägt die substantialistische Argumentation des Staatsbeamten, nicht ohne eine an die Adresse der Aleviten gerichtete versteckte Mahnung, ins Gegenteil um. Es geht um die durch und durch substantialistische Standortbestimmung der Aleviten, die sich jedoch nicht einfach auf die Regelung der Beziehungen zwischen verschiedenen Gemeinschaften beschränkt (was ja jeder unbenommen tun dürfte), sondern unmittelbar auf die Verteilung staatlicher Dienstleistungen und die öffentliche Anerkennung auswirkt:

„Geht das Alevitentum auf Ali zurück, betrifft es den Ali, dann ist es insofern auch eine Angelegenheit des Moslemtums. [...] Saz und Semah ist gleich dem Semah in der Mevleviorden. Analysiert man das Bektaschitum als Ordensgemeinschaft, kommt man auf interessante Sachen. Die Andacht von Cem ist Zikr der Ordensgemeinschaften. Wenn ihr aber sagt, daß es im Alevitentum kein Beten [namaz], kein Fasten [Oruc] gibt, dann bringt ihr den anatolischen Alevit in Schwierigkeiten. Dann taucht nämlich die Frage auf, welche Religion er denn nun hat. Dabei ist doch Ali Muslim. Das ist die Regel im Moslemtum, in der ganzen Welt.“ (in: Uluçay 1998: 493) ${ }^{54}$

Was also im Diskurs der Diyanet undenkbar ist, ist die Anerkenntnis dessen, was die Aleviten von sich aus zu sein behaupten. ${ }^{55}$ Diese Haltung ist so mächtig und muß wohl so wesentlich für die religiöse Kultur in der Türkei sein, daß auch über die Diyanet hinaus die Inklusion

dadurch nicht widerlegt. Man müßte also den Status dieser in der formalen Wertgeneralisierung waltenden "Substanzialität" genau bestimmen. Foucaults Ausführungen zur "politischen Rationalität", auf die sich die vorliegende Arbeit stützt, könnte man auch als die Genealogie der formalen Rationalität lesen.

54 Saz: türkisches Saiteninstrument; Semah: kultischer Tanz der Aleviten; Bektaschitum: ein alevitischer Orden, die auch unter den osmanischen Janitscharen sehr verbreitet war; Mevleviorden: die mystische Gemeinde des berühmten Mevlana Celaleddin Rumi; Zikr: Gemeinsames rituelles Beten, das oft in Trance endet.

55 Folgerichtig hat denn auch die alevitische Dachorganisation CEM die Stellungnahme abgegeben, daß eine Vertretung der Aleviten in der Diyanet aufgrund der "strukturellen und prinzipiellen Probleme" nicht anzustreben ist (Uluçay 1998: 501ff). 
der Aleviten tatsächlich nur ,erfolgt“", indem ihre Selbstbeschreibung völlig ignoriert wird. Was die Aleviten tun und für sich in Anspruch nehmen zu sein, das können die sunnitischen Geistlichen und Politiker mehrheitlich nur als Vorurteile, Mißverständnisse oder Verschwörung irgendwelcher dunkler Kreise deuten. Die Orthodoxie kann selber darauf nicht adäquat reagieren, daß die Religion in einer spezifischen Form als gesellschaftliche Gegenmacht in einem Identitätsdiskurs und in kritischer Absicht gegen ihre staatliche gestützte Vormachtstellung zur Sprache gebracht wird. Sie bleibt trotz aller bereits beschriebenen Friktionen voll an die Allianz mit der Staatsraison gebunden. Genau an diesem Punkt, nämlich an der Frage nach der Anerkennung spezifischer Identitäten setzt der intellektuelle Islamismus an (davon handelt das Kapitel II).

\section{Resümee 1}

Die vorangegangenen Ausführungen zum Thema Verwaltete Religion des laizistischen Staates haben ihren Ausgang von der Geltung der modernen politischen Rationalität genommen, die sich durch den produktiven Eingriff in die Lebensbereiche auszeichnet. Auch die Religion wird Gegenstand der Macht, die in Form der Staatsraison, abgelöst von religiösen Visionen, zwecks Vermehrung der Stärke des Staates strategisch operiert und dabei die Religion auch als strategisches Instrument einsetzt. Dabei werden der Religion spezifische Funktionen bei der Umsetzung der Vision, eine nationalstaatlich unterlegte Gesellschaft herzustellen, zugewiesen.

Der Zugriff der staatlichen Macht auf die Religion, verkörpert im Amt für Religiöse Angelegenheiten, erfolgt auf drei unterschiedlichen Weisen. Zunächst einmal wird die Breite von öffentlich zulässiger Religiosität formal bestimmt. Als Aufgabenbereiche des staatlichen Religionsapparates werden die Aspekte Glauben (itikat), Ritus (ibadet) und Ethik/Moral (ahlak) zugelassen, während die Aspekte kontraktuelle Vereinbarungen (muamelat) und Bestrafung (ukubat) wegfallen. Bei der zweiten Form wird die Religion durch die Tätigkeit des Amtes explizit in die Pflege bzw. Stärkung der nationalen Kultur eingebunden. Hier bekommt denn auch die verfassungsrechtlich eher im technischen Sinne vorgeschriebene religiöse Aufklärung nach und nach stark inhaltliche Züge, so daß nicht mehr vornehmlich die moralische Qualität der Einzelnen für die soziale Ordnung im Vordergrund steht, sondern die materiale Rechtleitung anhand der Verbreitung der rechten Lehre durch den Verwaltungsapparat des laizistischen Staates an die Menschen gebracht wird. Eine dritte Variante des staatlichen 
Zugriffs findet in Form technischer Dienstleistungen statt, wobei hier speziell von der Verwaltung der Gebetsanstalten die Rede ist.

Die Auswirkungen der religiösen Strategien, die im Rahmen der politischen Technik der Staatsraison und im Dienste der Vision von der „machbaren“ Gesellschaft eingesetzt werden, sind äußerst relevant für die spätere Entwicklung. Nicht nur verbreitet sich mittels des zentralstaatlichen Apparates ein vereinheitlichendes und standardisierendes, bis in die entlegendsten Ecken der Gesellschaft hineinstrahlendes Religionsverständnis. Die Religion avanciert dabei auch selber zu einem umkämpften und begehrten gesellschaftlichen Gut. Dem Amt für Religiöse Angelegenheiten kommt dabei eine ambivalente Rolle zu. Einerseits ist die Diyanet selber ein wirkungsmächtiger Bestandteil des gesellschaftlichen Diskurses um die Religion, profitiert auch wesentlich von dem zugunsten des Islam als öffentlicher Norm stattfindenden Stimmungswechsel in der Gesellschaft. Andererseits möchte die Orthodoxie die historische Allianz, die sie mit der Staatsraison eingegangen ist, nur zu ungern aufgeben, verdankt sie doch ihr Monopol auf Religionsangelegenheiten eben dieser Allianz. Sie kann aber auf die offensive Artikulation der Religion in den Identitätsdiskursen, nicht angemessen reagieren. Ihr fehlen die dafür erforderlichen diskursiven Mittel. Die Vormachtstellung der Orthodoxie, die unter dem Schein der „religiösen Aufklärung“, befugt durch den säkularen Staat, offenkundig eine partikulare Version des Islam, nämlich den sunnitischen Skripturalismus, an die Bevölkerung heranbringt, wird von zwei Seiten herausgefordert.

Die konfessionelle Minderheit der Aleviten organisiert sich selber im Medium des Anerkennungsdiskurses und tritt mit ihrer spezifischen religiösen Identität gegen die staatlich gestützte Vormacht der sunnitischen Orthodoxie auf, stellt die bisherige Praxis der Verwaltung der Religion kritisch in Frage. Die bisherigen diskursiven Mittel der Orthodoxie, die den expliziten Ausschluß der Aleviten bewirkten, scheinen in Bezug auf die neue alevitische Herausforderung nicht mehr zu greifen.

Die zweite Herausforderung stammt aus den Reihen der Islamisten, die sich mit der strategischen Einbindung der Religion in die Ziele der Staatsraison, die immer schon auch eine Unterordnung der Religion gegenüber dem säkularen Staat bedeutete, nicht abfinden, sondern den Islam als die öffentliche Norm der „machbaren“ Gesellschaft durchsetzen wollen. Es geht nun nicht mehr nur um den Islam als einen Kitt der sozialen Ordnung, sondern um ein alternatives Gesellschaftsmodell im Namen des Islam. Dem widmet sich die Analyse im folgenden. 



\section{ISLAM ALS WELTANSCHAUUNG DER UMMATISTISCHEN UTOPIE}

Der verwaltete Islam, der trotz seiner historisch erfolgreich erprobten Kooptierung in den politischen Apparat zugleich eine Eigenlogik bewahren konnte, bildet bekanntlich keineswegs die einzige Form der islamischen Religiosität in der modernen türkischen Geschichte. Dies war auch von der klassischen Geschichte des Islam nicht zu behaupten, durch die über die Jahrhunderte verschiedene Varianten dieses Glaubens wie Sufik, Heterodoxien oder auch die, wenn auch wirkungsgeschichtlich wenig relevante philosophische Schule getaumelt sind. Die in institutioneller Hinsicht laizistisch eingebundene Diyanet hatte sich zwar im Zeitalter des sich verbreitenden „Weltbildes“ eingerichtet, zur Formierung eines vereinheitlichten Islam beigetragen und damit den Weg zur Durchdringung der Gesellschaft durch explizit religiöse Lehren als öffentliche Norm vorbereitet. Trotz all dieser im Diesseits der Gesellschaft operierenden Aktivitäten hat jedoch die Orthodoxie keinen religiösen Aktivismus hervorgebracht, der den gesellschaftstechnischen Zug der modernen politischen Rationalität mit einer islamischen Weltanschauung durchtränkt hätte. Daher blieb der türkisch-islamischen Orthodoxie nichts so fern wie die Vorstellung von einem ,alternativen islamischen Gesellschaftsmodell“. Das letzte wird dagegen das eifrige Bestreben der sich besonders in den 80er Jahren formierenden intellektuellen Zirkel bestimmen. Das folgende Kapitel analysiert die durch den Intellektuellenislam in der türkischislamischen Vorstellungswelt ausgelösten Transformationen.

Die islamistischen Intellektuelle, von denen im folgenden die Rede ist, sind durch einen in der bisherigen Geschichte des, zumindest türkischen, Islam nicht bekannten spezifischen Diskurs hervortreten. Hierbei handelt es sich um die Ausarbeitung eines „alternativen Gesellschaftsmodells“. Konkret nimmt der Diskurs seinen Anlauf von einem Dokument, namentlich der Urkunde bzw. Gemeindeordnung von Medina, die der islamische Prophet kurz nach seiner Immigration in Medina (622) zwischen seinen Weggenossen aus Mekka und den einheimischen arabischen Stämmen mitsamt ihren jüdischen Beisaßen vereinbart hat. Die Vision von der idealen Urgemeinde, wie sie zu jener Zeit unter der Führung von Muhammad existiert habe, wird nun im islamistischen Diskurs rekonstruktiv bearbeitet und unter dem La- 
bel von „Vertrag von Medina“ (im folgenden als VM abgekürzt) zu einer gesellschaftlichen Alternative erhoben, nach der unterschiedliche Gemeinschaften in Anerkennung ihrer Besonderheit eine gemeinsame politische Ordnung bilden sollen. Die folgenden Überlegungen werden sich um die Frage drehen, was es denn nun bedeutet, daß der Islam als explizite, theoretisch ausgearbeitete Grundlage der gesellschaftlichen Konstitution konzeptualisiert wird.

$\mathrm{Zu}$ diesem Zweck wird zunächst kurz erläutert, wie in der islamischen Geschichte auf das Goldene Zeitalter (Asr-1 Saadet: Zeitalter der Glückseligkeit) Bezug genommen worden ist. Von zentraler Bedeutung ist dabei die These, daß die oftmals mit eschatologischen Visionen verbundene Bezugnahme - zumindest im sunnitischen Islam, von dem hier die Rede ist - weitgehend ohne chiliastische Aufladungen auskam oder zumindest der Chiliasmus selten in politisches Handeln umschlug. Diese Spezifizität bleibt selbst in verschiedenen Varianten des islamischen Modernismus relativ erhalten (Kapitel II.1). Gleichzeitig bahnt sich hier, an dem in den 70er Jahren in der Türkei stark rezipierten Neomodernismus von Fazlur Rahman gipfelnd, eine Entwicklung in Richtung der Verdiesseitigung der Religion an, in der der Islam anhand theoretischer und methodologischer Reflexionen als Weltanschauung einer Gesellschaftskonstitution konzeptualisiert wird (Kapitel II.2). Die kritische Analyse von Rahmans Überlegungen bereitet somit den Weg für den weiteren Verlauf der Darstellung, in der gezeigt werden soll, wie die in Rahmans Arbeit kulminierende Entwicklung in den hier zu behandelnden islamistischen Diskurs hineinschlägt und dort nun auch entgegen Rahmans eigenem Anliegen zu einem alternativen Gesellschaftsentwurf ausgearbeitet wird. Dabei werden zugleich auch die Kategorien der weiteren Analyse gewonnen. So werden die Funktionsweise des islamistischen Diskurses und dessen Instrumente auf die Reversion des analytischen Interesses auf die westliche Moderne, sodann auf die aktivistische Verdiesseitigung der Religion bzw. des religiösen Denkens, weiterhin auf die Verbindungen zu den global zirkulierenden Diskursen und schließlich die spezifische Übersetzung dieser Diskurse hin analysiert (Kapitel II.3 bis einschl. 6). Da allerdings diese letzten Punkte ineinander übergreifen und im Grunde verschiedene Dimensionen ein und desselben Phänomens darstellen, wird es nicht durchgehend möglich sein, den formalen Aufbau der Analyse strikt entlang eines linearen Schemas durchzuziehen. Am Ende der Analyse soll deutlich gemacht werden, wie die islamische Materie, hier: die klassische Vision von der idealen Urgemeinde, dem Goldenen Zeitalter, mit Hilfe von in dem Diskurs der Intellektuellen angewandten modernen Kulturtechniken Züge einer politischen Utopie erhält, in der die Urgemeinde durch willentliches Handeln hier und jetzt als reine Gemeinschaft ins Werk gesetzt werden soll. Die 
Verwaltung der Religion, die noch in das Programm, eine westlich orientierte Gesellschaft herzustellen, eingespannt werden konnte, schlägt in ein explizit islamisches Gesellschaftsmodell um. Unter Punkt II.7 wird das Gesamtkapitel resümiert.

\section{Ursprungsvisionen im Islam}

Anno 1995 wird in der von islamistischen Intellektuellen herausgegebenen elektronischen Zeitung Anadolu ein Gedicht abgedruckt. Das Gedicht, das aus der Feder eines Dilaver Cebeci hervorgegangen ist, ist mit Medina überschrieben, mit einer der Heiligen Stätten des Islam. Es ruft nun keine Verwunderung hervor, wenn in der Poesie die Kluft, die Jahrhunderte zwischen einem unermüdlich ersehnten Anfang und der verdammten Gegenwart aufreißen, in einem Atemzug überbrückt wird. Der Dichter kann ungehindert die Truppen von Ebu Cehil, die sich gegen den Propheten und seine Gemeinde im Anmarsch befinden, vor seinen Augen sehen. Das Leid, das er in pathetischen Versen herausschreit, dürfte indes ihre Herkunft genauso gut in der sogenannten authentischen Vergangenheit haben wie in der Gegenwart; einer Gegenwart, die, vom bekennenden Säkularismus ,verunreinigt“, für einen Islamisten nichts Anderes sein kann als eine Wiederauflage der Cahiliye (die vorislamische Zeit, die Zeit der Ignoranz); einer Gegenwart des sich immer stärker in den Menschen breitmachenden Verfalls, vor dem sich der Gläubige die ewige Wahrheit der goldenen Zeit herbeisehnt:

„Wäre ich doch in einer goldenen Zeit zur Welt gekommen / Wäre mir auch ein wenig vom Wissen der Wüste zuteil geworden!“(Cebeci 1995)

Es ist von jener Stadt die Rede, in der sich der Islam aus einer außerweltlichen Gemeinde mit eschatologischen Visionen in einen schlagkräftigen Staat verwandelte, der dann auszog, um die Welt Gottes Befehl zu unterwerfen. Drückt die Gegenwart mit aller Gewalt dergestalt, daß das irdische Leben für den Gläubigen zur Qual wird, dann flüchtet er sich in den mütterlichen Schoß der Stadt Medina: „Bevor mir der Grausame in die Brust zusticht / gewähre mir deinen Schutz, O du Medina, schütze mich.“ (Ebd.)

Der Dichter dieser Verse wird sich mit seiner Sehnsucht nach der Goldenen Zeit sicherlich in guter Gesellschaft befinden. Diese Sehnsucht ist kein Privileg der Dichter, ja nicht einmal haben wir es mit einem rein islamischen Phänomen zu tun. Der Glaube an eine reine Vergangenheit, die im krassen Gegensatz zur Gegenwart steht und den legitimen Boden für eine Abrechnung mit dieser Gegenwart bereit- 
stellt, läßt sich in vielen Kulturen wiederfinden. Ja, man kann behaupten, daß die Orientierung an einem Goldenen Zeitalter, oder islamisch gesprochen am Zeitalter der Glückseligkeit (Asr-1 Saadet), die vormoderne Form der Utopien überhaupt darstellte. ${ }^{56}$ Die Aufstände haben sich, bevor mit der modernen Umkehrung der Zeithorizonte die Schaffung einer Zukunft als Utopie ins Zentrum des politischen Handelns rückte, in der Regel auf eine mythische Zeit berufen, von der aus erst Legitimität beansprucht werden konnte. ${ }^{57}$ Dieses Phänomen hat der prominente Orientalist von Grunebaum als Kulturklassizismus folgendermaßen beschrieben:

„(1) Eine vergangene (oder bloß fremde) Phase kultureller Entwicklung wird als vollständige und vollkommene Verwirklichung menschlicher Möglichkeiten anerkannt; (2) diese Verwirklichung wird als rechtmäßiges Erbe oder Besitz angeeignet; (3) es wird als möglich zugelassen, daß die eigene Gegenwart nach vergangener (oder fremder) Vollkommenheit umgeformt wird; und (4) das Kulturwollen der Vergangenheit bzw. der Fremdkultur wird als mustergültig und für die Gegenwart verbindlich übernommen." (1960: 5)

Es gibt sicherlich verschiedene Formen, wie man sich auf eine Vergangenheit beruft. Von Grunebaum liefert hierzu eine detaillierte Palette, auf die hier nicht näher eingegangen wird. Was hier interessiert, ist sein darauf folgender Verweis auf die Sehnsucht nach „Rückkehr zu den ,rechtgeleiteten' Kalifen, nach Rückkehr zu dem Islam, wie er zu Lebzeiten des Propheten gewesen“ (a.a.O.: 17) sei. Dieser Klassi-

56 „Während der gesamten Antike ,verhindert' somit der Gedanke eines an das anfängliche Goldene Zeitalter anschließenden Zerfalls - mit dem damit verbundenen Gedanken der zyklischen Wiederkehr - , die Entwicklung eines authentischen Fortschrittgedankens' [...].“ (Marramao 1989: 83)

57 Selbst, ja erst recht bei neuzeitlichen, zukunftsorientierten Utopien wirkt die Vorstellung eines ,unschuldigen“ Anfangs, wie das z.B. beim marxistischen Historischen Materialismus der Fall ist. Der Historische Materialismus sieht im Kommunismus die Wiederherstellung des klassenlosen Urkommunismus auf einer dialektisch vermittelten, höheren Ebene vor. Jacob Taubes erblickt darin übrigens den eschatologischen Zug des Marxismus: „Das Eschaton ist das Einst im doppelten Sinn: das Einst der Schöpfung: Axiologie, und das Einst der Erlösung: Teleologie.“" (1947: 12) Allerdings darf der folgenreiche Unterschied in der jeweiligen Zeitökonomie des „mythischen Regresses“ und der neuzeitlichen „politischen Utopien“ nicht restlos geebnet werden. Zum Verhältnis von Zeiterfahrung und Säkularisierung bzw. damit zusammenhängenden Begriffen wie Revolution, Gesellschaft und Projekt s. Marramao (1989). 
zismus der Rückkehr ,will“, so von Grunebaum“, nicht nur den Geist, sondern auch den Buchstaben der Vergangenheit zurückholen“ (ebd.). So weitgehend auch immer die etablierte Vorstellung vom islamischen Goldenen Zeitalter mit der Zeit der rechtgeleiteten Kalifen identisch geworden ist, deckt andererseits ein geschichtlicher Streifzug unmißverständlich auf, wie umkämpft die Bestimmung der Grenzen dieser idealen Gemeinde war und wie sehr sie teilweise immer noch den Gegenstand heftiger Auseinandersetzungen bildet. Die reale Geschichte der idealisierten frühislamischen Gemeinde weist übrigens selber zweifellos einen enormen Grad an inneren Zwistigkeiten auf, die dann $\mathrm{zu}$ den ersten Spaltungen im Islam geführt haben, welche heute noch bestehen. Immerhin wurden drei von den rechtgeleiteten Kalifen, welche die vollkommene Umma symbolisieren sollen, infolge politischer Intrigen umgebracht. Doch kommt es, was die psychologische und politische Wirkung des Vorbildes anbelangt, nicht auf den Realitätsgehalt der idealisierten Gemeinde an. Von entscheidender Bedeutung ist hingegen die Natur der politischen Beziehung, welche zwischen dem idealisierten Vorbild und dem innerweltlichen Handeln geknüpft wird.

\subsection{Eschatologie ohne Roß und Reiter}

So sehr nun die Idee einer Rückkehr universellen Charakters sein mag, bedürfen die islamischen Visionen der Rückkehr doch einer spezifischen Betrachtung. Immerhin hat sich der Wunsch nach Rückkehr in die Urgemeinde in der islamischen Geschichte zu einem Dogma entwickelt. Die Konzeption vom Goldenen Zeitalter bezieht sich in der Geschichte der muslimischen Gesellschaften nicht nur auf die Zeit der rechtgeleiteten Kalifen. Die Zeit der Ummayaden und der Abbasiden, aber auch die jeweiligen Glanzperioden islamischer Reiche (wie z.B. die Zeit des Aufstiegs bei den Osmanischen Türken) dienen ebenfalls als die Goldene Zeit (ausführlich dazu vgl. Duran 1983). Beim sunnitischen Islam, von dem unser Buch handelt, fällt der Stellenwert der Urgemeinde bereits durch die Bezeichnung Sunniten (Traditionarer) auf, die besagt, daß die Sunna, nämlich die Worte und Taten des Propheten und die Lebensweise seiner Gemeinde, zum zentralen Bestand des Glaubens gehören. Für sie hat sich weitgehend die Zeit der vier Kalifen (Ebu Bekir, Ömer, Osman und Ali) als das Goldene Zeitalter durchgesetzt, während das Schiitentum die Goldene Zeit lediglich auf Ali als den legitimen Nachfolger des Propheten beschränkte.

Parallel zu den unterschiedlichen Bestimmungen der Goldenen Zeit hat sich das Verhältnis zwischen Herrschaft und Heilsfrage unterschiedlich entwickelt. Die dem Imam im Schiitentum zugesprochene 
Heilswichtigkeit wurde von den Sunniten weitgehend abgelehnt (vgl. Kapitel I.1), daraus entsprang dann folglich auch die geschichtswirksame Spannung zwischen dem Herrscher und der Ulema, wie sie zuvor in Bezug auf die Diyanet diskutiert worden ist (vgl. Kapitel I.4). Diese verschiedenen Konzeptionen haben wiederum im Hinblick auf das politische Handeln unterschiedliche Konsequenzen mit sich gebracht. Anders als im Schiitentum, in dem die Visionen der Rückkehr sehr leicht chiliastisch gewendet werden konnten (z. B. die iranische Revolution von 1979), wies die sunnitische Eschatologie selten chiliastische Züge auf.

„Auch im Sunnitentum gibt es chiliastische Züge, gewiß. Aber sie lassen sich nicht so leicht für die irdischen Ziele einsetzen. Die sunnitische Literatur, die sich mit den Vorgängen am Ende der Geschichte beschäftigt, ist sogar sehr umfangreich. Aber sie befaßt sich eben mit einem Eschaton, von dem wirklich niemand weiß, wann es hereinbrechen wird. Auf alle Fälle wird es nicht als eine in naher Zukunft bevorstehende, durch persönlichen Einsatz der Gläubigen zu beschleunigende Wende zurück zur prophetischen Urgemeinde verstanden, wie dies in manchen schiitischen Gruppierungen verstanden wurde.“ (Nagel 1981a: 313, Hervorhebung L.T.)

Bereits in der Formierungsphase (kurz nach dem Tode des Propheten), die von einer pessimistischen Grundstimmung durchsetzt war, erschien die Urgemeinde im Rückblick als ein Hort der Frömmigkeit. Und es setzt sehr früh ein, daß die Mitglieder der Urgemeinde dafür gerühmt werden, daß sie ,mehr als ihr (die jetzigen) auf das Diesseits verzichtet und nach dem Jenseits verlangt (haben)“ (Abdallah $b$. alMubarak, gest. 653, zit. n. Gramlich 1974: 115). Auffallend ist auch daher, daß sich die Aufstände wie beim Aufstand von Ali ibn Muhammad, des „Herrn der Zang“ (als Negeraufstand bekannt, ausführlich dazu vgl. Halm 1967) oft auf die Vision vom kommenden Mahdi berufen haben, die dann auch im Schiitentum institutionalisiert wurde.

Ähnlich wie Nagel, doch der chiliastischen Dimension mehr Gewicht zumessend, vertritt Al-Azmeh (1996: 76) die These, daß ,im islamischen Mittelalter [...] der radikale Fundamentalismus unfehlbar chiliastisch und mit jenem Ideenkomplex verknüpft war, den der Begriff Mahdismus umschreibt“". Auch Al-Azmeh kommt es allerdings auf die Differenz zwischen dem mittelalterlichen Chiliasmus der sunnitischen und schiitischen Bewegungen einerseits und dem islamistischen Radikalismus der Gegenwart an, für den es in der islamischen 
Geschichte kein Vorbild gebe (ebd.). Der gegenwärtige Islamismus zeichnet sich durch seinen utopischen Charakter aus (a.a.O.: 77). ${ }^{58}$

\subsection{Islamische Visionen von Rückkehr}

Bevor jedoch auf die spezifische Konzeptualisierung der Urgemeinde durch den neuzeitlichen Islamismus näher eingegangen wird, sollen noch einige Punkte erhellt werden. Es geht zunächst einmal um das klassisch-islamische Verständnis der Geschichte als Verfall, der bereits in der Idee der vollkommenen idealen Urgemeinde mit gegeben ist. Wenn nämlich der gläubige Muslim danach streben soll, nach der Weise der Altvordern zu leben, dann erscheint seine Existenz zunächst einmal in einer gewissen Entfernung zum Anfang: sowohl in persönlicher Hinsicht, daß er als Einzelmensch moralisch nicht die ideale Reife besitzt, als auch in historischer Hinsicht, daß seine Zeit durch die Kluft der Jahrhunderte von der Urgemeinde getrennt ist.

Wie oben angesprochen, ist bereits im Dogma der Urgemeinde die Tendenz gegeben, daß sich mit zeitlichem Abstand vom Ursprung eine Verfallsgeschichte einstellt. Mithilfe der Institution der HadithTradition (Überlieferungen vom Propheten) wurde selbst der Verfall in den Grundbestand islamischen Glaubens aufgenommen, indem vom Propheten folgender Satz überliefert wurde: „Die besten Menschen sind meine Zeitgenossen, dann die nächste Generation, dann die nächste. Dann werden Leute kommen, die auf ihr Zeugnis (immer) einen Eid folgen lassen und auf ihren Eid (immer) ein Zeugnis." (al-Buhari, zit. n. Gramlich 1974: 111)

In einer anderen Überlieferung wird die mit den letzten Sätzen gemeinte, mit dem zeitlichen Abstand wachsende Unzuverlässigkeit offener und dramatischer zur Sprache gebracht.

„Meine Gemeinde besteht aus fünf Generationen, deren jede vierzig Jahre dauert. Die erste Generation, ich und die Meinigen, sind Leute des Wissens und der Gewißheit, bis vierzig; die zweite Generation sind Leute der Frömmigkeit, bis achtzig; die dritte Generation sind Leute gegenseitigen Verbundenseins und Erbarmens, bis hundertzwanzig; die vierte Generation sind Leute gegenseitigen Beziehungsabbruches und Sichabkehrens und Unrechtzufügens, bis hundertsechzig.“ (Ibn al-Atir, z. n. Gramlich 1974: 111f.)

Andererseits predigt der Islam die Gewißheit, daß Gott den Menschen nie alleine läßt. Gott greift immer wieder durch seine Propheten in das

58 Auf die utopistischen Züge im islamistischen Denken haben in der Literatur in systematischer Hinsicht hingewiesen: Büttner (1996: 484), Al-Azmeh (1996, Kapitel 2) und Eisenstadt (1998, Kapitel 2 und 3). 
weltliche Geschehen ein, in deren Kette von Abraham bis Jesus sich Muhammad einreiht, um sie letztlich zu einem vollendeten Abschluß zu bringen. ${ }^{59}$

So erscheint die islamische Geschichte des Heils etwas anders als die „Heilsgeschichte“ im christlichen Sinne. Der Verfall tritt einerseits durchs Fehlgehen der Menschen ein, die sich immer weniger an der Befolgung Heilsgewißheit spendierender Gebote orientieren. Andererseits neigt der Mensch in seiner Alltäglichkeit dazu, sich vom rechten Pfad zu entfernen; je weiter entfernt vom Beginn, desto wahrscheinlicher stellt sich das Fehlgehen ein. Der Verfall erweist sich im Sinne eines universalen Heilsplans als ,unökonomisch“ (vgl. Wielandt 1971: 36). ${ }^{60}$

Es mag durchaus so sein, daß dem Dogma „Siegel der Prophetie“ zuweilen auch heilsgeschichtliche Visionen angehaftet haben (interessanterweise insbesondere ab dem 19. Jh.), die in der Folge der Prophetie eine voranschreitende Vervollkommnung propagierten. Zur Etablierung der Vorstellung von einer Heilsgeschichte hat dies nicht geführt.

„Wo der christliche Theologe in den Teilwahrheiten, welche die Heiden und Juden besaßen, eine praeparatio evangelica und den logos spermatikos einer natürlichen Religion erkannte und von da an eine Aufwärtsbewegung feststellte, die im Kommen Christi ihren Höhepunkt erreichte, da erblickte der Muslim ein sich oftmals wiederholendes Zerfallen des Glaubensgebäudes und ein sich oftmals wiederholendes Abtrünnigwerden von Gemeinschaften, die ohne ihren Stolz und ihre Nachlässigkeit das gewesen sein

59 Der Abschluß der Offenbarungs,,geschichte“ bringt zweifellos ein großes Problem mit sich, da jetzt erklärt werden muß, wie die Quelle des göttlichen Segens, die ja nicht versiegt bzw. versiegen darf, weiterhin in Erscheinung tritt. Der Koran und die Sunna haben diese Funktion zu erfüllen; nichtsdestotrotz fügte die islamische Theologie zu diesen Institutionen in Gestalt des Erneuerers eine weitere hinzu. Zur Begründung wurde dem die Hadith vom Propheten zugrundegelegt: „,Gott wird einem jeden Jahrhundert einen Mann aus den Leuten meines Hauses senden, der ihnen die Angelegenheiten ihrer Religion erklären wird“. (vgl. Goldziher 1967 [1871]: 53). Seine Aufgabe besteht wie die des Propheten - wenn auch in einer unvergleichlich abgeschwächten Form - darin, den Verfall zu stoppen.

60 In diesem Sinne vertritt von Grunebaum, daß das Böse in der islamischen Kultur nicht als Versuchung erscheint, sondern als Verwirrung, als das Verlassen des rechten Pfades (1969: 36). Dies führt er u.a. auf das Fehlen des Gedankens Erbsünde zurück. Der islamische Formalismus und Konventionalismus als Bürge der Heilsgewißheit (vgl. Weber 1975 [1920]: 335f; Stauth 1999: 19) hängt übrigens wesentlich damit zusammen. 
konnten, was am Ende der Islam werden sollte, nämlich Gottes beste Religionsgemeinschaft.“ (von Grunebaum 1969: 32)

„Seltener ist im Islam“ hingegen, so Fritz Meier (1960: 148), „die andere Auffassung, der Glaube an einen stetigen Fortschritt, an eine allmähliche Aufwärtsentwicklung der Welt." Diese vor allem in den mystischen Kreisen anzutreffende Vorstellung, die sich allerdings nicht auf das Weltgeschehen, sondern auf die durch Sufis vorgenommene Deutung der göttlichen Botschaft bezieht, hat sich nicht als allgemeines Kulturgut etablieren können.

Interessanterweise tauchen Elemente eines am Fortschritt orientierten Geschichtsbildes erst infolge der Konfrontation mit der westlichen Welt auf, die der muslimischen Welt eine sowohl auf der geistigen als auch auf der materiellen Ebene stattfindende Interaktion aufgezwungen hat. Für Musa Carullah (1875-1949), den frühen islamischen Modernisten, besteht kein Zweifel darüber, daß „es der Menschheit in Zukunft besser gehen wird als heute“ (vgl. Kara 1987, Bd. I: XVII). Der konservative Mehmed Akif (1876-1936), der, von der Abschaffung des Kalifats enttäuscht, lange Zeit in Ägypten gelebt hat, sprach auch in diesem eher pragmatischen Sinne von Fortschritt:

„Wie weit auch noch ein Volk vorangeschritten, wie hoch es auch emporstiegen sein mag, rotiert es an der Stelle, dann ist es um dieses Volk geschehen. Denn die ganze Menschheit eilt einem entfernten Punkt, einem Zweck entgegen. Die Menschheit fließt wie ein wildströmendes Wasser unaufhörlich in das Meer des Fortschritts hinein. Dieses Wasser ist nicht zu bändigen. So werden wir auch folglich entweder ertrinken oder mit dem Strom schwimmen. Offenkundig schreitet die gesamte Menschheit voran, nur wir bleiben auf der Stelle.“ (In: Kara a.a.O.: XVIII)

Dem ersten Versuch, den neuzeitlichen Fortschrittsgedanken islamisch zu wenden, begegnen wir jedoch bei Muhammad Abduh (18491905). Abduh verwandelt die ,im Islam ursprünglich gemeinte Vorstellung von der Aufeinanderfolge inhaltlich gleicher Offenbarungen von Adam bis Mohammed" in eine Geschichte der Rationalisierung der Gottesidee, die ihren Endpunkt im islamischen Monotheismus erreicht (vgl. Nagel 1990: 22). Auch bei seinem Schüler Iqbal (18751938) wurde der Fortschrittsgedanke affirmativ in den Bestand klassischer Visionen eingeflochten und religiös überhöht. Der intellektuelle Versuch Iqbals, den Fortschritt islamisch zu wenden, schlug sich in der Konzeptualisierung der Prophetie derart nieder, daß der Offenbarungsgeschichte eine heilsgeschichtliche Dimension zugefügt wurde. Die Herabsendung der koranischen Botschaft sollte sich nicht mehr in den Kreislauf einer sich wiederholenden Offenbarungsgeschichte einordnen lassen. Statt dessen erhält die Offenbarungsgeschichte vom 
Ereignis des Islam her ihren Sinn, so daß dieser nunmehr den anderen Buchreligionen heilsgeschichtlich vorausgeht (vgl. Haarmann 1994: 185; Wielandt 1971).

Trotz solcher Tendenzen kann man jedoch nicht behaupten, daß sich die Idee der fortschreitenden Geschichte in der islamischen Vorstellungswelt durchgesetzt hat. Die Verfallsidee als Grundmuster des islamischen Geschichtsverständnisses ist nicht nur keineswegs verschwunden, sondern hat im gegenwärtigen islamistischen Denken den Modus der Weltdeutung bestimmt. Umgekehrt verschwindet die Fortschrittsidee auch nicht völlig, sie paßt sich an die Vision der Verfallsgeschichte an, indem sie sich, wie später zu belegen ist, als fortschreitende Entfernung von der göttlichen Ordnung des Seins exakt ins Gegenteil des ursprünglichen Konzepts von Fortschritt verkehrt. Infolge der oben vorgenommenen knappen Überschau von Transformationen, die islamische Visionen von Rückkehr in der klassischen und modernen Form erfahren, sei somit zunächst einmal auf den Kontextbezug religiöser Reflexionen hingewiesen. Demnach bildet der Fortschrittsgedanke sowohl im Blick auf die Materie (affirmativ oder ablehnend) als auch auf die Struktur des Denkens (fortschreitender Verfall immer noch im Bannkreis desselben Denkens) den Dreh- und Angelpunkt auch der später einsetzenden islamistischen Reflexionen. Die kritische Auseinandersetzung der islamistischen Intellektuellen mit dem Fortschrittskonzept wird sich auf die klassischen Visionen von Verfall und Rückkehr auflagern, d.h. in den bestehenden Diskursbestand einfügen.

Ein weiterer bedeutsamer Punkt handelt von der Tendenz, die sich durch die Begegnung mit der westlichen Moderne im islamischen Denken abzeichnet. Es handelt sich darum, daß sich eine immer stärker werdende Profanisierung der religiösen Reflexion andeutet. $\mathrm{Ob}$ man nun die Einflüsse der Verwestlichung mitsamt ihren materiellen und ideellen Dimensionen islamisch einnehmen oder im Gegenteil verdammen will, letztlich zwingt die Omnipräsenz der westlichen Moderne das Denken der Muslime dazu, sich mit ihren Folgen auseinanderzusetzen, und sprengt folglich den thematischen Rahmen und Instrumentenbestand klassischer muslimischer Reflexionen. ${ }^{61}$

Im folgenden wird diesem Phänomen entlang der Überlegungen des pakistanischen Reformers Fazlur Rahman näher nachgestellt.

61 Der tunesische Schriftsteller, Lyriker und Filmemacher Abdelwahab Meddeb stellt diese jedem Nichteuropäer bekannte Erfahrung in den Anfang seiner Reflexionen zum Thema Europa als Extrem (1994: 32): „Der Nichteuropäer kann Europa als Problem nicht umgehen. Ob er sich dorthin begibt oder zu Hause bleibt, auf dem eigenen Kontinent, er wird mit der Gedankenwelt Europas und ihrer Verwirklichung konfrontiert, denn deren Folgen sind überall auf Erden sichtbar [...].“ 
Rahmans Bedeutung ergibt sich aus zwei Gründen: Erstens spielt dabei die doppelte Funktion, die ihm als aufmerksamer Beobachter und als Mitbeteiligter desselben Prozesses zukommt, eine wichtige Rolle für die Entscheidung, sein Denken in die Analyse einzubeziehen. Zweitens kann man Rahmans Neomodernismus als eine schillernde Etappe im zeitgenössischen islamischen Denken bezeichnen, in der zwar eine islamische Moderne systematisch angestrebt wird, jedoch gleichzeitig ungewollt der Weg für den Islamismus vorbereitet wird. Rahmans Ideen, die auf die Ausarbeitung einer islamischen Moderne abstellen, werden zwar von den hier zu besprechenden türkischen Islamisten abgelehnt, die Instrumente und Produkte seines Denkens sind aber auch für den islamistischen Diskurs von paradigmatischer Bedeutung. In der Analyse wird die Darstellung Schritt für Schritt auf die systematische Entwicklung des religiösen, diesseits gewendeten Aktivismus zugespitzt.

\section{Der Neomodernismus von Fazlur Rahman: Die Suche nach islamischen Werten}

Fangen wir die Analyse mit einer Beobachtung von Rahman an, die mit den oben vorgenommenen Beschreibungen korrespondiert. Es handelt sich um eine folgenreiche Transformation an der Perzeption der Religion, die fortan als ein dauerhafter Bestandteil von Erscheinungsformen islamischer Religiosität registriert werden muß. Auf diese neue Erscheinung, die über den islamischen Modernismus in die islamische Kultur Einzug erhält, macht der prominente Reformist Fazlur Rahman aufmerksam, indem er zunächst konstatiert, daß ,at the higher educational level the modernists thus eased the adoption of modern science for the younger generation“ (1982: 52). Damit einhergehend wird, so fährt Rahman fort, eine neue Form der moralischen Erziehung geprägt, die im Hinblick auf den Modus der Vermittlung von Inhalten durchaus an die althergebrachte Erziehung anknüpft und damit den Eindruck erweckt, sie stelle die Tradition in reiner Form wieder her.

„This was a major development since before this the only teaching of moral duties was through ,religious' books that emphasised the consequences of wrong doing both in terms of harm done to society or to the wrongdoer as part of the society, but in terms of heaven and hell.“ (Rahman 1982: 52)

Rahmans scharfsinniger Beobachtung über die Verschiebungen im Jargon der religiösen Erziehung muß man große Aufmerksamkeit schenken, um die radikale Transformation, die sich hier andeutet, in 
ihrer vollen Bedeutungsschwere ermessen zu können. Es wird zwar an die klassische Form der Geschichtserzählung angeknüpft, - die übrigens im intellektuellen Islamismus weitgehend verschwindet, - die Geschichten aber handeln jetzt mehr und mehr von den gesellschaftlichen Dingen. „This was”, so fährt Rahman fort, ,in line with the attitude of the premodernist reformers of the eighteenth and nineteenth centuries, who had conceived of superstitions and antisocial practices in terms of social and moral degeneration in this world rather than in terms of otherworldly consequences." (Ebd.)

Die Probleme der volkstümlichen Erziehung, so bedeutsam sie auch sind, interessieren hier aufgrund der Anlage des vorliegenden Textes, der sich mit intellektuellen und politischen Diskursen beschäftigt, nur insofern, als sich darin eine Verschiebung an der Ordnung der Bewertungskriterien für das moralische Handeln artikuliert. Rahmans Beobachtung unterstützt folglich nur zu gut die in den Kapiteln I.2 u. 3 über den neuzeitlichen Charakter der Gesellschaft angestellten Reflexionen. Die Bezugnahme auf den Islam kommt nun immer weniger umhin, sich mit der „Gesellschaft“ bzw. in der Verortung des muslimischen Subjekts in ihr zu befassen. ${ }^{62}$ Der Orientierungspunkt, von dem aus das weltliche Handeln bewertet wird, verschiebt sich von der Drohung mit Himmel und Hölle zum Erfolg und Scheitern, zu einer Befreiung oder Verdammnis in der Welt. Was ist nun Rahmans eigene Rolle in dieser Verschiebung, ist er nur ein Beobachter des Prozesses oder trägt er mit seinem Werk selber zu dessen Vollzug bei?

Rahman markiert mit seiner intellektuellen Leistung den Höhepunkt des islamischen Modernismus, sein Bemühen um die Reformation des Islam ragt unter verschiedenen Antworten auf die Stellung des Islam in der modernen Welt heraus. Mit seinem Werk setzt er sich von den Versuchen der vorangegangenen Modernisten im Kern dadurch $a b$, daß die innere Rationalität des islamischen Gesetzes zum

62 Eine parallele Entwicklung läßt sich übrigens vielleicht am Beispiel eines neuen Begriffs begreifen. Es wird unter den Islamisten auffallend immer mehr auf die Menschheit rekurriert. Natürlich waren bereits der Adressat der koranischen Offenbarung Menschen und nicht ein bestimmtes Volk. Doch scheint sich der Begriff verwandelt zu haben. In der Offenbarung fungierte Mensch nicht als Abstraktum, sondern bezeichnete den Einzelmenschen als moralisches Wesen, das von Gott angesprochen wird. Menschheit hingegen ist bereits eine Abstraktion. Der Koran verheißt den Einzelmenschen Errettung im Jenseits - nach einer weitläufigen Lesart auch im Diesseits -, aber keine Befreiung der Menschheit, die zukunftsgerichtet ist und erst im semantischen Feld der Revolution auftaucht (zur Zeitlichkeit der Revolution vgl. Marramao 1989). 
Gegenstand der Erneuerungstätigkeit gemacht wird. Selbst Iqbals mystisch unterfütterter Modernismus genügte nach Rahmans Ansicht dem Anspruch auf eine intrinsische Reform nicht. Solche Versuche fielen noch in die Kategorie des selektiven Umgangs mit dem Islam, im besonderen mit dem Koran.

„It must be remembered that whatever elements in his history the modernist praises and emphasises - even if these be apparently mutually disparate elements - he is not so much portraying the past but indirectly pointing to a future: in the past he is not primarily describing events but locating his faith in certain events.“ (Rahman 1979: 235f)

Rahman kämpft im Grunde an zwei Fronten. Während der Modernis$m u s$, so Rahman, die innere Rationalität der Religion unangetastet beläßt, um den Islam nur äußerlich und selektiv an die moderne Welt anzupassen (1966: 120f), haben sich die Ulema, also die Orthodoxie, in Rahmans Augen auf den Buchstaben des Gesetzes versteift (a.a.O.: 119). Das Fehlen des islamischen Ethos in beiden Strömungen verstärkt dabei für Rahman im Endeffekt den islamischen Fundamentalismus. In diesem geistigen Kräfteverhältnis entwickelt Rahman seine eigene historisch-kritische Methode, die dem Islam einen würdigen Platz in der modernen Gesellschaft vorbereiten soll.

Die von ihm in Angriff genommene kritische Methode zielt in Bezug auf den Gegenstand der kritischen Analyse nicht alleine auf die Sunna und fikıh (Jurisprudenz). Sie zeichnet sich vor allem dadurch aus, daß selbst der Koran einer historischen Lektüre unterzogen werden soll, wo Modernisten und die Ulema, so Rahman, noch zögerten, den entscheidenden Schritt zu unternehmen (a. a. O.:127). Im folgenden steht seine Auseinandersetzung mit der Orthodoxie im Zentrum des Interesses. Die Analyse dieser Auseinandersetzung ist aus zwei Gründen für unseren Argumentationsverlauf bedeutsam. Erstens knüpft sie an die im Kapitel I vorgelegten Ausführungen zur ,,verwalteten Religion" der Orthodoxie an und vertieft sie. Zweitens werden hier kategoriale Mittel und methodische Verfahren vorbereitet, die sich im intellektuellen Unternehmen der Islamisten in hypostasierter Form wieder finden.

\subsection{Die Einheit des Korans und die islamische Weltanschauung}

In dem, was Rahman der Orthodoxie vorwirft, nicht geleistet zu haben, kommt nun etwas zur Sprache, was die traditionelle Orthodoxie im Grunde nie hätte leisten können, ja was nicht einmal in ihren Problemkreis eintreten konnte. Daher eignet sich diese Kritik besonders gut dafür, die von Rahman nicht nur inhaltlich, sondern vielmehr 
strukturell mit vollzogene Transformation aufzuspüren. Mit anderen Worten, in Rahmans Kritik äußert sich etwas, was in dieser Form erst durch die Moderne denkbar geworden ist.

„For the failure to understand the Qur'an as a deeper unity yielding a definite weltanschauung, the greatest penalty was paid in the realm of theological thought. Whereas in the field of law, in the relative absence of such an internally discovered unity, the incorporation of foreign materials introduced a sufficient degree of practicality, the same process of adopting foreign ideas in the field of theology - again, in the absence of such an unitary vision of the Qur'anic weltanschauung - proved disastrous, at least in the case of Asharism, the dominant Sunni theology throughout medieval Islam.“ (1982: 3, Hervorhebungen im Original, L.T.)

Den Koran als eine Einheit verstehen, die man systematisch analysieren kann, um die den historisch eingebetteten Bestimmungen immanenten Prinzipien herauszuarbeiten, die dann auf die konkreten Einzelfälle angewandt werden sollen, so verfährt Rahmans Hermeneutik. Sie lebt grundsätzlich von der Idee, daß der Koran eine systematische Einheit besitze, welche die Orthodoxie wahrzunehmen nicht imstande gewesen sei. Rahman fragt hier nicht danach, ob die Bedingungen der Möglichkeit für die Idee von der systematischen Einheit des Korans in der Episteme ${ }^{63}$ (im Foucaultschen Sinne) gegeben waren, in der sich die Orthodoxie eingebettet war. Er verwendet Begriffe wie die Einheit und Weltanschauung des Korans als universale Tatsachen, denen in seiner Methodologie offenbar keine geschichtliche Dimension zugerechnet wird ${ }^{64}$ Rahman ist sich freilich dessen bewußt, daß die histo-

63 Foucault beschreibt Episteme folgendermaßen: „Es handelt sich eher um eine Untersuchung [eine archäologische, L.T.], in der man sich bemüht festzustellen, von wo aus Erkenntnisse und Theorien möglich gewesen sind, nach welchem Ordnungsraum das Wissen sich konstituiert hat, auf welchem historischen Apriori und im Element welcher Positivität Ideen haben erscheinen, Wissenschaften sich bilden, Erfahrungen sich in Philosophien reflektieren, Rationalitäten sich bilden können, um vielleicht sich bald wieder aufzulösen und zu vergehen. [...] Was wir an den Tag bringen wollen, ist das epistemologische Feld, die episteme, in der die Erkenntnisse, außerhalb jedes auf ihren rationalen Wert oder ihre objektiven Formen bezogenen Kriteriums betrachtet, ihre Positivität eingraben und so eine Geschichte manifestieren, die nicht die ihrer wachsenden Perfektion, sondern eher die der Bedingungen ist, durch die sie möglich werden.“ (1990: 24)

64 Einen umgekehrten Fehler macht Seufert. Er hat zwar überzeugend dargelegt, daß gerade die Sakralisierung weltlicher Begriffe, nach denen die religiösen Quellen (vor allem der Koran) durch Islamisten ,abgeklopft“ werden, zur „Verweltlichung des Heiligen (als) notwendige 
rische Tatsache, daß die Orthodoxie keine systematische Einheit im Koran erblickt hat, über eine praktische Unzulänglichkeit hinausweist: „Among the Orthodox", versichert uns der Kenner des islamischen Denkens, „there has not been a lack of men of deep insight, but there has been no systematic and coherent body of metaphysical thought fully informed by the Qur'anic weltanschauung, which is remarkably coherent." (1982: 132)

Er macht allerdings dafür alleine das Fehlen einer entsprechenden Methodologie verantwortlich, wobei er die Befragung keineswegs in die Richtung hin ausweitet, ob eine solche Methodologie hätte auftauchen können. Und wieso verwendet er, müßte man doch kritisch anmerken, unhinterfragt den Begriff der Koranischen Weltanschauung? Selbstverständlich gehören die Begriffe Einheit und Weltanschauung in den selben Bedeutungskontext. In der trefflichen Diagnose über den orthodoxen Islam, die Rahmans intellektuelle Fähigkeiten unmißverständlich bezeugt, deutet sich folglich seinerseits ein Bruch mit der klassischen Vorstellungswelt der Muslime an.

Offensichtlich bedürfen jetzt die Muslime einer islamisch begründeten Weltanschauung, wie dies in Rahmans Denken zum Ausdruck kommt. Rahman selber steht in einem infolge der kulturellen Austauschprozesse auch die islamische Kulturwelt umgreifenden geistesgeschichtlichen Kontext, in dessen Weltverständnis unmittelbar gehört (vgl. die Einleitung in diesem Buch), daß die Welt aus der Sicht eines souveränen Subjektes nach bestimmten Prinzipien betrachtet und gedeutet wird. Dies aber ist deshalb denkbar geworden, weil diese Welt jetzt als Gesellschaft auch eine entsprechende Bearbeitung durch das Subjekt verlangt. Ohne die Idee, die gute Gesellschaft sei machbar, wäre auch die Idee nicht denkbar, daß sie auch islamisch machbar sein müßte. Es geht also um eine Vorstellung, die der klassischen Orthodoxie wesentlich fremd war und auch in der Welthaltung ihrer Verlängerung in der modernen Türkei, der Diyanet, so nicht denkbar ist. ${ }^{65}$

Folge“ führt (1997b: 492). „Eine solche ,bewußte“, ,verfeinerte‘, ,kreative“ Nutzung der Tradition unterscheidet sich von der, gewohnheitsmäßigen', ,unreflektierten', ,restriktiven' in früheren Perioden, welche den Zusammenhang des Heiligen Textes wahrte.“ (Ebd.) Indessen ist an Seufert die Frage zu richten, inwiefern oder ob sich in diesem „Abklopfen" die Einheit des Textes, welche in der traditionellen Umgangsweise gewahrt sein soll, tatsächlich verflüchtigt. Oder wird die Einheit des Textes nicht noch rigider unterstrichen, wenn er zur Grundlage einer Weltanschauung avanciert?

65 In dieser Orientierung sieht Stauth die Tendenz, daß „ein unmittelbarer Anspruch der Religion nach Gestaltung der gesellschaftlichen Wirklichkeit geweckt wird“" (1996: 27f). 
Erst unter dieser Zielrichtung einer an den religiösen Prinzipien orientierten Gesellschaftskonstitution, unter weltanschaulichen Gesichtspunkten, taucht das Bedürfnis auf, den Koran als eine systematische Einheit zu betrachten. Die Orthodoxie konnte die Einheitsidee, die dem Islam als Weltanschauung zugrunde liegt, nicht hervorbringen. Sie wollte und konnte doch keine Gesellschaft (be-)gründen. Die Religion sollte in erster Linie den einzelnen Mitgliedern der Umma den Heilsweg zeigen, wenn auch immer darauf bedacht, den Zusammenhalt der Umma (bzw. die Einheit der Nation, wie es im Falle der türkischen Religionsbehörde dargestellt wurde) zu wahren. Es konnte also hauptsächlich darum gehen, als Sachwalter die Gewißheit der göttlichen Botschaft zu wahren und weiterzugeben, auf daß die Muslime nicht vom rechten Weg abirren.

\subsection{Realität als kritische Prüfungsinstanz}

Vor allem aber kannte die Vorstellungswelt der Orthodoxie eine für das moderne wissenschaftliche Denken elementare Form der Wahrheitsfindung nicht: die historische Realität als kritische Prüfungsinstanz des Wahrheitsanspruchs. Wenn die historische Realität auch in den Hadith-Sammlungen oder der Geschichtsschreibung vorkam, so besa $ß$ sie keinen erkenntnistheoretischen Wert. Sie hatte einerseits eine pädagogisch-erzählerische Funktion zu erfüllen, andererseits sollte sie Bürgschaft für die Authentizität der Tradition ablegen. Der Bedarf der die Heilsgewißheit verwaltenden Orthodoxie an Methode wird dann sicherlich von ganz anderer Natur gewesen sein als der vom wissenschaftlich aufgeklärten Rahman, für den der ursprüngliche Sinn jeweiliger Offenbarung erst aus dem realhistorischen Kontext erschlossen werden muß. Die ausgefeilte, traditionelle Methodik entwickelte sich ja auch nicht zufällig in den Hadith-Wissenschaften, denen es darum ging, die Authentizität der Überlieferung zu prüfen. Der Geschichte der Offenbarung, ihrem zeitlichen Ablauf, ihrer Chronologie eignet in Bezug auf die Erschließung des Sinnes keine konstitutive Bedeutung. Rahman scheint sehr verwundert darüber zu sein:

„It is strange, however, that no systematic attempt has ever been made to understand the Qur'an in the order in which it was revealed, that is, by setting the specific cases of the shu'un al-nuzul, or ,occasions of revelation', in some order in the general background that is no other than the activity of the Prophet (the Sunna in the proper sense) and its social environment." (1982: 143; vgl. auch 1970: 329, Hervorhebung L.T.)

Selbst die İctihad-Praxis der Orthodoxie (Rechtsentwicklung), die bis zu der sogenannten Schließung des İçtihad-Tores ausgiebig in Ge- 
brauch genommen wurde, dürfte nicht mit der von Rahman intendierten Erneuerung dieser Institution identisch sein. Unter theoretischen Annahmen liegt nahe, daß sich Rahmans Auffassung des İctihad als Akt der Generalisierung, ausgehend von einem zugrundeliegenden Prinzip (vgl. Rahman 1982: 8), das im Zusammenspiel von moralischen Lehren und historischen Bedingungen herausgearbeitet werden soll, weitgehend von der İçtihad-Praxis der traditionellen Orthodoxie unterscheidet. Rahman wollte die modernen Institutionen (den legalen Apparat) mit islamischem Ethos füllen. Dies war von einer ganz anderer Qualität als die übliche Praxis der traditionellen Orthodoxie, die weitgehend darin bestand, die gegebene politische Herrschaft unter Beibehaltung eines (oft minimalen äußerlichen) Bekenntnis zum islamischen Gesetz zu segnen, ${ }^{66}$ was ohne große Probleme auch von den islamischen Modernisten im Groben übernommen werden konnte. Die Mobilisierung der inneren Ressourcen für das Gesetz, die Rahmans Rekonstruktion letztlich vorschwebt; dieser „protestantische“ Gestus (daraufhin arbeitet Rahman im übrigen) also konnte der Orthodoxie nur wesensfremd sein.

\subsection{Werte, Diesseitigkeit und die Gesellschaftstechnik}

Es gibt noch zwei Punkte, welche ebenfalls im Denken der Orthodoxie nicht anzutreffen waren, und erst aus dem Zusammenhang moderner Kulturinstrumente und des interkulturellen Kontakts heraus denkbar geworden sind.

„But the substantive or ,constitutive“ [...] teaching of the Prophet and the Qur'an is undoubtedly for action in this world, since it provides guidance for man concerning his behaviour on earth in relation to other men. God exists in the mind of the believer to regulate his behaviour if he is religiomorally experienced, but that which is to be regulated is the essence of the matter. The Bane of later medieval Islam [...] was that what was regulative, namely, God, was made the exclusive object of experience and thus, instead

66 Die bezüglich der sich verändernden Herrschaftsverhältnisse von der sunnitischen Orthodoxie vollbrachten Anpassungsleistungen, die gar bis zur Anerkennung der unmittelbaren Delegation der Herrschaft an die Sultane ohne die Zwischeninstanz des Kalifs gingen, sind im Kapitel I.1 bereits besprochen worden. Man erinnere sich auch an das eigentümliche „Lavieren“ der türkischen Diyanet bei der Bestimmung ihres Verhältnisses zum Laizismus, zu dem sie sich einerseits sorglos bekennt und den sie andererseits mit einer inhaltlichen Religionspolitik völlig aushöhlt, ohne die potentiellen theoretischen Spannungen auch nur im Ansatz anzugehen. 
of men's seeking values from this experience, the experience became the end in itself." (Rahman 1982: 14, Hervorhebung L.T.)

Zwei Aspekte, die sich in einem systematischen Zusammenhang miteinander befinden, müssen hier gesondert beleuchtet werden: (a) seeking values from this [God's] experience und (b) action in this world.

Der „Fluch“ des mittelalterlichen Islam bestand nach Rahmans Auffassung darin, in der Gotteserfahrung stehen geblieben zu sein, ohne von dieser her wieder auf eine objektive Ebene der Werte wechseln zu können. Der mittelalterliche Muslim kannte anscheinend keine Werte, das wirft ihm Rahman vor. Die Feststellung ist zutreffend, die Kritik hingegen nicht berechtigt. Denn man kann dem Muslim des Mittelalters nicht vorwerfen, etwas nicht besessen zu haben, das er gar nicht besitzen konnte. Genauso wie der mittelalterliche Christ besaß auch der Muslim in der vormodernen Zeit kein Weltbild. Er diente Gott um Gottes willen, d.h. „the experience became“ tatsächlich „the end in itself". Nicht er blickte Gott an, um von ihm aus seine Welt zu beherrschen, sondern Gott schaute ihn an, darum strebte er danach, in die Erfahrung Gottes zu gelangen. Daher kannte er auch keine Werte im abstrakten Sinne, die man hinter den konkreten Erfahrungen und Aussagen aufspüren und aus den unvollkommenen, weil zeit- und milieugebundenen „Hülsen“ herausfiltern könnte. Selbst die Unterscheidung zwischen dem (milieugebundenen) historischen und dem ursprünglichen Islam konnte ihrerseits erst im Rückblick einer nach dem Authentischen Ausschau haltenden Lektüre wirksam artikuliert werden. Rahmans wissenschaftliche Rekonstruktion des authentischen Islam, wie er im Koran angelegt sei, soll sich auf der Aufdeckung solcher grundlegenden Werte erheben, die dann auf die konkreten Fälle anzuwenden sind, um das islamische Gesetz unter den Bedingungen der Modernität neu auszuarbeiten.

Die Orientierung an den Grundwerten des Islam ist andererseits mit einer action in this world als Zweck der prophetischen und Koranischen Erziehung verbunden. Natürlich haben der religiöse Glauben und das von der Religion geleitete Handeln immer schon praktische Konsequenzen, und die religiösen Lehren präparieren die Gläubigen immer schon für ein zugerichtetes weltliches Handeln. Selbst die Weltflucht kann innerweltliche, praktische Folgen mit sich bringen. Wohl ist aber ein wesentlicher Unterschied, ob die systematische Gestaltung dieser Welt, action in this World, als Zweck des religiösen Handelns gedacht, der Diesseitigkeit untergeordnet und schließlich mit einer Funktion ausgestattet wird, oder ob das innerweltliche Handeln das religiöse Handeln bestimmt. Ich will hier nicht behaupten, daß sich bei Rahman die Verdiesseitigung der Religion vollends vollzogen hat. Es finden sich aber bei ihm mehrere Elemente, die einen 
solchen Weg vorbereiten. Am Ende diesen Weges droht der islamischen Religiosität die Gefahr, daß sie um die Dimension der Transzendenz beschnitten wird. Der Preis für das Unterfangen, durch den Einsatz wissenschaftlicher Methoden zurück zu den Grundprinzipien des Korans, des authentischen Islam, vorzustoßen, um dem religiösen Gesetz eine Positivität in der Gesellschaft zu verleihen, ist keineswegs gering. ${ }^{67}$

Rahman war sicherlich in seinem Rückgang zum wahren Islam, wie er im Koran offenbart worden sei, den es mit wissenschaftlichen Methoden herauszuarbeiten gelte, darauf bedacht, die ,unaufhebbaren Spannungen zwischen Individuum und Gesellschaft, Prophetentum und Reich Gottes (zu) erhalten“ (Stauth 1996: 35). Die verstärkte Verdiesseitigung des Islam, die ihn in eine komplexe Technologie der Gesellschaftskonstitution verwandelt, zielt damit hier noch darauf, eine islamische Modernität zu konzipieren. Die systematische Freilegung der islamischen Weltanschauung läßt den Islam noch nicht notwendigerweise als ein ideologisches Gebilde oder geschlossenes Gesellschaftssystem erscheinen. Aus der diesseitigen Wendung des Islam springt noch keine widerspruchsfreie, hier und jetzt erlöste Gesellschaft hervor; die Dimension der Transzendenz bleibt noch gewahrt, wird allerdings gleichzeitig abgeschwächt. Der Koran und die Urgemeinde sind noch nicht vollends für das Subjekt verfügbar gemacht worden. Dennoch wird der Weg dafür vorbereitet, dem Subjekt die Verfügungsgewalt für die Urvisionen zu übertragen. Gegen die „Idee der produktiven Wendung innerer Spannungen und der dynamischen Entwicklung des Verhältnisses zwischen modernem Selbst und der Staats- und Rechtsordnung", die noch Rahmans Unternehmen auszeichnete, führen die militanten Erneuerer, so Stauth, eine „Ummatismus-Utopie“ ein, welche die „Vision einer kollektiven islamischen Selbstversicherung - durch revolutionäre und konventionelle Vermittlungen der Tradition - errichten will“ (ebd.).

Dies findet besonders in den verschiedenen Varianten des Fundamentalismus statt. Maududi (1903-1979; ein Pakistanischer Muslim wie Rahman und Begründer der Jamat-i Islam) spricht vom Islam in aller Klarheit als System, ja er macht überdies keinen Hehl aus seiner Sympathie für die totalitären Systeme, mit denen er den Islam auf der

67 In einem anderen Zusammenhang hatte sich der türkische Mystiker Said-i Nursi aus ähnlichem Motive zu der Forderung nach Wiederaufnahme der Içtihad-Praxis skeptisch verhalten: „Derzeit sind Politik, das weltliche Leben und Philosophie sehr beliebt. Diese beeinträchtigen die (sihha) Gesundheit der İctihad. [...] Der Wunsch derjenigen nach İçtihad, die sich der Politik, dem weltlichen Leben und der Philosophie verschreiben, führt dazu, sich vom Islam loszusagen." (zit. n. Kara 1987: LXIV) 
gleichen Ebene positioniert. Vor allem faszinierten ihn die Mobilisierungsfähigkeit und der Totalitarismus, durch die sich der Kommunismus und Faschismus auszeichneten. Alles läßt sich, so der Leitgedanke von Maududi, aus einem Grundprinzip ableiten (1971; vgl. auch Adams 1983). Damit kommt der gesellschaftstechnische Zug, der sich in den islamischen Bewegungen des 19. und 20. Jahrhunderts ansatzweise andeutete, und beim Neo-Modernismus von Rahman eine systematische Reflexion mit den oben beschriebenen Einschränkungen erfuhr, vollends zum Wirken.

Im Kontext der Gesellschaftstechnik paart sich der „mythische Regreß“ mit ,utopischen“ Visionen, welche die ursprüngliche Umma für das Subjekt verfügbar machen. Bemerkenswerterweise kommt heute der utopistische Zug nicht mehr über die Modernisten in den Islam, sondern gerade durch diejenigen Islamisten, die eine radikale Alternative zur Moderne überhaupt (als Epistemologie, als Gesellschaftsmodell, als Kultur usw. usf.) anbieten wollen. Al-Azmeh hat den wesentlichen Unterschied zwischen den klassischen Visionen der Rückkehr einerseits, die oben durch einen historischen Rückgriff skizziert worden sind, und der islamistischen Transformation derselben andererseits prägnant herausgestellt:

„Die exemplarische Geschichte des Medinensischen Kalifats ist das wahre Goldene Zeitalter, dem man sich annähern sollte, soweit das in einer unvollkommenen Welt wie der unseren möglich ist; es ist ein Zustand, der wiederholbar nur unter bestimmten Bedingungen ist [...]. Hier handelt es sich demnach nicht um eine ausgemacht totalitäre Utopie, sondern um eine Utopie, die sich in Begriffen des Hier und Jetzt artikuliert: Ein Anderswo, einige vorbildliche Fälle, aus denen man für das Hier und Jetzt Gesetzesbestimmungen gewinnen kann - eine moralisch, didaktische Utopie, die für das Rechtswesen von praktischem Nutzen ist, die sich aber nicht im vollen Umfang wiederholen läßt und deshalb auch mit keinem politischen Engagement verknüpft ist.“ (Al-Azmeh: 1996: 74)

Nach Al-Azmeh enthält der islamische Ursprungsmythos eine eschatologische Dimension, die im fundamentalistischen Projekt zugunsten einer diesseitigen Befreiungsideologie aufgegeben wird. Die Erlösung, die Vollkommenheit, ist im Mythos nicht von dieser Welt. ${ }^{68}$ Wie Al-

68 Martin Riesebrodt hingegen, ja nahezu in einer exakten Umkehrung der Position von Al-Azmeh, ordnet den ,mythischen Regreß“ dem Fundamentalismus zu. Dessen gesetzesethische Orientierung wird dann dem „utopischen Regreß“ sozialreformerischer, gesinnungsethisch orientierter Revitalisierungsbewegungen gegenüber gestellt (1990: 20f). Der Gegenstand der vorliegenden Arbeit, nämlich der islamistische Diskurs vom „Vertrag von Medina“, weist insofern utopische Züge auf, als die Rückkehr zur Urgemeinde mit einem Gesellschaftsentwurf verbunden 
Azmeh sagt, wurde die Zeit der Offenbarung demnach als ein Wunder verstanden. Sie galt nicht als Ergebnis einer politischen Handlung, das man nach Belieben wiederholen könnte, wenn man nur die entsprechenden Bedingungen dafür schuf. Die islamistische Variante der Urvisionen, der Rückkehr zu der idealen Gemeinde, verwandelt hingegen die „,didaktische Utopie“ von $A s r-1$ Saadet in eine ,politische Utopie““ ${ }^{69}$ Das Streben, die Grundrisse des Gesellschaftssystems auszuarbeiten, welches durch das politische Handeln errichtet werden soll, wird nunmehr das religiöse Denken von mehreren Generationen islamistischer Intellektuelle beschäftigen. Diese sollen hier nicht nachgezeichnet werden. Als ein besonders radikales Exemplar dafür sei hier Ali Schari'atis Vorstellung von der Ideal Society/the Umma wiedergegeben.

„The Ideal society of Islam is called the umma. [...] The infrastructure of the umma is the economy because, Whoever has no worldly life has no spiritual life'. Its social system is based on equity and justice and ownership by the people, on the revival of the system of Abel, the society of human equality and thus also of brotherhood - the classless society. This is a fundamental principle, but it is not the aim, as in Western socialism, which has retained the world-view of the Western bourgeoisie. The political philoso-

wird. Genau dieser Entwurfcharakter macht das Wesen der Utopien aus (zum Zusammenhang von Entwurf und Utopie vgl. Marramao 1989).

69 Seitenblicke zur christlichen Eschatologie können hier, zunächst einmal in einer assoziativen Hinsicht, wohl hilfreich sein. Jacob Taubes berichtet von revolutionären Ideen aus dem Christentum, die „Theologie der Geschichte mit einer Utopie der Gesellschaft" verbinden und später in die politische Praxis umgesetzt werden: „Die Apostelbrüder verlassen den Weg der mönchischen Propaganda und schreiten zur bewaffneten Empörung.“ (1947: 103) Er zeichnet eine Entwicklung nach, an deren Ende die christliche Eschatologie in einen revolutionären Utopismus umschlägt; eine Entwicklung also, die durchaus Parallele zu unserer Rekapitulierung klassischer sunnitischer Eschatologie aufweist man sollte sie natürlich mit systematischer Absicht weiter reflektieren. Hier möchte ich mich mit zwei Auszügen bescheiden: „Denn das Werk des wiederkehrenden Christus ist es, die Welt, deren Wesen bereits vergeht, endgültig zu beseitigen, und der Gläubige [im Frühchristentum, L.T.] soll dem eschatologischen Vollzug nicht eigenmächtig vorgreifen und nicht von sich aus die alten Ordnungen aufheben, in denen er sich bei seinem Eintritt in die Gemeinde Christi vorfindet." (S. 67f) „,[...] Denn die Sprache der revolutionären Eschatologie wendet einen Ton der Beweisführung an, der dem vorrevolutionären Menschentum fremd ist. [...] Zu Ende geführt wird die joachimitische Geschichtstheologie durch die Theologie der Revolution Thomas Münzers. Denn Münzer und die Täufer wollen das Reich Gottes, die ecclesia spiritualis auf Erden verwirklichen." (S. 85) 
phy and the form of regime of the umma is not the democracy of heads, not irresponsible and directionless liberalism which is a plaything of contesting social forces, not putrid aristocracy, not anti-popular dictatorship, not a selfimposing oligarchy. It consists rather of ,purity of leadership ' not the leader, for that would be fascism), committed and revolutionary leadership, responsible for the movement and growth of society on the basis of its world-view and ideology, and for the realisation of the divine destiny of man in the plan of creation. This is the true meaning of imamat!" (1979: 119)

Die heroische Phase islamistischer Revolutionäre der Türkei, für die Schari'ati, trotz (und linke Konvertiten gerade wegen) seines Marxismus, ohne Zweifel eine wichtige Figur gewesen sein dürfte, ist in der Türkei inzwischen abgeebbt. Der Dschihad für die ideale Gesellschaft wird neuerdings mit anderen Mitteln und Ideen fortgeführt. Nunmehr soll das „ursprüngliche“ Modell mittels des „Vertrags von Medina“ in die Tat umgesetzt werden. Davon handeln die folgenden Kapitel.

\section{Der Diskurs und sein zeitgeschichtlicher Kontext}

Der Diskurs zum Vertrag von Medina (fortan auch als VM abgekürzt) ist zum ersten Mal Mitte der 1990er Jahre in Umlauf gekommen. Sogleich entbrannte eine über die Grenzen der verfestigten politischen Lager hinaus greifende Debatte um das Konzept. Das Dokument hingegen, welches der islamische Prophet kurz nach seiner Ankunft in Medina zwischen verfeindeten Stämmen der Stadt initiiert hat, war in den historischen Quellen des Islam festgehalten, so daß man davon ausgehen kann, daß es der Nachwelt nicht unbekannt sein dürfte. So haben die renommierten Orientalisten Sprenger (1865), Wellhausen (1889) und Watt (1968) ihre Informationen zum VM aus der Sira des Ibn-Hisam und der Hadith-Sammlung von al-Buhari, den einschlägigen historischen Quellen, bezogen. Bisher unbekannt ist indessen irgendeine wirkungsgeschichtlich bedeutsame Bezugnahme aus der Geschichte des klassischen Islam auf das Dokument. Angesichts der reichhaltigen schriftlichen Quellen, welche die islamische Historiographie hervorgebracht hat, darf man nicht annehmen, daß es eine geschichtswirksame Wiederaufnahme der Vereinbarung des islamischen Propheten gegeben hätte, die jedoch aus welchem Grunde auch immer vor der Nachwelt verborgen geblieben wäre. Plausibel erscheint demgegenüber die Annahme, daß sich für das Ausbleiben einer politischen Berufung auf das Dokument systematische Gründe ausmachen lassen, die in das Wesen des (vormodernen islamischen) politischen Raumes führen. Das erste systematische Interesse widmeten denn auch bedeutsamerweise die Orientalisten dem Dokument. Selbst die Neo-Osma- 
nen, die türkischen Vertreter des islamischen Modernismus im 19. Jh., hatten keinerlei Bezug auf die Urkunde genommen, obwohl sie für ihren islamisch imprägnierten Konstitutionalismus einen solchen authentischen Beleg, ein Urmodell vertraglicher Regelung der politischen Herrschaft, hätten gebrauchen können. Außerdem war das Problem des Zusammenlebens unterschiedlicher Glaubensgemeinschaften im Osmanischen Reich des ausgehenden 19. Jh., anders als in der Türkei des ausgehenden 20. Jh., ein eminent praktisches Problem, weil die nichtmuslimischen Teile des Reiches immer mehr der Politik anhingen, sich von der osmanischen Herrschaft loszusagen. Aufschlußreich ist, daß die Leitfigur des Neo-Osmanismus, Namık Kemal, in seiner „Großen Geschichte des Islam“ auf das Verhältnis zwischen den Muslimen und Juden relativ ausführlich eingeht (1975 [das Original aus dem Ende des 19. Jh., o. J.]: 39-53), aber den Vertrag von Medina lediglich beiläufig erwähnt: „Dabei bestand eine Nachbarschaftsvereinbarung zwischen ihnen [Muslimen und Juden, L.T.].“ (a.a.O.: 47). Der zeithistorische Kontext begünstigte wohl eine Rekonstruktion des Dokuments nicht sonderlich. Was die Neo-Osmanen bewog, bestand nicht darin, das Zusammenleben der unterschiedlichen Religionsgemeinschaften auf der Basis einer inneren Autonomie aufzubauen, was ohnehin bis dahin der Fall war. Es kam jetzt eindeutig darauf an, von der nach Religionsgemeinschaften aufgebauten sozialen Organisation zu einer auf allgemeiner Ebene errichteten Gemeinsamkeit zu gelangen. Die neue, gemeinsame Identität könnte also nur entstehen, indem die partikularen Identitäten durch eine allgemeinere transzendiert würden. Um so plausibler erscheint daher die hier zu diskutierende Annahme, welche besagt, daß erst das Zusammentreffen bestimmter historischer Bedingungen das medinensische Modell als ein alternatives Gesellschaftsprojekt auftauchen ließ. Im folgenden handelt es sich um die Frage danach, welche Bedingungen zum Auftauchen des Diskurses über den VM geführt haben. Welche Bedingungen trafen in der Türkei der 90er Jahre zusammen, die in die Palette der Konzeptualisierungsweisen des Islam eine neue Variante hinzufügte, die je nach der Perspektive mit den bekannten Spielarten der bisherigen Tradition brach und gleichzeitig diese in einer neuen Form fortsetzte? Es handelt sich also um den geschichtlichen Kontext des Diskurses über den VM, den es als solchen in der vorherigen Geschichte des Islam, selbst in der späteren, bereits im Zeichen der Begegnung mit der westlichen Moderne stehenden Phase, nie gegeben hat. Es kommen zwei Gruppen von Transformationen in Frage, die auch die Trägerschaft des religiösen Diskurses gravierenden Wandlungen ausgesetzt haben: 1) Verschiebungen in der Trägerschaft des Islamismus; 2) Verschiebungen im diskursiven Feld. 


\section{1 Verschiebungen in der Trägerschaft des Islamismus}

Die Türkei durchlebte in den 80er Jahren eine zweite Welle von Binnenmigration, die, an der Dramatik ihrer Folgen bemessen, der ersten großen Welle (50er Jahre) in nichts nachsteht. Die zweite Landflucht unterschied sich von der ersten, zunächst den weltgeschichtlichen Kontext beiseite gelassen, vor allem darin, daß nunmehr ganze anatolische Städte in die Metropolen wanderten und dabei die gemeinschaftlich orientierten landsmannschaftlichen Strukturen unter den neuen Umweltbedingungen reaktiviert wurden. „Provinzialisierung der Städte“ (so z.B. Bora 1996) ist ein geläufiges Stichwort, mit dem diesem Prozeß in der türkischen Debatte Rechnung getragen wird. Die wissenschaftliche Debatte über den Islamismus schenkt dabei nicht nur der Situation neuer Immigranten in den Metropolen, von denen der heutige Islamismus getragen wird, Beachtung. Darüber hinaus handelt es sich auch um den umfassenden Prozeß, daß sich die Provinz mit einem ungemein rasanten Tempo der Weltwirtschaft öffnet. Sozialwissenschaftler wenden sich immer mehr den vielfältigen $\mathrm{Fa}$ cetten dieser ökonomischen und sozialen Umwälzungen zu.

Das ,islamische“, oder „Grünkapital“ ist ein weiteres Stichwort zur Umschreibung dieses Umstandes, das u.a. auch von den Militärs zwecks Bekämpfung des Islamismus mit in die politische Öffentlichkeit eingebracht wurde. ${ }^{70}$ Das „Grünkapital“ verweist auf die neu entstehende Unternehmerschicht, die, in Anspielung auf die fernöstlichen „Tigerstaaten“, einen Teil der sogenannten ,anatolischen Löwen“ enthält und mittlerweile in MÜSIAD (Müstakil İşadamları Derneği; zu dt.: Verband der unabhängigen Unternehmer) ihre organisatorische Form gefunden hat. Das „Grüne“ bzw. das „Islamische“ daran bezieht sich zunächst einmal auf die Träger des Kapitals, die man nach Kemal Can in ,a) Konservativ-religiöse Unternehmer, b) Unternehmer der Ordensgemeinden, c) Konzerne, Beteiligungen“" (Can 1997: 62) unterteilen kann. Kennzeichnend für die Unternehmer ist, daß sie die bis dahin vom wirtschaftlichen Kreislauf ferngehaltenen Privatersparnisse mittels entsprechender religiöser Segnung (wie z.B. der sogenannten, vermeintlich religiös reinen Gewinnbeteiligung anstatt islamisch verpönter Zinsen) in den ökonomischen Kreislauf einführen.

Das „Grüne“ drückt neben der Strategie der Kapitalakkumulation auch die Erschließung neuerer Absatzmärkte aus, auf denen die haupt-

70 Der von den Militärs zur Bekämpfung der Irtica (religiöser Fanatismus) errichtete „Arbeitskreis West“ hatte eine Liste von Unternehmen zusammengestellt, die im Verdacht standen, islamistische Politik zu unterstützen. Zum „islamischen Kapital“ vgl. vor allem Faik Bulut (1995), woraus auch die „Arbeitsgruppe West“ vermutlich ihre Informationen bezogen hat. 
sächlich aus religiösem Bedenken bis dahin untätigen Kunden nunmehr bedient werden können. Hier hat sich mittlerweile eine eigenständige, einen religiösen Lebensstil betonende islamische Mode mit Produkten zur Körperbedeckung (Parfüm, Badehosen etc.) entwickelt (vgl. Kıvanç 1997; zu ihren Auswirkungen auf die aufstrebenden muslimischen Frauen in Deutschland vgl. Nökel 2002). Die für die Verbreitung einer sich über Mode vermittelnden islamischen Identität unerläßliche Infrastruktur wird von den gezielt die islamische Kundschaft ansprechenden Medienkonzernen zur Verfügung gestellt.

Die vielfältigen Verwicklungen von Wirtschaft und Religion müssen Gegenstand einer eigenständigen Untersuchung sein, was hier nicht geleistet werden kann. Unser Interesse an ihnen rührt primär aus der pragmatischen Überlegung, daß man anhand dieser Prozesse plausibel darlegen kann, inwiefern sich der aktuelle Islamismus von seinen Vorläufern absetzt, die hauptsächlich den Charakter einer politischen Ideologie aufwiesen, die sich durch imperiale Visionen auszeichnete (Çiğdem 1996: 1231). Der sich zeitgeschichtlich vor allem im Zuge der iranischen Revolution entwickelnde Islamismus hingegen erscheint als „symbolischer Ausdruck“ der umfassenden sozialen Umwälzungen ,einer sich modernisierenden muslimischen Gesellschaft“ (Seufert 1997), in der sich neben den alten säkularen Eliten eine neue, über den religiösen Diskurs kommunizierende Mittelschicht herausbildet. Die Mitglieder dieser Schicht machen den etablierten Gruppen die Nutzung des öffentlichen Raums streitig und heben darauf ab, den Islam als öffentliche Norm durchzusetzen. Den meist staatlich sanktionierten Disziplinartechniken werden hier Selbsttechniken entgegengesetzt, mit denen die Individuen ihre Körper nach strikten, oft theoretisch unterlegten Vorstellungen purifizieren und die alternative Gesellschaft bereits an sich selbst, sodann in spezifischen Milieus und schließlich auf der Makroebene verwirklichen wollen. Dieser auf individuelle Subjekte bezogene Aspekt der Selbsttechniken, so wichtig er auch ist, muß allerdings im weiteren Verlauf der Argumentation ausgespart bleiben. Er bedarf eigenständiger Studien (vgl. z. B. Nökel 1999; Werner 1999). Ich werde mich hier ausschließlich mit dem intellektuellen Diskurs befassen, der den systematischen Rahmen für derartige Subjektkonstitution bereitstellt, an dem sich die besagten Selbstpraktiken orientieren und mittels derer sie sich über die individuelle Ebene hinaus in den Zusammenhang einer größeren Gemeinschaft fügen. 


\subsection{Verschiebungen im globalen Feld}

Um den Wandel in der Trägerschaft des Islamismus zu verstehen, darf man sich jedoch nicht alleine auf die oben beschriebenen Prozesse beschränken. Erforderlich ist, den Blick über den engen, türkeispezifischen Kontext hinaus auf die diskursiven Ereignisse auszuweiten, die den weltgeschichtlichen Kontext in den letzten Jahrzehnten bestimmt haben. Ohne diesen breiteren Kontext wäre der türkische Kontext mit seinen über die oben beschriebenen sozialen Prozesse hinausgehenden Komponenten nicht zu verstehen. Auch wenn es auf dem Hintergrund der Migrationprozesse, die neue soziale Gruppen auf den ökonomischen und politischen Markt geworfen haben, plausibel scheint anzunehmen, daß der diesen sozialen Gruppen seit jeher vertraute Islam vorrangig als das Symbolsystem der Kommunikation und sozialen Organisation in der neuen Umwelt in Frage kommt, würde eine solche Perspektive letztlich doch zu kurz greifen. Sie kann nämlich die Verschiebungen im diskursiven Feld nicht zur Kenntnis nehmen und läuft damit Gefahr, die Bedeutung des infolge der Globalisierungsprozesse intensivierten kulturübergreifenden Austausches nicht hinreichend erfassen zu können. Ungeklärt bleibt nämlich in diesem Fall die Frage, warum der Islam in den 60er und 70er Jahren nicht den Weg für einen Islamismus als symbolischen Ausdruck einer sozialen Bewegung vorbereiten konnte, wie dies hingegen in der durch die iranische Revolution eingeleiteten Epoche ohne Zweifel der Fall sein konnte. Genauso wie die Sunna des Propheten, die Medinensische Zeit seiner Prophetie, den Muslimen in ihrer langen Geschichte sehr wohl bekannt war, ohne daß zuvor darauf ein Gesellschaftsmodell zurück projiziert wurde.

Diese Überlegungen lassen die Richtung der Analyse auf das kulturwirksame Ereignis der letzten Jahrzehnte lenken, das man bekanntlich mit dem allgemeinen Begriff der „Postmoderne“ umschreibt. Der Begriff selbst ist mehrdeutig. Ist damit ein Geisteszustand oder eine gesellschaftliche „Realität“ gemeint; geht es um einen Bruch mit der Moderne oder ihre Radikalisierung etc.? Für Zygmunt Bauman ist bspw. die Postmoderne „eine treffende Veranschaulichung der Merkmale, welche die gesellschaftlichen Verhältnisse definieren, die im Verlauf des zwanzigsten Jahrhunderts überall in den reichen Ländern Europas und europäischer Herkunft aufgetreten sind und ihre gegenwärtige Gestalt in der zweiten Hälfte dieses Jahrhunderts angenommen haben“ (1995: 221). Und zu der Frage, in welchem Verhältnis die Postmoderne zur Moderne stehe, antwortet Bauman: „Man kann die Postmoderne als eine Moderne vorstellen, die sich ihrer wirklichen Natur bewußt ist - Moderne für sich.“ (Ebd.) „Die auffallendsten Merkmale des postmodernen Zustandes - institutionalisierter Plura- 
lismus, Vielfalt, Kontingenz und Ambivalenz -“, fährt Bauman mit seiner Umschreibung fort, ,sind alle in ständig steigendem Ausmaß von der modernen Gesellschaft produziert worden; in einer Zeit, in der die Institutionen der Moderne, von der modernen Mentalität vertrauensvoll reproduziert, für Universalität, Homogenität, Monotonie und Klarheit kämpften, sah man in ihnen jedoch Zeichen des Scheiterns, nicht des Erfolges, Beweise für die Unvollständigkeit der jeweiligen Anstrengungen“"(a.a.O.: 222).

Man könnte sicherlich weitere Vorschläge vorstellen, die angeboten wurden, um die Erscheinungen der Postmoderne zu bestimmen. Die dominierenden Themen der Postmoderne, nämlich Pluralität (d.h. Differenz), Ambivalenz, Kontingenz, sind hiermit aber bereits angesprochen. Entscheidend dabei ist nun die Wirkungsgeschichte der Postmoderne, bezogen auf ihre wirkungsgeschichtliche Verortung innerhalb des türkisch-islamischen Kontextes. Dabei kann man zunächst einmal völlig von der sicherlich durchaus relevanten Frage absehen, ob sich beim islamistischen Diskurs eine explizite, und wenn ja, was für eine Bezugnahme auf die Postmoderne feststellen läßt. Es genügt für den momentanen Stand der Argumentationslogik zu zeigen, wie das Brüchigwerden des laizistisch orientierten hegemonialen Modernisierungsdiskurses auf die postmoderne Kritik an den Meta-Erzählungen der Moderne zurückzubeziehen ist, und wie bestimmte Merkmale der Postmoderne (allerdings bedeutsamerweise nicht jedes beliebige) den islamistischen Diskurs mit konstituieren. ${ }^{71}$

71 Eine solche Analyse hat sich indessen der Verzeichnungen (oder Übersetzungen) der westlichen Modernitätskritik im islamistischen Diskurs bewußt zu bleiben und darf nicht jede Bezugnahme auf sie oder die Ähnlichkeiten mit ihr unkritisch als sachgerecht annehmen. In einem Aufsatz mit dem Titel „Das Wahrheitsregime der Verbrecher“ veranschaulicht Sadik J. Al-Azm (1996) unter vier Punkten, wie Islamisten Argumente aus der westlichen Diskussion zu Felde führen: ,a) Der Islam ist ein selbstgenügsames Diskursuniversum [...]; b) Das Diskursuniversum des Islam erlaubt keinen Vergleichsmaßstab mit einem anderen Diskursuniversum. Es ist inkommensurabel im Sinne von Thomas Kuhn und Michel Foucault [...]; c) Der Islam braucht einen klaren

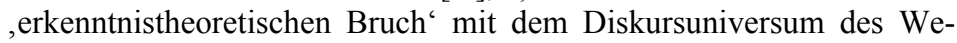
stens, um seiner Authentizität gerecht zu werden [...]; d) Der Islam verkündet außerdem den Tod des Menschen als universelle Kategorie zugunsten eines Vorrangs des muslimischen im Unterschied zum westlichen, im Unterschied zum orientalischen Menschentum usf." Dennoch setzt sich Al-Azim nicht mit Verzeichnungen dieser Konzepte auseinander, wobei sie in seiner Darstellung geradezu von selbst ins Auge stechen. So läßt sich bspw. Kuhn unmöglich in ein islamistisches Unternehmen einspannen, zielt doch sein Konzept vom Paradigmenwechsel unmißverständlich darauf, jegliche Grundlage für den ontolo- 
Meta-Erzählungen interessieren hier folglich nur in der türkischen Umsetzung ihrer zwei Hauptthemen: der Fortschrittsglaube, betrachtet im Bedeutungsgewebe von Universalität, Säkularität, wissenschaftlicher Objektivität etc. zum einen und nationalstaatliche Organisation, d.h. durch den Universalismus ausgelöste Produktion nationaler Identitäten zum anderen. Der türkische Name für dieses sich auf beiden Aspekten erhebenden Zivilisationsprojektes lautet Kemalismus. Will man den türkischen Islamismus verstehen, so muß man ihn innerhalb des diskursiven Feldes betrachten, das sich genau aus dem Spannungsverhältnis zwischen Kemalismus und Islamismus heraus konstituiert. $^{72}$

Der Diskurs der Verwestlichung hatte sich als die hegemoniale Sprechweise mit der Etablierung der laizistischen Republik vollends durchgesetzt. Die Etablierung der türkischen Verwestlichungsbewegung vollzog sich neben anderen Gründen dank zweier Versprechen: Die Verwestlichung bot den Eliten des auseinanderfallenden Osmanischen Reichs die Nation als einen neuen Integrationsmodus an, der zudem durch bittere Erfahrungen unterstützt zu werden schien, wie

gischen Wahrheitsanspruch für eine bestimmte wissenschaftliche Richtung, Ideologie, Glauben usw. zu zerstören. Ebenso wenig ist mit Foucault, der das Subjekt im Kontext von Macht- und Wissenkonfigurationen dezentriert, ein islamisches Subjekt zu konstruieren, welches den westlichen Meta-Erzählungen, verwandt zu ihrem Geist, lediglich den Islam als die alternative Meta-Erzählung gegenüberstellt. Womöglich ist der Islam der Islamisten die letzte Meta-Erzählung unserer Zeit. Erst recht ist mit Foucault keine Theorie der Authentizität zu entwickeln, die sich der Wiederbelebung eines Ursprungs verschreibt, wollte doch er gerade einen Abschied vom Ursprungsdenken herbeiführen. Deshalb ist an dieser Stelle eine Lesehilfe für den weiteren Gebrauch des Begriffs „Postmoderne“ vonnöten. Oft wird er hier als „postmodern geläutert" gebraucht. Damit wird erstens auf den durch die postmoderne Kritik ermöglichten Denkraum, in dem erst der Islamismus seine Alternativen entfalten konnte, zweitens auf die thematischen Einflüsse der postmodernen Diskurse und drittens auf ihren instrumentellen Gebrauch durch die Islamisten hingewiesen. So wie wir den Islamismus nicht einfach als eine moderne Bewegung bestimmen wollen, so soll er auch mit ihrer Modernitätskritik nicht umgekehrt in eine postmoderne Bewegung getauft werden. Es handelt sich also für uns folglich um die (modernen wie postmodernen) Spuren, die sich dem islamistischen Diskurs anlagern.

72 Bobby Sayyid (1994) mißt dem innertürkischen Antagonismus eine universelle Reichweite zu, indem er alle politischen Kräfte und Bewegungen der islamischen Welt den paradigmatischen Namen von Kemal Atatürk und Khomeini zuordnet, die als zwei Pole einer zivilisatorischen Alternative gegenüber gestellt werden. 
z.B. die, daß sich die arabischen Glaubensbrüder gar nicht um die Eintracht der Muslime (Umma) scherten, sondern voll im Zeichen der Zeit stehend ihre nationale Unabhängigkeit anstrebten. Dieses erste Versprechen war in seinem Wesen gleichzeitig mit dem zweiten verknüpft: Durch die Ausrichtung gesellschaftlicher Beziehungen und politischer Institutionen an westlichen Modellen sollte nicht nur der Niedergang des Staates gestoppt werden, sondern versprach man sich auch von der Fortschrittsutopie einen Sprung auf den Zivilisationszug. $^{73}$ In dieser geschichtlichen Situation hat sich eine „Äquivalenzkette" (Laclau/Mouffe 1991: 183ff.) gebildet, die den politischen Diskurs der Republik Türkei, durchaus mit folgenreichen Brüchen (vgl. die Ära der Demokratischen Partei 1950-1960 und die Regierungszeit von Özal in den 80er Jahren), bis zu dem Zeitpunkt konkurrenzlos beherrschte, da der Islamismus in seiner heutigen Form die politische Bühne betrat und die Kette vielerorts aufbrechen ließ. Die besagte Äquivalenzkette bestand aus einer Reihe von Formulierungen, die den politischen Raum mit einem scharfen Antagonismus in zwei entgegengesetzte Lager teilten: Westliche Lebensweise (z.B. Bekleidung) = Republik $=$ Laizismus $=$ wissenschaftlicher Fortschritt $=$ ökonomischer Wohlstand = nationale Eintracht (Frieden im Lande) = außenpolitische Sicherheit durch die Zugehörigkeit zur westlichen Welt (Frieden in der Welt) auf der einen Seite; rückwärtsgewandte Lebensweise (Turban, Verschleierung) $=$ Kalifat bzw. Sultanat $=$ Theokratie bzw. religiöser Fanatismus $=$ Wissenschaftsfeindlichkeit $=$ ökonomische Rückständigkeit $=$ fehlendes Nationalbewußtsein (Illusion der Umma) $=$ Revanchismus (Gefährdung der nationalen Sicherheit). Diese Kette von Äquivalenzen, die durch den laizistischen Diskurs hergestellt wurde, korrespondierte teilweise mit bestimmten Berufsständen: Die neue Elite, vornehmlich in Berufen wie Arzt, Offizier, Ingenieur, Lehrer als Vertreter des angestrebten Anschlusses an die moderne Zeit, stand den anderen gegenüber, für welche die Gruppe

73 In der inzwischen modischen Kritik an Kemalismus bzw. Laizität wird die seinsgeschickliche Dimension der Verwestlichung überhaupt nicht wahrgenommen. Statt dessen wird diese als ein voluntaristisches Projekt einer kleinen, den eigenen kulturellen Wurzeln entfremdeten Elite disqualifiziert. Indem die Verwestlichung nicht als „Geschick“ (im Heideggerschen Sinne), nämlich als das, was sich uns zuschickt, uns bedrängt, also als etwas, was auch die türkische Gesellschaft überkommt, verstanden wird, behandelt man das Thema vornehmlich in einem Pro-und-Contra-Modus. Dann kann es nur noch die Konsequenz geben, daß man ein „voluntaristisches“ Projekt in der gleichen voluntaristischen Manier durch ein anderes, z.B. islamistisches ersetzen will (vgl. dazu Tezcan 1997). 
von Hodscha (Geistlicher), Scheich und Aga (Feudalherr) als Inbegriff des ancien regime einstand.

Eine solche diskursive Aufteilung gesellschaftlicher Kräfte im türkischen politischen Raum schöpfte ihre Hegemonie vor allem aus der Selbstverständlichkeit der in der europäischen Aufklärung entstandenen und über die Vormachtstellung westlicher Staaten auch institutionell verbreiteten Idee des Fortschritts. Die Stabilität und Überzeugungskraft eines auf dem Streben nach Anschluß an die fortschreitende Menschheitsgeschichte basierenden Diskurses wird jedoch erheblich aufgerüttelt, wenn die Ideen, auf die er sich stützt, in ihrem Ursprungsrot mit Mißtrauen gar bis hin zur Ablehnung behandelt werden. Wenn also die westliche Zivilisation nicht die höchste Etappe eines weltgeschichtlichen Verlaufs markiert; wenn sie in ihrem Wesen ein hegemoniales Projekt gewesen sein soll, das sich erst durch das Ausschließen des Anderen konstituiert hat; wenn die moderne Wissenschaft nicht eine kulturunabhängige Objektivität betreibt, sondern ja selbst dieser Schein der kulturunabhängigen Objektivität das hegemoniale Wesen der westlichen Wissenschaft ausmacht; wenn die Moderne mitsamt ihren Institutionen respektive Nationalstaat in eine innere Verstrickung mit Totalitarismus gebracht wird, dann wird man erwarten dürfen, daß die soziale Wirkung der in der nichtwestlichen Welt funktionierenden, hegemonialen Äquivalenzkette ebenfalls unvermeidlich in Frage gestellt wird. Diese genealogische „Nachbarschaft" zwischen der postmodern condition und dem aktuellen islamistischen Diskurs wurde übrigens von einigen türkischen Sozialwissenschaftlern aufmerksam beobachtet (vgl. Gülalp 1999: 24).

Ohne die diskursiven Verschiebungen in den Zentren der ,Weltgesellschaft", die deren geistigen Kräfteverhältnisse grundlegend durcheinander wirbelten, wäre es vermutlich nie aus einer wie auch immer gearteten ,inneren“ Dynamik sozialer Prozesse in der Türkei zur Herausbildung von ,,counter-elites “ (Göle 1997: 56) gekommen, die sich in einem islamistischen Diskurs artikulieren, dessen Sprache, Referenz und Themen im erheblichen Maße mit dem als postmodern bezeichneten Phänomen korrespondieren (vgl. auch Çınar/Kadığlu 1999). Freilich sind „both the leaders and the followers of Islamist movements in Egypt, Iran, Pakistan, and Turkey [...] among the recently urbanised and educated" (Göle a.a.O.: 53; vgl. auch Çiğdem 1996: 1226f). Daß die entwurzelten Schichten ihre Identität jetzt in der Sprache des Islamismus konstruieren und nicht in einer, sagen wir, sozialistischen, wie dies bspw. in den 70er Jahren für breite Teile der Slumbevölkerung noch der Fall war, wo heute die islamistischen Gruppen vorherrschen, läßt sich ohne die Berücksichtigung der sich weltweit ereignenden paradigmatischen Veränderungen nicht deuten. 
Überhaupt scheint der Postmodernismus als eine kulturelle Strömung in der außereuropäischen intelligentsia sehr beliebt zu sein. So lesen wir z.B. bei dem in Cambridge lehrenden pakistanischen muslimischen Anthropologen Akbar S. Ahmed (1995: 43) ein Plädoyer für eine wohlwollende Perzeption der Postmoderne. Für Ahmed stehen als die ,positiven Seiten des Postmodernismus“ die „Vielfalt, Forschungsfreiheit, Abschaffung etablierter Ordnungsstrukturen und die Chance, sich gegenseitig anzuerkennen und zu verstehen" (ebd.).

Um die Bedingungen, unter denen der Diskurs von MV auftauchen konnte, genauer zu studieren, soll die Wirkung global zirkulierender Diskurse auf den spezifischen Boden des türkischen politischen Raums bezogen werden. Unten wird das diskursive Feld, in das auch die Islamisten mit ihrem alternativen Gesellschaftsmodell einzuordnen sind, in Bezug auf seine grundlegenden Konfliktlinien nachgezeichnet.

\subsection{Die Konfliktlinien}

Die Türkei stand in den 80er Jahren vor gravierenden Umwälzungen, von denen oben nur ein Aspekt (die Migration und die darauf folgenden Veränderungen im religiösen Milieu) dargestellt wurde. Tatsächlich zeugt diese Zeitspanne (bis in die heutige Zeit) von zentrifugalen Kräften, welche die Gesellschaft vor eine Zerreißprobe stellen. Dabei bestimmen nicht nur die zu den Geburtswehen der Republik gehörenden politischen Konflikte zwischen Islamisten und Laizisten und zwischen Türken und Kurden diese Phase von Verwerfungen. Die uralten konfessionellen Spannungen zwischen Aleviten und Sunniten rücken ebenfalls in das Zentrum des politischen Geschehens; nunmehr mit dem Unterschied, daß die Aleviten ihre jahrhundertslang erprobte Außenseiterposition aufgeben, um sich am Zentrum zu beteiligen (vgl. Kapitel I.4.4). Auf dem diskursiven Feld, das sich um diese Konfliktlinien herum konstituiert, tauchen verschiedene Diskurse auf, die untereinander um die überzeugendsten Antworten auf die Krise konkurrieren. In dieser äußerst angespannten geschichtlichen Situation tritt immer stärker die Frage nach dem friedlichen Zusammenleben in den Vordergrund. Die Kritik an der Staatsraison (einschließlich der Verwaltung der Religion), zu der auch die Kritik an der verwalteten Religion gehört, bildet den Knotenpunkt, an dem sich verschiedene Diskurse treffen.

Ein Teil der sozialistischen, postmodern beeinflußten Linken trug durch seinen Demokratisierungsdiskurs, in dem vor allem die staatliche Kurdenpolitik ins Visier genommen wurde, zum Wachsen der öffentlichen Aufmerksamkeit für die Diskussion um die Zivilgesell- 
schaft bei. Die Meta-Erzählung der nationalen Identität habe dabei die Differenzen, das Recht des Anderen auf eigene Identität, konstitutiv ausgeschlossen. Die umfassende Kritik der kemalistischen Grundlagen der Republik trifft über die Anklage gegen die nationalstaatliche Assimilationspolitik hinaus den offiziellen Laizismus. Man will sich der aufgezwungenen Dichotomie von Laizismus vs. Islamismus nicht beugen (vgl. İnsel 1996 und 1998). Es wird in der Opposition zur Staatsraison ein möglicher, islamisch artikulierter Beitrag zur Zivilgesellschaft, zur Demokratisierung, nicht nur nicht mehr ausgeschlossen, sondern auch darauf hin gearbeitet. So hat Ahmet Insel (1992) wohlwollend (und kritisch zugleich) auf das politische Angebot von Bulaç reagiert, der als erster den Vertrag von Medina in die öffentliche Debatte einbrachte. Einmalig in der türkischen politischen Geschichte öffneten sich die linksorientierte Birikim und das Organ der islamistischen Intellektuellen Bilgi ve Hikmet für Autoren von der anderen Seite.

Einen anderen Impuls gab die Politik der Zweiten Republik, getragen von einer Reihe liberaler (vorrangig) Journalisten, die den vom inzwischen verstorbenen türkischen Minister- und späteren Staatspräsidenten Özal eröffneten Weg zu einer wirtschaftlich und regionalpolitisch aufstrebenden Türkei betraten (für einen Überblick vgl. Sever/Dizdar 1993). Özal hatte in seiner Amtszeit die Tradition der Demokratischen Partei (Regierungszeit 1950-1960), die Religion in die politische Sprache zu integrieren, wieder aufgegriffen. Dabei hatte er nicht nur die islamistische Dichotomie „Westen vs. Islam“ zurückgewiesen, sondern auch die oben beschriebene hegemoniale Äquivalenzkette aufgebrochen. So konnte man durchaus, und dieses Image hat er in der Öffentlichkeit durchgesetzt, fromm - westorientiert wirtschaftsliberal sein. In die neue Kette reihte er dann auch den Anschluß an die alt-osmanischen imperialen Visionen ein, indem er während des zweiten Golfkrieges, auf die Unterstützung der USA setzend, Machtansprüche im Nahen Osten öffentlich äußerte und dabei mit einem Einmarsch in den mehrheitlich von Turkmenen besetzten Teil des Irak liebäugelte. Die Vertreter der Zweiten Republik folgten hiermit dem von Özal vollzogenen Tabubruch, der vornehmlich darin bestand, an die osmanische Tradition, damit an die vorlaizistische Zeit, wieder anzuknüpfen. Nicht zufällig werden einige unter ihnen als Neo-Osmanisten bezeichnet. Nicht zu vergessen ist auch Özals unverkrampfte Haltung gegenüber der Kurdenfrage, welche zusammen mit den anderen Elementen, nämlich Demokratisierung, staatlich verordnetem Laizismus und islamischer Tradition der türkischen Gesellschaft als Moment eines Diskurses mit artikuliert wurde.

In dieser politischen Atmosphäre, die durch den Veränderungswillen gekennzeichnet war, kam es dazu, daß der Islam zum ersten 
Mal - jenseits der herkömmlichen Beschwörung moralischer Tugenden und einer nicht genau ausformulierten Forderung nach der Wiedererrichtung der Scharia - als Name eines alternativen Gesellschaftsprojektes in Umlauf gebracht wurde. Auch hier bildeten die Kritik an der homogenen, nationalen Identität (konkret bezogen auf die Kurdenfrage), die Kritik am staatlich verordneten Laizismus und die Rede von der Zivilgesellschaft die Bestandteile des Diskurses. Der Diskurs über den VM erzeugte anschließend eine Anziehungskraft, die über die intellektuellen Kreise hinaus bis auf das Parteiprogramm und die Reihen der Refah-Partei übergriff und gar die Anregung zu islamischen „Kommunen“ wie dem Akevler-Projekt gab.

Im Fokus der Studie steht nicht die Frage, inwiefern ein solches Projekt tatsächlich praktikabel ist. Die Relevanz des Diskurses besteht in dem Einfluß, der auf die politische Kultur der Türkei ausstrahlt und somit sowohl die ideellen Grundlagen für ganze Generationen junger muslimischer Intellektuellen abgibt als auch in das Programm politischer Parteien Eingang findet.

Der gemeinsame Kern der oben umschriebenen drei diskursiven Stränge (die sozialistische Linke, die Zweite Republik und der Vertrag von Medina) läßt sich am Ideologem der „Anerkennung des Anderen“ bestimmen. Der Diskurs über den VM konstituiert sich somit als eine islamistische Antwort auf die Anerkennungsfrage. Er reagiert allerdings dabei nicht bloß auf eine jenseits aller politischen Kämpfe vorgängig bestehende Anerkennungsproblematik, sondern erhebt sie zugleich performativ zu einer zentralen Ordnungsproblematik. Es ist, auf einer allgemeinen theoretischen Ebene gesprochen, dieser performative Charakter des Diskurses, welcher ihn jenseits des Basis-ÜberbauSchemas als soziale Praxis erscheinen läßt.

\section{Aspekte der islamistischen Modernitätskritik}

Will man vom Islam heute sprechen, dann muß man, so die implizite Leitidee des vorliegenden Buches, unentwegt von anderen Dingen sprechen. In Bezug auf den intellektuellen Islam als eine junge Spielart des Islamismus bedeutet dies, die globalen Diskussionen in Betracht zu ziehen, die immer stärker zum Bestandteil der lokalen Kulturproduktion werden. Kritik der Fortschrittsidee, Vernunftkritik, Multikulturalismus, Anerkennung der kulturellen Differenz, Anerkennung der Identität u.ä. sind dabei die Stichworte einer kulturwirksamen globalen Diskussion. Das Vorhaben eines alternativen, islamischen Gesellschaftsprojekts, konkretisiert am „Vertrag von Medina“, konnte nur dem Streben einer neuen, sich islamisch definierenden intellektuellen Schicht entspringen, die mit den global operierenden 
Diskursen westlicher Provienz mindestens genauso gut vertraut sind wie mit dem klassischen Kulturbestand des Islam. Die Existenz und Rezeption solcher Diskurse werden im folgenden an entsprechenden Stellen dargestellt.

Die intellektuelle Dominanz dieser Themen kann man andererseits von der praktischen Brisanz ethnischer und religiöser Konflikte nicht isolieren. Der türkische Islamismus reflektiert diesen Umstand und nimmt die politischen Probleme unserer Zeit in ihre Ideologieproduktion auf. Der Ideengeber, ja wenn man so sagen darf: der Konstrukteur des Diskurses über den VM, Ali Bulaç, formuliert die Kontextbedingungen des eigenen Diskurses folgendermaßen:

„Folglich bleiben in diesem Zusammenhang zwei Fragen unbeantwortet: Wie kann man eine Lösung für die ethnischen und religiösen Konflikte finden, die im Kontext des Nationalstaats stattfinden und voraussichtlich verstärkt anhalten werden? Wie werden die Minderheiten in kulturellen und sozialen Bereichen ihre Identitäten ausleben, mit welchen konkreten und praktischen Mechanismen werden die Demokratien die ,Minderheitenfrage“ überwinden?“(1994a: 5)

Es handelt sich dabei nicht bloß um eine religiös motivierte Einmischung in die öffentliche Debatte, die es als solche in der türkischen Politik seit den 50er Jahren schon immer gegeben hat. Was der intellektuelle Islam auf eine eigentümliche Weise intendiert, drückt sich in dem Willen aus, die Antworten des Islam auf die globale Krise zu entwickeln. Rahmans action in this World war noch vorsichtig formuliert und er warnte davor, den Islam zum Mittel verkommen zu lassen, das die Welt vor den Fehlleistungen des Westens retten soll (vgl. Kapitel II.2). Der Islamismus von Bulaç will hingegen unerschrocken und uneingeschränkt eine zivilisatorische Alternative ausarbeiten, die sich an der Frage orientiert, wie die Moderne selbst überwunden werden kann. $^{74}$

74 Es gibt unter den Islamisten wenige, die sich mit aller Konsequenz weigern, den Islam als alternative Zivilisation zu verstehen. Ismet Özel ist der erste, der grundsätzlichen Widerspruch gegen die Idee einer islamischen Zivilisation angemeldet hat. Zwei Bedenken führt Özel an. Der erste Bedenken besagt, daß die Höhepunkte der islamischen Zivilisation (Abbasiden, Andalusier, Osmanen) in dem Maße vom Islam abgewichen seien, als sie sich zivilisiert hätten. Zweitens würde die Sorge um den Islam den menschlichen Konzepten und dem Ideal, eine islamische Zivilisation zu gründen, unterworfen (1998: 140ff). „Denkt man den Islam als Zivilisation, versteht man den islamischen Kampf als einen um Zivilisation und Kultur, so reduziert man ihn auf eine geschichtliche Kategorie, sperrt man ihn in den Rahmen der Geschichte ein.“" (a.a.O.: 123). Nicht den ,selbst auch noch so alternativen, An- 
„In dieser Zeit, da in Politik, Verwaltung, gesellschaftlicher Organisation, unterschiedliche Identitäten und in der Frage nach einem Zusammenleben nach neuen Bestimmungen gesucht wird, sind die Muslime gehalten, sich an diesem Prozeß zu beteiligen. Dies aus zwei Gründen: Zum ersten ist der Islam ein Gesamtpaket, das sich von Glauben bis Recht, von der inneren Welt bis hin zu den sozialen Handlungen des Individuums erstreckt. Zweitens befinden sich die Muslime wie alle anderen inmitten der im universellen Umfang präsenten Probleme. In diesem Zusammenhang haben die Muslime unmißverständlich darzutun, warum sie an der Organisationsform des modernen Staates Kritik üben, anhand welcher Kriterien, mittels welcher Projekte sie diese entpersönlichte, totalitäre Brutalität [Gewaltherrschaft] überwinden wollen.“ (Bulaç 1994a: 9, Hervorhebung L.T.)

Der Islam als „Gesamtpaket“ kann aber dann in Frage kommen, wenn der Westen bzw. die Moderne als ein geschlossener Komplex konzipiert wird. Daher wird das Zentrum des heutigen islamistischen Theoriegebäudes vollauf mit den Elementen einer durchaus bemühten Analyse der Moderne bestückt. Die Betonung eines epistemologischen Bruches, Entwicklung islamischer Wissenschaften, Herausarbeitung islamischer Werte und Prinzipien der Gesellschaftsordnung sind Effekte des westlichen Denkens und setzen gleichzeitig ein analytisches Wissen von ihm voraus.

Das analytische Interesse der Muslime an der westlichen Moderne ist an sich ein neues Phänomen. In der klassischen Periode des Islam (d.h. bis zur Begegnung mit dem modernen Westen im 18. Jh.) kann man bspw. kein Interesse am „Westen“ auffinden, der ja auch für die Muslime als solcher nicht existierte. Lewis berichtet, daß die Muslime die Welt lange Zeit nach geographischen Kriterien einteilten, wobei die Einteilung in „Zonen“, wenn eine religiöse Identifikation nötig war, damit noch unterlegt wurde, ob in der jeweiligen „Zone“ der Is-

schluß an die Geschichte soll der Muslim anstreben. Der Muslim soll sich, so formuliert Özel seine kompromißlose Position, an Gottes Befehlen orientieren (ebd.). Sofern mit Zivilisation eine Vermittlung in die Beziehung zu Gott eingeführt wird, womit die von Menschen geschaffenen Institutionen deren Leben lenken, sollen die Muslime nach Ansicht von Özel davon Abstand nehmen (a.a.O.: 142). Aus diesem Grunde war es konsequent, daß Özel sich von der Debatte um den Vertrag von Medina ferngehalten hat. Von dem gleichen Bedenken läßt sich auch Çelik leiten (1994b), wobei er damit quasi seinen positiven Beitrag zur Konstruktion des VM (1994a) ein Stück weit korrigiert, oder zumindest relativiert haben dürfte. Bulaçs eigenes Bekunden gegen die Idee einer alternativen Zivilisation (1994a: 9) ist hingegen, ähnlich wie teilweise bei Çelik, angesichts des von ihm betriebenen Unternehmens eines alternativen Gesellschaftsmodells irrelevant. 
lam herrschte oder nicht (1995: 645f). Das Wort Europa hält nach Lewis recht spät, etwa im 19. Jh., Einzug in den Sprachgebrauch der Muslime (abgesehen von den frühen arabischen Werken) (a.a.O.: 647). Auch das Interesse der Muslime im allgemeinen und später des klassischen Islamismus im besonderen an der Genese und der Funktionsweise der modernen Gesellschaft, modernen Philosophie und Wissenschaften zeichnete sich weniger durch den analytischen Zug als vielmehr durch einen selektiven Umgang aus. ${ }^{75}$,(N)ur der Westen hat das Interesse an anderen Kulturen entwickelt, nur der Westen zeigt die Neigung, andere Sprachen zu lernen, andere Lebenswelten zu studieren und ihre Leistungen zu achten" (a.a.O.: 650)" hatte Bernard Lewis einmal konstatiert, ohne jedoch eine Erklärung dafür anzugeben.

Ähnliches läßt von Grunebaum für die aktuelle Phase gelten, in der die muslimischen Gesellschaften bereits auf einen reichhaltigen Erfahrungsschatz in Bezug auf die westliche Moderne zurückblicken können:

„Das Interesse am Westen, als Bemühung um historisch-analytisches Verständnis seines Kulturwillens und in diesem Sinne Selbstzweck, ist in der arabischen Welt nur gelinde zu verspüren. Eine östliche ,Okzidentalistik ${ }^{\text {‘ }}$ ist als Gegenstück zur westlichen Orientalistik nicht ins Leben getreten. Was fesselt, ist nicht das Studium der Fremdkultur, sondern die Selbstkonstruktion, die Selbstmanipulation im Lichte des westlichen Phänomens, das man, sei es durch teilweise Einbeziehung, sei es durch zielbewußten Rückgriff auf die Vergangenheit, bewältigen muß.“ (1969: 255)

Das mangelnde analytische Interesse an den fremden Kulturen trifft sich bedeutsamerweise mit dem Modus der Selbstschau zusammen, welche die Muslime ihrer eigenen Kultur gegenüber pflegten. Auch hier geht es in der klassischen (ebenso weitgehend modern-islamistischen) Geschichtsschreibung nicht darum, die Vergangenheit und die gegenwärtige eigene Kulturwelt mit begrifflichem Instrumentarium zu durchdringen, um sie zu beherrschen. Vielmehr orientiert man sich an der Weitergabe der Lehre, Taten, Erfolge usw. und der Anpassung an die Zeit (vgl. Grunebaum a.a.O.: 154). ${ }^{76}$

75 Die Frage nach dem analytischen Interesse an den fremden Kulturen (d.h. auch an der eigenen Kultur) in der islamischen Kulturwelt ist zu bedeutsam, als daß man dies im Rahmen der vorliegenden Arbeit leisten könnte. Auch wenn sie den Kern der hier entwickelten Überlegungen betrifft, ist eine eigenständige Untersuchung hierzu vonnöten. Unser Beitrag zur Thematik kann hier daher nur darin bestehen, das empirische Material dafür zu liefern und zudem Reflexionen für eine solche spezifische Analyse in vorbereitender Absicht anzustellen.

76 „Die große Geschichte des Islam“ (1975), die von einem türkischen Vorläufer des islamischen Modernismus, Namik Kemal, (Ende des 19. 
Inwiefern sind diese durchaus auch auf gründlichen Kenntnissen der islamischen Kultur beruhenden Überlegungen im Hinblick auf den Intellektuellenislam zutreffend? Kann man angesichts des unten darzulegenden empirischen Materials von einer vollständigen Umkehrung des ,ethnologischen“ Blicks auf den Westen, von einem den von Edward Said initiierten, umgedrehten Orientalismus vertiefenden Interesse als eine Forschungsrichtung sprechen? Ein Blick auf die unten nach und nach darzustellenden Themen der islamistischen Intellektuellen veranlaßt den Leser zunächst einmal zu der These, daß das Interesse jedenfalls unübersehbar festzustellen ist. Wie hätte es denn auch angesichts der Tatsache anders sein können, daß die besagten Islamisten allesamt ihre akademische Sozialisation in säkularen Schulen genossen und ihre Ideen unter den Bedingungen des sich intensivierenden globalen Kulturaustausches entwickelt haben (vgl. Göle 1997: 54; Meeker 1997: 261-266), welcher auch die Muslime immer mehr in den Prozeß wechselseitiger Beobachtungen hineinsaugt. Die auf Innerlichkeit beruhenden, ,subtilen, reversiven Formen der Fremderkenntnis" als Folge der Verbreitung der „Universalkultur“ (Stauth 1993: 10) bestimmen auch die Funktionsweise des islamistischen Diskurses.

„Unter Universalkultur verstehe ich dagegen eine zunehmende Verallgemeinerung kultureller Ziele und institutioneller Macht, sie zu verfolgen. Dabei wird unterstellt, daß das Ziel der Verallgemeinerung von Kulturzielen und der sie tragenden institutionellen Macht selbst erst aus dem subjektiven Kontext der Selbsterfahrung im Kontakt mit anderen Kulturen geboren wird. Universalkultur wird in der Intensivierung des Interkulturkontakts geschaffen." (Stauth 1993: 13)

An einer anderen Stelle geht Stauth ausführlicher auf die Funktionsweise des interkulturellen Kontaktes ein und macht dabei auch auf die Folgen der Universalisierung der Kulturziele aufmerksam:

„Es ist die perzipierte Vision ,Europas‘, die das Eigenverständnis der islamischen Welt tiefer geprägt hat als das eigene historische Gedächtnis oder deutlicher: Es ist das von Europa appropriierte Geschichtsbild, das alle Rekonstruktionen der eigenen Geschichte prägt (Laroui). Die appropriierte

Jh.) verfaßt worden ist, steht weitgehend im Zeichen der klassischen islamischen Geschichtsschreibung, in der die Ereignisse und die Herrschaftsfolge chronologisch Revue passieren. Eine analytische Perspektive wird auf die historischen Ereignisse nicht gerichtet. Die Funktion dieser genealogischen Geschichtsschreibung ist völlig anders als die der modernen Historie und wesentlich, wie das mittelalterliche Geschichterzählen, an die Repräsentation der Souveränität gebunden (zur genealogischen Historie als „Ritual der Macht“ vgl. Foucault 1986). 
Geschichte wirkt technisierend und instrumentalisierend zurück. Entsprechend sind ,Orientalismus' (Said) und ,Eurozentrismus' (Amin) universelle Effekte der kulturellen Deprivation. Wenn europäische Identitätspolitik erst die Kolonisierung der nichteuropäischen Welt möglich machte, so mündete die provozierte Forderung nach kultureller Anerkennung der Kolonisierten in einen radikalisierten Zwang zur Selbstbehauptung. Sie trieb die Nichteuropäer nicht nur zur Nachahmung, sondern auch in den Sog eines komplementären Wechselspiels: ,Europa' heißt auch, die Suche nach einer ,eigenen', einer verlorengegangenen, ,großen' Vergangenheit politisch und kulturtechnisch zu radikalisieren. Symbole und Inhalte der ,eigenen' Kulturwerden so dauerhaft mit ,fremden' Mitteln rekonstruiert. [...] So trägt der moderne Kampf um letzte Werte auch dazu bei, den bildlichen und normativen Zivilisationsbestand zu totalisieren, selektiv einzuholen, zu erneuern und zu befestigen. Im Rückbezug auf letztendliche Werte werden neue , Rationalitäten' als Orientierungspunkte für politische, wirtschaftliche und gesellschaftliche Entwicklungen gesetzt. Dies ist ein Effekt Europas. Nichtwestliche Kultur macht ihn sich zu eigen.“ (Stauth 1995: 95f)

Eingedenk einer derart subtil ablaufenden und radikal durchgreifenden Einbindung der islamistischen Rekonstruktion in die Struktur der modernen Suche nach dem authentischen Ursprung lassen sich die Erklärungen der Islamwissenschaft (vgl. oben die Passagen von Lewis und von Grunebaums) nicht mehr umstandlos auf den heutigen Islamismus anwenden.

Der gemeinsame Nenner, unter dem man die Anzeichen eines historisch-analytischen Interesses der Islamisten an der westlichen Moderne subsumieren kann, ist eine dem eigenen Anspruch nach radikale Modernitätskritik, die erst aus dem Strudel des Wechselspiels der Beobachtung hervorgeht. Unsere These lautet daher: Eine solche, dem Anspruch nach komplette Modernitätskritik, die an der Genese der westlichen Moderne ansetzen und sich mit ihren philosophischen und sozialen Voraussetzungen befassen will, erfolgt nicht völlig jenseits der Mechanismen des Kulturaustausches, sie ist bereits in ihrer Anlage in die Denkweisen derselben Moderne (vor allem respektive der die Moderne von Anbeginn begleitenden westlichen Modernitätskritik) verwickelt. Die Diskussion dieser These bedarf zuvor Klärung der Frage, wie die westliche Moderne in einem an der Konstitution der Gesellschaft orientierten islamistischen Diskurs überhaupt rekonstruiert wird?

\subsection{Die Moderne als „totale Krise“}

Wir finden zuallererst einen im westlichen Denken, ja allgemein in den westlichen Selbstbeschreibungsweisen weithin bekannten Gedanken wieder: Die Moderne als Bruch mit der Natur, Bruch mit der 
kosmologischen Ordnung. Im westlichen Denken wird die Idee des Bruches nicht selten mit der Einführung der Geschichtlichkeit in die menschliche Geschichte verknüpft. Die Affirmation der Geschichtlichkeit, die zugleich mit der Idee der Freiheit verbunden wird, wird nun in der islamistischen Perzeption fallengelassen. Was noch übrigbleibt, kann nun als Verfallsgeschichte in die klassische Sprache des Islam, mitunter von eschatologischen Konnotationen durchsetzt, übersetzt werden. Die Moderne ist demnach ein Wegfall aus dem von den Religionen immer schon gehüteten Schreiten der Menschheit zu Gott.

Aus der Sicht der Protaganisten des VM wäre es allerdings zu kurz gegriffen, wenn man die Krise in einem bestimmten Bereich, z.B. in der Politik oder in der Ökonomie etc., verorten würde.

„Viele Menschen wollen nicht einmal akzeptieren, daß das wichtigste Problem in der Epoche der neuen Krise, in die wir hinein getreten sind, auf der universellen Ebene entsteht und die genannte Krise nicht primär in der Wirtschaft, sondern in Recht und Moral, welche den epistemologischen Bruch begleiten, erlebt wird. Wenn wir unseren Blick neben der Epistemologie und Moral auch auf die Unbestimmtheit, Gleichgültigkeit und sogar zuweilen bis an Frechheit reichende, bohemische Unbekümmertheit im juristischen Bereich lenken, werden wir sehen, daß die Wurzeln der Krise einzig und allein mit einem ganz neuen religiösen Blick können erfaßt werden. Wohl ist es klar, der Tod der Kunst, der Philosophie und Theologie, den wir nicht mehr bloß schwer verstehen, sondern nicht einmal mehr einfach wahrnehmen können, ist ein tragischer Zustand, der mit dem Schwund der Religion aus unserem Bewußtsein viel zu tun hat." (Bulaç 1994b: 5)

Im Ursprung des Verfalls liege „die Abkoppelung des Seins von der göttlichen Ordnung", die durch den Säkularismus vollzogen worden sei. Die praktischen Folgen, welche sich von dem Konsumismus über den politischen Totalitarismus bis hin zur Vernichtung der Natur führten, könnten allerdings nicht mit den Mitteln der modernen Wissenschaft aufgefangen werden, da diese selber die Katastrophe mit verursacht habe (Bulaç 1992a: 19). Die moderne Wissenschaft reduziere, so weiter, das aus der göttlichen Ordnung herausgerissene Sein auf einen Gegenstand, den man im analytischen Weg meßbar machen könne. (a.a.O.: 20). Der Rationalismus, der die moderne (entwurzelte) Vorstellung von der Wirklichkeit beherrscht, schneide immaterielle und göttliche Dimension des Seins ab; die mechanische Sicht des Universums töte die Idee vom lebendigen System ab; die wissenschaftliche Methode ,ermöglicht nun letztlich, die Natur aggressiv und erbarmungslos zu zerstören und in ihr sensibles Gleichgewicht einzugreifen. (a.a.O. 21)

Die reichhaltige Applikation dieser Kritik auf die einzelnen Gegenstandsbereiche trifft sich mit verschiedenen Versionen der westli- 
chen Modernitätskritik, in ihren fundierten (vgl. auch die in der Einleitung des vorliegenden Buches vorgestellten Gedanken von Heidegger) wie auch populären Versionen. Wichtig ist dabei, daß die bisherige, und weiterhin dominante, nach dem Überholen der westlichen ökonomischen und militärischen Macht strebende Variante des Islamismus selbst als eine islamische Spielart des Modernismus disqualifiziert wird. Wenn die Moderne ein technologischer, politischer, wissenschaftlicher und ökonomischer Komplex ist, dann muß man ihn in allen Bereichen konsequent überwinden.

Der philosophische Kern einer solchen Modernitätsanalyse liegt vor allem darin, einen epistemologischen Bruch mit der Moderne vorzubereiten. Dadurch soll die aus den göttlichen Fugen geratene Ordnung wieder in die richtige Bahn gelenk werden. Die altislamische Idee von der Sünde als Verwirrung, als Abgehen vom rechten Pfad, taucht hier unverkennbar wieder auf, indessen eingehüllt in eine wissenschaftliche Sprache, die wesentliche Modifikationen an der Struktur der alten Idee herbeiführen wird.

\subsection{Kritik an der Fortschrittszeit}

Ein wesentlicher Aspekt der westlichen Moderne, an der die islamistische Kritik ansetzt, ist die Idee von Fortschritt, welche wesentlich an eine bestimmte Zeiterfahrung gekoppelt ist. ${ }^{77}$ Die im Ursprung der westlichen Moderne verwurzelte Idee von Fortschritt, ${ }^{78}$ die Vorstellung von der Geschichte als aufwärts fortschreitendem Verlauf, wurde

77 Zum Zusammenhang zwischen Zeiterfahrung und Weltdeutung schreibt Marramao: „Jede Kultur beginnt stets zusammen mit einer bestimmten Zeiterfahrung, und jede kulturelle Veränderung schließt deshalb zwangsweise eine grundlegende Veränderung der Zeiterfahrung ein, die den Rahmen der Werte und damit auch der Politik entscheidend prägt.“ (1989: 13)

78 Die islamistische Kritik an der Moderne hängt allerdings den geistigen und sozialen Entwicklungen in der westlichen Moderne hinterher. Nicht nur im philosophischen Diskurs hat die Idee des Fortschritts ihrer Beliebtheit ziemlich eingebüßt. Auch in soziologischer Hinsicht wird heute nicht mehr von der linearen Zeit des Fortschritts gesprochen (vgl. dazu Marramao 1989, Kapitel V). Die viel rezipierten Theorien heutiger Zeit wie die Systemtheorie oder die poststrukturalistisch beeinflußte Sozialtheorie haben den Begriff des Fortschritts längst aufgegeben. Man merkt, daß der türkische Islamismus zwar die Moderne als solche meint, um eine universelle Antwort auf eine universelle Krise vorzulegen, aber sich dabei vorrangig an der ungebrochenen Fortschrittsmoderne der türkischen Laizisten orientiert. 
in ihrer islamischen Rezeptionsgeschichte entweder, wie in der klassischen Version des Islamismus, instrumentell und selektiv beansprucht (Bejahung des technischen Fortschritts) oder gänzlich bejaht, gar theologisch eingeflochten (wie im islamischen Modernismus von Iqbal). Die dem Fortschritt innewohnende Zeitlichkeit sollte aber erst im postmodern ermutigten Islamismus ,systematisch“ betrachtet, explizit problematisiert und in einen Zusammenhang mit der politischen und sozialen Ausgestaltung moderner Gesellschaften gebracht werden.

Zumindest ein Grundzug der klassischen Moderne wird von den Islamisten treffend beobachtet. Die Erschließung gesellschaftlicher Bereiche (gar der Gesellschaft als Objekt) für systematische Bearbeitung durch das aktivistische Subjekt - in der islamistischen Sprache schlicht mit Totalitarismus identisch - ist ohne den Zusammenhang der Umstellung der Zeitökonomie auf eine säkulare Teleologie nicht $\mathrm{zu}$ verstehen. Was in den großen Utopien der Moderne zur Sprache kam, war eben die ursprünglich religiöse Verheißung von Erlösung, die ihre Wurzeln durchaus in der christlichen linearen Zeit auf einen Endpunkt hin fand und in der säkularen Wendung in eine erlöste Gesellschaft im Diesseits umschlug. Die prominenteste Version davon ist sicherlich die kommunistische Gesellschaft des Marxismus. Es ist diese Idee vom „Paradies auf Erden“, welche die Islamisten ins Zentrum ihrer Perzeption der Moderne rücken. Sie verdanke ihre Entstehung auf den durch die wissenschaftliche Sichtweise verursachten Verlust der Transzendenz, so die islamistische Kritik, wodurch die Zeit ihre Öffnung ins Jenseits verliere und den Menschen auf der Erde einkerkere.

„Jede Lebensweise, die sich nicht auf das Göttliche und Heilige beruft, kann man als eine ,Utopie', eine ,konstruierte, in sich geschlossene Welt ${ }^{`}$ bestimmen, die den Menschen ins Verderbnis stürzt. [...] Folglich konstruierte sich die Moderne, indem sie ihrer neuen Wahrheitsdefinition die Erde zugrunde legte, eine ,geschlossene Welt' (Utopie). Es setzt dann im christlichen Bewußtsein ein Wandlungsprozeß vom Glauben ins Wissen ein.“ (Arslan 1994: 15f)

Bei den Ausführungen über das Weltbild wurde auf die Heideggersche Idee hingewiesen, daß ,das Christentum seine Christlichkeit zu einer Weltanschauung (der christlichen Weltanschauung) um(deutet)“ und „sich so neuzeitgemäß (macht)“ (vgl. Einleitungskapitel). Der Grundzug dieser Denkfigur kommt in dem oben zitierten Passus deutlich zum Ausdruck. Der sich in der Wissensordnung vollziehende Bruch, durch den die Weltdeutung nunmehr in Gestalt der Weltanschauungen 
stattfinde, wird von den Islamisten zutreffend bemerkt. ${ }^{79}$ Die Kritik an der weltimmanenten Zeitlichkeit, die nicht auf eine jenseitige Öffnung verweist, gehört daher auch zum Grundbestand jedes islamistischen Intellektuellen. Hier kommen die Einflüsse der sicherlich fundierteren westlichen Modernitätsanalyse unverkennbar zur Geltung. Man könnte etliche explizite wie auch implizite Verweise, Verwandtschaften dokumentieren, ganz zu schweigen von den zeitgenössischen Autoren wie Lyotard, Feyerabend, Giddens etc. ${ }^{80}$

So radikal nun die islamistische Kritik an den Wurzeln des modernen Denkens und der modernen Gesellschaftlichkeit anmuten mag,

79 Das Schwerpunktthema von Bilgi ve Hikmet Heft 6/1994 handelt von „Zukunftsentwurf der Religionen“. In den meisten Beiträgen dort wie aber auch in anderen Heften wird der religiöse Zukunftsentwurf, der sich nicht diesseitig erschöpfe, dem modernen, weltanschaulichen $\mathrm{Zu}$ kunftsentwurf gegenübergestellt.

80 Eine rein inhaltsanalytische, ja schon quantitative Studie könnte helfen, die geistigen Quellen der Islamisten aufzudecken. Hier möge ein Beispiel genügen. In einem anderen, mit Peygamber Ümmetinden Ulus'un Devletine (zu dt.: Von der Umma des Propheten zum Staat der Nation) betitelten Text von Arslan (1993), von dem oben die Rede war, sind 55 Fußnoten enthalten. Unter anderem kommen dort als Zeugen für die vom Autor vertretenen Thesen Antony Giddens und David Held je 8 mal vor. Sie werden gefolgt von $J . K$. Galbraith mit 7 maliger, $R$. $D$. Sack und E. Shils mit 4maliger, Balibar/Wallerstein mit 3maliger Würdigung. Es wird lediglich zwei muslimischen Autoren (I. R. Faruqi und Hayrettin Karaman) die Ehre zuteil, in den Zitationsapparat aufgenommen zu werden. Der Text wird, nachdem die analytische Aufgabe erledigt, nämlich die Natur des Nationalstaates geklärt worden ist, schließlich mit drei Koransuren abgeschlossen. Der letzte Punkt, also die Anführung der Koransuren, ist eigentlich ein Thema für sich, dem man eigens nachgehen sollte. Eine wichtige Frage, die man zu klären hätte, wäre dabei die, welchen Status die Koransuren unter den zur Prüfung stehenden, im Prinzip widerlegbaren Thesen von den zitierten $\mathrm{Au}-$ toren in einem analytischen Text haben. Werden die Koransuren hier nicht auf reine Beweisstücke reduziert? Sie werden in einen Wissensdiskurs eingeführt, der auf der prinzipiellen Kritisierbarkeit der Aussagen basiert, obwohl die Suren ihre Macht nicht aus der kritischen Überprüfbarkeit beziehen können. Im klassischen Diskurs, welcher der Realität als Prüfungsinstanz der Wahrheit von Aussagen keinen epistemologischen Status zubilligte, durften die angeführten Koransuren und Hadithe (Überlieferungen vom Propheten) als unumstößliche Wahrheiten lediglich kommentiert werden. Die Urteile hatten sich dann an deren Kompatibilität mit ihnen zu messen. Dies führte in der Wissensordnung des klassischen Diskurses jedoch nicht zu Problemen, da der Diskurs sich ausschließlich innerislamisch abspielte und nicht an eine allgemeine Öffentlichkeit richtete. 
man darf sich nicht allzu leicht täuschen lassen. Was auf der Signifikatsebene hier in kritischer Manier vorgetragen wird, muß auf der Signifikantenebene noch lange nicht zwangsläufig genauso funktionieren. Könnte es denn nicht sein, daß entgegen dieser Kritik an der auf der Basis der Weltanschauungen funktionierenden Fortschrittszeit, die dem Ziel der modernen Utopien, eine ideale Gesellschaft zu erschaffen, innewohnt, das utopistische Denken gerade in dem Vorhaben, eine islamische Gesellschaftsalternative aufzustellen, unterschwellig auch den islamistischen Diskurs trägt? Inwiefern sind denn die islamistischen Intellektuellen mit ihrem ,alternativen Gesellschaftsmodell“ wirklich gefeit vor den Strukturen des „Weltbilddenkens“ ?

Diese Frage sollte nicht aus den Augen geraten, sie muß die hier angestellten Reflexionen begleiten und an den entsprechenden Stellen immer wieder aufgenommen werden. Die hier betriebene Dekonstruktion der islamistischen Rekonstruktion der Moderne hat an dieser Stelle noch einen weiteren wichtigen Punkt zu beleuchten. Das Setting dieses Kapitels wurde mit der These eröffnet, daß sich der Diskurs des Intellektuellenislam um die Anerkennungsfrage konstituiert. Man wird die Kontexteingebundenheit des Diskurses über den VM und seine Funktionsweise erst dann erfassen können, wenn die islamistische Modernitätskritik auf dessen wesentliches Moment, nämlich auf die Anerkennungsproblematik bzw. die Frage nach dem Zusammenleben unterschiedlicher Gruppen hin gelesen wird. Nirgends sonst kann man die Übernahme der Kulturinstrumente und ihre Verknüpfung mit islamischen Urvisionen, aber auch die kulturspezifische Übersetzung, so überzeugend veranschaulichen wie am Beispiel der Anerkennungsthematik.

\subsection{Modus der Anerkennung des Anderen: Benennen oder Definieren?}

$\mathrm{Da}$ in einer islamischen Sprache von dem Anderen gesprochen wird; daß also der Umgang mit dem Anderen zum Gegenstand theoretischer Reflexionen gemacht wird, ist, bezogen auf die islamische Geschichte, eigentlich recht befremdlich. Auch die ordnungspolitische Umsetzung dieser Frage, nämlich worin das „Formel eines friedlichen Zusammenlebens" bestehe, dürfte den gleichen Befremdungseffekt nur noch verstärken. Das bedeutet nicht, ich wollte dabei etwa der Annahme frönen, daß die vormoderne islamische Gesellschaft auf der Assimilation der Differenzen gründete. Ganz im Gegenteil, sie basierte auf der relativen „Autonomie“ der Gemeinschaften in der Regulierung interner Angelegenheiten, was jedoch auf der anderen Seite ausschließlich durch die Herrschaftsbeziehungen zwischen den substantialistisch vor- 
geschriebenen sozialen Einheiten geregelt wurde. So hat sich denn auch im islamischen Denken eine reichhaltige Literatur zur Stellung der Minderheiten, vor allem der „Zımmis“ (Schutzbefohlenen, Anhänger der monotheistischen Religionen) entwickelt.

Allerdings stellte sich die Frage nach Anerkennung als Anspruch nicht, oder zumindest nicht in dieser Radikalität und nicht mit derselben Konsequenz für Identitäten. „In den Gesellschaften früherer Zeiten“, schreibt der Sozialphilosoph Charles Taylor (1997: 21) „war das, was wir heute Identität nennen, weitgehend durch die gesellschaftliche Stellung des Einzelnen festgelegt". Es handelte sich um ein Nebeneinander verschiedener Gemeinschaften, das nicht über an die Öffentlichkeit appellierende politische Diskurse geregelt werden konnte. ${ }^{81}$ Dies galt im Großen und Ganzen auch für die muslimischen Gesellschaften. $^{82}$

81 Am Beispiel der indischen Bewegungen dekliniert Martin Fuchs die These, daß die ,modernen Diskurse die Idee der Diskriminierung und Differenz und den Gleichheitsanspruch nicht erst schaffen, daß sie jedoch ein Idiom bereitstellen, in dem derartige Erfahrungenskonzepte prinzipiell an Andere vermittelbar und, da dieses Idiom einen von jenen akzeptierten Legitimitätsanspruch zu verkörpern scheint, einklagbar sind“" (1999: 328). So werde z.B., schreibt Fuchs in einem anderen Text, „die Dalit-Bewegung ihre Botschaft in allgemein verständliche Idiome übersetzen, die etwa die Universalität der „Erlösung oder die staats- oder menschenrechtliche Formalisierung der modernen Konzepte vom Subjekt in den Vordergrund stellen“ (1998: 124f). In der „Notwendigkeit und gleichzeitigen Einschränkung der Selbstauslegung im Horizont der Fremdauslegung" sieht Fuchs aber auch die Ambivalenz solcher Gruppen, indem er beschreibt, wie diese gleichzeitig den in den modernen Idiomen enthaltenen universalistischen Geltungsansprüchen auszuweichen versuchen (a.a.O.: 125). In die Konzeption der vorliegenden Arbeit überführt, betrifft dies die später zu diskutierende Frage nach der kulturrelevanten Übersetzung der gleichen Erfahrung, nämlich der Erfahrung der Kontingenz. Diese besagt, daß die Selbstverständlichkeit einer islamischen Referenzordnung im politischen Diskurshorizont nicht mehr trägt. Ob der Islamismus diese Erfahrung konsequent übernimmt, oder ob diese doch letztlich an die Ränder der Religionsgemeinschaften verbannt und damit im Grunde abgebunden wird, diese Frage soll im Laufe der Diskussion nach und nach geklärt werden.

82 Çiğdem hat zu Recht auf die Modernität der Frage nach dem Zusammenleben hingewiesen: „Da der Wille zum Zusammenleben, die Modernität dieses Willens, seine Verwirklichung nur durch Zustimmung zu einem Grundsatz im Sinne eines moralischen Imperativ wie bei Kant möglich werden kann, muß Bulaç Klarheit darüber verschaffen, ob die- 
Wird eine solche Formelsuche in das Zentrum eines islamischen Diskurses hinein gepflanzt, dann kann dies nicht mehr als eine akzidentielle Veränderung an konkreten Diskursen abgehandelt werden. Stattdessen birgt sie eine Verschiebung in der Ordnung des Diskurses schlechthin, was besagt, daß man jetzt nicht mehr mit rein innerislamisch gehaltenen Diskursen zu tun hat, sondern daß es hier um einen Diskurs mit einem virtuell über die islamische Gemeinde hinausweisenden Adressat geht, mit dem man auf der Basis der Gleichheit einen Vertrag schließen will, um eine gerechte, allen gleichermaßen Anerkennung spendende Gesellschaftsordnung zu gründen. Es geht nicht mehr um die den Glauben versichernden Beschwörungspraktiken, auch nicht alleine um die besonders für das Christentum und etwas abgeschwächt auch für den Islam geltende, missionarische Tätigkeit, sondern darum, den neuartigen Sachverhalt, den Glauben als politisches Programm, als eine Meinung unter anderen, an eine anonyme Öffentlichkeit zu richten.

Nahezu für alle Verfechter des VM gleicht die These, daß die moderne Form der Anerkennung den Anderen in Wirklichkeit der eigenen Herrschaft unterwerfe, indem sie definierend in dessen Wesen eingreife, mittlerweile einem religiösen Dogma. Die systematische Begründung für diese durchaus sehr spannende Beobachtung lieferte dafür zunächst Bulaç in seinem Text (1994b) ,Din-dışı'nın seküler sitesinden ,ed-din'in sahici dünyasina (Vom säkularen Ghetto des Nicht-Religiösen zur wahren Welt der Religion). Demnach trenne eine unüberbrückbare Kluft das klassische, religiöse Benennen des Anderen von der modernen Definition desselben. Keine Religion hätte sich in der langen Menschheitsgeschichte angemaßt, die anderen Religionen zu definieren, statt dessen hätten sich die Religionen auf die Selbstbeschreibung, auf die Kundgabe des eigenen Selbst bezogen.

„Wenn man unbedingt vom Definieren sprechen muß, dann bedeutet das Definieren für die außerhalb des Modernismus stehenden, legitimen Traditionen, zu denen auch der Islam gehört, sich kundgeben [kendini beyan etme], sich herausstellen, offenkundig werden [açı̆̆a vurma]. Es ist besser, dies als Bekanntmachung [tanitma] zu verstehen denn als Definition [tanımlama].“ (Bulaç 1994b: 3)

Was das wahre Anerkennen ausmache, bestehe, anders als beim Modernismus, darin, den Anderen so zu nehmen, wie er sich verkündigt. Kritisiert wird im Grunde der analytische Geist der Neuzeit. Dieses im 17. Jh. einsetzende Denken führte Foucault auf einen Bruch mit dem Denken der Ähnlichkeit zurück.

ser Grundsatz mit dem Islam identifiziert werden kann oder nicht.“ (1996: 1230) 
„Am Anfang des siebzehnten Jahrhunderts, in jener Periode, die man zu Recht oder zu Unrecht das Barock genannt hat, hört das Denken auf, sich in dem Element der Ähnlichkeit zu bewegen. Die Ähnlichkeit ist nicht mehr die Form des Wissens, sondern eher die Gelegenheit des Irrtums, die Gefahr, der man sich aussetzt, wenn man den schlecht beleuchteten Ort der Konfusionen nicht prüft.“" (Foucault 1990: 83)

Indem durch den analytischen Geist das Inkommensurable der Dinge abgeschnitten wird, kann nun alles ,,in Termini der Identität und des Unterschieds, des Maßes und der Ordnung“ (Foucault a.a.O.: 84) analysiert, kann das Seiende als Gegenstand des analytischen Blickes meßbar, damit auch später der technischen Reproduktion zugänglich gemacht werden. Setzt sich denn nicht erst unter diesen Bedingungen das reine Vergleichen durch, durch das auch die verschiedenen Kulturen dem analytischen Blick freigegeben werden? Die islamistischen Intellektuellen konstatieren diese radikale Wendung in der Wahrnehmung der Welt nicht nur zutreffend. Sie nehmen auch die praktischen Konsequenzen dieser Wendung zur Kenntnis, wenn sie wie folgt befinden: „Vielleicht zum ersten Mal in der Geschichte hat im totalitären Universum der Moderne, die ,den Anderen' nicht dulden kann, die Antropologie diese universale Regel übertreten und sich das Recht zuerkannt, ,andere Kulturen, Traditionen und Religionen zu definieren." (Bulaç 1994b: 4)

In der Tat entstand das analytische Interesse an anderen Kulturen erstmals in der westlichen Moderne, und man würde mit der Behauptung nicht falsch liegen, daß diese Art des Umgangs mit anderen Kulturen weiterhin hauptsächlich von den westlichen Wissenschaftlern praktiziert wird. Nichtsdestotrotz läßt sich die eigentümliche Verwicklung in diese Denkweise auch bei den Islamisten feststellen, sofern sie, von der Dynamik des kulturübergreifenden Austausches zur Standortbestimmung getrieben, Aussagen über die Funktionsweise der westlichen Wissenschaften machen, um die eigene Authentizität davon abzusetzen. Sie übernehmen dabei, entgegen der erklärten Absicht, letztlich partiell die analytische Technik, durch die erst die Instrumente und Herangehensweise der modernen Sozialwissenschaften ins Denken der Islamisten einziehen. Eine Art der Durchsoziologisierung des islamischen Denkens deutet sich somit auch in der Türkei in Ansätzen an. Die islamistische Analyse des modernen Denkens, das seinerseits die Welt als Untersuchuchungsgegenstand behandelt, will aber, trotz ihrer unausweichlichen Übernahme der wohl oder übel 
praktizierten analytischen Methode, die Welt genau von den Folgen dieses Blickes kurieren. ${ }^{83}$

Was nun den Islamismus an dem theoretisch abgelehnten, doch praktisch in Gebrauch genommenen, analytischen Denken in erster Linie interessiert (besser gesagt: stört), sind die politischen Implikationen dieses „definierenden“, sich über die „Substanzen“ hinwegsetzenden Denkens. Die moderne Bürgergesellschaft und im besonderen die moderne Demokratie (wie auch der moderne Kapitalismus) wären ja ohne dieses Absehen von den substantiellen Qualitäten nicht denkbar geworden. Die nationalstaatliche Ordnung löste bereits die „natürlichen" Strukturen der Ständegesellschaft auf. Das türkische Gegenstück, der türkische Nationalstaat, annulierte schließlich die relative innere „Autonomie“ der Religionsgemeinschaften, ${ }^{84}$ unterwarf sie einem einzigen politischen Ordnungsprinzip, indem er alle Untertanen in prinzipiell gleichberechtigte Bürger verwandelte und in den Wirkungsbereich ein und derselben Rechtsordnung einschloß.

Die nationalstaatliche Ordnung, deren Legitimität der klassische Islamismus mit seinen imperialen Visionen im Prinzip nie bestritten hat, rückt dementsprechend folgerichtig ins Visier der ",postmodernen“ Islamisten. Nichts verkörpert also den neuzeitlichen „Verfall“ für den islamistischen Diskurs so anschaulich und folgenreich wie der Nationalstaat mit seinem die religiösen Grenzen transzendierenden Bürgerstatus, mit dem gemeinsamen öffentlichen Raum, in dem sich Bürger jenseits ihrer ethnischen und religiösen Bindungen dem Prinzip nach streiten können, und dem positiven Recht, das die Pluralität der Rechtsordnung nur bedingt duldet (wie im Falle des Kirchenrechts in Deutschland). ${ }^{85}$ Auf eine logische Weise scheint die Frage nach

83 Mittlerweile gehört auch die empirische Sozialforschung in den Intrumentenbestand der Islamisten. So will bspw. die islamistische Autorin Cihan Aktas (1992) in ihrer empirischen Untersuchung zum Thema Verschleierung und Gesellschaft die authentische Sicht der sogenannten Kopftuchfrauen in den Blick bringen. Dabei läßt sie sich wohl auf die „,natürliche Tochter der Heiligen Inquisition „, ein, wie Alois Hahn (1982: 407) die empirische Sozialforschung, auch mit Verweis auf Foucaults Analyse der Selbsttechniken, auf die Tradition der christlichen Geständnispraktiken zurückführt.

84 Faktisch vollzog sich jedoch dieser Prozeß in der Weise, daß der Status religiöser Minderheiten mit dem Friedensvertrag von Lausanne (1923), der die Unabhängigkeit des neuen türkischen Staates bescheinigt, international geregelt wurde. Anders als in der osmanischen Ordnung gelten diese aber als gleichberechtigte Bürger.

85 Abdurrahman Arslan setzt das Bürgersein gleich mit Totalitarismus identisch, und ihn stört auch die Idee der Gleichheit, der gegenüber er 
dem Recht den neuralgischen Punkt zu betreffen, um den herum sich der islamistische Diskurs entfaltet. Denn im formalen Recht materialisiert sich das Prinzip des reinen Vergleichs, die Universalisierung des Vergleichs, der mit der Idee der Gleichheit innerlich verbunden ist. In Opposition dazu gestellt, ist dann auch das Konzept der Anerkennung, das zentrale Thema des islamistischen Diskurses, nur noch partikularistisch und auf der Basis gemeinschaftlicher Identitäten einzuholen.

Sosehr auch die Auswahl der Themen, die das Beschäftigungsfeld der islamistischen Intellektuellen ausmachen, und der analytische und argumentative Modus der Wissensproduktion auf eine starke Profanisierung des religiösen Denkens hinweisen, so wenig darf man aus den Augen verlieren, daß es sich hier letztlich um einen sich im religiösen Idiom artikulierenden Diskurs handelt. Er exponiert sich zwar als eine Meinung in einer anonymen Öffentlichkeit, und seine Adressaten sind auch deswegen nicht alleine diejenigen, die sich ebenfalls durch den religiösen Duktus angesprochen fühlen, sondern auch die säkularen Intellektuellen, also die Anderen, mit denen man gemeinsam auf der Basis der Anerkennung zusammenleben will. Gleichwohl muß und will der Diskurs auch die religiös orientierten Menschen ansprechen. Immerhin handeln bzw. schreiben die Protagonisten des Diskurses aus einem religiösen Hintergrund. Daher muß sich der Diskurs neben den philosophischen und soziologischen Reflexionen auch in der Domäne des religiösen Denkens schlechthin, nämlich in der Theologie, bewegen können. Unten werden die onto-theologischen Quellen der Kritik am modernen „Verfall“" vorgestellt.

\subsection{Eine monotheistische Lektüre der Zeit}

So sehr auch die verfallsgeschichtlich angelegte islamische Eschatologie von einer vorwärtsstrebenden Geschichtstheologie entfernt sein mag, im Dogma des „Siegels der Prophetie“ ist letztlich die Möglichkeit mitgegeben, eine Aufwärtsbewegung in die menschliche Geschichte hinein zu artikulieren. Die zunächst einmal in geschichtsphilosophischer Hinsicht unökonomische Pendelbewegung zwischen dem Verfall und der prophetischen Wiederherstellung der göttlichen Ordnung treibt unter der Zielsetzung der Gesellschaftskonstitution selbst bei aller entschiedensten Ablehnung der utopistischen Zeitlichkeit der Moderne zu einer voranschreitenden, ja geradezu dialektisch verlaufenden Vervollkommnung der göttlichen Weisheit, die sich in Gestalt von Muhammad als dem letzten Propheten artikuliert. Bulaçs Theolo-

die Gerechtigkeit präferiere, weil auch die Gleichheit Totalitarismus hervorbringe (vgl. 1993: 27). 
gie gliedert in diesem Sinne die Geschichte der Menschheit entlang der prophetischen Botschaft in drei Epochen auf.

Die Menschheitsgeschichte beginnt entsprechend der jüdischchristlichen Tradition auch im Islam mit der Ursünde, die Adam und Eva begingen. Ihr Vergehen war es in Bulaçs Deutung, „die Bestimmungen des Vertrags zu übertreten, den wir [mit Gott, L.T.] geschlossen hatten“ (1992c: 54; Hervorhebung im Original). Die Ursünde überträgt sich allerdings, anders als im Christentum, nicht auf die Nachwelt. Adam und Eva haben demnach ihre Prüfung auf der Erde bestanden, die Pendelbewegung bleibt hingegen für die Nachwelt weiter gültig und konstitutiv.

Bulaçs Geschichtskonstruktion, die für junge Generationen islamistischer Intellektuellen paradigmatische Bedeutung besitzt, bezieht sich weitgehend auf eine Überlieferung vom Propheten:

„Die Zeitspanne, die für euch bestimmt wurde, verglichen mit jener, die euch vorangehenden Völkern zugewiesen wurde, ist wie die Zeit zwischen dem Nachmittagsgebet und dem Sonnenuntergang.

Den Juden wurde die Thora gegeben. Sie beschäftigten sich mit diesem Buch, bis sie zur Mittagszeit ermüdet waren. Als Lohn wurde ihnen ein Qirat gegeben. Darauf wurde den Christen das Evangelium gegeben. Und sie studierten es, bis sie zur Zeit des Nachmittagsgebets ermüdet waren. Auch sie wurden mit einem Qirat belohnt. Im Anschluß daran wurde uns der Koran gegeben. Wir lasen ihn bis zum Sonnenuntergang. Und als Lohn wurden uns zwei Qirat gegeben. [...]“" (al-Buhari 1997, IX/12: 128f.)

Im islamistischen Diskurs wird daraus eine Art Teleologie entwickelt. Sie besteht aus drei Epochen.

Zwischen Morgendämmerung (safak) und spätem Vormittag (kusluk) haben „die Kinder von Adam und Eva“" als eine einzige Umma gelebt (Bulaç 1992c: 54). Diese Zeit wird auch als das Zeitalter der „reinen (unentstellten) Weisheit" konzipiert, die zu der uralten Vorstellung vom Goldenen Zeitalter Parallelen aufweist (Bulaç 1994c: 60f), was wiederum von der Gleichursprünglichkeit philosophischer und religiöser Ideen bzw. von der Ursprünglichkeit monotheistischer Weisheit zeugt. ${ }^{86}$ Die Menschen haben aber wieder einmal ihren Vertrag mit Gott gebrochen und Gott hat darauf hin die Sintflut auf die Erde hereinbrechen lassen, die uns von den Sünden reingewaschen hat.

In der Mittagszeit (ögle) erging der göttliche Ruf durch Abraham noch einmal. Sein Ruf wurde in Folge dann von Moses und Jesus

86 Auch Marx mit seinem Konstrukt vom am Beginn der Menschheitsgeschichte stehenden Urkommunismus wird als Zeuge in den Verweiskatalog aufgenommen (Bulaç 1992c: 56). 
wiederholt. Dies ist gleichzeitig das Zeitalter der „entstellten Weisheit", wobei etwa 124000 Propheten unterschiedlichen Ranges (darunter gehören auch Philosophen, prominente Ärzte etc.) die Menschen immer wieder an den vergessenen, verschüttenen Brunnen der einen göttlichen Wahrheit herangeführt hätten (vgl. Bulaç 1994c: 63).

„Besonders im Hinblick auf die orientalische Linie der Weisheit ist es eine historische Tatsache, daß allen mesopotamischen Denkrichtungen mehr oder weniger, mit unterschiedlicher Entfernung, die Weisheit wesentlich innewohnt. Man darf die Tatsache nicht ignorieren, daß in dem Ursprung und der weiteren, historischen Entwicklung orientalischer und griechischer Weisheit, deren Wissenschaft und Denken, die reine Weisheit der Prophetie gewirkt hat.“(Ebd.)

All die Religionen, Konfessionen, Glaubensdoktrinen, philosophischen Strömungen etc. sind demnach Erscheinungen der entstellten Weisheit, mit der Funktion ausgestattet, die Entstellung rückgängig zu machen.

Am Nachmittag (ikindi), im ,Zeitalter der Wiederbelebung der Weisheit" wiederholt, bestätigt, vollendet und erneuert Muhammad „den Ruf aller ihm vorangegangenen Propheten, Weisen und Richter“ (Bulaç 1992c: 54 und 1994c: 64). Die Erneuerung vollzieht sich an zwei Punkten: Er ist „der letzte Prophet“ und wird herabgesandt ,an die gesamte Menschheit“"

„Einerseits wird er mit der Aufgabe betraut, eine neue und universelle Umma in politischen, ökonomischen, militärischen und gesellschaftlichen Bereichen zu gründen. Andererseits lehrt er auf der Basis der Offenbarung ,das Buch, die Wissenschaft und die Weisheit'. Das bedeutet, das göttliche Unternehmen, den Menschen mittels Offenbarung und Prophetie Wissen und Weisheit zu belehren, erhält ihre Vollendung.“ (Bulaç 1994c: 65)

Damit erreicht die Geschichte der offenbarten Weisheit - fast möchte man sagen: in einer dialektischen Bewegung - ,ihre letzte und höchste Epoche“, in der das „Äußere/die Erscheinung (zahiri) und das Innere/das Verborgene (batini) zusammengefügt werden“" (a.a.O.: $65 f$ ) ${ }^{87}$ Diese theologischen Überlegungen weiten sich fürderhin auf die Stellung der westlichen Geschichte der Offenbarung aus, die als eine Art Abklatsch, eine verdünnte Version der orientalischen Geschichte erscheint (ab Descartes dann ein völliger Abfall aus der Quelle der

87 An einem anderen Verweis auf die Überlieferung sticht die Endzeitvision besonders hervor: „Zwischen mir und dem jüngsten Gericht besteht nur so viel Kluft wie zwei Fingerbreite.“ (Bulaç, Abraham'ın EVlatları [zu dt.: Abrahams Söhne] in der Tageszeitung Zaman vom 11. April 2000. 
Weisheit, daher die endzeitliche Abirrung). Wichtig ist in diesem $\mathrm{Zu}$ sammenhang, die Funktion dieser Gedanken für die Konstruktion des Vertrages von Medina auszudeuten: Die Einheit der Menschheit erfährt ihre Legitimation mittels der einen Offenbarung, die sich in unterschiedlichen historischen Epochen in Gestalt verschiedener Religionen geäußert hat, was zugleich die Idee von der Einheit der Religionen noch einmal unterstreicht. Allerdings erscheinen hier Religionen als Gesellschaftsformationen, die sich durch eine jeweilige rechtliche Grundlage (Scharia) auszeichnen sollen. Entscheidend scheint also die Vielfalt der Wege und Formen (Scharia), in denen die göttliche Botschaft ihre historische Verkörperung erfahren hat. Dementsprechend funktioniert jede Lebensweise nach einer eigenen Scharia, und darin besteht das Formel eines friedlichen, den Anderen anerkennenden Zusammenlebens. Die Moderne habe, so zurück zu der Frage nach der Institutionalisierung der Onto-Theologie, mit ihrem Zentralstaat (das sei bereits Totalitarismus) eine einzige Form von Recht (Scharia) allen anderen Lebensformen aufgezwungen, während das prophetische Medina mit ihrer auf sozialen Blöcken basierenden Ordnung die wahre Anerkennung exemplifiziert habe. Die vertragliche Konstitution der politischen Ordnung avanciert zum zentralen Punkt der Überlegungen über den aktualisierten „Vertrag von Medina“.

\section{Das prophetische Medina im Gegensatz zum „totalitären" Nationalstaat der Moderne}

\subsection{Die Umma: Von der Gemeinschaft der Muslime zur Gemeinschaft schlechthin}

Bestand nun die „Sünde“ des modernen Nationalstaates darin, sich über bestehenden Differenzen hinwegzusetzen, um alle nach dem Parameter eines Bürgerstatus zu definieren, so soll der „Vertrag von Medina“, den der indisch-muslimischen Verfassungsrechtler Hamidullah (1993 und 1998), unermüdlich als ,die erste geschriebene Verfassung der Menschheitsgeschichte" feiert, eine den partikularen Identitäten gerechte Ordnung anbieten. Wie wird die Gemeindeordnung/Vertrag/Verfassung/Urkunde/Erlaß (in den verschiedentlich gebrauchten Formulierungen) von Medina in der Türkei am Ende des 20. Jahrhunderts unter den oben beschriebenen Kontextbedingungen rekonstruiert? Über welche Schritte wird der Islam als ein Gesamtpaket für weltliche Angelegenheiten, und zwar über die Regelung des moralischen Handelns der Einzelnen im Alltag hinaus, konzipiert? Wenn nun der Islam die Grundlagen einer Gesellschaftstechnologie abgeben soll, von welcher Art wird die zu konstruierende Gemeinschaft sein? 
Oder anders gefragt: Welche Folgen bringt die Rekonstruktionslogik, mit der die Vision der Urgemeinde ins Werk gesetzt werden soll, wenn sie an eine Gesellschaftstechnik gekoppelt wird?

\subsubsection{Die Prinzipien der Gemeinschaft}

Die Umma, welche bisher sowohl aus der Binnenperspektive der Muslime als auch aus der Beobachterperspektive immer schon als die Gemeinde der Muslime verstanden wurde, erfährt jetzt eine in der islamischen Geschichte einmalige Umdefinition: Im Ursprung der islamischen Geschichte war die Umma, so die Grundidee der Konstruktion, keineswegs rein islamisch. Sie habe die Gemeinschaft schlechthin bezeichnet, an der verschiedene soziale und religiöse Gruppen mit Wahrung ihrer Eigenständigkeit teilhaben durften. Unten wird die Umdeutung der Umma in eine politische Gemeinschaft schlechthin nachgezeichnet, wobei anschließend die aus dem Unterfangen resultierenden Friktionen problematisiert werden.

Bulaç eröffnet das Setting mit dem Hinweis, daß der Prophet die Urkunde keineswegs per Gewalt dem nichtmuslimischen Rest der Medinensischen Bevölkerung aufgezwungen hat.

„Denn es ist nicht ernsthaft zu glauben, daß ein Mensch, der sich nachts heimlich von Mekka nach Medina begab und dessen Anhänger nicht mehr als $15 \%$ der Stadtbevölkerung ausmachten, einen nach seinen Wünschen und künftigen Interessen dienenden Vertragstext den zahlenmäßig und militärisch Überlegenen aufdrücken könnte. Plausibel ist das keineswegs.“ (1992b: 108)

Auf die partnerschaftliche Schließung des Vertrags aus freien Stücken legen die Verfechter des VM besonderen Nachdruck. Das Erfolgsergebnis, das der Prophet kurz nach seiner Ankunft in der zerstrittenen Stadt verbuchen konnte, wird historisch erklärt. Als „einer der wichtigsten Faktoren“ dafür wird der chaotische Zustand des 120 Jahre lange von Kriegen und Feindschaften zerrütteten Medina angeführt. Genau ,,in einem solchen kritischen Moment taucht ein Fremder auf und zeigt allen anwesenden Gruppen die Wege des Zusammenlebens“, ruft sie alle auf der Basis des Rechts auf, nach dem Grundsatz: „Bleibe so, wie du bist“ zu leben. Das dringlichste Problem jener Zeit habe darin bestanden, so Bulaç, „die Formel herauszufinden, gemäß der ein auf der Gerechtigkeit und Billigkeit aufbauendes Zusammenleben“ errichtet werden könne (ebd.).

Anschließend möchte Bulaç im Lichte des historischen Beispiels programmatisch unterstreichen, daß „dank dieses Projekts“ niemand dem Joch der Anderen unterworfen werde und man gegenseitig die 
Existenz der Anderen als Realität anerkenne sowie die Lebens- und Denkweise der Anderen unter Rechtsschutz gestellt werde. Anders als der moderne Staat mit all seinen diversen politischen Formen einschließlich der Demokratie, die alle letztlich auf Herrschaft basierten, zeichne sich das Medinensische Modell durch Partizipation aus. Der Vertrag von Medina sieht dann ,für alle sozialen Blöcke ein gesellschaftliches Projekt nicht auf der Basis von ,Herrschaft', sondern von ,Partizipation“ vor.“ Innerhalb des vom Vertrag umrissenen Rahmen werden, so wird das alternative Gesellschaftsmodell weiter beschrieben, „Muslime als freie Menschen in der von Gott und Muhammad (sav) angezeigten Richtung leben und ihre Religion verkünden. Die gleichen Rechte gelten auch für die Juden und die Anderen." (1992b: 108)

Von hier aus werden nun die immanenten Prinzipien des historischen Vertrages herausgelesen. Mit der Frage nach immanenten Prinzipien wird übrigens ein Akt vollzogen, den die klassischen Muslime, auch der Gesamtapparat der Orthodoxie so nicht kannten. Einen elaborierten Versuch in dieser Richtung hatte zuvor Fazlur Rahman in Angriff genommen. Rahman blieb mit seinem Versuch, den modernen Institutionen islamischen Geist einzuhauchen, allerdings für Bulaçs Geschmack weiterhin innerhalb des modernen Paradigmas stecken. Dennoch beschreitet Bulaç selber methodologisch den gleichen Weg. Den Bedarf nach den explizit gemachten, konstitutiven Prinzipien spürt man erst, so kann man theoretisch formulieren, wenn sich ein abstraktes Regelverständnis entwickelt hat, das von den konkreten Bezügen absieht. Schauen wir uns die Grundprinzipien an, die dem Zweck der planvollen Gründung einer Gesellschaftsordnung dienlich gemacht werden sollen.

\section{Prinzip 1: Vertragliche Bestimmung der politischen Ordnung}

Zunächst einmal wird die vertragliche Basis einer legitimen politischen Ordnung betont. Obgleich der Islam zumindest auf der Ebene des individuellen Bekenntnisses eine Religion des Vertrags ist, den der Gläubige mit Gott eingeht und sich durch den Bekenntnisspruch zur Einhaltung der im Vertrag vorgesehenen Gebote verpflichtet, läßt sich die Idee auf die politische Ebene nicht sogleich ausweiten. Man könnte zwar vermuten, daß sich die vertragliche Verpflichtung des Gläubigen zu Gott auch auf die Ausgestaltung der politischen Herrschaft erstreckt. Die geschichtliche Praxis muslimischer Gesellschaften liefern jedoch kaum Belege für diese Behauptung. Es sei denn, daß damit die Verpflichtung des Herrschers auf das göttliche Gesetz gemeint ist. Nur hier könnte man von der Präsenz der Idee eines vertraglichen Verhältnisses sprechen, wobei man hinzufügen muß, daß die Idee allerdings kaum praxisrelevant institutionalisiert worden ist. 
Die Idee der vertraglichen Vereinbarung, welche sich in der islamischen Geschichte vornehmlich auf die Glaubensfragen beschränkte, so daß der Gläubige durch sein Bekenntnis einen Vertrag mit Gott schließt, wird nunmehr auch auf die Regelung sozialer Ordnung erweitert. Gesellschaft als ein vertraglicher Zusammenschluß, diese in den Selbstbeschreibungen der westlichen Moderne überaus prominente Idee, die in den konstitutionellen Demokratien ihre institutionelle Form erfährt, gibt den Rahmen der intellektuellen Herausforderung ab, auf den sich die Islamisten einlassen, wobei sie sich anschicken, die Idee in das islamische Gewand einzuhüllen. So gehen die islamistischen Intellektuellen über den geschichtlichen Islam hinaus zum „ursprünglichen“, „unverdorbenen“ Anfang zurück. Die Rekonstruktion beruft sich vor allem auf die ersten „Artikel“ des Dokuments:

„§1. Urkunde von Muhammad dem Nabi, zwischen den Gläubigen und den Muslimen von Quraisch und Jathrib, und denen die ihnen folgen und sich ihnen anschließen und mit ihnen kämpfen.

§2. Sie bilden eine einzige Gemeinde, gegenüber den Menschen.“ (Wellhausen 1889: 67)

Von dem historischen Moment der Urkunde von Medina aus wird nun das „erste konstitutive Prinzip“ der politischen Ordnung bestimmt: „Ein richtiges, gerechtes, sich am Recht orientierendes und auf wahren Frieden unter Menschen abzielendes, ideales Projekt muß aufgrund eines Vertrages zwischen (religiös, rechtlich, philosophisch, politisch etc.) unterschiedlichen Gruppen entstehen.“ (Bulaç 1992b: 108; Hervorhebung im Original) ${ }^{88}$

Die islamistische Politik des Zusammenlebens, wie es im Diskurs konstruiert wird, hängt wesentlich von der Unterscheidung zwischen den Sphären der Übereinstimmung und der Differenz ab. Während der Vertrag den Bereich der allgemeingültigen Regeln abstecke, die in „Übereinstimmung“ erarbeitet werden sollen, gehörten die Bestimmungen, die den substantiellen Wertvorstellungen entsprächen, in die Domäne der „Autonomie“, in der nicht die Übereinstimmung, sondern die Differenz das gemeinschaftliche Leben organisiere. Anders als die westliche Demokratie, welche uneingeschränkte Hegemonie der Mehrheit bedeute (Bulaç 1992c: 60), komme hier der wahre Pluralismus,

88 Der vordergründig vertraute Anklang der Beschwörung des Vertrages an Vertragstheorien verstummt, wenn man die Tatsache in Betracht zieht, daß diese im Prinzip nicht von einem empirischen Vertrag ausgehen, sondern mit Hilfe eines archetypischen Konstruktes die Konstitutionsbedingungen der politischen Ordnung diskutieren. 
die Vielheit in der Einheit, zum Ausdruck; auch anders als die „postmoderne Vielheit ohne Einheit" (ebd.).

\section{Prinzip 2: Partizipation statt Herrschaft}

In der Selbstaffirmation der Moderne wird Partizipation als ihr Grundzug gegenüber der vormodernen Welt hervorgehoben. Auch die laizistische Republik der Türkei legitimierte sich über den Vorzug, den sie im Unterschied zum Osmanischen Sultanat den Bürgern des Staates gewähre. Das bis dahin unumstrittene Motto der Republik: „Souveränität geht vom Volke aus“, ihr Herzstück, das sie im Kampf gegen die religiösen und revanchistischen Bestrebungen unumstritten behaupten konnte, wird nun diskursiv umgedreht und soll als Herrschaftsstrategie enthüllt werden.

Das Kriterium dafür, ob eine politische Ordnung auf Partizipation oder Herrschaft beruht, wird aus dem Differenzdiskurs gewonnen.

„Das zweite konstitutive Prinzip betrifft Partizipation, nicht die Herrschaft. Denn in einem totalitären und unitären politischen Gebilde werden die Differenzen nicht zugelassen. Der Vertrag von Medina zählt die Muslime und Juden Geschlecht für Geschlecht (einzeln) auf. Auch die Ungläubigen werden in einem Artikel erwähnt. [...]

$\mathrm{Da}$ die Geschlechter einzeln aufgeführt werden, sichert und beglaubigt die Anerkennung der Identitäten ethnischer und religiöser Gruppen. Vermutlich haben es die Stammesführer so verlangt.

Daraus folgt: Jede religiöse und ethnische Gruppe besitzt vollständige Autonomie in Kultur und Recht. Das heißt, in Religion, Legislative, Judikative, Erziehung, Handel, Kultur, Kunst, Alltagsleben usw. wird jeder das sein, was er ist, und wird sich innerhalb der Standards artikulieren, mit denen er sich definiert. Den Garant für die besagte religiöse und rechtliche Autonomie liefert der Artikel 25, der besagt: ,Die Juden behalten ihre Religion, die Muslime behalten ihre Religion. Sowohl sie selber als ihre Beisassen. ““89 (Bulaç 1992b: 109)

So erfolgt die Partizipation auch in der sich darauf berufenden Rekonstruktion nicht auf der Grundlage eines Gemeinwesens von Bürgern, welches republikanisch die bestehenden partikularistischen Gemeinschaftsidentitäten übersteigt. Es geht auch nicht um eine Polis, in der die freien Menschen gemeinsam um die öffentlichen Angelegenheiten streiten. Sie wird stattdessen von der Basis der einzelnen Bürger auf eine Ebene verschoben, auf der sich die ethnischen und religiösen

89 Der Urtext selber ist nicht nach Artikeln aufgegliedert. Die westlichen Orientalisten, die den Text zum ersten Mal im 19. Jahrhundert wieder entdeckten, haben ihm die heutige nach (47) Artikelnummern gegliederte Struktur verliehen. Hamidullah hat das Dokument auf 52 Artikeln umorganisiert. 
Gemeinschaften begegnen und miteinander als Blöcke verhandeln sollen. Dies wirft die Frage nach der Bestimmung ihrer Beziehungen untereinander auf, die letztlich auch die Frage nach der Rechtsordnung betrifft.

\section{Prinzip 3: Der Rechtspluralismus und die Gesellschaft der „Scharias “}

Wurde die politische Ordnung auf vertragliche Vereinbarungen zwischen autonomen Gemeinschaften gestellt und ihr Mechanismus als Partizipation statt Herrschaft deklariert, so bedarf die Gestaltung der Umma, die jedoch zugleich ihre Durchpolitisierung zur Folge hat, eines weiteren Prinzips, welches die Beziehungen zwischen den verschiedenen, konstituierenden Gruppen regeln soll:

„In einer pluralistischen Gesellschaft können gleichzeitig mehrere Rechtsordnungen Gültigkeit beanspruchen. Falls es deswegen zu Rechtsstreitigkeiten zwischen den Blöcken kommen sollte - und das geschieht freilich -, dann werden solche Prozesse von den mit entsprechenden Befugnissen betrauten Gerichten abgewickelt oder man wählt den Weg, einen aus den Vertretern der Rechtsgemeinschaften zusammengesetzten Obergerichtshof zu installieren." (Bulaç 1992b: 109)

Nach der Ansicht von Bulaç soll in solchen Fällen der Benachteiligte die Rechtsordnung frei aussuchen dürfen, nach der geurteilt werden soll. Zurecht weist er dabei auf die osmanische Rechtspraxis hin, die den Prozeßbeteiligten diese Möglichkeit einräumte - allerdings mit der Beschränkung, daß nur die Nichtmuslime sich für eine Beurteilung nach dem islamischen Recht entscheiden durften. ${ }^{90}$

Der Funktion des islamischen Propheten in dieser Ordnung kommt dabei eine besondere Rolle zu. Sie ist äußerst ambivalent. Muhammad habe, so wird seine Position im Diskurs interpretiert, nicht als Hakim (Richter) fungiert, was nach dem Duktus des Diskurses gleichsam der Funktionsweise des auf einem einzigen Rechtssystem fußenden Nationalstaates entspreche, sondern als Hakem (Schiedsrichter), der sich in seiner Tätigkeit auf das von den Betroffenen ausgesuchte Rechts-

90 Man kann natürlich genauso gut auch die christlich-spanische Praxis vor dem Fanatismus der Reconquista erwähnen, wonach den Muslimen eine solche Wahl zur Verfügung stand (vgl. Lapidius 1988: 388; ausführlicher dazu vgl. Akyol 1998: 14ff). Daß eine dem Konstruktionszwang geschuldete, dermaßen radikalisierte Wahl der Rechtsordnung durch die Einzelnen die Grundlagen jeder Rechtsordnung zerstören würde, sei hier in polemischer Absicht nur angemerkt. Uns interessiert hier nicht so sehr die Realisierbarkeit solcher Modelle, sondern es interessieren die Mechanismen der Ideologieproduktion, und vor allem die simulativen Folgen des kulturübergreifenden Austausches, die noch aufzuweisen sind. 
system einlasse und dementsprechend die Rechtsprechung betätige. Während die Institution des Hakim nur innerhalb einer bestimmten Rechtsordnung Urteile fällen kann, schlichtet Hakem zwischen verschiedenen Gruppen, die unterschiedliche Vorstellungen von Recht und Gerechtigkeit, jedoch keine gemeinsame, verbindliche Rechtsinstanz haben. So überlassen sie die Entscheidung auf einen Dritten, dessen Entscheidung sie sich freiwillig unterwerfen. ${ }^{91}$

\subsubsection{Die Umdeutung der Umma und ihre Friktionen}

Die Suche nach den Prinzipien einer gerechten Gesellschaft, die aus der gleichwertigen Partizipation von Gemeinschaften entstehen soll, geht dabei mit einer Umdeutung der Umma einher, die allerdings keineswegs reibungslos funktioniert. Die Umma soll nun ursprünglich die Gemeinschaft schlechthin bezeichnet haben, die jedoch aufgrund historischer Vorkommnisse, zunächst bereits zur Zeit des Propheten und dann durch die fortschreitende Abweichung der späteren Königreiche vom ursprünglichen Islam, immer mehr auf die Muslime beschränkt worden sei. Dafür wird vor allem auf den Artikel 2 rekurriert: „Sie bilden eine einzige Gemeinde, gegenüber den Menschen.“ (Wellhausen 1889: 67)

91 Die Unterscheidung zwischen diesen Funktionen dient im Diskurs der Islamisten dazu, den Bereich des ,internen Rechts“ von dem des ,externen Rechts" abzukoppeln (Dilipak 1992: 27). Daß eine solche Trennung beider Funktionen die Rechtsordnung auflöst, hat Ragip Ege (1993) in seiner Kritik am Konstrukt des VM sehr prägnant dargestellt. Das Recht institutionalisiert demnach qua Definition das Eingreifen eines Dritten, des Außen, in das Innere, das wiederum erst durch diese Entäußerung der Urteilsinstanz überhaupt zu einer Ordnung findet. Daher könne es in dem hier gebrauchten Sinne kein internes Recht geben. Ege qualifiziert denn auch den ursprünglichen Vertrag von Medina lediglich als eine frühe Stufe der Rechtsordnung, die den komplexen Bedingungen moderner Gesellschaften nicht gerecht werden kann (a.a.O.: 38). Wir schließen uns hier an seine Kritik an. Unsere Untersuchung befaßt sich jedoch hauptsächlich mit der Konstruktion und der Funktionsweise des Diskurses. Die Funktion der Rede vom „internen Recht“ ist daher zunächst einmal zu bestimmen. Sie ist nur zu verstehen, wenn man den Begriff vom ,internen Recht" in den Kontext der utopistischen Konstruktion der Umma als die ideale, erlöste Gemeinschaft stellt. Erst in einer Gemeinschaft, die mit sich identisch ist und die Entfremdung durch Politik nicht kennt, kann das Recht als ein rein internes Moment verhandelt werden. Auf die Umma als die utopische Gemeinschaft wird unten ausführlicher eingegangen. 
Den Bestimmungen des ursprünglichen Dokuments kann man für die Zeit des Propheten tatsächlich zweierlei Neuigkeiten entnehmen, die nicht nur die Islamisten zur Umdeutung des Begriffs angeregt haben, sondern auch von den westlichen Orientalisten gewissermaßen ähnlich interpretiert worden sind. Die arabischen Stämme, die den Islam übernommen hatten, definierten nunmehr ihr Verhältnis untereinander nicht mehr alleine über das Stammesrecht. Das ideologische Band des Islam durchkreuzte nämlich die auf Blutsband basierenden Bindungen und ließ ein neues, ,ideologisches“ Gemeinschaftsband hervortreten. In diesem Sinne bedeutet die Umma „nicht Verwandtschaftsverband, sondern Gemeinde schlechthin“ (Wellhausen 1889: 74).

Zweitens fällt auf, daß unter der Umma, zumindest anfänglich nicht alleine die Gemeinschaft der Muslime verstanden wurde. Die muslimischen Immigranten aus Mekka und die muslimischen Araber von Medina gehörten zu ihr genauso wie die nichtmuslimischen Araber. Ebenso darunter zu subsumieren waren diejenigen, die den im Dokument erwähnten arabischen Stämmen folgen. Dabei handelte es sich um eine altarabische Schutz-Beziehung, die kleinere Stämme zu den stärkeren unterhielten. ${ }^{92}$ Die Umma war also ,zunächst eine lose politische Einheit" (Wellhausen 1889: 76), die sich indes wirkungsgeschichtlich sehr rasch, ja gleich zu Lebzeiten des Propheten selbst, in Richtung einer muslimischen Gemeinde entwickelt hat. Hamidullah, an dem sich türkische Islamisten orientieren, hebt im Hinblick auf die ideologische Dimension der Umma die Freiwilligkeit hervor. Die als Stamm bezeichnete soziale Organisation wurde, so Hamidullah, an eine von Grund auf neue Ideologie angeknüpft, so daß sie auf keinerlei Weise qua Geburt, Verwandtschaft und als nach außen geschlossen definiert werden konnte. Nach diesem neuen Verständnis von Stamm mutierte ein sozialer Körper in eine auf freiem Willen des Individuums basierende dynamische Organisation." (1993: 192) ${ }^{93}$

Allerdings bezieht sich Hamidullah auf den ersten Aspekt, nämlich auf die Gegenüberstellung von Blutsverwandtschaft und religiösem Bekenntnis als der konstitutiven Grundlage der Gemeinschaftsbildung. Andererseits muß man hier anmerken, daß selbst dieser Punkt nicht unumstritten ist. Die Orientalisten sind bspw. anderer Meinung. Was in der islamistischen Rekonstruktion ins Gewand einer prinzipiengeleiteten Politik eingehüllt wird, erscheint bei Wellhausen als Zeichen einer politischen Klugheit, nach der die Umma als eine Organi-

92 Nach der Ansicht von Montgomery Watt (1980: 97) „handelt es im wesentlichen um einen Bündnisvertrag, der den traditionellen arabischen Grundsätzen entspricht".

93 Dabei beschränkte sich doch die freie Entscheidung, das soll hier kritisch angemerkt werden, lediglich auf die muslimische Gemeinde. 
sation von Geschlechtern gedacht wird. Wellhausen fragt in diesem Zusammenhang, warum Muhammad die Gläubigen nicht konsequent aus ihrer Verwandtschaft genommen und die Atome neu organisiert hat, zieht dann die folgende Erklärung vor:

„Das tut er nicht; er sagt ausdrücklich, daß die Geschlechter - auch die Muhagira [Emigranten] zählen als selbständiges Geschlecht - bleiben sollen wie sie sind und als solche in die Umma eintreten sollen. Er nimmt die alte Organisation ruhig in das neue Ganze herüber; der Gedanke der Möglichkeit einer nicht von Natur gegebenen, sondern gemachten Gemeinschaftsgliederung ist ihm vielleicht überhaupt nicht in den Sinn gekommen." (1889: 76)

Muhammad hätte, so Wellhausen, andernfalls Friede und Ordnung in Medina nicht stiften können. „Hätte er“ also „nur die Gläubigen um sich gesammelt, so wäre ein neuer eigenartiger Verband zu den alten hinzugetreten, und Zank und Fehde hätten kein Ende genommen“ (ebd.). Die These von einem durch den Vertrag in die Vorstellungen von politischer Ordnung eingeführten radikalen Schnitt will auch Montgomery Watt nicht in dieser Radikalität gelten lassen. „This document", so Watt, ,is no invention of a political theorist, but is rooted in the mentality and moves of pre-islamic Arabia“ (1968: 6; Watt/Welch 1980: 97).

Selbst wenn man die kritischen Anmerkungen der Orientalisten gelten läßt, bleibt die Tatsache, daß der islamische Prophet in die arabische Welt eine neue, die bestehenden Gemeinschaftsformen durchkreuzende Ordnungsform eingeführt hat. Diese mag die alten Bindungen nicht abgeschafft haben. Sie hat aber den anderen Gemeinschaftsbindungen einen eigenen Code aufgezwungen, dem sich die herkömmlichen Stammesbindungen nicht gänzlich entziehen konnten. Viel brisanter und umstrittener sowie für den Diskurs selbst problematischer scheint hingegen der zweite Aspekt zu sein, welcher vom Status der Juden in Medina handelt. Der Status der Juden bleibt nun auch für die Rekonstruktion des ursprünglichen Dokuments folgenreich. Darauf soll unten ausführlicher eingegangen werden.

\subsection{Der Stachel des historischen Ereignisses, die Risse der Konstruktion}

\subsubsection{Der umstrittene Status der Juden}

Auf welche Weise bildet nun die mit dem Propheten ansetzende, sich entlang der abrahamitischen Tradition material begründende und in der darauf folgenden islamischen Geschichte fast durchweg ange- 
wandte Praxis, den Andersgläubigen (in der Regel den Christen und Juden, teils auch weitere Gruppen eingeschlossen) in der Regulierung innerer Angelegenheiten weitgehende Autonomie, zu gewähren, die Basis für einen Diskurs, welcher im Geiste des Urmodells dessen Anwendungsbereich aus einem Prinzipiendenken heraus auf alle sozialen Gruppen ausweiten will?

Ein auf der vollendeten Offenbarung fußendes Gesellschaftsmodell, das sich durch die Entsprechung zur göttlichen Harmonie des Universums auszeichnen soll, darf keine Risse aufweisen, die oft drohen, wenn man der Kontingenz des Vergangenen ein komplettes Modell abringen will. Es muß gegen die aus der Geschichtlichkeit des Urbildes entspringenden „Unstimmigkeiten“ abgedichtet werden, bei denen sich aber das Urmodell um die Konsistenz eines zukünftig aus ihm selbst abzuleitenden Modells nicht beeindrucken läßt. Die Bürde der Konsistenz gilt der Nachwelt, nicht dem historischen Ereignis. Und zwar müssen sowohl die Einwände aus dem säkularistischen bzw. linken Milieu (z.B. İnsel 1992; Ege 1993;) effektiv zurückgewiesen als auch der islamistischen Kritik, die sich ebenfalls auf die Urgemeinde beruft, plausibel begegnet werden. Mit dem Status der Juden ist bereits ein für die Effektivität des Diskurses essentieller Konfliktpunkt angesprochen. Welche Probleme tauchen denn beim Unternehmen auf, das historische Handeln des Propheten bezüglich der Juden mit seiner dogmengebenden Wirkungsgeschichte in ein Prinzip zu übersetzen, mit dem eine gottgefällige, jedoch ebenso für Nichtmuslime attraktive Gesellschaft in der Gegenwart errichtet werden soll? Wir haben es also erstens mit einem Vertrag zu tun, dem die Juden freiwillig beigetreten sein sollen. Zweitens wird der Status der Juden aufgrund bestimmter Vorkommnisse vom Propheten selbst degradiert, auf daß drittens die ganze bisherige islamische Praxis nicht nur die Juden, sondern auch die Christen in Berufung auf diese Tradition als Zımmi, d.h. als Schutzbefohlene, die allerdings nicht auf dem gleichen Status mit der muslimischen millet-i hakimiye (herrschender Nation), behandelt hat.

Für die Mainstream-Islamisten, für die der Islam kein abstraktes Prinzip der gesellschaftlichen Konstitution ist, ergibt sich aus diesem Zusammenhang kein Problem. I. Süreyya Sırma bringt dies unmißverständlich zum Ausdruck.

„Die mit diesem Vertrag den Juden zuerkannten Rechte sind nicht politischer, sondern religiöser Natur. So konnten wir denn auch nirgends einem Beleg dafür begegnen, da $\beta$ der Prophet in politischen Angelegenheiten die Juden zu Rate gezogen, oder sie wenigstens in Kenntnis gesetzt hat. So sind wir auch folglich der Ansicht, daß in einem Staat, in dem auch Nichtmuslime leben, der Beitrag der Nichtmuslime zu diesem Staat nur soweit gedeihen darf wie von dem Koran und der Sunna zugelassen." (Sirma 1994: 53) 
Auch die Bestimmung der Funktion des Propheten ist nicht unumstritten, erfährt ebenfalls eine nicht einfach von der Hand zu weisende Kritik von den klassischen Islamisten. I. Süreyya Sirma führt als Gegenbeweis einen Fall an, in dem Muhammad sich dafür entschied, einen jüdischen Stammesführer wegen Kollaboration mit den Mekkanern ermorden zu lassen. Dabei habe sich der Prophet nicht genötigt gesehen, sich einen Rat bei den Anderen einzuholen. „Falls er [der Prophet, L.T.] im islamischen Staat von Medina kein Hakim [Richter], sondern Hakem [Schiedsrichter] gewesen sein sollte“, so Sirma, „dann hätte er sich bei der einen jüdischen Anführer betreffenden Angelegenheit mit jüdischen Stämmen beratschlagt und nicht eigenständig gehandelt" (Sirma 1994: 53).

Anders als die türkischen Verfechter des VM, die, wie gleich zu sehen ist, ihr Konstrukt so selbstverständlich auf die angenommene, gleichwertige Partizipation der Juden am Vertrag und infolge dessen am Gemeindeleben aufbauen, verhehlt Hamidullah, der muslimische Entdecker des Urdokuments, deren uneindeutigen Status nicht.

„Wenn man den Text analysiert, stellt man fest, daß er die jüdischen Stämme keineswegs offenkundig als eigenständige Gruppe bestimmt und klassifiziert. Im Gegenteil, im Verfassungstext werden eine Reihe von in den Islam übergetretenen arabischen Stämme aufgezählt und davon berichtet, daß die und die jüdischen Stämme als Verbündete dieser oder jener arabischer Stämme diese oder jene Rechte haben. Nach der äußeren Form der angesprochenen Artikeln scheinen diese Juden am Körper des Stadtstaates nicht beteiligt zu sein; deren Status kann man als Zuflucht in der bzw. Anschluß an die herrschende(n) muslimisch-arabische(n) Gemeinde charakterisieren. “ (Hamidullah 1993: 194)

Indessen schickt sich Hamidullah anschließend an, nachzuweisen, daß die Juden, wenn auch nicht zu Beginn, so doch später in den Vertrag aufgenommen worden sind. Die orientalistischen Gelehrten weisen ähnlich darauf hin, daß sowohl die drei großen jüdischen Stämme $Q u$ rayza, Banu an-Nadir und Banu Qaynuqa, deren Namen bedeutsamerweise in der Urkunde nicht vorkommen, als auch kleinere jüdischen Stämme Schutzverbündete der vorherrschenden großen arabischen Stämme Aus und Khazradj waren. Somit fallen die jüdischen Stämme vermittels dieser Beziehung unter die Definition der Umma. Wellhausen bezweifelt zudem, daß es überhaupt einen Vertrag zwischen $\mathrm{Mu}$ hammad und Juden gegeben hat. Die Juden hätten sich nämlich nie auf ein Dokument berufen.

„Die Quraitza behaupten, es bestehe kein Bund zwischen ihnen und $\mathrm{Mu}-$ hammad (BH. 675). Ihr Haupt, Ka'b b. Asad, zerreißt nicht ein Schriftstück, sondern einen Schuhriemen, um seinen Bruch mit den Medinensern 
symbolisch zu bekräftigen (Vaq.197). Indessen bezweifle ich darum doch nicht die Authentie der von Ibn Ishaq uns mitgeteilten Gemeindeordnung von Medina. Sie enthält aber keinen Vertrag mit den Juden, sondern nur eine weniger ihnen als den Ansar [den Medinensern, L.T.] gegebene Bestätigung ihrer alten Verhältnisse, unter gewissen durch die Lage der Dinge notwendig bedingten Beschränkungen. Sie ist überhaupt keine wirkliche und eigentliche Vereinbarung. [...] Es ist ein einfacher Erlaß Muhammads, worin er die Ordnung des Gemeinwesens, wie sie sich seit seiner Ankunft in Medina praktisch schon entwickelt hat, kodificirt. Es ist kein Gesetz das hätte von den Parteien vereinbart und beschworen werden müssen; sondern nur eine öffentliche Darlegung der Hauptartikel des geltenden Staatsrechtes der Umma. Von seinem historischen Werte verliert es natürlich dadurch gar nichts.“ (Wellhausen 1889: 82f)

Es gehört zum dogmatischen Bestand des Islam, daß sich der Prophet in die jüdisch-christliche Offenbarungsgeschichte als deren Abschluß einreiht. $\mathrm{Da}$ den Juden und Christen in der folgenden islamischen Geschichte die Freiheit im Kultus gewährleistet wurde, kann man ohne die für den Islam so zentrale Idee von der Zusammengehörigkeit der Buchreligionen nicht verstehen. ${ }^{94}$ Die islamwissenschaftlichen Studien von Sprenger (1865: 29-60) berichten dazu noch biographisch in Anlehnung an die islamischen Standardquellen (Hadith-Sammlungen und Siras) von Muhammads anfänglicher Hoffnung in Medina, sich bei den beiden Religionen, vor allem bei den Juden eine Anerkennung als Prophet verschaffen zu können. Davon berichtet der Koran in Sure 5:

„44. Wir haben die Tora hinabgesandt, in der Rechtleitung und Licht enthalten sind, damit die Propheten, die gottergeben waren, für die, die Juden sind, (danach) urteilen, und so auch die Rabbiner und die Gelehrten, aufgrund dessen, was ihnen vom Buche Gottes anvertraut wurde und worüber sie Zeugen waren. [...] 45) Und wir haben ihnen darin vorgeschrieben: Leben um Leben, Auge um Auge, Nase um Nase, Ohr um Ohr, Zahn um Zahn; und auch für Verwundungen gilt die Wiedervergeltung. Wer aber dies als Almosen erlässt, dem ist es eine Sühne. Diejenigen, die nicht nach dem urteilen, was Gott herabgesandt hat, das sind die, die Unrecht tun. 46) Und wir ließen nach ihnen Jesus, den Sohn Marias, folgen, damit er bestätige, was von der Tora vor ihm vorhanden war. Und wir ließen ihm das Evangelium zukommen, das Rechtleitung und Licht enthält und das bestätigt, was von der Tora vor ihm vorhanden war, und als Rechtleitung und Ermahnung für die Gottesfürchtigen. 47) Die Leute des Evangeliums sollen nach dem urteilen, was Gott darin herabgesandt hat. Und diejenigen, die nicht

94 Allerdings wäre es falsch, den Status der Andersgläubigen einfach aus einem religiösen Dogma abzuleiten. Es handelt sich dabei vielmehr um ein Zusammenspiel von imperialer Politik, besonderen Steuereinnahmen und religiösen Ideen. 
nach dem urteilen, was Gott herabgesandt hat, das sind die Frevler. 48) [...] Für jeden von euch haben wir eine Richtung und einen Weg festgelegt. Und wenn Gott gewollt hätte, hätte ER euch zu einer einzigen Gemeinschaft gemacht. Doch will ER euch prüfen in dem, was ER euch hat zukommen lassen. So eilt zu den guten Dingen um die Wette. Zu Gott werdet ihr allesamt zurückkehren, dann wird ER euch kundtun, worüber ihr uneins waret.“ (Der Koran 1987: 85f)

Schon bald mußte aber Muhammad seine Hoffnung aufgeben, von den Juden als Prophet anerkannt zu werden. Das hoffnungsvolle Bemühen schlug rasch in Abgrenzung zu den Juden und dem Judentum um. In diese Zeit fiel z. B. die Verlegung der Gebetsrichtung von Jerusalem nach Mekka. Nicht mehr die Traditionsfolge wurde im Handeln des Propheten betont, sondern die Differenzen wurden markiert. Der Rest war dann nur noch eine zunehmende Feindschaft zwischen den Muslimen und Juden, wobei die letzteren schließlich aus verschiedenen Anlässen verfolgt, massakriert und unterworfen wurden.

\subsubsection{Der intellektuelle Zwang zur Konsistenz}

Wie kann man also in einem islamistischen Diskurs das historische Ereignis der Ausschließung der Juden durch den Propheten, die sinnbildlich für den Anderen schlechthin im Modell für das Zusammenleben unterschiedlicher Gruppen einstehen, und die daran anschließende historische Praxis in der muslimischen Geschichte reibungslos mit dem gesellschaftspolitischen Projekt einer vermeintlich auf Gleichheit der Blöcke gründenden Umma in Einklang bringen? Dies ist keineswegs ein von außen an das Modell herangetragener Einwand, sondern er entspringt dem Modell selbst und der Diskurs setzt alle Mittel ein, um den inneren Riß zuzunähen.

Der islamistische Diskurs als ordnungsgenerierende Bedeutungspraxis wird insofern eine Hegemonie innerhalb des diskursiven Feldes entfalten können, als er verschiedene Elemente als die Momente seiner Einheit artikulieren kann. Die thematische Garantie der diskursiven Einheit wird hier durch die Konstruktion der Umma gewährleistet. Konkret gesprochen, muß dabei einerseits der Abstand zur Geschichte und Tradition, welche vom Makel befallen ist, der göttlichen Weisheit verlustig zu gehen, kenntlich gemacht werden. Sonst funktioniert die Wiedererrichtung des unverdorbenen Urmodells nicht. Außerdem würde der Versuch, als performative Bestätigung der Idee von Einheit in Vielfalt (die Formel des Zusammenlebens) hier und jetzt mit Andersdenkenden und Anderslebenden in Dialog zu treten, kläglich scheitern. Elemente wie Zivilgesellschaft, Pluralismus, ethische Politik (wie gleich unter dem Titel öffentliches Glück zu diskutieren ist), 
Gesellschaftsvertrag, Anerkennung des Anderen müssen also als Bestandteile des Diskurses integriert werden, andernfalls bricht der Diskurs zusammen.

Andererseits darf die historische Erfahrung der Umma nicht völlig verworfen werden, da der islamistische Diskurs nicht alleine durch einen Dialog mit den „Nichtmuslimen“ existieren kann. ${ }^{95}$ Tatsächlich operiert dieser Diskurs in einem historisch bestimmten politischen Raum, in dem die geschichtliche Mission der Türken auf ihre Verdienste bei der kriegerischen Verbreitung des Islam hin gedeutet wird. Der zivilisatorische Höhepunkt der „Anerkennungspolitik“ gipfelt in dem Urteil von Mehmet dem Eroberer in seinem Einzug ins damalige Konstantinopel, daß die Christen ihre Kirchen behalten, aber keine neuen bauen dürfen. In diesem politischen Raum wird zudem der Zerfall des Reiches auf die konstitutionellen Regelungen von 1876 und 1908 zurückgeführt, da diese den Nichtmuslim dem Muslim gleichgestellt hatten. Es handelt sich letztlich um einen politischen Raum, den man endlich von den laizistischen Usurpatoren befreien will. Ausgerechnet die zentrale Affäre der Rekonstruktion des VM, der Status der

95 Ohnehin mußten sich die Protaganisten den Vorwurf gefallen lassen, sich völlig ignorant gegenüber der historischen Erfahrung der Umma verhalten zu haben, um denn nur Anerkennung bei den Linken zu erheischen. Dazu schreibt z.B. I. Süreyya Sırma: „Falls wir Muslime Forschungen über den Vertrag von Medina oder irgend ein anderes islamisches Thema anstellen, kann unser Ziel keineswegs darin bestehen, den nach dem Zerfall des Bolschewismus orientierungslos gewordenen Marxisten oder den Demokraten, die seit etwa 70 Jahren ihr Regime nicht in Ordnung bringen können, oder auch den Laizisten der Türkei, deren Kapital lediglich darin zu sehen ist, bei jeder Gelegenheit die Muslime zu attackieren, einen Ausweg zu zeigen bzw. sie ins Glück zu geleiten. Unser Ziel soll darin bestehen, in Allahs Gnade zu gelangen.“ (1994: 46f)

In der Stellungnahme des Radikalislamisten Aksu, der den sociological turn im islamischen Denken zutreffend konstatiert, hört sich der kritische Ton härter an: „Schließlich wurden die Muslime, besser gesagt: islamistische Intellektuelle, in einem steigenden Maße vertraut mit den westlichen Sozialwissenschaften. Tag und Nacht verbringen sie mit Sozialwissenschaften, denken mit den letzten Paradigmen der zeitgenössischen Sozialwissenschaften, ergehen sich im Bemühen, alternative Gesellschaftsprojekte oder künftige Gesellschaftsmodelle zu entwickeln. An diesem Punkt haben die islamistischen Intellektuellen keine Anstrengung darum unternommen, die westliche Wissenschaft, welche mit der eigenen Denktradition nichts gemeinsam hat, ihre Produkte und ihre Verfahrensweise kritisch zu betrachten, zumindest den historischen Kontext, in dem diese entstanden sind, zu beleuchten und erklären.“ (Aksu 1992: 49) 
Nichtmuslime, sucht somit den Diskurs selbst heim. Jedem Beitrag zur Konstruktion des VM drängt sich die Erklärung der historischen Ereignisse unabwendbar auf. Immer wieder scheint zwar an einigen Stellen das Begehren auf, die geschichtlichen Erfahrungen sowohl der arabischen als auch - und das ist weitaus wichtiger - der türkischen Muslime mit Hilfe der Autorität des Urvertrages beiseite zu schieben, und zuweilen sogar ein anarchistisches Staatsverständnis (so z.B. bei Çelik 1994a: 22) aus der Rekonstruktion hervorgehen zu lassen. Es setzt sich aber letztlich doch eine eigentümliche Konstruktion durch, die sich irgendwo dazwischen postiert. Wie versuchen die Islamisten den im Diskurs tiefsitzenden Stachel des historischen Ereignisses herauszuziehen, was zu tun sie aufgrund des Begehrens, das Ursprungsmodell buchstäblich wieder zu beleben, gehalten sind?

Die zweitrangige Stellung der Nichtmuslime in der islamischen bzw. osmanischen Ordnung wird zunächst einmal von nahezu allen Verfechtern des VM freimütig eingestanden, jedoch ihr Status nicht selten an das Verhalten geknüpft, das sie gegenüber dem Islam angenommen haben. Kadir Canatan, ein weiterer Protagonist des VM, läßt sich auf das Regime der Behandlung der Nichtmuslime in der islamischen Geschichte ein, um die historische Erfahrung in den Diskurs hinein zu artikulieren:

„Gibt es denn Differenzen zwischen dem unter der Führung seiner Heiligkeit des Propheten Muhammad gegründeten islamischen Staat und dem Status, den der Eroberer [Sultan Mehmet II] Nichtmuslimen gewährt hat? Falls ja, wie kann man das erklären? [...] Dann sind das Medinensische Modell, dem Gleichheit, Partizipation und Autonomie zugrunde liegen, und das hierarchische, totalitäre, vor Partizipation verschlossene und auf Ungleichheit basierende osmanische Modell definitiv verschieden." (1994: 106)

Wie erklärt nun der Islamist von heute auf seiner Suche nach einem idealen, doch historisch praktizierten Modell den Unterschied zwischen dem Urmodell und dessen Abwandlungen? Zunächst führt er eine bevorzugte Position aus der allgemeinen islamistischen Diskussion an:

„Wie kann man aber diesen Unterschied erklären? Nach einer unter den Muslimen weit verbreiteten Meinung ist für uns das osmanische Modell nicht bindend. Denn die ab der Umayyidenzeit einsetzenden Abweichungen vom Islam haben bei den Osmanen fortgedauert und der Islam konnte nie seine reine gesellschaftliche Praxis entfalten. Deswegen sollten wir, wenn wir bezüglich der Gegenwart Abstraktionen der Geschichte vornehmen, nicht das osmanische Modell zum Ausgangspunkt nehmen, sondern das Medinensische Modell.“ (Ebd.) 
Doch gibt sich der Islamist mit dieser Antwort nicht ganz zufrieden. Den „osmanischen Totalitarismus“, den die radikaleren Islamisten, für die nur in der Urgemeinde der ,wahre“ Islam praktiziert worden sei, will er nicht ohne weiteres gelten lassen. Hier setzt eine historisierende Erklärung an, in der die Realität als Prüfungsinstanz für die Wahrheit der Aussagen dienen soll. Die Erläuterung der historischen Bedingungen soll die historische Erfahrung situieren und somit der Differenz zwischen dem Urmodell und dessen Abwandlungen die Spannung nehmen:

„Obwohl diese Meinung in mancherlei Hinsicht richtig ist, befriedigt eine solche Herangehensweise nicht, da sie die Systemfrage auf den Willen der Kalifen und Sultane reduziert. Sowohl Taner Akcam ${ }^{96}$ als auch Bilal Eryilmaz betonen, daß das osmanische Millet-System auf die willkürlichen Verfügungen oder moralischen Tugenden der Sultane nicht zu reduzieren und daß es mit Sicherheit eine notwendige Folge des islamischen Rechts ist. Der christlich-arabische Historiker P. Hitti, berichtet, daß das Zımmi-Recht nicht nur in der Anfangsperiode des Islam, sondern auch unter den Umayyiden, Abbasiden, Seldschuken und Osmanen praktiziert worden ist.

96 Der Verweis auf Akcam ist, öffnet man einen Nebenschauplatz, äußerst bedeutsam, um den Diskurs, dessen Adressaten und Träger, vor allem dessen intertextuelles Funktionieren herauszustellen. Akcam ist kein Historiker, ist auch nicht mit Arbeiten über die osmanische Geschichte hervorgetreten. So kann der Verweis keinen fachlichen Hintergrund haben. Er gehört zum linken Spektrum und ist darin insbesondere mit der Betonung der Menschenrechte und den Fragen nach minimalen Bedingungen friedlichen Zusammenlebens hervorgetreten. Die Kritik des Nationalstaates ist eines seiner Hauptthemen; ein anderes, mit dem er seine eigene politische Vergangenheit kritisch überwand - er war unter den Anführern einer marxistischen, revolutionären Massenorganisation vor dem Militärputsch von 1980 - handelte vom Eurozentrismus. Akcam lebte jahrelang im Exil in Deutschland, hat sich hier vornehmlich in den Kreisen der GAL (Grüne Alternative Liste Hamburg) bewegt. Er war übrigens die treibende Kraft dafür, daß der Multikulturalismus und die Anerkennung der kulturellen Identität, die Kritik des Eurozentrismus Eingang in das politische Imaginäre türkischer Organisationen in Deutschland fand. Der Prozeß, den er in Gang gesetzt hat, ist keineswegs abgeschlossen. Es sind religiöse Gruppen der Türken (Moscheevereine) angetreten, um den Diskurs über Multikulturalismus und Anerkennung kultureller Differenz in der Öffentlichkeit zu repräsentieren (zu den religiösen Gruppen im Konflikt um den muslimischen Gebetsruf in Duisburg vgl. Tezcan 2000). Zurück zum Gegenstand der vorliegenden Arbeit, Akcam hat sich an der Debatte um den VM aktiv beteiligt, gehört zu den Nichtislamisten ganz vorne, die sich von dem Modell viel für eine demokratische politische Kultur in der Türkei versprechen. 
Warum stimmen dann aber das Medinensische Modell des Propheten Muhammad und das osmanische Millet-System nicht überein? Konfligieren sie denn etwa? Meiner Ansicht nach gibt es einen Schlüssel zur Lösung dieses Problem, und das betrifft die anfängliche Ausgestaltung der Machtverhältnisse. Der berühmte muslimische Gelehrte Ebu Ubeyd (770-839) trifft bei der Analyse der Eroberungspolitik der Muslime eine wichtige Unterscheidung. Demnach unterscheidet sich die Politik gegenüber den kriegerisch eroberten Ländern bzw. ihren Völkern von der Politik gegenüber den friedlich eroberten Ländern bzw. ihren Völkern. In den mit Gewalt erworbenen Ländern kann das Staatsoberhaupt das gesellschaftliche und kulturelle Leben mit bestimmten Restriktionen belegen und sein eigenes Recht aufdrücken. Denn hier haben die Muslime ihre Herrschaft auf eigene Faust durchgesetzt. So hatten die Muslime denn auch in den unter diese Kategorie fallenden Gebieten historisch den Bau neuer Tempel, Glockengeläut und Weinverkauf verboten.

In den Orten, die friedlich in die Herrschaft der Muslime übergegangen sind, durften die Nichtmuslime das eigene Rechtssystem praktizieren. Diesbezüglich gegen sie zu intervenieren und Verbote zu verhängen, ist nicht zulässig. Omar benahm sich in seinem Einzug in Damaskus verbieterisch, als die Einheimischen ihn mit Schwertspielen und wohlduftenden Blumen empfingen. Nachdem ihm aber berichtet worden war, daß das ein persischer Brauch sei, Omar gebot: ,Belasset sie bei ihrem Brauch'.

Also bestimmte das Verhalten des einheimischen Volkes oder der Häuptlinge dessen darauf folgenden gesellschaftlichen Status. Diese Unterscheidung erklärt meines Erachtens die unterschiedlichen Politiken gegenüber Zımmis und deren unterschiedlichen Status. Der Prophet zog in Medina friedlich ein, nicht infolge eines Krieges. Er hat den Vertrag von Medina mit Nichtmuslimen unter freien Gegebenheiten und in Partizipation zustandegebracht. Die Osmanen hingegen haben, einschließlich Istanbuls, den Balkan durch Krieg erobert und deswegen als herrschende politische Macht eigene Autorität aufoktroyiert. Mit anderen Worten, sie haben entgegen dem Willen der nichtmuslimischen Untertanen Verbote und Einschränkungen verhängt. Der Unterschied zwischen den besagten Modellen rührt daher.“"(a.a.O.: 106f)

Die den Kontextbedingungen Rechnung tragende Erklärung soll auBerdem dem Muslim von heute die Handlungsanweisungen geben:

„Diese Unterscheidung beeinflußt unsere Haltung bei einem Problem, das uns auch heute begegnen könnte. Wenn die Muslime friedlich, d.h. ohne Gewaltanwendung, über den demokratischen Weg an die Macht kommen, wird ihre Haltung gegenüber denen, die nicht zu ihnen gehören, anders ausfallen, als wenn sie mit Gewalt die Macht bekommen. Schließlich ist die Art und Weise, wie die Muslime an die politische Macht gelangen, ein Faktor, der das spätere Machtverhältnis zwischen Muslimen und nichtmuslimischen Gemeinschaften bestimmen wird.“ (a.a.O.: 107)

Tatsächlich findet man hier die in der vorherigen Geschichte des Islam gar nicht bekannte Unterscheidung zwischen zwei Regimen der Be- 
handlung von Nichtmuslimen, nämlich einmal die konstruierte, vermeintlich gleichwertige Behandlung auf der Basis eines freiwilligen Vertrags, und zweitens den untergeordneten Zimmi-Status, auch bei den anderen Vertretern des VM.

Es ist nicht meine Absicht, das „Urmodell“ und die Rekonstruktion gegeneinander auszuspielen, um den inauthentischen Charakter der zweiten zu denunzieren. Das Interesse der hier vorgelegten Analyse besteht darin, die Mechanismen und Strategien der Rekonstruktion und deren Kontext aufzudecken. Das wird hier allerdings nicht deswegen getan, um sie für bare Münze zu nehmen, nicht um uns vor der islamistischen Erfolgsstory, dem irdischen Paradies des versöhnten Medina - in der Vergangenheit wie im Zukunft - huldigend zu verbeugen. Es gilt den Bruchstellen der Konstruktion nachzuspüren; es geht darum, aufzuzeigen, was der Diskurs verbirgt, verschüttet, zu vernähen versucht, um überhaupt zu funktionieren, und schließlich darum, wo die Operationen des Diskurses aufbrechen.

In diesem Sinne äußerst sich das Problem des islamistischen Diskurses darin, die geschichtliche Praxis nicht gänzlich zu verteufeln, dennoch die Reinheit des Urmodells unter den Bedingungen der Gegenwart zu bewahren, in der man den Islam nicht mehr mit Gottes Schwert verbreitet. Die konstruierte Reinheit des Urmodells und die Reinheit der vorgestellten Utopie zu retten, die man bloß nicht als Utopie deklarieren will, darin besteht das Unterfangen.

Diese Anstrengung läßt Bulaç ebenfalls von den differenten Modi der islamischen Praxis sprechen.

„In diesem kategorialen Rahmen muß man das vom Islam vorgesehene Zımmi-Recht gesondert behandeln. Denn der Zımmi-Status drückt die rechtliche Regelung für diejenigen Nichtmuslime aus, die mit den Muslimen nicht zusammenleben wollen, Kriege gegen sie führen und dabei unterliegen. Wovon wir hingegen hier handeln, umschreibt den Umstand, daß sich die Nichtmuslime, welche wie in Medina mit den Muslimen zusammenleben wollen, nach den Bestimmungen des auch von ihnen unterzeichneten Vertrages als freie Menschen, freie Rechtsgemeinschaften an der völlig auf die Exekutive beschränkten politischen Organisation beteiligen." (1994a: 15, Fn. 12)

Bulaç greift an einer anderen Stelle diese Idee unter einer verwandten Frage noch einmal auf: Wann können die Muslime die Teilung der Macht akzeptieren, wann sind sie berechtigt, über die absolute Macht zu verfügen? (1995: 286). Solange die Muslime zwei Missionen verfolgen können, gelte demnach die Teilung der Macht: „Daß er den Geboten seiner Religion leben und er ungehindert seine Religion kundtun kann" (ebd.). Nun müßte eigentlich die ganze muslimische Geschichte daraufhin gegengelesen werden, wo sich der Islam fried- 
lich verbreitet und dementsprechend das politische Leben auf vertraglicher Basis geregelt hat (so z.B. müßte man vom indischen Subkontinent sprechen können, wo der Islam über Händler Einzug hielt). Jedenfalls bietet die Geschichte für ein solches, konsequent durchgehaltenes Prinzip keinen Anhaltspunkt, es sei denn für die Zımmi-Praxis. Was uns interessiert, ist hier lediglich dies, die Konstruktionszwänge eines Diskurses aufzudecken, der aus einem historischen Ereignis eine konsistente Geschichtsidee produziert und die Geschichte dem intellektuellen Heilsinteresse, nämlich der Konsistenz - und das auch nicht glücklich gelungen -, aufopfert. Der Zwang zur Konsistenz entspringt also dem Diskurs selbst, weil er sich anschickt, das im ursprünglichen „Modell" enthaltene Heil mit analytischen Mitteln argumentativ in einem öffentlichen Diskurs plausibel an die Dritten zu vermitteln.

\subsubsection{Wiederkehr der verdrängten Machtfrage: Die Umma als muslimische Herrschaft}

So kehrt nun die Frage der politischen Macht, die Frage nach der Institutionalisierung einer „multikulturellen Gesellschaft“, in welcher sich der Staat den einzelnen Gemeinschaften unterzuordnen habe, um so gewaltiger wieder, als sie immer im Namen der Aufbewahrung autonomer Lebensweisen verdrängt worden war. Dies wird besonders deutlich, wenn man die Kennzeichen eines islamischen Staates, auch durchaus aus der Sicht der Autoren des VM, wieder in Erinnerung ruft. Sie lassen Zweifel an dem aufkommen, was über die Gleichheit der Bestandteile der Gesellschaft, über den auf Verwaltungsaufgaben reduzierten Staat und schließlich über die neuartige Umma-Konzeption, die eigentlich dem theoretischen Anspruch nach nicht auf die Gemeinschaft der Muslime beschränkt werden sollte: a) Der Imam steht beim Freitagsgebet der Gemeinde vor. Das Freitagsgebet ist ,in diesem Sinne inhaltlich ein Ritus mit politischen Inhalten und Botschaften“; b) Zakat (Almosensteuer) eintreiben und zuteilen; c) Strafen ausführen; d) Dschihad (heiligen Krieg) erklären. (Bulaç 1995: 279ff). Nicht nachzuvollziehen ist, wie sich eine solche, der historischen Realität muslimischer Reiche vollkommen entsprechende Umschreibung der politischen Macht noch mit einer „neutralen“ Teilung der Macht verträgt. Auch wenn Bulaç wie die anderen mit aller naiven Unschuld die Beteiligung der Nichtmuslime an einer solchermaßen eindeutig beschriebenen Macht beteuern, fällt die anvisierte praktische Institutionalisierung des Projektes in die alten Bahnen der osmanischen Millet-Ordnung zurück. Diese Konfusion, die an vielen anderen Stellen der Beiträge der Konstrukteure ins Auge sticht, darf man nicht 
als Schönheitsfehler übergehen. Sie ist auch nicht bloß die Folge eines noch nicht ausgereiften Reflexionsstandes über das alternative Gesellschaftsmodell - so etwas würde jeden Sterblichen treffen. Sie stellt sich eben zwangsläufig ein, sobald man mit Hilfe von Kategorien und Ideen moderner Politik unter den Bedingungen des nationalstaatlichen Apparates die Gesellschaft auf Gemeinschaften, Gemeinschaften auf Religion (bzw. Weltanschauung), Religion auf Gesetz reduziert und das religiöse Gesetz als positives Recht denkt. Bei Bulaç und einigen Anderen wird Scharia durchaus weiter gefaßt als ein positives Gesetz, indem sie in ihrer allgemeinen Bedeutung als der Weg bestimmt wird. Diese weite Fassung schwindet allerdings in dem politischen Projekt und die Scharia erscheint doch letztlich als positives Gesetz. Ob die beiden Konzeptionen der Scharia (nämlich als der ethische Weg bzw. gar das symbolische Gesetz einerseits und als positives Gesetz andererseits) zusammengehören, bleibt in der Tat ein umstrittener Punkt, auch im innerislamischen Diskurs.

Das positive Recht, welches mit seinem formalen Verfahren einen gemeinsamen Rahmen für unterschiedliche partikulare Gemeinschaften zur Verfügung stellt, wird nun als tyrannisch verworfen. Tatsächlich muß man der islamistischen Kritik an einem Punkt betreff des modernen Rechts recht geben. Es ist keineswegs ein bloßes Verfahren, das sich zu den partikularen Gemeinschaften vollkommen neutral verhält. Bereits in der Formalisierung der Behandlung wird bestimmten Interpretationsweisen partikularer Gemeinschaften Legitimität entzogen, da sie gezwungen werden, sich innerhalb eines bestimmten Rahmens zu bewegen, in dem sie vielleicht ihre Heilsaufgaben im Sinne einer bestimmten diskursiven Ausformulierung nicht mehr wahrnehmen können. So verhält es sich auch tatsächlich mit einer fundamentalistischen Interpretation des Islam. Bereits am Beispiel der türkischen Religionsbehörde (Kapitel I.4.2.1) wurde gezeigt, daß die Bestimmung der öffentlich-politisch zulässigen Religiosität den Aspekt der Bestrafung (ukubat) als einen Bestandteil islamischer Religiosität ausschließen muß, damit der säkulare Staat überhaupt funktionieren kann. In diesem Sinne sehen wir auch in der auch noch so formalen Bestimmung eine bestimmte Form der „Substantialität“.97 Auf jeden Fall arbeitet hier die Spannung zwischen Partikularismus und Universalismus, die nicht völlig aufzuheben ist. Der Islamismus will den „Neutralitätsschein“ des modernen Rechtsstaates zerreißen und ein „gerechtes, gleichberechtigtes Zusammensein partikularer Gemeinschaftsvorstellungen" organisieren, ohne daß sich eine bestimmte partikulare Institution den anderen aufdrücke. Daß diese ,paradiesischen“

97 Für Ch. Taylor ist daher der Liberalismus nicht einfach (kultur-)neutral, er ist zugleich eine „kämpferische Weltdeutung“ (1997: 57). 
Vorstellungen bereits von ihren Vertretern selbst unbeabsichtigt und unbemerkt (das ist schon bemerkenswert) im nächsten Zug gebrochen werden, lenkt allerdings das Interesse weg von der Frage nach dem Wahrheitsgehalt solcher Konzepte hin zu ihrer Funktionsweise und ihren Konsequenzen. Anhand solcher Stellen bekommt man Aufschlüsse über die Vorstellungswelten islamistischer Intellektueller.

Wie sich das irdische „Paradies“ von Gemeinschaften funktionell letztlich doch als eine islamische Herrschaft entpuppt, zeigt sich nicht allein in der oben zitierten, fast offenkundigen Drohung von Canatan, die in diesem Zusammenhang noch harmlos bleibt. Es ging nämlich bei ihm um die Vorhersage, die besagte, daß der Modus der Behandlung von Nichtmuslimen davon abhängt, wie die Muslime an die Macht kämen: ob gewaltsam oder friedlich. Das Problem ist, was das denn noch für eine gemeinsam geteilte Macht ist, wenn sie in der Hand der Muslime sein soll. An einer anderen Stelle wird es noch deutlicher, wo Canatan sich anschickt, nachzuweisen, daß unterschiedliche Paradigmen [gemeint sind im Grunde wieder einmal die Religionen] auf einer gemeinsamen Grundlage miteinander kommunizieren könnten:

„Ein anderer Punkt, der den Islam vom Kontextualismus unterscheidet, besteht darin, daß der Islam zwischenmenschliche und interkulturelle Kommunikation sowie die Übereinkunft auf gemeinsamen Nenner für möglich hält. Nach Kontextualisten wie Kuhn und Feyerabend ist ein Paradigma nur innerhalb seiner eigenen Einheit zu verstehen und dort ein konsistentes Modell. Dadurch wird unmöglich, daß Personen mit unterschiedlichen Paradigmen sich gegenseitig verstehen und auf gemeinsamen Nenner kommen. Dagegen hält es der Koran selbstverständlich für möglich: ,Sprich: O ihr Leute des Buches, kommt her zu einem zwischen uns und euch gleich angenommenen Wort: $\mathrm{Da} ß$ wir Gott allein dienen und $\mathrm{Ihm}$ nichts beigesellen, und daß wir nicht einander zu Herren nehmen neben Gott" (3/64).“ (Canatan 1994: 108)

Die Gemeinsamkeit, von der der Koran spricht und zu der der Prophet selbst während seines Wirkens unermüdlich aufgerufen hat, ist dabei eindeutig: Es geht nicht nur um substantialistisch begründete, genealogisch bestimmte Gemeinsamkeit abrahimitischer Buchreligionen, sondern der absolute Monotheismus soll den Inhalt (Materie) und den Modus (die verfahrenstechnische Form) der Gemeinsamkeit gleichzeitig bilden. Die koranische Sprache kennt denn auch eine solche, für die modernen Institutionen typische Unterscheidung zwischen dem wertgebundenen, d.h. partikularen Inhalt und dem formalen Verfahren nicht. Wahrscheinlich führen solche Stellen exakt in das Zentrum des Diskurses, d.h. in das, was der Diskurs zu vernähen, zu verbergen sucht. Und die Bruchstellen des Diskurses ergeben sich dem Blick 
dort, wo das Verdrängte, das Unheimliche, das den Diskurs heimsucht, wiederkehrt; an der Stelle, wo der Verfechter des VM nicht weiter reflektieren kann, nicht weiter reflektieren darf, wenn er verhindern will, daß sein Modell birst. Der intellektuelle Versuch, den Ursprungsmythos auf einer rationalen Basis zu rekonstruieren, d.h. ihn transparent zu machen, um daraus ein Gesellschaftsmodell zu gewinnen, in dem sich auch die Anderen (die Nicht-Muslime) wiederfinden sollen, geht nicht auf. Das ursprüngliche „Modell“ und dessen historische Ausprägung holt den Diskurs ein, untergräbt ihn, vereitelt die Versuche, eine transparente Ordnung aus ihm hervorgehen zu lassen.

Von hier aus erscheint nun auch das ursprüngliche Dokument in einem anderen Licht. Zwei Sätze aus dem Urdokument bieten sich hier zur Zeugenschaft an. Am Ende des ersten Dokuments, das sich an die arabischen Geschlechter wendet und von den Gläubigen spricht, steht die Ermahnung: „Wenn ihr über irgend eine Sache im Streit sei, so muß sie vor Gott und vor Muhammad gebracht werden" (Artikel 23; Wellhausen 1889: 70; Hervorhebung L.T.). Die hier beteuerte Gemeinsamkeit wird also eindeutig über den islamischen Gott und seinen Propheten verbürgt. Ganz zum Schluss des Gesamtdokuments wird dann das Herrschaftsverhältnis, wenn auch noch ohne den Wert materieller Sanktionen zu besitzen, unmissverständlich unterstrichen:

„§ 47. Wer sich etwas zuzieht, zieht es sich selber zu. Gott wacht über die ehrlichste und billigste Ausführung dieser Schrift. Diese Urkunde schützt keinen, der offen oder geheim Unrecht begeht. Wer zu Felde zieht, genießt Sicherheit, und wer zu Haus bleibt, genießt Sicherheit in Medina, ausgenommen wer offen oder geheim Unrecht begeht. Gott ist der Schutzherr dessen, der redlich und fromm ist, und Muhammad der Bote Gottes.“ (Wellhausen a.a.O.: 73)

Es ist dieser unbedingte Wille, der das prophetische Charisma ausmacht, welches später in der islamischen Geschichte in der ZımmiPraxis institutionalisiert wurde. Der Diskurs der Intellektuellen will ja gerade dieses Charisma weiterhin pflegen, will eigene Legitimität aus ihm schöpfen. Die Mittel, die in ihm zu diesem Zweck eingesetzt werden, und die vordergründige Akzeptanz der gesellschaftlichen Tatsache, daß die Muslime eine Meinung unter den anderen bildeten, geraten gleichwohl in Konflikt mit der Aufgabe, das Charisma auf diese Weise zu pflegen. Nicht jedes geschichtliche Ereignis eignet sich wohl dafür, mit beliebigen Mitteln für beliebige Zwecke artikuliert zu werden. Seine Geschichte gräbt sich auch in die späteren Konstrukte so ein, daß man ihre Spuren nicht beliebig übersetzen kann. Ähnlich verhält es sich auch mit den westlichen Begriffen, die in den Diskurs der Islamisten aufgenommen werden. Ihre Aufnahme geschieht mitunter 
nicht ohne den Preis, daß die ursprünglichen Konnotationen nicht einfach verschoben werden, was sich bei jeder diskursiven Artikulation naturgemäß einstellt, sondern u. U. völlig verloren gehen. Unten wird exemplarisch auf derartige Unternehmen eingegangen. Es werden dabei zum einen die kulturspezifischen Übersetzungen solcher Begriffe dargelegt. Zum anderen wird gezeigt, wie durch den Einsatz westlicher Konzepte die Vorstellung von Gesellschaft dahingehend modifiziert wird, daß sie als die ideale Gemeinschaft konzipiert wird, und zwar nicht mehr einfach auf den Mythos bezogen, um sich daran zu orientieren, sondern als dessen buchstäbliche Verwirklichung, als das Ins-Werk-Setzen des Ideals.

\section{6. Übersetzungen der westlichen Konzepte}

\subsection{Der „wahre Pluralismus“ des Islam, die „Zivilgesellschaft“" der apokalyptischen Reiter}

Damit die verwaltete Religion eine islamisch begründete Kritik erfuhr, die über die Übernahme der staatlichen Macht hinaus zielt, bedurfte es anscheinend, daß der postmodern sensibilisierte Islamismus die Anerkennungsthematik in ein alternatives Gesellschaftsprojekt umsetzt, indem er den analytischen Blick reversiv auf die westliche Welt richtet. Die Überleitung des postmodernen Unbehagens an eurozentristischen Meta-Erzählungen in einen islamistischen Diskurs buchstabiert auf der einen Seite kritisch die Genealogie der modernen Staatsraison aus, welche die Konstitutionsbedingungen auch des islamistischen Gesellschaftsmodells bereitstellte. Auf der anderen Seite entfalten sich hier die kulturell bedingten Eigentümlichkeiten, die aus der Übernahme moderner Kulturtechniken andere Wege hervorgehen lassen, welche konträr zu der postmodernen Dezentrierung des Subjekts verlaufen.

Der Sinn der Geschichte wird im islamischen Denken nicht als Freiheit gedeutet, er lokalisiert sich in der Pendelbewegung zwischen dem Verfall und der Wiederherstellung der göttlichen Weisheit, die dem Menschen ein „Schreiten zu Gott" auferlegt. Freiheit bedeutet hier zweierlei: Die eigene Religion ungehindert praktizieren und die göttliche Botschaft an die Menschen verkündigen. Wenn nun der göttlichen Weisheit nur durch die jeweilige Scharia entsprochen werden kann, die weit über eine individuelle ethische Haltung hinaus den rechtlichen Rahmen der Gemeinschaften bestimmen soll, dann kann die aktuelle Aufgabe des Muslims nach diesem Diskurs nur darin bestehen, die Geschichte der modernen politischen Rationalität zurückzudrehen, um an die Urformen wieder anzuknüpfen. Die Reinigung 
nicht nur des inneren Selbst, sondern die institutionelle Reinigung, die den staatlichen Eingriff zurückdrängen und die Macht wieder in die „Zivilgesellschaft“ zurückgeben soll, bilden die Grundsätze des politischen Handelns und Denkens intellektueller Muslime. Indessen stellt sich bei diesem Unternehmen die Tradition in den Weg, und in einem auf gesellschaftliche Konstitution abstellenden Diskurs muß nicht nur sie neu (kritisch) gelesen werden. Es wird auch die gesamte politische und Sozialgeschichte muslimischer Gesellschaften rekonstruiert. Die Rekonstruktion wird übrigens, das ist sehr bedeutsam, mit Konzepten wie ,Zivilgesellschaft vs. Staat“, „Totalitarismus“, „Gemeinschaft vs. Gesellschaft“ oder ,gute Politik“ bzw. „öffentliches Glück vs. Staatsraison" durchgeführt. Es sind allesamt Begriffe, die zum kategorialen Bestand der westlichen Sozialwissenschaften und politischen Philosophie gehören - das sei hier vorweggeschickt.

Was ist der wahre Pluralismus? Die Frage gehört mittlerweile in das Zentrum islamistischer Überlegungen zum Vertrag von Medina. Das „trojanische Pferd“ der modernen Sozialwissenschaften in der türkischen Gesellschaft, nämlich die laizistischen Intellektuellen, richten diese Frage an die Islamisten. Je nach der politischen Orientierung denunzieren sie entweder, oder sie ermutigen gar das Einklinken der Islamisten in die Debatte um die Pluralität. So adressiert der Historiker Türköne, der sich mit der These hervorgetan hat, der Islamismus sei eine moderne Ideologie, seine Frage an die Protagonisten des VM:

„Kann man aus den Grenzmarkierungen der islamischen Religion ein pluralistisches Gesellschaftsprojekt hervorholen? Kann man in einem solchen Projekt universelle humanitäre Werte und Demokratie zumindest mit minimalen Standards aufrechterhalten? Dies ist zweifellos eine Frage, welche die Muslime beantworten können. Allerdings sind der Adressat dieses Unternehmens die Nichtmuslime. Die Anhänger anderer monotheistischer Religionen, i.e. die Atheisten, Paganen und Agnostiker (selbst diejenigen, die ein laizistisches Islamverständnis pflegen) stellen die Objekte dieses Gesellschaftsprojektes dar." (Türköne 1992: 22)

Symptomatisch ist diese Aussage aber deswegen, weil sich hier die Differenz verfestigende Logik der Anerkennungspolitik in unverhüllter Form bereits andeutet: Die Weltanschauungen werden in soziale Identitäten übersetzt, welche die Grundelemente einer sozialen Ordnung bereitstellen sollen. Zwar geht Türköne selbst nicht so weit, dennoch knüpft er seine Hoffnung auf ein islamisches Modell des Pluralismus an das Unternehmen des VM. Eine zivilgesellschaftliche Entwicklung, in der die Muslime wie die anderen sich wiederfinden und zusammenleben könnten, käme, so will sein Vorschlag nahe legen, ohne die religiösen Gemeinschaften nicht aus. Denn das „Gegenstück zivilgesellschaftlicher Strukturen des Westens in den muslimischen 
Gesellschaften“, behauptet Türköne weiter, „sind die religiösen Gemeinden“ (1992: 24). Man dürfe die Tatsache nicht ignorieren, daß, wenn sich die unteren Schichten in einer religiösen Sprache artikulieren, es dabei immer um mehr gehe als bloß um Religion. Die Religion diene den unteren Schichten, ihre sozialen Forderungen gegenüber der laizistischen Elite auszuformulieren, womit man folglich bereits bei der Zivilgesellschaft angelangt sei (ebd.). ${ }^{98}$

Ähnlich dieser soziologischen Umtaufe der Zivilgesellschaft in Religionsgemeinschaften, jedoch mit umgekehrten Vorzeichen, macht Sarıbay auf den politischen Kontext aufmerksam, aus dem die islamistische Antwort auf die Frage nach Pluralismus und Zivilgesellschaft ihre Motivation schöpft. Die ,intellektuellen Debatten über die Festigung der Demokratie und den Aufbau der Zivilgesellschaft", konstatiert Sarıbay (1993: 14), ,treiben letztlich jede politische Strömung dazu an, ein Gesellschaftsprojekt vorzulegen“. Anders als Türköne äußert er jedoch grundsätzliche Bedenken, vor allem in Bezug auf den islamischen Einheitsglauben (tevhid), den monotheistischen Anspruch, mit dem sich eine Zivilgesellschaft, zu welcher der zivile Ungehorsam konstitutiv gehöre, nicht vertrage (a.a.O.: 19). Worüber beide Autoren bei der Bewertung des Diskurses über den VM trotz aller Differenzen einig sind, ist das Insistieren der Islamisten darauf, nicht vornehmlich auf die Ergreifung der staatlichen Macht abzustellen. Tatsächlich wollen die Islamisten ihren Zugang in den politischen Diskurs genau mit der Kritik des Staates legitimieren. Im prophetischen Medina, das ist die Quintessenz des rekonstruierten Vertrags, habe ein Gesellschaftsmodell die Bühne der Geschichte betreten, das nicht auf den Staat setze, sondern die politische Macht an die Gesellschaft delegiere. Mit dieser Entscheidung nehmen aber die Verfechter des VM die Bürde auf sich, die ganze islamische Tradition im Lichte neuer Fragestellungen, neuer Herausforderungen und neuer Begriffe durchsehen zu müssen. ${ }^{99}$

98 Selbst Mardin scheint sich von den neuerdings in der türkischen wissenschaftlichen Literatur sehr beliebten Rückprojektionen aktueller Begriffe in die Vergangenheit gelegentlich mitreißen zu lassen: „Insgesamt ist also anzunehmen, daß der osmanische Islam die Fähigkeit be$\mathrm{sa} \beta$, das religiöse Recht und rituelle und praxis-orientierte Institutionen wie die Sufi-Orden mit den staatlichen Mechanismen in Gleichgewicht zu halten. Der osmanische Islam kann daher als die Quelle der ,Zivilgesellschaft ‘ außerhalb des osmanischen Staates gesehen werden.“ (1997: 365). Indessen mögen die Anführungszeichen davon zeugen, daß Mardin den Begriff jedenfalls nicht ohne Vorbehalte verwenden will.

99 Das Durchkämmen der Geschichte auf ihre „zivilen“ und „totalitären“ Momente hin wird aber jenseits der Konstruktionsbestrebungen vor al- 
Die Frage nach Islam und Pluralismus wird von den Islamisten offensiv aufgegriffen. Unter einem philosophisch aufpolierten Titel (Medine Vesikası. İslam'ın çoğulculuk referansı. Çoğulcu epistemolojik düzlem; zu dt.: Vertrag von Medina. Pluralismus des Islam. Die pluralistische epistemologische Ebene) konstatiert Köktaş, ein weiterer Protagonist des VM, nachdem er rhetorisch fragt, ob „,der Islam zum Aufbau einer pluralistischen Ebene beiträgt oder diesen verhindert": „Die historische Erfahrung der Umma enthält Pluralismus“ (1994a: 55). Habe man den Pluralismus in den islamischen Diskurs eingeführt, so tauche für den Muslim die Möglichkeit (und zugleich die Aufgabe) auf, ,in die Begriffe wie Zivilgesellschaft semantisch zu intervenieren“ (Köktaş 1994b: 166). Für den einflussreichen Journalisten Dilipak besaß der Islam vor 1400 Jahren, was der Westen heute mit Multikulturalismus sucht.

„Heute versucht vielleicht der Westen in seiner Suche nach Demokratie, mit der Multikulturalismusthese die göttliche Wahrheit des Islam vor 1400 Jahren. Auch in der arabischen Gesellschaft, in die der Islam hinabgesandt wurde, herrschte ein monistisches Denken und innerhalb eines Stammes waren andere Glaubensrichtungen nicht gestattet und folglich nahmen die Kriege zwischen den Stämmen kein Ende. [...]. Zum ersten Mal hat der Islam in Medina ein Rechtsdokument vorgelegt, das sicherte, daß Menschen unterschiedlichen Glaubens multikulturell, friedlich zusammen, frei und glücklich leben konnten.“(1991: 170)

Das Thema der aktuellen Multikulturalismusdebatte wird in die Vergangenheit zurückprojiziert und die vorangegangene Geschichte auf die Bedürfnisse der Gegenwart dermaßen angepasst, daß jene Geschichte ihre Besonderheit in unseren Wünschen völlig verliert. Ein heute aus dem Zusammenhang westlicher Gesellschaften und deren sozialwissenschaftlicher Reflexionen entstandenes Kulturkonzept und die aktuellere Debatte darum werden unbekümmert in die Vergangenheit muslimischer Gesellschaften verlegt. Dieses Unterfangen durchzieht den ganzen Diskurs.

Das systematische Interesse des vorliegenden Buches an dieser Geschichtslektüre besteht daher darin, aufzuzeigen, wie im islamisti-

lem von einer aktuellen Sorge motiviert. Die in den nichtislamistischen Kreisen verbreitete Befürchtung, daß ein zum politischen Konstitutionsprinzip erhobener Islam, d.h. der Islamismus (in der authentischen Formulierung: religiöser Fanatismus) die Anderen vernichten werde, soll mit der Umkehrung des Totalitarismusvorwurfs beantwortet werden. Es geht also um eine in der türkischen Gesellschaft weitverbreitete Furcht, die durch die iranische Revolution und die afghanische Talibanherrschaft, aber auch durch das damals noch sehr aktuelle Massaker an Aleviten in Sivas (1993) nicht gerade entkräftet wurde. 
schen Ursprungsdenken bestimmte kategoriale Mittel um einer Identitätspolitik willen umdefiniert und die über den Kulturaustausch globalisierten Diskurse kulturspezifisch übersetzt werden.

Der Anachronismus, auf dem die Rekonstruktion der Urgemeinde beruht, kulminiert an einer Dichotomie, die ebenfalls in die früheren Gesellschaften und im Spezifischen in die islamische Tradition verlegt wird: Die offizielle Gesellschaft (resmi toplum, d.h. der Staat) ${ }^{100}$ vs. Zivilgesellschaft. Die Abwärtsbewegung islamischer Eschatologie (Verfall) im Hintergrund behaltend, wird man zurecht erwarten, daß die anfängliche Harmonie unter der zersetzenden Wirkung zeitlicher Entfernung vom Ursprung immer brüchiger wird, bis sie, angelangt in der Moderne, vollständig dem Totalitarismus weicht. In diesem $\mathrm{Zu}$ sammenhang erhält das typisch neuzeitliche Gefühl der Nostalgie quasi zwangsläufig ein islamisches Gewand. Die Bezeichnung Totalitarismus, die zweifellos erst im 20. Jahrhundert datiert werden muß, erstreckt sich freizügig gar auf das vorislamische Mekka (so z.B. bei Köktaş 1994a: 58). Auf die Stammesordnung mit ihren Göttern in Mekka, gegen die sich der Islam durchzusetzen hatte, wird nun ein Staat zurückprojiziert, um davon dann eine Gesellschaft abzukoppeln, die von jenem unterdrückt und durch den Islam gerettet werden soll. Man kann dann, wie es der Autor reflexiv einwirft, „mit heutiger Begrifflichkeit formuliert, von einer unter der Tyrannei einer ungläubigen Oligarchie stehenden zentralistischen und totalitären Ordnung in Mekka“ sprechen. Die Herrschenden ,hingen demnach der Götzendienerei als ,offizieller Ideologie' und zwangen sie der Gesellschaft auf.“ (Köktaş 1994b: 164) ${ }^{101}$

Unverkennbar ist selbstverständlich, daß die Mekkanische Oligarchie dem türkischen Staat gleichkommt, dessen Laizität und ,verwaltete Religion“ als Synonyme für die „offizielle Ideologie“ fungieren.

100 Den Begriff der offiziellen Gesellschaft hat der postmodern beeinflußte Islamismus in das islamische Vokabular eingeführt. Die Orthodoxie und der klassische Islamismus haben ihn entweder gar nicht, oder nicht konzeptionell und systematisch gebraucht.

101 „Offizielle Ideologie“ ist ein stehender Begriff im politischen Diskurs der Regimekritiker in der Türkei. Sie bezeichnet im Prinzip den Kemalismus. Im „Zentralismus“ drückt sich das Wesensmerkmal des türkischen Staates aus. Die Zentralismus-These verträgt sich indes nicht mit der Information, daß die öffentlichen Aufgaben in Mekka auf verschiedene Geschlechter aufgeteilt waren und daß dort keine staatlichen Strukturen und städtischen Behörden (vgl. Wellhausen 1889: 21) im heutigen Sinne existierten. Die Anführungszeichen, mit denen der Ausdruck offizielle Ideologie versehen ist, und der Verweis auf die zeitgenössische Genese der Begrifflichkeit heben jedoch, da sie keine theoretischen Konsequenzen entfalten, keineswegs den Anachronismus auf. 
Bulaç liefert gar eine nichtmaterialistische Version des HISTO$\mathrm{MAT}^{102}$, die von der Verfallsgeschichte der Zivilgesellschaft erzählt:

„1.Die Epoche, in der die offizielle ${ }^{103}$ und die Zivilgesellschaft durch und durch pluralistisch waren. Diese ist das kurz anhaltende Asr-1 Saadet.

2. Die erste Sultanatsepoche, in der sich die offizielle Gesellschaft von der Zivilgesellschaft abgekoppelt, totalitäre und unterdrückerische Züge angenommen hat, dennoch die Zivilgesellschaft ihren Pluralismus gänzlich bewahren konnte. Diese geht bis in die mittlere Phase der Abbasidenherrschaft hinein.

3. Ab diesem Datum gewinnt die offizielle Gesellschaft die Oberhand über die Zivilgesellschaft, die Sphären Recht und Erziehung fallen in die Hände des Staates. Der erste Bruch vollzog sich im Rechtsbereich, indem Ebu Yusuf das Justizministerium bei den Abbasiden übernahm, und im Erziehungsbereich mit der Gründung der ersten Medrese durch Nizamülmülk.

4. Bei den Seldschuken und Osmanen hebt die offizielle Gesellschaft ihre Abgrenzung von der Zivilgesellschaft deutlich hervor, um sich vollkommen abzusichern. In dieser Epoche wird der zivile Bereich der Scharia, der offizielle Bereich dem traditionellen Recht (örf-i Hukuk) zugeteilt.

5. Die vollständige Okkupation des zivilen Bereichs durch den offiziellen setzt mit der zweiten Konstitution [im Jahre 1908, L.T.] an und wird mit dem Ausrufen der Republik abgeschlossen." (Bulaç 1993: 44; Hervorhebungen L.T.)

In der Schematik des sozialgeschichtlichen Verfalls erfährt somit der Verfall der göttlichen Weisheit seine Materialisierung. Solange die Intention der Islamisten darin besteht, eine totalistische Lösung der Probleme heutiger Gesellschaft vorzulegen, wird die Rekonstruktion der Geschichte sklavisch dazu dienen, die ganze Geschichte als eine fortlaufende Entfremdung von den wahren Urformen zu deuten. Im

102 HISTOMAT: Historischer Materialismus, der schematische Ablauf der Menschheitsgeschichte nach dem Marxismus. Zuerst war die primitive Kommune, die dann durch die Sklavengesellschaft abgelöst wurde. Dann betrat der Feudalismus die Bühne der Geschichte, mußte aber durch den Widerspruch zwischen der Entwicklung der Produktivkräfte und der der Produktionsverhältnisse dem Kapitalismus weichen. Dieser wird entsprechend dem Motor der Geschichte ebenfalls unausweichlich Platz machen. Bei Bulaç findet sich, das ist bemerkenswert, eine explizite Bezugnahme auf den Urkommunismus der primitiven Gesellschaft zur Bekräftigung der These der "unentstellten Weisheit"(Goldenes Zeitalter).

103 Unter diesem Kunstwort (resmi toplum) ist der Staat zu verstehen. Ich übersetze ihn nach dem originalen Wortlaut, um nicht zuletzt einen Eindruck von der Begriffsbildung zu vermitteln. 
Hinblick auf die in die Vergangenheit zurück verlagerte Dichotomie erscheint der VM in einem ,zivilgesellschaftlichen“ Licht, indem er eine politische Einheit begründen soll, welche der Gesellschaft die Priorität einräume und nicht dem Staat (so z.B. bei Köktaş 1994a: 59). Verschlägt man den sich verselbständigenden Staat auf die Seite des Übels, so bleibt am Pol des Heils die reine Gemeinschaft, oder das reine Volk, dessen Vertretung, ja dessen Verteidigung gegenüber dem Staat in der Geschichte immer schon von der Ulema wahrgenommen worden sei (Köktaş 1994a: 60). ${ }^{104}$ Die Umma als unverzerrte ideale Gemeinschaft in realhistorischer Verkörperung werde demnach in ihrem historischen Gang stets durch den Staat korrumpiert, der seinen Machtbereich illegitim über die vom Propheten selbst mit Hilfe von VM praktizierte, anfängliche Aufgabenbestimmung hinaus erweitert habe.

Die legitime Form des Staates wurde von Bulaç mit einem aus dem Urdokument herausgelesenen konstitutiven Prinzip auf die Judikative und Verteidigung bzw. Kriegführung begrenzt (Bulaç 1992: 110). Bisweilen wird auch ein Hadith des Propheten hinzugezogen, nach dem sich die Aufgaben der Verwaltung in Steuereintreiben, Rechtsprechung und Verteidigung erschöpften, während die alle anderen Bereiche in die Hand der Zivilgesellschaft gehörten (ebd.; vgl. auch Köktaş 1994b: 167). In der Tat wird hier, das muß man zugeben, die vormoderne politische Macht relativ zutreffend beschrieben. Das was aber ihre soziologische Bedeutsamkeit ausmacht, nämlich ihre Historizität, wird jedoch dem Streben danach aufgeopfert, die künftige Gesellschaft nach einem (religiösen) Modell herzustellen. Somit wird zugleich der Buchstabe des Urmodells idealisiert und das Ereignis selbst seiner Geschichtlichkeit beraubt. Dies hat Konsequenzen für das politische Denken im Islam.

104 Die Gegenüberstellung Staat vs. Zivilgesellschaft der Umma wird folgerichtig auch auf die aktuelle Geschichte des islamischen Regimes im Iran appliziert. So wird die von Khomeini installierte Instanz der Velayet-i Fakih [zu dt.: Herrschaft der Rechtsgelehrten] als eine Garantie der Zivilgesellschaft interpretiert: ,[...] Obendrein hat er [Khomeini] mittels Velayet-i Fakih den Ulema die Befugnis übertragen, die politische Macht im Namen der Umma aus der Distanz zu kontrollieren und $\mathrm{zu}$ befehligen. Dies war eine Entscheidung, selbst in einem islamischen Regime die Zivilgesellschaft vor der offiziellen Gesellschaft zu schützen und ihr den Vorrang zu geben. Ist denn nicht dieses Projekt, das übrigens weiterhin in Kraft ist, ein Projekt der Zivilgesellschaft? Macht dies nicht Khomeini, selbst wenn man es nicht ,zivil' nennen sollte und das muß man nicht -, zu jemandem, der für die Zivilgesellschaft ist?" (Bulaç 1995: 284) 
Das historische Mißtrauen der Ulema gegenüber dem Herrscher, um die Verwaltung des Heilserbes nicht in der Politik aufgehen zu lassen, wird aus der rekonstruktiven Perspektive des Diskurses über den VM als das Zeichen einer reinen Einheit von muslimischem Volk (Umma) und Ulema interpretiert. Der Staat war im klassischen islamischen Denken ein notwendiges Übel. Das Notwendige resultierte aber aus der Erkenntnis, daß die menschliche Gemeinschaft unvollkommen ist, und diese Vorstellung hatte mit einer Unterscheidung zwischen Staat und Gesellschaft nichts zu schaffen, welche im heutigen Sinne ohnehin nicht bekannt war. Die Grenze verlief stattdessen zwischen dem Herrscher und dem göttlichen Gesetz, das allerdings keineswegs mit dem Volk in einen konstitutiven Zusammenhang gebracht wurde. ${ }^{105}$

Der islamistische Diskurs hingegen, trotz der wiederholten Betonung der schwachen Natur des Menschen, konstruiert ein für die islamische Kultur ungewohntes Menschenbild. Der Mensch wird, so z.B. nach der Konzeption von Çelik - ebenfalls einem der führenden Köpfe des Intellektuellenislam -, in seinem Bemühen, sich in der Interaktion Sinn zu verschaffen, systematisch von der politischen Macht schikaniert. „Das Begehren der politischen Macht, die Interaktion zu bestimmen, " behauptet Çelik, ,verhindert das Funktionieren der ,unverzerrten Sprache“" (1994b: 23). Also steht dem Menschen in seiner vom unmittelbaren Wort ermöglichten, unverzerrten Interaktion die Politik mit Tyrannei und Schranken gegenüber (ebd.). Auch hier drängt sich der in ideologischer Hinsicht verteufelte, trotzdem den islamistischen Diskurs unterschwellig durchziehende, utopistische Zug unüberhörbar auf: „Die Überwindung der Polarisierung zwischen der Sinnsuche des Menschen und der Autorität wird“, - so schlägt die islamische Heilszusage in eine soziologisch ausgerüstete politische Diesseitsutopie um -, , an und für sich schon die Eckpfeiler des Zusammenlebens bereitstellen." (Çelik 1994b: 24) Für Çelik kann dann selbst „das gegenseitige Mißtrauen ziviler Gruppen“ (immer als Religionsgemeinschaften $\mathrm{zu}$ verstehen) ,auch jenseits des offiziellen [staatlichen, L.T.] Bereichs“ nur noch als „die Widerspiegelung der gegebenen Autorität, eine Reflexion der politischen Macht“ (ebd.) gedeutet werden. Die versöhnte Gesellschaft ist folglich dann nicht nur denkbar. Es werden auch kategoriale Mittel dafür vorgelegt, daß sie machbar ist. ${ }^{106}$ Mehr noch, im Grunde existiert sie schon immer. Sie

105 Seufert (1997b) hat auch auf die durch den Islamismus vorgenommene, funktionelle Gleichsetzung von Volk und Allah hingewiesen.

106 Selbstverständlich bedeutet die von uns hier gebrauchte Formulierung der versöhnten Gesellschaft nicht, daß für Çelik dadurch alle Probleme einer Gesellschaft auch empirisch lösen ließen (vgl. Çelik 1994b: 24). 
vermag bloß nicht zum Vorschein zu gelangen, befindet sie sich doch in den Klauen der Macht eingefangen. Die wortgewaltig vorgetragene Utopiekritik entpuppt sich alsbald selber ungebrochen utopistisch. Die ideologische Verdiesseitigung der Religion als Gesellschaftsmodell sucht aus der genuin historischen Erfahrung, in vollkommener Negierung derselben, eine makellose Idealität herauszulesen. Es gibt dann kaum Mittel mehr dafür, - um die der Neomodernismus von Rahman noch besorgt war -, die Geschichte vor der Willkür des Konstruktionszwangs zu verhüten. Wie könnte man sonst erklären, wenn nicht mit dem identitätspolitisch sich selbst auferlegten Konsistenzzwang der intellektuellen Modellsuche aus dem gegenwärtigen Kontext heraus, daß die interreligiösen Relationen in den früheren Gesellschaften plötzlich im Modus der wechselseitigen Anerkennung, interpretiert werden? Hat man die Unterscheidung zivil-staatlich einmal in die Geschichte zurück verlagert; fließt alles soziale Leben aus der einen Göttlichen Weisheit aus, die sich in Religionsgemeinschaften verkörpert, welche wiederum auf eigenen Scharias fußen; ist nun konsistent mit dieser Onto-Theologie der Staat als entfremdet und die Gemeinschaft (Umma) als authentisch gesetzt, dann kann die tatsächlich vorkommende Zwietracht zwischen den und innerhalb der Gemeinschaften ihrerseits auf das Konto der Politik zurückgeführt werden. Der „Ummatismus“ (Stauth 1996) verlegt hiermit die reine Gemeinschaft in die Vergangenheit, welche sich völlig konträr zu der politischen Geschichte und der sozialen Realität verhält und statt dessen eine islamische Übersetzung der Jakobinischen ${ }^{107}$ Kulturtechniken durchführt. Im folgenden wird dieser Übersetzung, Brechung des Übernommenen, anhand eines Beispiels vertiefend nachgegangen.

\subsection{Die islamistische Konzeption des „öffentlichen Glücks“}

Die Analyse des Diskurses über den VM, wie sie in der vorliegenden Untersuchung betrieben wurde, hat sich auf zwei Ebenen bewegt. Auf der einen Seite wurde der inhaltliche Aspekt der Ideologiebildung beleuchtet. Dabei wurden klassisch islamische Ideen und Visionen rekonstruiert und ihre Verknüpfung mit den in das Vokabular muslimischer Gesellschaften hereingebrochenen Konzepten dargestellt. Auf einer anderen Ebene operierte die Analyse, indem die durch den Gebrauch westlicher Kulturinstrumente ausgelösten Transformationen in

Mit der Formulierung wird hier die Idee umschrieben, die von der grundsätzlichen Aufhebbarkeit der Entfremdung ausgeht.

107 Das ,jakobinische Moment“ der Moderne spürt Eisenstadt scharfsinnig in den fundamentalistischen Utopien als dessen religiöse Wendung auf (vgl. 1998, insb. Kapitel 3). 
Konzeptualisierungsweisen der islamischen Religion in Richtung von modellhaft gedachter Gesellschaftskonstitution nachgezeichnet wurden. Das ambivalente Verhältnis zwischen der ideologischen Kritik an der westlichen Moderne und der strukturellen Verwicklung in die moderne Kultur wurde allerdings auch immer auf die Übersetzungen wissenschaftlicher und politischer Konzepte hin befragt. Ich war dabei bemüht darum, mich vor einer bekenntnisartigen Letztentscheidung hinsichtlich der Frage zu bewahren, ob denn nun der Islamismus den Islam modernisiert oder einen antimodernen Schutzwall aufbaut. Der Darstellungsmodus der Analyse dürfte bereits die Art und Weise islamistischer Übersetzung verdeutlicht haben. Dieses Unternehmen soll jetzt am Beispiel eines weiteren spezifischen Falls noch einmal geprüft und somit auch zugespitzt werden. Es handelt sich um eine höchst symptomatische Indienstnahme der politischen Philosophie, genauer gesagt einiger in der westlichen Philosophie weitgehend bekannter Kategorien. Dabei tritt auch die Natur der willentlich herzustellenden Gesellschaft der Islamisten besonders klar zu Tage.

Die Kategorien des öffentlichen Raums und des öffentlichen Glücks werden nun ähnlich zu den anderen kulturellen Instrumenten des westlichen Denkens (Vertrag bzw. Vertragstheorie, Zivilgesellschaft, Verfassung, Pluralismus und Anerkennung der Differenz), in den Dienst eines islamischen Gesellschaftsmodells genommen. Man kann sich nun, aufgrund der bisherigen Darstellung über genügend Fälle verfügend, relativ leicht ausmalen, in welche politisch intendierten Übersetzungsprozesse die beiden eben angeführten Begriffe hineingezogen werden. Vergewissern wir uns jedoch zuvor der Umwandlungen, die einige zentrale Begriffe im Diskurs über den VM erfahren hatten. Vertrag bzw. Vertragstheorie werden nicht als archetypische Konstrukte genommen, mit Hilfe derer die Frage beantwortet wird: „Wie ist die soziale Ordnung möglich?“, sondern als realhistorisches Ereignis. Der fiktive Charakter der Theorie des Gesellschaftsvertrags wird überdies dieser auch noch angelastet, da sie nicht auf einen realen Fall zurückgehe, sondern Kopfgeburt von Theoretikern sei; also ganz anders als der Vertrag von Medina, der etwa zehn Jahre lang in Kraft geblieben sei. Sodann wird Zivilgesellschaft mit Religionsgemeinschaften identisch gesetzt. Gleichzeitig verwandeln sich die Religionsgemeinschaften umstandlos (und restlos) in Rechtsgemeinschaften. Die Anerkennungsproblematik, die in ihren westlichen Konzeptionsweisen - selbst bei den radikal kommunitaristischen - nie ihre Verknüpfung mit der individuellen Anerkennung verliert und sich stets in dem Spannungsverhältnis von Gruppe und Individuum bewegt (vgl. Taylor 1997; kritisch dazu und nur für eine individuelle Authentizitätssuche vgl. Benhabib 1999: 42), entkompliziert sich im islamistischen Denken in die Anerkennung geschlossen nebeneinander be- 
stehender Gruppen. ${ }^{108}$ So ist dann auch nachvollziehbar, daß gemäß der islamistischen Logik nur eine in kollektive Identitäten aufgeteilte Gesellschaft den wahren Pluralismus beanspruchen kann - Pluralismus nicht „bloß“ verschiedener Meinungen und Lebensstilen, sondern der Pluralismus der Scharias, sprich: Rechtspluralismus, womit verhindert werden solle, daß der öffentliche Raum von einem Guten dominiert werde. Ähnlich verhält es sich von hier aus gesehen mit dem Öffentlichen, d.h. dem öffentlichen Raum und dem öffentlichen Glück.

Bei der Konstruktion des islamischen Gesellschaftsprojekts taucht die über den Kommunitarismus populär gewordene Kritik am liberalen Politikverständnis nur knapp zeitversetzt auf. ${ }^{109}$ Bulaç wirft, indem er das Verhältnis zwischen Regierung ${ }^{110}$, Politik und Macht problematisiert, die Frage auf, ,was eine gute Regierung/Verwaltung ist und wie in einer guten Regierung das Verhältnis von Politik und Macht

108 Stauth bemerkte zu Taylors Authentizitätskonzept im Hinblick auf seine im Kontext der kulturübergreifenden Interaktion auftauchenden Folgen, auf den Islam angewandt: „Insbesondere etwa aus der Sicht des Islams, wo sich das handelnde Individuum auf eine Immanenz und Transzendenz unmittelbar verbindende Heilsgewißheit verlassen kann, kann Authentizität nicht als individuelle, sondern nur als kollektive ,Differenz' gedacht werden. Die Ethik der Authentizität steht also nicht im Dienst des Selbst, sondern im Dienst der von Obligationen geleiteten Öffentlichkeit des Kollektivs. Hier heißt Authentizität Aufforderung zur äußeren Repräsentation der religiösen Bedingung des Selbst.“ (1999: 17)

109 Die intellektuelle Welt wurde in den 90er Jahren durch eine kommunitaristische Welle erfaßt, die erst in den USA als eine politische Angelegenheit einsetzte und von dort aus nach Europa, aber auch in die muslimische Welt überschwappte. Was mit dem Kommunitarismus verbunden wird, läßt sich selbstverständlich nicht einheitlich beschreiben. Indes kann mehr oder weniger der „Gemeinsinn“ als die ethische Dimension des Handelns als gemeinsamer Nenner unterstellt werden (bspw. die Studie von Bellah u.a. 1987). In diesem Kontext ging es also um die Vorstellungen vom guten Leben, um die sich die Politik drehen soll, und dasselbe Interesse dürfte auch zur zunehmenden Aktualität von Hannah Arendt in der Welt beigetragen haben.

110 Das hier verwendete türkische Wort yönetim bedeutet im gewöhnlichen Gebrauch Verwaltung. Aus dem Sprachgebrauch des Autors geht das nicht deutlich hervor. Nach seiner Konstruktion von politischem Apparat im VM wird darunter eher Verwaltung verstanden, die mit der Durchführung öffentlicher Aufgaben betraut wird. Hier hingegen scheint der Begriff, wie gleich zu sehen ist, allgemeiner gefaßt zu sein. Daher entscheide ich mich dafür, beide Begriffe, Regierung und Verwaltung, gleichzeitig anzugeben. 
geregelt werden soll“. Es gebe zwei Antwortmöglichkeiten dazu. Die erste verwirft er sogleich:

„Wenn wir unter Regierung (Verwaltung) die breiteste politische Organisation der Gesellschaft verstehen, dann sind wir gezwungen, zu akzeptieren, daß zwischen dem Staat/Apparat, der das Regieren/die Regierung (Verwaltung) unter seinem Dach ermöglicht, und den Regierten eine gewisse Kluft besteht. In dieser Definition ist die Macht in den möglichen Mitteln der Regierung (Verwaltung), damit im Staatsapparat, versammelt.“ (Bulaç 1994a: 10, Hervorhebung im Original)

Eine solche Entfremdung kennzeichne die modernen Demokratien, welche die Macht an den Staatsapparat und dessen zahlreichen Institutionen delegierten. ${ }^{111}$ Die zweite Definition der Regierung/Verwaltung verlagert die Macht vom Staatsapparat auf die Regierten zurück: „Definiert man die Regierung/Verwaltung als die breiteste politische Organisation von Menschen und Gemeinschaften, die zusammenzuleben haben, dann bedeutet das, daß die Macht in den Regierten verinnerlicht ist.“ (Bulaç 1994a: 10.)

Die ummatistische Utopie von einer befreiten Gesellschaft (oder der Ansammlung, Konföderation von Gemeinschaften), in der die Entfremdung zwischen Herrscher und Beherrschten aufgehoben wird, kehrt an dieser Stelle wieder. Die Macht kann durch die Regierten nur dann verinnerlicht werden, wenn sie diesen nicht in der vermeintlich neutralen Gestalt des modernen Zentralstaates mit der Herrschaft einer Rechtsordnung entgegentritt, welche eine ethische Bindung nicht hervorzubringen vermöge. In der Scharia (jeder Gemeinschaft), als ethischer Wegweisung und rechtlichem Rahmen in einem, wird folglich, so läßt sich die Denklogik verlängern, die gute Politik möglich werden, die erneut von der in der Moderne verschwundenen Weisheit getragen werden wird.

111 Auf die Hervorhebung des Wortes Gesellschaft sei achtgegeben. Denn die ganze Konstruktion des VM operiert sehr wohl auf der Basis der zentralen Begrifflichkeit der Soziologie, nämlich der Unterscheidung zwischen Gesellschaft und Gemeinschaft. Während die Gesellschaft ein künstliches Konstrukt sei, meint Gemeinschaft auch in islamistischer Version eine gewachsene, quasi-natürliche Einheit. Man bleibt im Wirkungsbereich des soziologischen Denkens, kehrt dabei die Deutung der geschichtlichen Entwicklung entsprechend der islamischen Verfallseschatologie derart um, daß nunmehr die Gegenwart, nämlich die Epoche der „Rückkehr der Religionen“, einen Rückgang von Gesellschaft zu Gemeinschaften erlebe; das Zurechtrücken des aus der Bahn gebrachten Gangs der Menschheit, das sei schon immer die Mission von Religionen gewesen. 
Die Anlage des Diskurses, wie sie im bisherigen Verlauf des Textes dargelegt worden ist, bezeugt durchweg das Begehren, Ethik und Recht bzw. Individuum und Gemeinschaft mit einem inneren Band restlos zu vereinigen. Gesellschaftstheoretisch gewendet, bedeutet das Unterfangen nichts geringeres, als daß eine ,nicht entfremdete“ Politik darauf abzielen muß, die Vorstellungen vom guten Leben, die durch das „freiwillige Bekenntnis zu einer Scharia“ (Religion oder auch Weltanschauung) zum Ausdruck kommen, in den Institutionen zu verkörpern. War im westlichen Denken allerdings die Frage nach dem gemeinsamen Guten, bzw. guter Politik, in der Regel auch mit dem gemeinsamen, öffentlichen Raum verbunden, der die bestehenden partikularen Differenzen transzendiert, so verwandelt sie sich hier in ein Instrument dafür, den öffentlichen Raum in ein Bündnis von geschlossenen partikularen Machtblöcken zu übersetzen (vgl. dazu auch Seufert 1997b: 454). Was bleibt dann aber angesichts der festgezurrten Identitäten vom öffentlichen Raum noch übrig? Aus der Sicht der politischen Philosophie würde die Antwort eindeutig ausfallen: Er hört auf, zu existieren. Nun, halten wir uns als Soziologe doch zurück und stellen die Frage in abgewandelter Form: Wie wird der öffentliche Raum in einer solchen islamis(tisch)en Wendung konzeptualisiert?

Man kann andere Verfechter des VM heranziehen, die das Konzept des öffentlichen Raums expliziter in den Vordergrund gerückt haben, wobei die theoretischen Folgen im Hinblick auf die Institutionalisierungsfrage gleich lauten. Zur Ergänzung der obigen Darstellung wird unten auf Çeliks Gebrauch des öffentlichen Raums eingegangen. Die Analyse seiner Konzeption empfiehlt sich nicht zuletzt deswegen, weil hier die Einflüsse des kulturübergreifenden Austauschs offenkundig am Werke sind und deren Transformationen um so deutlicher nachvollzogen werden können.

Die Kenntnisse der Geschichte des westlichen Denkens, die virtuelle Auseinandersetzung mit dem westlichen Denken, aber auch die des öfteren erfolgende Affirmation westlicher Autoren gehören zu den konstitutiven Elementen des Denkens islamistischer Intellektueller, das sei hier in deskriptiver Absicht wiederholt. Affirmativ Bezug genommen wird freilich vor allem auf die vormoderne ,gute Politik“, die aus dem Wahrheitsbestand positivistischer Wissenschaften ausgeschlossen wurde.

„Infolge dieser Trennung stützte sich die positivistische Politik auf die eindeutige Unterscheidung zwischen ,Tatsache ${ }^{\natural}$ und ,Wert ${ }^{\star}$. So wurde die Politikwissenschaft zu einer Wissenschaft, die nicht das, ,was sein soll‘, sondern das, ,was ist', erklären will. Wie bei David Easton klar zu sehen ist, wird die Suche danach, ,wie soll eine gute politische Regierung/Verwaltung aussehen' oder ,wie soll ein gutes politisches Gemeinwesen aussehen?', die als ,vorwissenschaftlich' aus der positivistischen Politikwissenschaft ausge- 
schlossen wird, als belanglos für die Bildung einer modernen politischen Theorie erachtet.“ (Çelik 1994a: 26)

Der Vertrag von Medina, der sich auf der Institutionalisierung jeweiliger Suche nach guter Gemeinschaft erhebt, könne nun den Weg dafür freilegen, Politik und Ethik miteinander zu verbinden. Die mit Machiavelli einsetzende Trennung zwischen politischer Wissenschaft und politischer Philosophie könne dadurch behoben werden.

„Die im Projekt vorgesehene Verbindung zwischen ,Politik ${ }^{‘}$ und ,Ethik“ wird durch die Suche unterschiedlicher Rechtssysteme nach einem jeweils gemeinsamen Guten und Gerechten (sic.) gewährleistet, um den Regierungs-/Verwaltungsapparat über Partizipation und nicht über Herrschaft aufzubauen.“ (Çelik 1994a: 27)

So erweise sich der rekonstruierte Vertrag von Medina, indem er die jeweilige Suche nach Gutem nicht im Namen eines durch den Staat aufoktroyierten offiziellen Guten vernichte, als überlegen gegenüber der modernen Demokratie (ebd.). Diese Überlegenheit dränge sich besonders im Hinblick auf Freiheit auf. Die „,negative Freiheit“ werde zwar im Projekt vorgesehen, aber das Projekt gehe darüber hinaus, indem noch weitere Freiheiten, die es im gewissen Sinne auch in der Praxis des historischen Islam gegeben habe, vorgesehen würden. Gemeint sind z.B. die Freiheit, zwischen differenten Rechtsformen wählen zu dürfen, die Freiheit, die eigene Sprache zu sprechen, oder die Autonomie im Erziehungswesen (ebd.). An dieser Stelle gewahrt man übrigens auch zur Geschichte des historischen Islam eine klare Distanzierung. Es gehe um ,das Mitspracherecht nicht nur der Mehrheit, sondern auch der Minderheit im öffentlichen Raum“. Im politischen Denken des historischen Islam habe die dominante Linie die Macht vor der Kritik der Umma bewahrt. Infolge dessen sei die Partizipation der Muslime am öffentlichen Leben eingeschränkt worden, während die Teilnahme der Nichtmuslime am öffentlichen Leben, obwohl ihre rechtliche Autonomie unangetastet blieb, nicht zugelassen worden sei. $\mathrm{Zu}$ dieser Geschichtsdeutung soll nun auch Hannah Arendt Dienste erweisen:

„Was Hannah Arendt ,öffentliches Glück‘ meint, wird so ausgeweitet, daß der Begriff alle einschließt. Der liberale Freiheitsbegriff versteht die politische Macht im Widerstreit mit Freiheit und schränkt das Glück gänzlich auf die Privatsphäre des Hauslebens ein. Indem die Grenzen der Macht eindeutig gezogen werden, werden Menschen frei, nach den Mitteln des Glücks, das sie sich ausgesucht haben, zu jagen. Arendt hingegen setzt die Freiheit identisch mit der gesunden Teilung der Macht und zeichnet den Rahmen des Begriffs vom öffentlichen Glück im Sinne von Begeisterung, den öffentlichen Raum mit anderen zu teilen." (Çelik 1994a: 28) 
Eine solche offensichtliche Verdrehung eines Konzeptes genau ins Gegenteil dessen, was damit ursprünglich gemeint wurde, müßte allerdings Verwunderung auslösen. ${ }^{12}$ Da wir hinsichtlich der großzügigen Umdeutungen etablierter Konzepte nicht mit Einzelfällen zu tun haben, ja, da der ganze Diskurs (d.h. auch die Produktion der intellektuellen Kultur) auf diese Art und Weise funktioniert, kommt es hier eher wenig auf eine inhaltliche Kritik an. Viel wichtiger ist der systematische Stellenwert der vordergründigen Begriffsverflachungen. Denn inhaltlich gesehen, kann es keinen Zweifel darüber geben, daß sich der öffentliche Raum, um bei der zur Zeugenschaft geladenen Hannah Arendt zu bleiben, erst dann überhaupt konstituiert, wenn er nicht von vornherein unter bestimmten Gemeinschaften feudal oder paritätisch, wie man es nehmen möchte, aufgeteilt wird.

Hannah Arendt strebte tatsächlich in ihrer politischen Philosophie an, an die antike Tradition von öffentlichem Glück als Leitmaxime der Politik anzuknüpfen. Der „Tätigkeit der Arbeit“, die den biologischen Stoffwechselprozess des Menschen reguliert, und der Tätigkeit des „Herstellens“ in der „Objektwelt“ steht demnach das „Handeln“ „als die einzige Tätigkeit der Vita activa, die sich ohne die Vermittlung von Materie, Material und Dingen direkt zwischen Menschen abspielt", gegenüber (1981 [1967]: 14). Für Arendt beginnt, so wäre es auf eine Formel zu bringen, Menschsein durchs Handeln im öffentlichen Raum.

Der öffentliche Raum kann demnach nur insofern existieren, als sich die Menschen bei der Regelung ihrer Angelegenheiten über die vorgegebenen partikularen Grenzen hinaus ansprechen und angesprochen fühlen können. Diese Idee wurde später u.a. von Lefort aufgegriffen und in dem Sinne gedeutet, daß die Stelle der Macht in der Demokratie „symbolisch leer“" zu bleiben hat (1990: 293). Damit ist nichts anderes gemeint als die Unmöglichkeit einer Letztbestimmung (bzw. -Begründung) von Macht und von Identitäten; das ist genau das Gegenteil von der Aufteilung des öffentlichen Raums nach festgezurrten Gemeinschaftsidentitäten, welche jeden Hauch eines gemeinsamen politischen Raums überwindet. Erstaunlich ist der Vorgang dieser Uminterpretation der Arendtschen Ideen vor allem in Bezug darauf, daß der gemeinsame Raum auf der Basis von partikularen Glaubensbekenntnissen und deren Institutionalisierung gründen könnte. Dabei läßt Arendt, die eigentlich eine kritische Haltung zur Moderne an den Tag legt, keinen Zweifel darüber aufkommen, wenn es um

112 Mindestens ebenso verwunderlich ist aber auch der Umstand, daß solche mitunter vergröbernde Umdeutungen von den Beobachtern der islamistischen Bewegung kaum systematisch berücksichtigt werden, geschweige denn sie zum kritischen Mißtrauen anzuregen. 
das Verhältnis von Religionsgemeinschaften und Politik geht. An zwei Stellen macht es Arendt unmissverständlich deutlich.

Für ein Mißverständnis hält Arendt z.B. die in der ,Auseinandersetzung der freien Welt mit dem Totalitarismus“ aufgeworfene These, daß der Begriff der Freiheit ursprünglich christlich-religiösen Ursprunges sei. Es dürfte, so Arendt, äußerst schwierig sein, zu zeigen, „daß ein auf Freiheit gegründetes System ein religiöses ist“ (1994: 310). Die christliche Freiheit war, so Arendt, eine Freiheit von der Politik (ebd.), - und das kann man auch im gewissen Sinne auf den Islam beziehen. Die Verfechter des VM (Çelik vor allem, aber auch Bulaç) betrachten die Politik tatsächlich als unwesentlich, akzidentiell. Arendt führt in diesem Zusammenhang das historische Beispiel an, daß „die christlichen Kirchen, indem sie an der Lehre der Gleichheit aller Menschen vor Gott festhielten, gegenüber der Frage der Sklaverei indifferent bleiben konnten.“ Genau „deshalb hätten“, fährt Arendt fort, „weder die christliche Gleichheit noch die christliche Freiheit jemals aus sich heraus zu der Vorstellung eines „Government of the people, by the people, for the people" oder irgendeiner anderen modernen Definition der politischen Freiheit führen können." (Arendt 1994: 310)

$\mathrm{Da} 3$ sich das Beispiel Arendt im Gegenteil gerade für den Zweck, die islamistischen Umdeutungen zu konterkarieren, besonders gut eignet, kann man an der Bestimmung von Politik und Religion, also an der Säkularitätsfrage, weiter verfolgen. Für Arendt bedeutet die säkulare Trennung nicht, daß sich „die Politik von der Religion im Allgemeinen losgelöst hat, sondern speziell vom christlichen Glaubensbekenntnis“ (a.a.O.: 318). Die These läßt sich nicht minder auf den Islam hinsichtlich des türkischen Laizismus beziehen. Auch hier konnte sich ein öffentlicher Raum überhaupt, und dies ganz ungeachtet all der empirischen Probleme, welche die türkische Laizität belasten, erst herausbilden, indem die Verbindung zwischen der Politik und dem islamischen Glaubensbekenntnis abgekappt wurde. Nun will der Islamismus diese historische „Abirrung“ von der Geschichte, den modernen Abfall aus der Geschichte, zurückdrehen, indem die Politik wieder an Glaubensbekenntnis(se) gekoppelt wird. Eine Wiederherstellung der alten Kooperation zwischen Politik (Herrschaft) und Religion(en), da diese jedoch unter ganz anderen Kontextbedingungen stattfindet, wird dennoch nicht bloß die alte Ordnung aus den verschütteten Schichten der Geschichte wieder zu Tage fördern. So wie die Rekonstruktion des VM nicht den ursprünglichen Zustand exakt (oder auch nicht einfach mit einigen nebensächlichen Anpassungen an die neuen Umstände) reaktiviert (auch nicht reaktivieren kann), so wird ebenfalls bei der erneuten Koppelung der Religion mit der Politik die alte Beziehungsökonomie zwischen Religion und Politik aus den Angeln gehoben. Es ist sehr bedeutsam, daß wir hier u.a. Hannah A- 
rendt, die ausgerechnet für die islamistische Regierung des politischen Raums herhalten muß (was sie zweifellos ungemein beunruhigen würde), auf eine entscheidende Weise die Sensibilität dafür verdanken, die in diesem Unternehmen lauernden totalitären Züge wahrzunehmen.

„Die moderne Geschichte hat immer wieder gezeigt, daß Allianzen zwischen ,Thron und Altar ${ }^{6}$ nur beide in Misskredit bringen können. Doch während die Gefahr in der Vergangenheit hauptsächlich darin bestand, die Religion als reinen Vorwand zu benutzen und damit das politische Handeln wie den religiösen Glauben mit dem Verdacht der Heuchelei zu belasten, ist sie heute unendlich größer. Für uns, die wir mit einer voll ausgebildeten Ideologie konfrontiert sind, besteht die größte Gefahr darin, dieser eine eigene Ideologie entgegenzuhalten. Wenn wir ein weiteres Mal ,religiöse Leidenschaft' in das öffentlich-politische Leben hineinzutragen oder Religion als ein Mittel politischer Unterscheidungen zu gebrauchen versuchen, dann könnte dies die Transformation und Perversion der Religion in eine Ideologie sowie die Korrumpierung unseres Kampfes gegen den Totalitarismus durch einen dem eigentlichen Wesen der Freiheit äußerst fremden Fanatismus zum Ergebnis haben.“ (Arendt 1994: 324)

Die Kennzeichen des besagten Fanatismus lassen sich unmittelbar dem gleichen Text von Arendt entnehmen. In Bezug auf den Totalitarismus spricht Arendt zunächst einmal vom ,inneren Zwang, den die totalitären Ideologien auf die Seele des Menschen ausüben“ (a.a.O.: 323). Der innere Zwang ist jedoch nicht schon auch Totalitarismus. Dazu kann er erst in der Verbindung zur „Vergesellschaftung der Menschen" werden, welche Arendt auch im Marxschen Begriff der „gesellschaftlichen Menschheit“ aufspürt (a.a.O.: 318). In diesem Zusammenhang bestätigt sich eine Grundidee meines Konzeptes. Die frühere Allianz zwischen „Thron und Altar“, die in der verwalteten Religion in der türkischen Gegenwart mit neuen problematischen Folgen fortbesteht, kannte diesen ,inneren Zwang“ nicht. Der Islam als Ideologie der Vergesellschaftung (oder als öffentliche Norm) baut genau auf diesen Zwang als Bekenntnis zu einer „selbstgewählten“ Rechtsordnung auf. Die Existenz und Geltung der Rechtsordnung wird abhängig von ideologischer Überzeugung. Der springende Punkt dabei ist nicht in der Frage zu sehen, ob auf diese Weise eine funktionsfähige Rechtsordnung überhaupt eingerichtet werden kann. Mindestens genauso wichtig scheint die Frage danach zu sein, welche (wenn auch zunächst nur theoretischen) Folgen die unmittelbare Verknüpfung des Rechts mit Überzeugung für die soziale Organisation hervorrufen wird. Die islamis(tis)che Übersetzung des Anerkennungsdenkens setzt eine Maschinerie in Gang, in der virtuell jede Überzeugung, jeder Lebensstil dazu getrieben wird, sich durch Bekenntnis öffentlich kenntlich zu machen und die gemeinschaftlichen Grenzen 
festzusetzen. Jeder Einzelne ist dann gezwungen, sich einer gemeinschaftlichen Identität mit rechtlichen Konsequenzen zu unterwerfen, welche die Existenz eines gemeinsamen politischen Raums von vornherein zerstört. Man kann nun nicht mehr einfach ein Atheist sein, ohne sich dadurch in einem mit diesem Label gekennzeichneten sozialen Club mit interner Rechtsregelung zu platzieren. Selbst Atheisten müssten sich dann in einer „Religionsgemeinschaft" organisieren, davon ganz zu schweigen, daß die Muslime qua Zugehörigkeit zum islamischen Glauben einer religiösen Ordnung unterworfen werden. Bewirbt sich bspw. ein Atheist oder ein Alevit oder ein Christ oder ein Jude um eine öffentliche Stelle, so tritt er dann nicht als Individuum, sondern als Mitglied eines auf Überzeugung basierenden sozialen Blockes in Erscheinung. In den Worten eines Theoretikers der islamistischen Refah-Partei, Süleyman Akdemir, wird die Institutionalisierung des VM wie folgt formuliert:

„Jeder, der eine neue Arbeitsstelle antritt, muß sich vorher ein Leumundszeugnis seiner Religionsgemeinschaft (din cemaati) besorgen. Wir nennen diese Urkunde Bürgschaft über die Vertranenswürdigkeit (teminatli güven belgesi). Angenommen, ein Religionsloser bewirbt sich um eine Stelle. Der geht dann eben zur Atheistengemeinschaft (ateistlerin cemaati) und besorgt sich die Urkunde. [...] Der Soundso ist ein aufrechter, integrer (namuslu) Religionsloser. Wir bürgen für ihn, Wenn er sich nun als schlechter Mensch herausstellt und Betrügereien begeht, wird der Staat sich an seine Gemeinschaft halten, die den von ihm angerichteten Schaden ersetzen muß." (Zit. n. Seufert 1997b: 451, Hervorhebung L.T.)

In einer auf Bekenntnisgemeinschaften basierenden Gesellschaft, in der die Ethik und Recht unmittelbar miteinander verknüpft werden sollen, würde die Zugehörigkeit durch Bekenntnis bezeugt werden müssen. Andernfalls würde es nämlich Muslime geben, die nicht in einer der islamischen Scharia unterstellten Gemeinschaft leben wollten. Diese würden nunmehr dazu gezwungen, „Farbe zu bekennen“, da sie ja einer Gemeinschaft angehören müssen. Überhaupt würde sich allen Gesellschaftsmitgliedern ein Zwang zum öffentlichen Bekenntnis auferlegen, da sie sich unausweichlich gemeinschaftlich positionieren müssten. Die Ideologisierung des sozialen Lebens und Politisierung des Ritus wären die Folgen einer solchen Wiederherstellung der altosmanischen Millet-Ordnung unter den Bedingungen von Bekenntnisgemeinschaften, die sich auf dem der politischen Rationalität der Staatsraison bearbeiteten Boden institutionalisieren. Eine weitere Folge deutet sich auch bereits in dem oben zitierten Passus an. Wenn die jeweilige Gemeinschaft für jedes Mitglied gegenüber der Gesellschaft mit entsprechenden Sanktionen bürgen müßte, wie die Islamisten es vorsehen, dann würde die soziale Kontrolle einen enormen 
Auftrieb bekommen. Sie würde dann nicht mehr nur faktisch in der Alltagswelt funktionieren, sondern auch rechtlich flankiert werden. ${ }^{113}$ Sicher kann man angesichts dieses Umstandes nicht unbedingt von einem die Gesamtgesellschaft übergreifenden, „horizontalen Totalitarismus" sprechen, den Bulaç der modernen Gesellschaft attestieren möchte. Ob es sich dafür in einem auf diese Weise konzeptualisierten Islam allerdings lediglich um eine auf Gemeinschaft begrenzte ,vertikale Totalität" (Bulaç 1994b: 5) handelt, ohne totalitär zu sein, ist allerdings mehr als strittig.

Die Brisanz solcher theoretischer Überlegungen wird übrigens besonders deutlich, wenn man bedenkt, daß sich die durch den Diskurs zusätzlich verstärkten und zudem intellektuell untermauerten Gemeinschaftsvorstellungen in den politischen Diskurs einfließen. Immerhin war der Architekt des „Gesellschaftsprojektes“, Ali Bulaç, eine Zeit lang Berater des inzwischen abgesetzten Oberbürgermeisters von Istanbul. Diese Ideen schlugen sich übrigens auch im Programm der Refah-Partei nieder, ganz zu schweigen von dem Einfluss, den der Diskurs in seiner intellektuellen und theoretischen Manier, gepaart mit der Idee vom Islam als Gesamtpaket, auf jüngere Generationen von muslimischen Intellektuellen ausgeübt hat.

Die Reflexionen über die islamistische Transformation islamischer Urvisionen sollen hier abgeschlossen werden. Die theoretischen Ergebnisse werden unten im Resümee 2 komprimiert. Dabei bewege ich mich nicht konsequent entlang des formalen Aufbaus des Abschnitts, sondern gliedern den Ertrag in zwei Aspekten auf: (a) Aktivismus (Gesellschaftskonstitution), (b) Umdeutung westlicher Begriffe.

113 Daß dies ,,vorzüglich“ im Militärapparat (z.B. in der türkischen Armee) exakt so funktioniert, ist sehr symptomatisch für das Modell. Dort wird nämlich beim Fehlgehen eines Soldates im Drill gleich die ganze Einheit, zu der er gehört, mit bestraft. Durch diesen Sanktionsmechanismus wird trefflich dafür gesorgt, daß die ganze Gruppe einen Druck auf den Einzelnen ausübt. Man stelle sich eine nach dem Prinzip der Armee funktionierende Gesellschaft vor.

114 In einer unter den islamistischen Studenten in Istanbul durchgeführten empirischen Untersuchung nannten $26 \%$ aller Befragten $(\mathrm{N}=500)$ auf die Frage, von welchem Autor sie am meisten beeinflußt worden sind, Ali Bulaç. Damit stand er ganz oben auf einer Liste mit bekannten nationalen und internationalen Namen aus der muslimischen Welt (Narlı 1993, hier in: Nokta vom 22-28. August 1993). 


\section{Resümee 2}

Der Verlauf des vorliegenden Kapitels hat sich methodisch an der Diskursanalyse und materiell an den Überlegungen von Eisenstadt zu modernen fundamentalistischen Bewegungen orientiert. Eisenstadt hatte zwei Grundkomponenten der Moderne hervorgehoben, die man in Betracht ziehen muß, will man moderne fundamentalistische Bewegungen verstehen: Die Transposition der immer wiederkehrenden Protestthemen - Gerechtigkeit, Freiheit und dergleichen - in die zentrale politische Arena (a) tritt gepaart mit der Vorstellung von der Gesellschaft als einem Objekt auf, das gemäß einer solchen Vision rundum erneuert werden kann. Dabei erweist sich die antimoderne Ideologie des Islamismus als ,grundlegend in eine hochmoderne Struktur eingebunden“ (Eisenstadt 1998: 84). Das „Hauptkennzeichen ihrer ,Reaktion“ auf die Moderne“, so fährt Eisenstadt fort, ,,ist ihre totalistische Konstruktion einer geschlossenen utopisch-konfessionellen Vision und deren Legitimation in Begriffen einer ideologisierten Tradition" (a.a.O.: 85). Im gleichen Zusammenhang hatte Stauth die Aufgabe unterstrichen, ,wie nun aber in die Analyse der diskursiven und dialogisch-interaktiven Dimension der Rekonstruktion ,innerer Werte' der verschiedenen Zivilisationen die modernen reflexiven Techniken einzubeziehen sind“ (1995: 95). „Die historisch-geistigen Tiefenstrukturen etwa des Islam können“, so Stauth, „doch nur als Objekte solcher Techniken und Vermittlungsprozesse verstanden werden, nicht als Prinzipien, aus denen heraus sich die eigentlich mobilisierenden Kräfte kultureller Rekonstruktionsbewegungen wie z.B. der Fundamentalismus entwickeln" (ebd.).

Damit ist jedoch die Frage nicht sogleich beantwortet, sondern um eine zusätzliche Dimension erweitert: Wie ist das Verhältnis zwischen den Objekten und den Prinzipien der Techniken theoretisch zu bestimmen? Ist mit dem Objekt, d.h. der Materie, eine bloße Masse gemeint, die mithilfe der Techniken beliebig geformt werden kann? Stimmt man diesem Vorgehen $\mathrm{zu}$, dann ist daraus folgerichtig zu schließen, daß es sich bei dem Islamismus um eine Art Modernisierung des Islam nach dem westlichen Modell handelte. Meines Erachtens wird die Studie von Seufert (1997b) von dieser Idee getragen. Oder geht vom Objekt, d.h. dem Gegenstand, ein gewisser Widerstand aus, der dafür sorgt, daß dieselben Techniken, appliziert an verschiedener Materie, unterschiedliche Folgen hervorbringen. Dann wäre aber das hier gemeinte Objekt mehr als bloße Materie. Sie wäre in eine Ordnung eingelassen, die aus verschiedenen miteinander verwobenen Mustern, aus aufeinander gelagerten Spuren besteht, die den übernommenen Konzepten und Techniken nicht äußerlich bleibt. 
Die vorliegende Studie ist dieser zweiten Deutung gefolgt und war stets bestrebt, die Spannung durchzuhalten, die sich zwischen der Übernahme der universalisierten Techniken und der kulturspezifischen Brechung bzw. deren Funktionsweise im Hinblick auf die Folgen auftut.

Bereits im utopistischen Charakter des Islamismus, welcher die Zeitökonomie des bisherigen islamischen Imaginären völlig umwirft, deutet sich dessen Verwicklung in die Strukturen der Moderne an. Um die Funktionsweise des Diskurses in der bezeichneten Spannung empirisch darzustellen, wurde der Diskurs vom Vertrag von Medina ins Zentrum der Analyse gerückt. Im Diskurs wird eine islamische Urvision aufgegriffen - nämlich ein Ausschnitt aus dem politischen Leben im prophetischen Medina. Die Analyse bestätigte die These von Eisenstadt, daß ,das wesentlichste Moment dieser Auswahl [der traditionellen Themen, die ideologisiert werden, L.T.] die Betonung einer Urvision“ und „die Totalisierung dieser Vision, die Unterordnung der verschiedenen Aspekte der Tradition unter die vorweggenommenen Implikationen dieses einen Prinzips und deren damit einhergehende Hierarchisierung" (ebd.) sind. ${ }^{115}$ Dabei wurde der Hinweis auf die Hegemonie dieses einen Prinzips unsererseits dahingehend vertieft, daß die mehrschichtige historische Erfahrung und deren Reflexion im klassischen politischen Denken bzw. durch die Sachwalter des Heilserbes nunmehr der Herrschaft eines nach Prinzipien ausschauenden, mit analytischem Anspruch gerüsteten und dem Konsistenzzwang verpflichteten Denkens zu weichen hat. Die Suche nach Prinzipien steht in einem unmittelbaren Zusammenhang mit der Frage nach den letzten islamischen Werten, die nunmehr als Grundlagen im Dienste einer alternativen Gesellschaftskonstitution konstruiert werden müssen. Wird nun der Islam als einheitliches System gedacht, dem ein eigenes Gesellschaftsprojekt eigne, das durch willentliches Handeln künftig ins Werk gesetzt werden soll, so nimmt das Wirken religiöser Ideen in der Welt einen utopistischen Charakter an. Zudem weichen dabei die eschatologischen Visionen in einem ideologischen Wettlauf völlig einem weltimmanenten Wirken, oder, sofern sie beibehalten werden, werden sie chiliastisch aufgeladen. Allein dieser Chiliasmus läßt sich weniger aus der sunnitischen Tradition heraus begründen als vielmehr durch die Auswirkungen des kulturübergreifenden Austausches. Dieser baut die Instrumente der an gesellschaftliche Ziele gekoppelten Rekonstruktion der eigenen Geschichte auch in das Imaginäre der islamischen Welt ein.

115 Die Totalisierung der einen Vision wird derart radikal konzipiert, daß der Vertrag selbst über ,den Koran, die Thora und das Gewohnheitsrecht" gestellt wird (so jedenfalls bei Bulaç 1992b: 109). 
Die Ordnung von Medina firmiert zwar weiterhin unter der Bezeichnung „Wunder“ (Bulaç 1994a: 12). Indem es aber dem politischen Subjekt verfügbar gemacht wird, welches mit dem entsprechenden Engagement in Anleitung eines Projektes das Wunder ins Werk setzen $^{116}$ können soll, droht es seine transzendente Dimension einzubüßen. Die Rede von Wunder läßt dann nur noch das simulative Licht von Etwas aufblinken, das es als solches im islamischen Denken immer weniger gibt. Bedeutsam ist daher auch, wie in einem solchen diskursiven Rahmen selbst der Prophet seiner Wunderdimension, seiner Außerordentlichkeit, verlustig zu gehen droht. Mevlüt Özcan, ein Kolumnist der islamistischen Zeitung Milli Gazete (vom 20.05.2000), spricht vom Propheten als ,unserem Führer“, und vergleicht ihn mit anderen weltlichen Führern, um zu unterstreichen, daß der Prophet der beste unter ihnen ist. Der Prophet bekommt zwar die beste Note, wird aber dadurch nunmehr in einen aufrechnenden Vergleich mit anderen gestellt. Gewiß ist, daß der islamische Prophet nicht den gleichen Status genießt wie Jesus Christus im Christentum. Es wird auch im islamischen Denken immer wieder unterstrichen, daß Muhammad letztlich ein Mensch bleibt und nicht Gottes Sohn ist wie Jesus im christlichen Glauben. Hierzu war er tatsächlich auch ein militärischer und politischer, jedoch immer schon mit dem Nimbus des Außerordentlichen umwobener, Anführer. Gleichwohl ist er nicht irgendein Mensch, auch nicht einfach besser als die Anderen, es geht um eine grundsätzliche Differenz. Er ist letztlich als Siegel der Prophetie, als der letzte Verkünder der göttlichen Botschaft auserwählt. Wie schon in der oben zitierten Kolumne an einer weiteren Stelle bemerkt wird, wird er von Gott vollauf unterstützt und auch stets vor Fehltritten bewahrt. Ihn auf eine Vergleichsebene mit politischen Führern zu stellen, reduziert ihn auf seine innerweltliche Funktion als Anführer. ${ }^{117}$

116 Der Gedanke von Ins-Werk-Setzen der Gemeinschaft, das deren Undarstellbarkeit aufhebt und dadurch die Gemeinschaft in eine völlige Immanenz auflöst, wurde vom französischen Philosophen Jean-Luc Nancy (1988) entwickelt. Das Ins-Werk-Setzen, das dem kommmunistischen Gesellschaftsideal zugrundelag, mündet für Nancy in Totalitarismus.

117 Hier sei, wenn auch in assoziativer Absicht, auf eine durch den Calvinismus herbeigeführte parallele Entwicklung im Christentum hingewiesen. Louis Dumont schreibt in Bezug auf Calvin: „Anstatt in einer anderen Welt die Zuflucht zu finden, mit deren Hilfe wir uns schlecht und recht durch die Unvollkommenheiten dieser Welt hindurchbeißen, haben wir allem Anschein nach beschlossen, jene andere Welt in unserem Handeln, das wir auf die Welt hier richten, selbst zu verkörpern. Hier stoßen wir - was von ungeheurer Bedeutung ist - auf das Modell des modernen Artifizialismus überhaupt [Fn.: verstanden 
Ein ähnliches Beispiel führt Karin Werner (2000) aus ihrer Feldforschung in Ägypten an. Die purifizierenden Selbsttechniken, denen sich junge Frauen konsequent unterziehen, verwandeln den Islam in eine Technologie des Selbst im Sinne von Foucault. Wie Werner eindrücklich beschreibt, streben die islamistischen Frauen dabei an, so perfekt zu sein, wie der Prophet selbst; dabei ist das eine „Anmaßung", die im sogenannten Volksislam so niemals vorkommen konnte, obwohl die Orientierung an der Sunna des Propheten gleichsam ein Dogma ist. Man soll es freilich anstreben, kann es aber als Nichtauserwählter niemals erreichen. Der Prophet ist eben Prophet und nicht ich oder du. Droht dann nicht ausgerechnet der Islamismus, der die Transzendenz wieder in die Welt einführen will, sie zu zerstören?

Der durch den Islamismus eingeführte Aktivismus, die willentliche Entschließung dazu, die Gesellschaft durch einen innerweltlichen Akt auf konstruierte Grundlagen zu stellen, macht den für die Neuzeit typischen utopischen Zug aus, der die islamistische Transformation islamischer Urvisionen auszeichnet, auch wenn er stets in der Theorie durch die islamistischen Autoren explizit verworfen wird. Im Lichte der Transformation der Vision in eine politische Utopie erscheint die Umma als reine Gemeinschaft. Zwar gelingt es den Islamisten nicht, die Unklarheit wettzumachen, obwohl sie stets betonen, daß die Umma nicht alleine die Muslime umfasse. Ganz gleich aber ob die Umma rein islamisch ist oder, wie in dem Diskurs über den VM konstruiert, auch Nichtmuslime auf der Basis der Autonomie einbegreifen soll, sie wird auf jeden Fall von Entfremdung bereinigt und erscheint somit als eine versöhnte Gesellschaft.

als Allmachtsphantasie, die Gesellschaft qua Willensakt auf gänzlich neue Fundamente stellen zu können, A. d. Ü.], die systematische Übertragung eines von außen herbeizitierten Wertes auf die Dinge dieser Welt. Nicht eines Wertes, der aus unserer Zugehörigkeit zur Welt hergeleitet wird, aus ihrer Harmonie oder unserer Harmonie mit ihr, sondern eines Wertes, der in unserer Ungleichartigkeit in Bezug auf sie verwurzelt ist: die Gleichsetzung unseres Willens mit Willen Gottes (Descartes: der Mensch wird sich zum ,Herrn und Besitzer der Natur machen). Der derart auf die Welt angewandte Wille, das angestrebte Ziel, das zugrundeliegende Motiv oder die Triebfeder des Willens kommen von außen - sind außerweltlich. Die Außerweltlichkeit konzentriert sich nun im individuellen Willen. Das entspricht genau Tönnies' Unterscheidung zwischen ,Naturwillen' und ,Kürwillen', und wir sehen, wo die ,Willkür' ihren Ausgangspunkt nimmt. Meines Erachtens liegt diese Struktur auch dem zugrunde, was Weber die Rationalität der Moderne genannt hat.“ (Dumont 1991: 68f) 
Indessen sind wir trotz des starken Anscheins, den die Analyse des islamistischen Diskurses vermittelt haben mag, weit entfernt davon, eine eindeutige Antwort bezüglich der Frage zu favorisieren, ob sich denn der Islam dadurch nicht modernisiert habe. Darauf kommt es vielleicht auch gar nicht mehr an. Von entscheidender Bedeutung ist vielmehr nachzufragen, welche spezifischen Übersetzungen der Einsatz der Instrumente des modernen Denkens erfährt. Dieser Punkt wurde anhand einiger zentralen Kategorien ausführlich dargelegt. Will man aber unbedingt von einer Modernisierung des Islam durch den Islamismus sprechen, dann muß man hinzufügen, daß es dabei um unterschiedliche, kulturell gebrochene Formen der Moderne und um differente, institutionelle Ausgestaltungen gehen kann und nicht um eine noch nicht soweit gediehene, aber durchaus auf dem gleichen Weg befindliche Modernisierung. Von dort aus kann man dann vielleicht sinnvoll mit Eisenstadt von multiple modernities (2000) sprechen. Die Soziologie des Islam, die moderne Spuren im Islam aufspüren will, darf daher die spezifische Wirkung der islamischen Muster und Ideen und deren Transformationen unter den modernen Kontextbedingungen nicht dem Konzept einer gleichmacherischen Modernisierung aufopfern.

In diesem Sinne wurde weiterhin die Bedeutung westlicher Diskurse unterstrichen, vor allem wurde die postmoderne Kritik an den Meta-Erzählungen der Moderne als Ermöglichungsgrund für die Entstehung des islamistischen Diskurses über den VM verfolgt. Man konnte übrigens unschwer beobachten, wie sich die paradigmatischen Verschiebungen in der westlichen Geisteswelt in der globalen Welt fast unverzüglich auch in der islamischen Welt niederschlagen. Weder den Neomodernismus von Rahman in den 60er Jahren noch den postmodern geläuterten, türkischen Intellektuellenislamismus in den 90er Jahren kann man allein aus einer innerislamischen Entwicklung heraus verstehen. Wir haben nicht nur die modernen Spuren in den Strukturen des Denkens und der Wahrnehmung aufgespürt, sondern konnten auch den üppigen Gebrauch von Kategorien aus dem westlichen Kulturbestand aufzeigen. Dabei waren wir stets darum bemüht, bei der Beschreibung zugleich einen kritischen Blick beizubehalten, um die im islamistischen Diskurs vorgenommenen Umdeutungen wahrzunehmen, und nicht um uns in der vordergründigen Übernahme der Kategorien zu erquicken. ${ }^{118}$

118 Angesichts der offensichtlichen Verschiebungen, die bis zu krasser Aushöhlung der ursprünglichen Konzepte ausarten, ist es äußerst befremdlich, daß die Beobachter des Islamismus ihren kritischen Sinn völlig ausschalten. Unbekümmert spricht z.B. Rainer Hermann von einer „neuen Generation liberaler muslimischer Intellektueller“. Herrmann befindet, daß ,auch sie die Begriffe wie Zivilgesellschaft, Kon- 
Es stellte sich in der kritischen Betrachtung übernommener Begriffe zudem heraus, daß die begrifflichen Umdeutungen, die man als die strategischen Mittel der Identitätsvergewisserung bezeichnen kann, kaum Anzeichen dafür bieten, eine liberale politische Kultur hervorzubringen. Im Gegenteil werden die Kontingenzerfahrungen, die sich weitgehend aus dem Schwund sozialmoralischer Milieus im städtischen Kontext einstellen, in Gestalt der festgezurrten Gemeinschaftsidentitäten abgebunden (vgl. Seufert 1997b: 452ff.). Nach diesem Modell werden die Grenzen der religiös definierten Gemeinschaften nicht nur sittlich, sondern auch rechtlich bewacht. Die Kontingenz des eigenen Selbst soll nur noch an den Rändern der eigenrechtlichen Bekenntnisgemeinschaften wandeln dürfen, während „drinnen“ die Gemeinschaftswärme das heimische Gefühl in einer unheimlichen Welt ausstrahlen (oder vortäuschen ?) wird. Und für ein solches versöhntes Leben muß der Gläubige nicht einmal aufs Jenseits warten.

Was hat nun die gefeierte Gemeinschaft, die seit dem Ausgang aus dem Goldenen Zeitalter der prophetischen Urgemeinde stets im Verschwinden begriffen sein soll, für eine Bewandtnis? Ist sie tatsächlich der Name dessen, was sich mit dem Auftauchen der Gesellschaft aufgelöst, von dieser deplaziert worden ist? Hat es sie als eine verschmolzene Einheit, als eine Bezeichnung für ein keine Entfremdung kennendes soziales Band, jemals gegeben? Oder taucht diese Idee der Gemeinschaft selbst, wie Nancy vorzüglich in Bezug auf die westliche

sens und Pluralismus verteidigen“" (1996: 46). Er problematisiert jedoch keineswegs die Umdeutungen, die solche Begriffe im islamistischen Diskurs erfahren.

Seufert hingegen geht ausdrücklich auf die inhaltliche Ausfüllung der besagten Kategorien kritisch ein, weist wohl auch auf die hier stattfindenden Verschiebungen hin. Wissenssoziologisch erklärt er dabei den von den ursprünglichen Bedeutungen abweichenden Gebrauch damit, daß die Islamisten „Begriffe wie Demokratie, Pluralismus und Parlamentarismus“ als das rezipieren, „was der türkische Staat aus ihnen gemacht hat (und mit Unterstützung seiner westlichen Verbündeten machen konnte)““. Für Seufert führt das dazu, „daß nicht die Wertorientierungen, die diese Konzepte implizieren, diskutiert werden, sondern daß ihr Charakter als Waffe in der ideologischen Auseinandersetzung zwischen Laizisten und Muslimen in den Vordergrund tritt" (1997b: 447). Sosehr auch der türkische Staat dazu beigetragen haben mag, den Bedeutungsgehalt dieses oder jenes Begriffes zu verflachen, eine weitreichende Erklärung ist damit keineswegs gegeben. Seufert (wie Hermann 1996) scheint die Entwertungmechanismen, welche die von der Authentizitätsuche getriebene Identitätspolitik in einer auf die Repräsentation des kollektiven Selbst gerichteten Kultur auslöst, nicht konsequent zu bedenken. 
Gemeinschaftssuche darauf insistiert, nicht eher erst in der Erfahrung der Gesellschaft ,als das, was uns zustößt“ (1988: 31) auf?

„Nichts ging also verloren und daher ist auch noch nichts verloren. Verloren sind nur wir selbst, auf die unsere eigene Erfindung, das, gesellschaftliche Band' nämlich (die Verhältnisse, die Kommunikation), wie das Netz einer ökonomischen, technischen, politischen und kulturellen Falle erdrückend herabfällt. Da wir uns in seinen Maschen verfangen haben, haben wir uns das Phantasiegebilde von der verlorenen Gemeinschaft ersonnen.“ (Ebd.)

Greift denn in dem islamistischen Nachgesang an die verlorene, und nun erneut herzustellende Gemeinschaft nicht bereits ein dem modernen Menschen wohlbekanntes Gefühl, nämlich die Nostalgie, um sich? Bryan Turner beschrieb einmal die Komponenten des nostalgischen Paradigmas wie folgt:

„First there is the notion of history as decline and fall, involving a significant departure from a golden epoch of homefulness. There is an intellectual linkage here with the postmodern view of posthistorie. Second, there is the idea that modern social systems and their cultures are inherently pluralistic, secularised and diverse; this pluralization of life-worlds brings about an intense fragmentation of belief and practice. Third, there is the nostalgic view of the loss of individuality and individual autonomy, since the autonomous self is trapped within the world of bureaucratic regulation under the dominance of a modern state. Finally, there is the sense of the loss of simplicity, authenticity and spontaneity. The regulation of the individual within a bureaucratic and administered world prohibits genuine feeling and emotion. The process of civilisation thereby involves the taming of savage feeling." (1994: 120f)

Es ist im Rückblick festzustellen, daß diese Komponenten im islamistischen Diskurs mehr oder weniger vorkommen. Bei einigen kann man natürlich, wie z.B. departure from a golden epoch of homefulness, davon ausgehen, daß sie im Islam bereits dogmatisch begünstigt sind. Jedoch gehörte diese Vision zu einer gänzlich anderen Wissensordnung, in der die Urgemeinde als ein Wunder verstanden wurde, dem man sich annähern kann, und nicht als Gegenstand eines aktivistischen Programms (vgl. Al-Azmeh 1996: 74). Die nostalgische Modernitätskritik, auf der sich der islamistische Diskurs erhebt, und die aktualisierte reine Gemeinschaft als Lösungsalternative, also die „Rückkehr“ zur Gemeinschaft, verdanken sich daher mindestens genauso sehr der schicksalhaften Verstrickung in die Wahrnehmungswelten der Moderne.

In den Wahrnehmungswelten der Moderne ist es aber um die Transzendenz schlecht bestellt. Hier droht das Wunder von Medina 
(wie das Wunder Muhammads) seine Aura einzubüssen, von der es dereinst umwoben war. Die Transzendenz steht somit als Gegenstand des Begehrens, das sie zwingt, sich dem Subjekt zu ergeben - zum Greifen nahe. Es stellt sich daher die Frage, ob die Verfügbarkeit der Welt (wie im Diskurs über den Vertrag von Medina) nicht gerade durch den Islamismus in die muslimische Vorstellungswelt eingeführt wird, und dadurch die Transzendenz zu verschwinden droht, wo der Islamismus ideologisch vorgibt, die westliche Verweltlichung der Welt durch das Gedenken der göttlichen Transzendenz rückgängig zu machen. Ist das denn nicht die List der Geschichte, daß sich das von den Islamisten theoretisch denunzierte Weltbilddenken gerade derjenigen bedient, um sich in den Köpfen und Herzen des letzten Muslims niederzulassen, die entgegen ihrer vorlauten Bekämpfung desselben selber im eigenen verbissenen Unternehmen hoffnungslos der Welt verfallen, weil sie diese zu ernst nehmen? 



\section{SCHLUSSFOLGERUNGEN UND AUSBLICK}

\section{Zusammenfassung der Ergebnisse}

Die hier vorgelegten Untersuchungen ließen sich von der Idee leiten, daß sich die Analyse des Islam nicht auf die Suche nach einem jenseits aller historischen Erscheinungsformen in der Tiefe schlummernden Wesen begeben soll. Beim Studium des Islam muß unabdingbar die konstitutive Bedeutung der Geschichtlichkeit gewürdigt, d.h. der Gegenstand in den je spezifischen geschichtlichen Kontext eingeordnet werden. Die Rechtspraktiken im islamischen Kulturkreis, die ,faktische Laizität", zeugen mit ihrer gewissermaßen institutionalisierten doppelten Lagerung zwischen dem (z.B. altarabischen bzw. türkischen) Gewohnheitsrecht und dem religiösen Gesetz (Scharia) von der Geschichtlichkeit, von der der Islam unmittelbar erfaßt ist.

Der Geschichtlichkeit wurde gemäß dieser Prämisse auch in der Analyse des neuzeitlichen türkischen Islam konstitutive Bedeutung zugemessen. Das Verständnis des Islam mit seinen unterschiedlichen Ausformungen in der Türkei erforderte folglich die Einbeziehung der Einflüsse, die aus der Begegnung mit der westlichen Moderne hervorgegangen sind. Dies hatte in verschiedener Hinsicht Konsequenzen.

In methodischer Hinsicht mußte sich die vorliegende Studie weitgehend auf die historische Materie einlassen und sich mit konkreten gesellschaftlichen Diskursen und ihrer institutionellen Umsetzung beschäftigen.

In methodologischer Hinsicht wurde vermieden, zwischen unterschiedlichen Artikulationsweisen des Islam nach dem Maßstab der Authentizität zu entscheiden. Selbstverständlich kommen die jeweiligen Konzeptualisierungen des Islam wie z. B. die laizistische oder die islamistische nicht ohne den Wahrheitsanspruch aus. Für die Akteure ist es immer der „wahre“ Islam, den sie jeweils formulieren und institutionell umzusetzen anstreben. Für eine soziologische Studie gebot es sich allerdings, den Islam immer schon als diskursiv umkämpft zu verstehen und die verschiedenen Konzeptionen desselben als Artikulationen gleichermaßen ernst zu nehmen. In diesem Sinne ist die laizistische Konzeption des verwalteten Islam, für die Religion letztlich eine Gewissensangelegenheit bleiben soll, genauso „authentisch“ wie die Version der Orthodoxie. Im gleichen Sinne wurde die im islamisti- 
schen Diskurs artikulierte Version des Islam ebenfalls nicht am Maßstab seiner vermeintlichen Authentizität oder Nichtauthentizität bemessen. Jenseits dieser diskursiven Ausgestaltungen existiert kein reiner, außerdiskursiver Islam, an dem man die konkreten Artikulationen nach ihrer Ferne oder Nähe bewerten könnte. Für eine diskursanalytisch verfahrende Untersuchung ist die Bedeutung des Islam immer schon in dem Sinne umkämpft, daß die Bedeutung dessen, was der „wahre“ Islam sei, aus konkurrierenden Antworten hervorgeht. Dabei beziehen sich die jeweiligen Positionen auf spezifische Aspekte des Islam, intensivieren sie, während andere Aspekte bzw. historische Erfahrungen unterbelichtet werden. In diesem Prozeß der Artikulationen, in denen die Bedeutungen von dem, was Islam sein soll, fixiert werden, wird jedoch nicht einfach ein vorgängig abgeschlossener Islam mehr oder weniger wiedergegeben. Es ereignen sich unvermeidlich Transformationen des Islam in den unterschiedlichen Rekonstruktionen jenseits der subjektiven Intentionen der Beteiligten.

In theoretischer Hinsicht galt es die jeweiligen Artikulationen, die nicht im Hinblick auf ihre vermeintliche Authentizität gegeneinander ausgespielt werden dürfen, auf den geschichtlichen Kontext zu beziehen. Die Instrumente, Modi und spezifischen Inhalte jeweiliger diskursiver Artikulationen waren daher erst aus dem Kontext des kulturübergreifenden Austausches heraus zu verstehen. Die Aneignung der islamischen Kulturbestände erfolgt demnach nicht jenseits der gravierenden Folgen, welche die Verwestlichung der Welt (in der ,Zeit des Weltbildes"), auch in den nichtwestlichen Kulturen ausgelöst hat. Die Machbarkeit der Gesellschaft ist die allgemeine Bezeichnung für die Vision, ohne die politische Entwicklungen auch in den muslimischen Gesellschaften der Neuzeit nicht angemessen erfaßt werden können. Es sei denn, man will die lange Geschichte der Modernisierung in der muslimischen Welt gemäß dem Duktus des spezifischen islamistischen Diskurses als einen „Irrweg“ in der gesamtislamischen Geschichte diffamieren.

Diese gesellschaftstechnische Vision ist auch in der Türkei sowohl über theoretische Diskurse als auch in Gestalt praktischer Politik infolge der Übernahme moderner politischer Rationalität (hier vorrangig als Staatsraison praktiziert) wirksam geworden. Die diskursiven Artikulationen des Islam stehen mit mehr oder weniger Intensität und auf je eigentümliche Weise im Zeichen dieser Vision bzw. ihrer praktischen Umsetzung mit Hilfe von Staatsraison. Damit sind auch die drei Elemente der Analyse wiedergegeben:

a) Im modernistischen Diskurs führte Staatsraison als die dominante politische Technik dazu, die Religion aus dem öffentlich-politischen Bereich als explizite politische Ideologie vorweg auszuschließen, um 
sie gleichzeitig in den Staatsapparat einzubinden, wobei die Verwaltung der Religion infolge der Machtverhältnisse mehr und mehr inhaltliche Züge annahm. Die Staatsraison trug dabei zur Formierung einer Gesellschaft bei, in der sich die Religion aus einer Vielzahl von lokalen Praktiken und Ideen zu einer zentral verbreiteten und verwalteten Angelegenheit entwickelte. Religion sollte hiernach zunächst den moralischen „Kitt“ für den gesellschaftlichen Zusammenhalt bereitstellen. Nach und nach übernahm sie jedoch die Funktion eines ideologischen Ferments. Somit hat die laizistische Verwaltung der Religion bei gleichzeitiger Beschränkung derselben auf spezifische gesellschaftliche Funktionen und auf eine private Gewissensangelegenheit zugleich die infrastrukturellen Bedingungen für eine zentral geschaltete, religiöse Durchdringung der Gesellschaft vorbereitet. Die Religion entwickelte sich aber durch ihren strategischen Einsatz zu einem Instrument in Machtspielen, die sich nicht mehr auf das alte Herrschaftsverhältnis zwischen dem Souverän und den Untertanen beschränken lassen. Dies ist eine Ambivalenz, die wesentlich in den strategischen Einsatz der Religion eingebaut ist. In ihr sind nämlich gleichzeitig die Bedingungen der Möglichkeit dafür gegeben, daß die in die Gesellschaft hineingespielte strategische Handhabe der Religion in der Gesellschaft selbst als Gegenmacht aufgegriffen und gegen die staatliche Macht eingesetzt wird.

b) Das institutionelle Mittel der Verwaltung der Religion ist die in der Diyanet organisierte Orthodoxie, deren Verhältnis zu den gesellschaftstechnischen Zielen der politischen Macht sich durch ein eigentümliches In-der-Schwebe-Lassen auszeichnet. Sie bekennt sich zu der bzw. akzeptiert die Laizität, ohne daß sich dadurch für die Orthodoxie grundsätzliche Widersprüche ergäben, welche die innere Rationalität der Lehre beträfen und deshalb zum Gegenstand diskursiver Auseinandersetzungen erhoben werden müßten. Dabei kann sie ihre Haltung weitgehend aus ihrer erfolgreich praktizierten historischen Praxis heraus begründen, die immer schon eine gewisse Allianz mit dem Herrscher enthielt.

Die Ambivalenz stellt sich allerdings auch für die Orthodoxie, da sie sich mit der „bescheidenen“ Religionspolitik der Staatsraison, selbst in ihrer später immer stärker werdenden inhaltlichen Wendung, nicht ganz zufrieden geben kann. Letztlich ist doch das formelle Bekenntnis des Staates zum religiösen Gesetz nicht unerheblich, und von diesem Ziel würde die Orthodoxie nicht endgültig absehen. Ein solches Bekenntnis würde nämlich der Orthodoxie die aus der Laizität entspringenden Unwegsamkeiten ersparen, wie sie z.B. in Konfliktfällen zwischen dem profanen und dem theokratischen Gesetz oder in der grundsätzlichen Kritik an der Religionspolitik eines säkularen 
Staates vorkommen. Vor allem würde eine solche explizite Verpflichtung des Staates zur religiösen Rechtleitung die institutionelle Vormachtstellung der sunnitischen Orthodoxie gegenüber den identitätspolitischen Forderungen konfessioneller Minderheiten (wie z. B. von Aleviten) aufrechterhalten. Nichtsdestotrotz nimmt der Dissens zwischen der Orthodoxie und der laizistisch verpflichteten Politik nicht den Charakter eines prinzipiellen Konfliktes an. Entscheidend bleibt, daß der Staat unterhalb des offiziellen Bekenntnisses zur Laizität durch die Orthodoxie die „rechte Lehre“ betreibt und die Gesellschaft „religiöse Aufklärung“, tatsächlich jedoch „Rechtleitung“, erhält.

c) Das Gesellschaftsmodell islamistischer Intellektuelle wendet sich gegen die „uneindeutige“ Haltung der beiden zuvor Genannten in Bezug auf den Platz der Religion in der Gesellschaft und konzipiert den Islam im Modus einer alternativen Gesellschaft. Die Islamisten reflektieren den gesellschaftstechnischen Zug der Staatsraison, bauen ihre ideologische Produktion, weitgehend beeinflußt von den diskursiven Entwicklungen aus der westlichen Welt, genau auf seine Identifizierung und Kritik auf. Nicht nur wird dabei die staatliche Funktionalisierung der Religion durch deren Verwaltung angeprangert. Der Islamismus enthält auch gewisse bedrohliche Züge für die Orthodoxie, sofern er mit der zwischen der politischen Macht und der Orthodoxie bestehenden historischen Allianz schlechthin brechen will. Dabei wird auch das Monopol der Orthodoxie bei der Verwaltung des Heilserbes in Frage gestellt, indem die Islamisten, nahezu allesamt säkular gebildeten Laien, das Deutungsrecht für den „Text“ für sich in Anspruch nehmen. Die Auflösung der „Uneindeutigkeit“, ja der Ambivalenz, die sowohl in der laizistischen Religionspolitik als auch im Verhalten der Orthodoxie festgestellt werden kann, verwandelt sich jedoch im islamistischen Diskurs in eine Paradoxie. Ausgerechnet die Suche nach einem von den westlichen Einflüssen nicht kontaminierten, ,authentischen" islamischen Gesellschaftsprojekt treibt den Islamismus in die Vorstellungswelt der Moderne, in der die Ursprungsvisionen, der „mythische Regreß“, utopische Züge entwickeln. Aus der Vision der „machbaren“ Gesellschaft, die auch die Religion als einen spezifischen Bereich der Macht behandelte und ihr dabei eine bestimmte Funktion zuwies, wird die Idee einer islamischen Gesellschaft geboren. Die „Authentizität" der islamistischen Rekonstruktion der Urvisionen verrät nur zu deutlich ihre genealogische Herkunft aus der modernen Gesellschaftsidee.

Das islamistische Gesellschaftsmodell greift ohne Zweifel auf die materialen Kulturbestände des Islam zurück. Diese werden jedoch in einem spezifischen Diskurs rekonstruiert, dessen Instrumente, Wis- 
sensmodi und teilweise auch Inhalte nicht alleine aus dem klassischen Bestand des Islam stammen. Über diese einzelnen Formen der unbeabsichtigten Übernahme aus der modernen westlichen Kultur hinaus und sich auf deren Basis erhebend drückt sich die durch den Islamismus ausgelöste Transformation des Islam vor allem in der Konzeption von Gesellschaft aus. Es wird eine Gesellschaftsvorstellung in das islamische Denken eingeführt, die in ihrem Wesen bereinigt von Macht bzw. versöhnt erscheint und durch willentliches Handeln ins Werk gesetzt werden kann.

Die Behandlung der Frage, welche spezifischen Prägungen aus der Wirkung moderner Kulturinstrumente und deren institutionellen Verkörperungen in den islamisch geprägten Gesellschaften hervorgehen, greift allerdings solange nicht radikal genug aus, als deren Zusammenhang mit den kulturell wirksamen Formen der Selbstkonstitution aus der Analyse ausgeschlossen bleibt. Dieser „Mangel“ hat offengestanden auch unsere Reflexionen von Anfang an begleitet, obgleich das diesbezüglich erforderliche Problembewußtsein stets offen an den Tag gelegt wurde. Die Problematik mußte jedenfalls zunächst herausgestellt werden: Dafür wurden die laizistische Verwaltung der Religion und die reflexive Wendung der Ordnungsprinzipien durch den Islamismus analysiert. Die Bezugnahme auf Foucaults Analyse politischer Rationalität signalisierte tatsächlich bereits eine Sensibilität für die Aufgabe, sich mit der Genealogie der modernen Macht in einem Rahmen zu befassen, in dem die Formen und Funktionsweise der politischen Technologien und der Selbstkonstitution miteinander verknüpft werden sollen. Man müßte davon ausgehen, daß die realen Ausformungen der Machtpraktiken und Wissensformen nicht nur untereinander, sondern auch in Beziehung zu den Formen stehen, wie die Individuen ihr Selbst gestalten. Es gilt diese Beziehungen zwischen den übernommenen Machttechniken (Staatsraison) und Wissensformen (Einflüsse moderner Wissenschaften) noch um diejenigen zu den Selbstverhältnissen zu erweitern (oder zu erklären, falls dies nicht paßt). Die Dominanz der Staatsraison in der politischen Kultur gegenüber den liberalen Regierungstechnologien und das historische Arrangement der Orthodoxie mit der Staatsraison dürften wohl auch mit den Formen der Selbstkonstitution zu tun haben. Die Frage, warum die moderne politische Rationalität in Gestalt der Staatsraison am türkischen Beispiel so rasch in „Rechtleitung“ umschlug und sich nicht einfach auf die Sorge um die moralische Qualität der Bevölkerung beschränkte, wie Foucault es für die Staatsraison herausgearbeitet hatte, kann ebenfalls von hier aus im Hinblick auf die kulturspezifischen Brechungen globaler Diskurse, Praktiken und Institutionen behandelt werden. Das gleiche gilt auch für die Frage, wie sich die übernommenen Wissensformen hier tatsächlich etablierten und ob es dabei 
auf eine ähnliche Weise zu spezifischen Brechungen kam; vor allem in Bezug auf deren innere Verknüpfung mit Machttechniken.

Im folgenden wird die Thematik der Selbstkonstitution vornehmlich in für die künftige Forschung vorbereitender Absicht angerissen. Die vorläufigen Ausführungen sollen hier lediglich das Problembewußtsein schärfen.

\section{Ausblick: Kultur des Geständnisses, Kultur des Konventionalismus}

Foucault war überzeugt davon, daß sich die moderne Macht in einem Zusammenhang mit Praktiken entfalten konnte, die das individuelle Selbst über Jahrhunderte hinweg durch besondere Enthüllungspraktiken geprägt haben. Die Durchsetzung der Biomacht, die ,äußere“ Führung, war also in der westlichen Geschichte ohne die Vorbereitung der ,inneren“ Führung durch die Selbsttechniken nicht zu denken.

Mit dem Hinweis auf die Selbsttechniken ist bereits ein für die künftige kulturübergreifende Forschung wesentlicher Punkt angesprochen. Die Bedeutung des Geständnisses als einer im Abendland angewandten Selbsttechnik erläutert Foucault durch eine kulturvergleichende Gegenüberstellung, auf die er aber nicht mehr zurückkommt. Er macht im Hinblick auf seinen Untersuchungsgegenstand Sexualität „Zwei große Verfahren aus, die Wahrheit des Sexes zu produzieren“, deren systematische Bedeutung jedoch zweifellos über den spezifischen Gegenstand hinausweist. Der grundlegende Unterschied zwischen der in orientalischen Gesellschaften noch vorherrschenden ars erotica (1983: 74) auf der einen Seite und der modernen scientia sexualis besteht darin, daß diese ,im Laufe von Jahrhunderten um die Wahrheit des Sexes zu sagen Prozeduren entwickelt hat, die sich im wesentlichen einer Form von Macht-Wissen unterordnen, die der Kunst der Initiationen und dem Geheimnis des Meisters streng entgegengesetzt ist“ (a.a.O.: 75). Es „handelt sich um das Geständnis“ (ebd.), das wirkungsgeschichtlich zu einer unendlichen Vermehrung der Diskurse geführt hat.

Die Überlegungen zu den Technologien des Selbst, die sich mit der Frage befassen, ,wie wir auf direkte Weise unsere Identität geschaffen haben mit ethischen Selbsttechniken" (Foucault 1993b: 169), münden bei Foucault in dem Urteil: „Im Abendland ist der Mensch ein Geständnistier geworden“ (Foucault 1983.: 77). Wenn auch mit bedeutsamen Veränderungen in ihrer Funktion, bildet die Selbstenthüllung, das ist die Quintessenz seiner Studien für unsere Überlegungen in prospektiver Sicht, eine lange Tradition in der abendländischen Geschichte. Foucault interessiert sich vor allem für verbalisierende Prak- 
tiken der Selbstenthüllung respektive die eigentümliche, ethisch relevante Verknüpfung von Macht und Wissen, die ein besonderes Wahrheitsverhältnis konstituiert und in säkularisierter Form später die Matrix für die politische Rationalität und die Humanwissenschaften abgegeben hat. Eine solche Praktik erblickt Foucault in der Pastoraltechnik. Hier wird der Gläubige dazu angehalten, dem „Hirten“ die Wahrheit über sich selbst lückenlos zu erzählen. Dies perpetuiert nicht nur die bereits in der Antike entwickelte Technik der Selbstbeobachtung und daran anschließende genaue Aufzeichnung der Ergebnisse in Briefen und Tagebüchern, sondern stellt auch den Selbstbeobachter ins Machtverhältnis zu einer äußeren Instanz.

Die Geständnispflicht, die zunächst innerhalb der Praktiken der Buße lokalisiert war, weitet sich später in andere Bereiche aus. Sie steht dann, mit erheblichen Modifikationen, als Modell einer politischen Rationalität zur Verfügung, die sich ebenfalls, doch auf ihre eigene Art und Weise, um das Wohl der Einzelnen kümmern wird, indem diese zum Gegenstand von miteinander verknüpften Machtpraktiken und Wissensformen gemacht werden. Protestantismus (vgl. dazu auch Hahn 1982: 416ff), pädagogische und medizinische Disziplinen haben zudem erheblich dazu beigetragen, daß die Beichte ihre rituelle und exklusive Lokalisierung verloren hat. Seit dem 18. Jahrhundert bis in die Gegenwart ,sind die Techniken der Verbalisierung von den sogenannten Sozialwissenschaften in einen anderen Kontext transformiert worden“ (Foucault 1993a: 62; vgl. auch Hahn 1982: 407). So wurde auch die Geständnistechnik in unterschiedliche Beziehungen wie zwischen „Schüler und Pädagogen, Kranken und Psychiater, Delinquenten und Experten“ (Foucault 1983: 82) eingeflochten. Die Kultur des Geständnisses arbeitet somit in unterschiedlichsten Bereichen durch eine unendliche „Anreizung zu Diskursen“. In der „Vorliebe“ $\mathrm{zu}$ Geständnispraktiken und im Hinblick auf deren zivilisatorischen Folgen liegt ein grundlegender Unterschied zwischen der orientalischen und der okzidentalischen Kulturentwicklung.

Was sind die Konsequenzen der These, daß die Institutionen, Ideen und Instrumente einen spezifischen kulturellen Hintergrund aufweisen, für ihre Übernahme in andere Kulturen? Die Freilegung dieses Hintergrundes darf selbstverständlich nicht der Intention folgen, die Unmöglichkeit der Übernahmeprozesse nachzuweisen. Sie kann aber dazu dienen, sich für die unterschiedlichen Folgen des Einsatzes der übernommenen Instrumente, Konzepte und Techniken zu sensibilisieren. Die Relevanz der Fragestellung besteht darin, daß die besagten politischen Techniken und Wissensformen in einer Gesellschaft zum Wirken kommen, deren historisch-kultureller Hintergrund sich nicht mit Geständnistechniken in eine Verbindung bringen läßt, ja, sogar 
auf einer Kultur beruht, die ihren Mitgliedern gerade von den Praktiken der Selbstenthüllung abrät.

Die Schwierigkeiten, die trotz der hohen Relevanz einer solchen Perspektive der Umsetzung der Foucaultschen Analyse von Selbsttechniken im Wege stehen, liegen schon im ersten Blick auf der Hand. Bereits die geschichtliche Konstitution des Begriffs von Technik im allgemeinen und Selbsttechniken im besonderen bzw. ihrer Transformationen gemahnt zur Vorsicht bei dessen umstandlosen Übertragung auf die Praktiken der Selbstkonstitution in der islamischen Kulturentwicklung. Ob nicht schon der Umstand, daß das Selbst zum Gegenstand von Techniken gemacht wird, eine kulturspezifische Entwicklung ist, müßte noch im Vorfeld geprüft werden. Daher sollte sich eine solche Untersuchung nicht von vornherein auf die Identifizierung von Selbsttechniken beschränken, statt dessen allgemeiner ansetzen und nach den (geschichtlichen) Formen der Selbstkonstitution fragen.

Wie bereits oben eingestanden, kann ich hier lediglich auf die Bedeutung dieses Aspektes hinweisen; eine eingehende Analyse kann hier nicht geleistet werden. Gleichwohl kann man einige Anhaltspunkte für die spätere Beschäftigung mit dem Thema anzeigen, auch ohne die eben angezeigte Schwierigkeit zuvor vollständig geklärt zu haben.

Wenn nicht direkt über mögliche Selbsttechniken, so könnte man sich wenigstens doch über eine spezifische Dimension des in den islamisch geprägten Gesellschaften wirksamen Wahrheitsverständnisses und der damit zusammenhängenden Selbstkonstitution an die Thematik herannähern. Es handelt sich um den rituellen Konventionalismus, der für den Modus der alltäglichen Kommunikation von paradigmatischer Bedeutung ist. Seine Relevanz müßte ebenfalls für die politischen Praktiken und Wissensformen noch herausgearbeitet werden.

Mit dem Begriff wird hier der Umstand beschrieben, daß das mögliche Verhältnis zwischen dem rituellen Akt und der inneren Haltung unterbrochen ist. Die Einhaltung des (nicht nur religiösen) Ritus geschieht konventionell und ohne einen kulturell bedeutsamen Zwang zur inneren Wertvertiefung. Das Thema ist bisher kaum behandelt worden, es lassen sich aber einige verstreute Hinweise in der Literatur finden. So besteht für Stauth das orientalische Wahrheitsverständnis in der „Akzeptanz des Ritus und nicht in seiner Essentialisierung“ (1993: 196). Der Islamwissenschaftler Tilman Nagel merkt in Bezug auf die „geläufige Form der islamischen Religiosität" an, daß sie sich weitgehend auf den äußeren Vollzug des religiösen Ritus verlasse. Und er bringt sie in ein Oppositionsverhältnis zu der individual-ethischen Haltung, die demgegenüber entsprechend schwach ausfalle: „An die Stelle der Herausbildung eines gemeinschaftsdienlichen Ichs tritt somit der eher äußerliche Vollzug der gemeinschaftlichen Rituale und 
Bekenntnisse. Sie werden, losgelöst von ihrer individual-ethischen Deutung und Bedeutung, für die große Masse zur eigentlichen Lebensmitte des islamischen Gemeinwesens.“ (Nagel 1981b: 347; Hervorhebung L.T.) Bezogen auf den spezifischen Umgang mit dem religiösen Gesetz zeigte Rahman ein Gespür davon, wenn er sich anschickte, die verschiedenen Methoden des muslimischen Umgangs mit der Moderne auseinanderzuhalten. Auch der islamische Modernismus war nach Rahmans Meinung im Konventionalismus eingefangen, sofern sein Unternehmen hauptsächlich darin bestand, die Tradition und die Koransuren selektiv zu gebrauchen, um sie an die modernen Bedürfnisse anzupassen (1966: 119ff). Die Formen des Konventionalismus wurden auch hier nicht aufgebrochen. Erst eine historischkritische Lektüre, wie sie von Rahman entwickelt wurde, könne die innere Verbindung zwischen dem moralischen Geist und dem legalen Level herstellen (a.a.O.: 120).

Vom Islam, der sowohl von dieser Kultur des Konventionalismus mitgeprägt ist als auch auf sie selbst prägend gewirkt hat, sind, um auf die Thematik der Selbstkonstitution zurückzukommen, folglich keine Impulse ausgegangen, die eine auf Selbstenthüllung aufbauende Kultur vorbereitet hätten. Ganz im Gegenteil, haben die islamischen Anforderungen an das Selbst eine mißtrauische Haltung gegenüber der Selbstanalyse und der Introspektion kultiviert, die dem individuellen Subjekt ein inneres Wahrheitsverhältnis zu einer äußeren Instanz abverlangen. So hat sich auch folglich ein solches Verhältnis nicht zu einem gesellschaftsrelevanten Phänomen in der muslimischen Kulturwelt entwickelt. Es gibt kaum einen kulturrelevanten Bereich, in dem ähnliche Techniken dafür eingesetzt würden, das Selbst in seinen innersten Regungen zum Sprechen zu bringen, die Ergebnisse der Selbstbeobachtung, die intimsten Regungen seines Selbst als „heilsrelevant" (Hahn 1982: 409) genauestens in Tagebüchern oder anderen Medien festzuhalten, und dies letztlich auch einer ,äußeren“ Instanz zur Verfügung zu stellen. Es gibt zwar Hinweise darauf, daß die Hirtenmetapher, der Foucault eine paradigmatische Bedeutung zuschreibt, auch in der islamischen Kulturgeschichte vorkommt. Sie ist aber völlig anders angelegt, und steht in keinerlei Zusammenhang mit irgend einer wie auch immer gearteten „Pastoraltechnik“. Sie treibt die Herde nicht zu einer ständigen Selbsterforschung an, sondern regelt hauptsächlich die Pflichten zwischen dem Herrscher und den Beherrschten. „Der Herrscher gewährt der Herde, was ihr zukommt“, berichtet Tilman Nagel als das Ziel der wechselseitigen Beziehung (1981a: 164) aus dem Frühislam, ,und die Herde erfüllt ihre Pflicht gegenüber dem Herrscher." Von einer inneren Wahrheitsbeziehung ist nirgends die Rede. Diese ist weitgehend in der Einhaltung der Obligationen bereits abgedeckt. 
Man kann an dieser Stelle ansetzen und nach Praktiken bzw. „Techniken“ suchen, die sich in einem verwandtschaftlichen Zusammenhang mit diesem Wahrheitsverständnis befinden. Einen Anhaltspunkt, dem anderorts systematisch nachgegangen werden müßte, kann man bereits der Literatur entnehmen (vgl. dazu G. E. von Grunebaum 1963, insb. Teil II). Von der frühen Zeit bis in die Glanzepoche der islamischen Zivilisation hinein entwickelte sich, so von Grunebaum, neben ilm (Wissenschaft) eine weitere „Technik“, adab, zur Gestaltung des islamischen Selbst. Adab läßt sich, grob gesprochen, als Disziplinierung und Übung des Geistes, Beherrschung der formellen Vollkommenheit, Besitz der Eleganz übersetzen und bezeichnet im Alltagstürkischen die Gesamtheit des sich geziemenden Verhaltens. ${ }^{119}$ Die praktische Ausgestaltung der Adab ihre kulturellen Wirkungen und geschichtlichen Transformationen müssen noch herausgearbeitet und in den theologischen Bestand des Islam in Beziehung gesetzt werden. Von Grunebaum hat dies seinerseits im Hinblick auf die spezifische Frage, inwiefern sie eine individualisierte Persönlichkeit förderlich ist, unternommen. Er legte dar, daß ein Gutteil arabischer autobiographischer Schriften sich auf bestimmte Tatsachen wie Geburt, Studium, Positionen beschränken, so daß die Persönlichkeit gar nicht in den Vorschein treten könne (a.a.O.: 344). Die Formzwänge in der

119 Beispiele für die Verankerung dieser „Technik“ im alltäglichen Leben gibt es viele. Man denke z. B. nur an das symbolische Spiel, das sich nahezu in jedem türkischen Haushalt zwischen Vater und Sohn (neuerdings auch Tochter) abspielt. In Anwesenheit des Vaters darf der Sohn, selbst wenn er seinerseits höheres Alter erreicht hat, nicht rauchen. Nun, fast jeder türkische Vater weiß davon, wenn sein Sohn raucht, und es kommt jedesmal ein wunderbares Spiel zwischen den beiden in Gange. Väter und Söhne (bzw. Töchter, wenn auch seltener) befolgen dabei verschiedene Strategien der Vermeidung, des Nichtwissens, obwohl man es weiß, daß der andere es weiß. Es widerspricht nicht der $A d a b$, wenn der Sohn in der Wohnung raucht, während sich der Vater dort, aber auf jeden Fall in einem anderen Raum, aufhält. Wichtig ist, daß er im Falle einer unvermeidlichen Begegnung die Zigarette in der Hand nicht sichtlich hält, damit dem Vater noch die Möglichkeit bleibt, das Spiel des „Als-ob“ weiter zu betreiben. Der Sohn darf in der Regel nicht durch seine Handlung, schon gar nicht durch verbale Äußerungen gestehen, daß er nun einmal dieser Last frönt. Mit der nichtverbalisierten, und offiziell im Modus des Verbots verbleibenden Tatsache kann der Vater leben, der Sohn auch. Darauf kommt es ja auch schließlich an. Der Respekt ist an die Form gebunden, und sie bleibt gewahrt. Der symbolische „Vatermord“ besitzt, sollte man diese alltagskulturelle Praktik über die empirische familiäre Beziehung hinaus in einen allgemeinen Zusammenhang führen, keine kulturrelevante Bedeutung. 
literarischen Verfeinerung des islamischen Selbst weisen daher eine unmittelbare Parallelität zur Pflege der Frömmigkeit auf, die sich unschwer auf die sich von der Orthopraxie ausstrahlende Heilsgewißheit verlassen kann.

Es dürfte nun nicht mehr verwunderlich sein, daß eine solche literarische und religiöse Bearbeitung des Selbst eine mißtrauische Haltung gegenüber der Selbstanalyse und Introspektion präferiert. Eine solche Haltung pflegte noch 1934 der ägyptische Reformer Taha Hussein: „Selbstanalyse und Introspektion sollen“, so faßt von Grunebaum dessen Gedanken zusammen, „nicht zu eindringlich werden, denn der zivilisierte Mensch sollte sich nicht einmal vor sich selbst entblößen“ (1963: 566, Fn. 45). Nicht die Selbstenthüllung soll der Gebildete anstreben, sondern die Schamhaftigkeit ist die geeignete Form. Für von Grunebaum wird im islamischen Menschenideal das Individuum durch seine an Regeln geübte Wandlung entpersönlicht, bis es ,typengerecht“ (a.a.O.: 298) wird. Wenn die Anpassung des individuellen Ich an den vorgeprägten Typus das muslimische Menschenideal ausmacht, dann wird das Ziel der sittlichen Bildung weder in der „Entfaltung des Selbst liegen, noch wird sie nach einer „,fortschreitende(n) Heilung auf dem Wege der Selbstverwirklichung" (a.a.O.: 284) streben. Man könnte folglich von hier aus eine Erklärung dafür herausarbeiten, warum die „unsichtbare Religion“, die von Luckmann als die moderne Form der Religion beschriebene Kultur der Selbstverwirklichung, in der türkischen Gesellschaft noch kaum nennenswerte kulturelle Verwurzelung erfahren hat.

Das islamische Selbst artikuliert sich, so könnte man diese vorläufigen Bemerkungen zusammenfassen, indem es seine Besonderheit zurücknimmt. Es ist bestrebt, sich seiner Einzigartigkeit durch die Angleichung an die Sunna (Tradition: Taten und Worte des Propheten und seiner ersten Gemeinschaft) zu vergewissern und in den anerkannten Formen auszudrücken. Die vielgepriesene islamische Toleranz dürfte wohl nur zusammen mit dieser Kehrseite ihrer selbst, mit dem Konventionalismus, möglich sein. Solange der Geächtete den Konventionen öffentlich Folge leistet, solange sich also seine Spezifizität nicht mit einer Wertforderung zur öffentlichen Anerkennung verbindet, d.h.: solange die Abweichung nicht öffentlich eingestanden (bzw. der Abweichler zum Eingeständnis aufgefordert) wird und mit Partizipationsforderung verbunden wird, wird der Abweichler aus der Kommunikation nicht ausgeschlossen. Man müßte die Einflüsse dieser Kultur der bewußten Vermeidung oder des In-Grenzen-Haltens der Diskursivierung (hier: des Selbst), welche die Zurückhaltung gegenüber diversen Formen von „coming out“ als die oberste Maxime vor- 
schreibt, auch bei der Analyse der politischen Kultur berücksichtigen. ${ }^{120}$

Die türkische Staatsraison kam in einem solchen kulturellen Umfeld zum Einsatz. Sie hat verschiedene Techniken aus dem Repertoire der modernen, von Foucault eindringlich beschriebenen Biomacht zur Geltung gebracht, vor allem die Disziplinartechniken. Dies alles geschah allerdings, ohne daß die türkischen Menschen gleichzeitig eine breite Palette von den subjektivierenden Selbsttechniken anwendeten, die von Foucault in einem historisch-kulturellen Wirkungszusammenhang mit den Disziplinartechniken, auf deren Genealogie in den christlichen Geständnistechniken hin, brillant analysiert worden sind. Die „Führung“ der Individuen durch die Staatsraison operierte also ohne die Begleitung einer „Führung der Seelen“, verstanden in dem ganz spezifischen Sinne, daß die Individuen über die Praktiken der Selbstenthüllung in ein Wahrheitsverhältnis nicht nur zu sich selbst (das innere Moment), sondern auch zu einer äußeren Instanz (Beichtvater, Pädagoge, Psychologe etc.) treten. ${ }^{121}$ Symptomatisch ist auch daher der Tatbestand, daß die Geständnistechnik sich im türkischen Kontext fast ausschließlich im polizeilichen Verhör etabliert hat; also in jenem Bereich, welcher unverkennbar der Maxime der Staatsraison unterliegt.

Eine künftige Studie kann an dieser Stelle ansetzen. Sie müßte selbstverständlich die hier in vorbereitender Absicht angestreiften Formen und Praktiken gründlich und systematisch freilegen, mit denen das islamische Selbst (individuell wie kollektiv) konstituiert wird

120 Die alevitische Forderung nach der Anerkennung religio-kultureller Identität, die erst in den letzten Dekaden der türkischen politischen Geschichte denkbar werden konnte, wurde denn auch eher im Modus der Anerkennung alevitischer Gemeinschaft unter dem inhaltlichen Gesichtspunkt verhandelt, daß man über Aleviten bisher nur falsch informiert gewesen sei und es im Grunde keine substantielle Differenz zwischen ihnen und Sunniten bestehe (vgl. Kapitel I.4.4).

121 Man könnte die Frage, warum sich in der eigentlich so autoritätshörigen türkischen Gesellschaft die totalitären Tendenzen lange Zeit nur sehr schwer entwickeln konnten, in einem Zusammenhang mit dem „Fehlen“ der Verknüpfung von äußerem und innerem Moment der Führung zu beantworten suchen. Insofern blieb der türkische Staat trotz seiner repressiven Praktiken ein Obrigkeitsstaat. Selbst der türkische Faschismus als eine gesellschaftliche Kraft hat es übrigens nicht fertig gebracht, eine totale Kontrolle über die eigenen Anhänger selbst zu haben, geschweige denn über die Mehrheit der Bevölkerung, die sich zwar der Autorität in der Regel beugt, aber nicht unbedingt dafür auch noch eifrig mobilisieren läßt. Erst der islamische Fundamentalismus scheint imstande zu sein, eine solche ständige innere wie äußere Mobilisierung der Individuen bewirken zu können. 
(vgl. Mihçıyazgan 1994a, 1994b). Ein solches Unternehmen müßte auch die Dynamik der Transformationen im Blick behalten, die sich gesellschaftlich, und zwar in einem rasanten Tempo, einstellen. Dabei ist sowohl an die islamistischen (vgl. Nökel 2002, allerdings die islamspezifische Ausgestaltung nicht berücksichtigt) als auch die säkularistischen Ausgestaltungen der Selbstkonzepte zu denken. Die islamistische Herausforderung des verwalteten Islam müßte dann auch in den Formen der Selbstkonstitution aufgespürt werden können. Man könnte hier fragen, was aus dem Formalismus und der „Laxheit“ des rituellen Konventionalismus wird, und ob denn nicht im politischen Essentialismus der Islamisten die Einheit von Ritus und Lebensform bzw. der inneren Haltung tendenziell hergestellt wird.

Es müßte dann daran die Frage nach den Auswirkungen der Veränderungen an der Selbstkonstitution auf die politische Ordnung respektive die Staatsraison anschließen. Um es allgemeiner zu formulieren: In welchem dynamischen Zusammenhang stehen die spezifischen Ausgestaltungen der politischen Kultur mit Blick auf die Verschiebungen an ihr und den ethischen Selbstkonzeptionen? 



\section{LITERATUR}

Adams, Charles J. (1983): „Mawdudi and the Islamic State“. In: John

L. Esposito $(\mathrm{Hg})$, Voices of resurgent Islam, New York/Oxford: Oxford University Press, S. 99-133.

Ahmed, Akbar S. (1995): Postmodernizm ve İslam, Istanbul: Cep Kitapları.

Akçura, Yusuf (1987 [1904]): Üç Tarz-1 Siyaset, Ankara: Türk Tarih

Kurumu Basımevi.

Akçura, Yusuf (1990 [1928]): Türkçülük, Istanbul: Toker.

Aksu, İsmail (1992): „Çağdaş İsrailiyat ve Müslümanlar. Sosyal

Bilimler, Bilim Feslsefesi, Sivil Toplum ve Çoğulculuk Tartışmaları". In: Dünya ve İslam 12, S. 47-58.

Aktay, Yasin (1997): Body, Text, Identity. The Islamist Discourse of Authenticity, Diss. Ankara.

Akyol, Taha (1998): Medine'den Lozan'a. Istanbul: AD Kitapçılık.

Aktaş, Cihan (1992): Tesettür ve Toplum. Başörtülü Öğrencilerin Toplumsal Kökeni Üzerine Bir İnceleme. Istanbul: Nehir.

Al-Buhari (1997): Sahih al-Buhari. Nachrichten von Taten und Aussprüchen des Propheten Muhammad, Stuttgart: Reclam.

Algül, Hüseyin (1994): „Asr-1 saadette idari hayat“. In: Bilgi ve Hikmet 5, S. 61-67.

Al-Azim, Sadik J. (1996): „Das Wahrheitsregime der Verbrecher. Postmoderner Relativismus und die Frage der Menschenrechte“. In: Frankfurter Rundschau vom 26. November 1996.

Al-Azmeh, Aziz (1996): Die Islamisierung des Islam. Imaginäre Welten einer politischen Theologie, Frankfurt/New York: Campus Verlag.

Ali, Kemal (1987): „Cevabımı““. In: Yusuf Akçura, Üç tarz-1 Siyaset, Ankara: Türk Tarih Kurumu Basımevi, S. 37-44.

Arendt, Hannah (1981 [1967]): Vita Activa oder Vom tätigen Leben, München: Piper.

Arendt, Hannah (1994): Zwischen Vergangenheit und Zukunft. Übungen im politischen Denken I, München: Piper.

Arkoun, Muhammed (1995a): „İslami Düşüncede Otorite Kavramı“.

In: İslam'da Siyaset Düşüncesi (o. Hg.). Istanbul: İnsan.

Arkoun, Muhammed (1995b): „İslam’1 ve Laikliği Bugün Yeniden

Düşünmek“. In: Oliver Abel/Muhammed Arkoun/ Şerif Mardin (Hg.), Avrupa'da Etik, Din ve Laiklik, Istanbul: Metis , S. 15-26. 
Arslan, Abdurrahman (1993): „Peygamber Ümmetinden Ulus'un Devletine“. In: Bilgi ve Hikmet 3, S. 16-36.

Arslan, Abdurrahman (1994): „Geleceğin Kurgulanımı veya Bir Kurgunun Geleceği“. In: Bilgi ve Hikmet 6, S. 14-20.

Aydın, Suavi (1998): „Türkiye'de Devlet Geleneği Söylemi“. In: Birikim 105/106, S. 63-82.

Bauman, Zygmunt (1995): Ansichten der Postmoderne, Hamburg/Berlin: Argument Sonderband, AS 239.

Robert Bellah u.a.(Hg.) (1987): Gewohnheiten des Herzens. Individualismus und Gemeinsinn in der amerikanischen Gesellschaft, Köln: Bund.

Benhabib, Seyla (1999): Kulturelle Vielfalt und demokratische Gleichheit. Politische Partizipation im Zeitalter der Globalisierung, Frankfurt/M.: Fischer.

Bernand, M. (1987): „Muamelat“. In: Encyclopaedia of Islam. Bd. VII, Leiden: Brill, S. 256-257.

Becker, C. H. (1967): Islamstudien Bd. I. Vom Werden und Wesen der islamischen Welt, Hildesheim: Georg Olms Verlagsbuchhandlung.

Bielefeldt, Heiner (2001): Kants Symbolik. Ein Schlüssel zur kritischen Freiheitsphilosophie, Freiburg/München: Verlag Karl Alber.

Bilgi ve Hikmet (1994): Dinlerin Gelecek Tasarımı. (Monatszeitschrift, mehrere Beiträge) 6 .

Birikim (1998): Bir Heyula. Resmi ideoloji (Monatszeitschrift, mehrere Beiträge) 105/106 und 107.

Bora, Tanıl (1996): „Taşralaşan ve Taşrasını kaybeden Türkiye“. In: Birikim 86/87, S. 101-106.

Büttner, Friedemann (1996): „Der fundamentalistische Impuls und die Herausforderung der Moderne“. In: Leviathan. Zeitschrift für Sozialwissenschaft 24, S. 469-492.

Bulaç, Ali (1992a): Din ve Modernizm, Istanbul: Beyan.

Bulaç, Ali (1992b): „Medine Vesikası Hakkında Genel Bilgiler“. In: Birikim 38/39, S. 102-110.

Bulaç, Ali (1992c): „Sözleşme Temelinde Toplumsal Proje“. In: Birikim 40, S. 53-62.

Bulaç, Ali (1994a): „Bir Arada Yaşamanın Mümkün Projesi: Medina Vesikası“. In: Bilgi ve Hikmet 5, S. 3-15.

Bulaç, Ali (1994b): „Din-Dışı'nın Seküler Sitesinden ,ed-Din'in Sahici Dünyasına. In: Bilgi ve Hikmet 6, S. 3-13.

Bulaç, Ali (1994c): İslam Düşüncesinde Din-Felsefe/Vahiy-Akıl İlişkisi, Istanbul: Beyan.

Bulaç, Ali (1995): Modern Ulus Devlet, Istanbul: İz Yayıncılık.

Bulaç, Ali (2000): „İbrahim'in Evlatları“. In: Tageszeitung Zaman vom 11. April. 
Bulut, Faik (1995): Tarikat Sermayesinin Yükselişi, Ankara: Öteki.

Can, Kemal (1997): „Yeşil Sermaye Laik Sisteme Ne Yaptı?“. In: Birikim 99, S. 59-65.

Canatan, Kadir (1994): „Toplum Tasarımları ve ,Birlikte Yaşama“ Felsefesi“. In: Bilgi ve Hikmet 5, 98-108.

Cebeci, Dilaver (1995): „Medine“. In: Anadolu 5, http://www. wakeup.org/anadolu/05/1/siir4.html

Ceylan, Hasan H. (1989): Cumhuriyet dönemi din-devlet ilişkileri, Istanbul: Risale.

Çelik, Ömer (1994a): „Beraber yaşama sorunu, insanın anlam arayışı ve siyasal otorite" In: Bilgi ve Hikmet 5, S. 16-32.

Çelik, Ömer (1994b): „Kadim hayat çağrısının rasyonel tehdide eklemlenmesi. Dinler ve gelecek tasarımı“. In: Bilgi ve Hikmet 6, S. 21-32.

Çınar, Menderes / Kadığlu, Ayşe (1999): „An islamic critique of modernity in Turkey: politics of difference backwards". In: Orient 40, S. 53-69.

Çiğdem, Ahmet (1996): „Islamcılık“. In: Cumhuriyet Dönemi Türkiye Ansiklopedisi, Bd. 15, Istanbul: İletişim, S. 1225-1231.

De Bellefonds, Y. Linant (1997): Kanun. In: The Encyclopaedia of Islam, Bd. IV, Leiden: Brill, S. 556-557.

Diyanet İşleri Başkanlığ 1 (1987): Teşkilat Tarihçesi (1924-1987). Ankara: (o. V.).

Diyanet İşleri Başkanlığı (1997): (Broschüre), Ankara: (o. V.).

Dilipak, Abdurrahman (1991): Laisizm. Istanbul: Beyan.

Dilipak, Abdurrahman (1992): Medine Vesikası Üzerine Aykırı Düşünceler. In: Birikim 27, S. 26-28.

Dreyfus, Hubert L/Paul Rabinow (1994): Michel Foucault. Jenseits von Strukturalismus und Hermeneutik, Weinheim: Athenäum.

Dumont, Louis (1991): Individualismus. Zur Ideologie der Moderne, Frankfurt/M.: Campus.

Duran, Khalid (1983): „,The ,Golden Age‘ Syndrome. Islamist Medina and Other Historical Models of Contemporary Muslim Thought". In: Schweizerische Zeitschrift für Soziologie 9, S. 703-716.

Dursun, Davut (1992): Din bürokrasisi. Yapısı, Konumu, Gelişimi, Istanbul: İşaret.

Ege, Ragıp (1993): „Medine Vesikası mı, hukuk devleti mi? “. In: Birikim 47, S. 21-39.

Eisenstadt, Shmuel N. (1987): Kulturen der Achsenzeit, Teil 1, Frankfurt/M.: Suhrkamp.

Eisenstadt, Shmuel N. (1992): Kulturen der Achsenzeit, Teil 3, Frankfurt/M.: Suhrkamp. 
Eisenstadt, Shmuel N. (1998): Antinomien der Moderne. Die jakobinischen Grundzüge der Moderne und des Fundamentalismus, Frankfurt/M: Suhrkamp.

Eisenstadt, Shmuel N. (2000).: Multiple Modernities, (last draft), inzwischen erschienen in: Dadealus, Nr. 129, 2000, S. 1-30.

Esposito, John L. (1984): Islam and Politics, Syracuse, New York: Syracuse University Press.

Faruqi, Suraiya (1989): „Die Legitimation des Osmanensultans: Zur Beziehung von Religion, Kunst und Politik im 16. und 17. Jahrhundert". In: Zeitschrift für Türkeistudien 2, S. 49-67.

Foucault, Michel (1976a): „Macht und Körper“. In: Mikrophysik der Macht. Über Strafjustiz, Psychiatrie und Medizin, Berlin: Merve, 105-113.

Foucault, Michel (1976b): „Die Macht und die Norm“. In: Mikrophysik der Macht. Über Strafjustiz, Psychiatrie und Medizin, Berlin: Merve, S. 114-123.

Foucault, Michel (1977): Überwachen und Strafen, Frankfurt/M.: Suhrkamp.

Foucault, Michel (1983): Sexualität und Wahrheit 1: Der Wille zum Wissen, Frankfurt/M: Suhrkamp.

Foucault, Michel (1986): Vom Licht des Krieges zur Geburt der Geschichte, Berlin: Merve.

Foucault, Michel (1990): Die Ordnung der Dinge, Frankfurt/M: Suhrkamp.

Foucault, Michel (1991): „Governmentality“. In: Graham Burchhell (Hg.), The Foucault Effect: Studies in Governmentality, London [u.a.]: Harvester Whetsheaf.

Foucault, Michel (1993a): „Technologien des Selbst“. In: Luther H. Martin/Huck Gutmann/Fatrich H. Hutton (Hg.),Technologien des Selbst, Frankfurt/M: Fischer, S. 24-62.

Foucault, Michel (1993b): „Die politische Technologie der Individuen“. In: Luther H. Martin/Huck Gutmann/Fatrich H. Hutton (Hg.),

Technologien des Selbst, Frankfurt/M.: Fischer, S. 168-187.

Fuchs, Martin (1998): „Erkenntnispraxis und die Repräsentation von Differenz". In: Aledia Assmann/Heidrun Friese (Hg.), Identitäten. Erinnerung, Geschichte, Identität 3, Frankfurt/M.: Suhrkamp, S. 105-137.

Fuchs, Martin (1999): Kampf um Differenz. Repräsentation, Subjektivität und soziale Bewegungen. Das Beispiel Indien. Frankfurt/M.: Suhrkamp.

Gellner, Ernest (1985): Leben im Islam, Stuttgart: Clett-Kotta.

Glassen, Erika (1979): „Krisenbewußtsein und Heilserwartung“. In:

Ulrich Haarmann/Peter Bachmann (Hg.), Die islamische Welt zwi- 
schen Mittelalter und Neuzeit, Beirut/Wiesbaden: Franz Steiner Verlag, S. 167-179.

Gökalp, Ziya (1975 [1923]): Türkçülüğün Esasları, Istanbul: İnkılap Kitabevi.

Göle, Nilüfer (1997): „Secularism in Turkey: the Making of Elites and Counter-Elites“. In: Middle East Journal 51, S. 46-58.

Goldziher, Ignas (1965): Fikh, in: The Encyclopaedia of Islam, Vol. II, Leiden/London: E. J. Brill/Luzac \& Co., S. 886-887.

Goldziher, Ignas (1967 [1871]): „Zur Charakteristik Gelal ud-din usSujutis und seiner literarischen Thätigkeit“. In: Gesammelte Schriften Bd. 1, Hildesheim: Georg Olms Verlagsbuchhandlung.

Goldziher, Ignas (1968 [1889]): „Muhammedanisches Recht in Theorie und Wirklichkeit". In: Gesammelte Schriften, Bd. 2, Hildesheim: Georg Olms Verlagsbuchhandlung, S. 353-370.

Goldziher, Ignas (1970 [1914]): „Katholische Tendenz und Partikularismus im Islam“. In: Gesammelte Schriften, Bd. 5, Hildesheim: Georg Olms Verlagsbuchhandlung, S. 285-312.

Gordon, Colin (1987): „The Soul of the Citizen: Max Weber and Michel Foucault on Rationality and Government". In: Scott Whimster/Scott Lash (Hg.), Max Weber, Rationality and Modernity. London-Boston-Sydney: Allen \& Unwin, S. 293-316.

Gordon, Colin (1991): „Governmental rationality: an introduction“. In: Graham Burchhell (Hg.), The Foucault Effect: Studies in governmentality, London [u.a.]: Harvester Whetsheaf, S. 1-51.

Gramlich, Richard (1974): „Vom islamischen Glauben an die ,gute alte Zeit“". In: ders. (Hg.), Islamwissenschaftliche Abhandlungen, Fritz Meier zum sechzigsten Geburtstag. Wiesbaden: Franz Steinert, S. 110-117.

Gülalp, Haldun (1999): „Political Islam in Turkey: The rise and fall of the Refah Party“. In: The Muslim World 89, S. 22-41.

Haarmann, Ulrich (1994): „Ein Mißgriff der Geschichte. Muslimische und westliche Standpunkte zur Geschichte der islamischen Welt im achtzehnten Jh.“. In: Hilmar Kallweit/Wolfgang Küttler (Hg.), Geschichtsdenken. Anfänge des modernen historischen Denkens, Frankfurt/M: Fischer

Hahn, Alois (1982): „Zur Soziologie der Beichte und anderer Formen institutionalisierter Bekenntnisse: Selbstthematisierung und Zivilisationsprozeß“. In: Kölner Zeitschrift für Soziologie und Sozialpsychologie 34, S. 408-434.

Halm, Heinz (1967): Die Tradition über den Aufstand Ali ibn Muhammad des „Herrn der Zang“. Eine quellenkritische Untersuchung. Bonn: Univ. Diss. an der Rheinischen Friedrich-WillhelmUniversität Bonn. 
Hamidullah, Muhamed (1993): İslam Peygamberi, Bd. 1, Istanbul: İrfan.

Hamidullah, Muhamed (1998): İslam anayasa hukuku, Istanbul: Beyan.

Heidegger, Martin (1950): „Die Zeit des Weltbildes“. In: ders., Holzwege. Frankfurt/M: Vittorio Klostermann, S. 69-104.

Heitmeyer, Wilhelm/Anhut, Reimund (2000): Bedrohte Stadtgesellschaft. Soziale Desintegrationsprozesse und ethnisch-kulturelle Konfliktkonstellationen. Weinheim/München: Juventa Verlag.

Hermann, Rainer (1996): „Die drei Versionen des politischen Islam in der Türkei“. In: Orient 37, S. 35-57.

Hülagü, Metin (1994): Pan-İslamist Faaliyetler, Istanbul: Bogaziçi.

İnalcık, Halil (1978): „Suleiman the Lawgiwer and Ottoman Law“. In: ders., The Ottoman Empire. Conquest, Organization and Economy. Collected Studies, London: Variorum Reprints.

İnsel, Ahmet (1992): „Totalitarizm, Medine Vesikası ve özgürlük“. In: Birikim 37, S. 29-32.

Insel,Ahmet (1996): „RP ve Kemalizm“. In: Birikim 91, S. 29-31.

İnsel, Ahmet (1998): „Cumhuriyet ve Demokrasi“. In: Birikim 115, S. 30-39.

Jäggi, Christian J./Krieger, David J. (1991): Fundamentalismus. Ein Phänomen der Gegenwart, Zürich/Wiesbaden: Orell Füssli.

Jaspers, Karl (1955): Vom Ursprung und Ziel der Geschichte, Frankfurt/M. u. Hamburg: Fischer.

Kara, İsmail (1987): Türkiye'de İslamcılık Düşüncesi, Bd. 1, Istanbul: Risale.

Kehl-Bodrogi, Krisztina (1996): „Tarih Mitosu ve Kollektif Kimlik“. In: Birikim 88, S. 52-61.

Keskin, Ferda (1997): „Foucault’da Öznellik ve Özgürlük“. In: Toplum ve Bilim 73, S. 30-46.

Kemal, Namık (1975): Büyük İslam Tarihi [das Original aus Ende des 19. Jh., o. J.]: Istanbul: Hürriyet

Kıvanç, Ümit (1997): „İslamcılar \& Para-pul: Bir Dönüşüm Hikayesi“. In: Birikim 99, S. 39-58.

Köker, Levent (1993): „Kimlik krizi, meşruluk krizi, Kemalizm ve sonrası“. In: Toplum ve Bilim 71, S. 150-167.

Köktaş, Eyüp (1994a): „Medine Vesikası: İslamın coğulculuk referansı/çoğulcu epistemolojık düzlem“. In: Bilgi ve Hikmet 5, S. 5560.

Köktaş, Eyüp (1994b): „İslam, sivil toplum ve iktidarın meşruiyeti“. In: Tezkire 7/8, S. 163-169.

Der Koran (1987), (Übersetzung von A. Th. Khoury, unter Mitwirkung von M. S. Abdullah) Gütersloh: Gütersloher Verlagshaus Gerd Mohn. 
Laclau, Ernesto/Chantal Mouffe (1991): Hegemonie und die radikale

Demokratie, Wien: Passagen.

Laçiner, Ömer (1995a): „Postmodern bir dini hareket: Fethullah Hoca

Cemaati“. In: Birikim 76, S. 3-11.

Laçiner, Ömer (1995b): „Fethullah Hoca Cemaati““. In: Birikim 77, S. 3-10.

Lapidus, Ira M. (1988): A History of Islamic Societies. Cambridge/New York: Camridge University Press.

Lefort, Claude (1990): „Die Frage der Demokratie“. In: Ulrich Rödel (Hg.), Autonome Gesellschaft und libertäre Demokratie, Frankfurt/M: Suhrkamp, S. 281-297.

Lemke, Thomas (1997): Eine Kritik der politischen Vernunft. Foucaults Analyse der modernen Governementalität, Berlin/Hamburg: Argument.

Lewis, Bernhard (1995): „Eurozentrismus“. In: Merkur 49, S. 644651.

Luhmann, Niklas (1996): „Religion als Kultur“. In: Otto Kallscheuer, Das Europa der Religionen, Frankfurt/M: S. Fischer, S. 291-316.

Luckmann, Thomas (1991): Die unsichtbare Religion, Frankfurt/M: Suhrkamp.

Maier, Hans (1966): Die ältere deutsche Staats- und Verwaltungslehre (Polizeiwissenschaft). Neuwied am Rhein und Berlin: Luchterhand.

Mardin, Şerif (1983 [1969]): Din ve İdeoloji. Istanbul: İletişim.

Mardin, Şerif (1991): Türkiye' de Din ve Siyaset. Istanbul: İletişim.

Mardin, Şerif (1992): Bediüzzaman Said Nursi Olayı. Istanbul: İletişim.

Mardin, Şerif (1997): „Anmerkungen zu normativen Konflikten in der Türkei“. In: Peter L. Berger (Hg.), Die Grenzen der Gemeinschaft: Konflikt und Vermittlung in pluralistischen Gesellschaften, Gütersloh: Verlag Bertelsmann-Stiftung, S. 355-397.

Marramao, Giacomo (1989): Macht und Säkularisierung. Die Kategorie der Zeit, Frankfurt/M: Verlag Neue Kritik.

Martin E. Marty/R. Scott Appleby (1996): Herausforderung Fundamentalismus. Radikale Christen, Moslems und Juden im Kampf gegen die Moderne, Frankfurt/M u. New York: Campus.

Maududi, Abul Ala (1971): Weltanschauung und Leben im Islam, Freiburg: Herder.

Meddeb, Abdelwahab (1994): „Europa als Extrem. Vom Tode Gottes im christlichen Europa und im Islam“. In: Lettre International 25, S. 32-37.

Meier, Fritz (1969): „Sufik und Kulturzerfall““. In: Gustav E. Grunebaum/Willy Hartner (Hg.), Klassizismus und Kulturverfall, Frankfurt a.M.: Vittorio Klostermann, S. 148-180. 
Meinecke, Friedrich (1963): Die Idee der Staatsräson, München: R. Oldenburg Verlag.

Meeker, Michael (1993): „Türkiye Cumhuriyetinde Yeni Müslüman Aydınlar". In: Richard Tapper (Hg.), Çağdaş Türkiye'de İslam, Istanbul: Sarmal, S. 261-299.

Mihçıyazgan, Ursula (1994a): „Die religiöse Praxis muslimischer Migranten. Ergebnisse einer empirischen Untersuchung in Hamburg“. In: Ingrid Lohmann / Wolfram Weiße (Hg.), Dialog zwischen den Kulturen. Erziehungshistorische und religionspädagogische Gesichtspunkte interkultureller Bildung, Münster/New York: Waxmann, S. 195-206.

Mihciyazgan, U., 1994b: „Identitätsbildung zwischen Selbst- und Fremdreferenz. Überlegungen zur Beschreibung der Identität muslimischer Migranten“. In: Peter Schreiner (Hg.), Identitätsbildung in multikultureller Gesellschaft. Münster: Comenius Institut, S. 3148.

Nagel, Tilman (1975): Rechtleitung und Kalifat. Versuch über eine Grundfrage der islamischen Geschichte. Bonn: Selbstverlag des Orientalischen Seminars der Universität Bonn.

Nagel, Tilman (1981a): Staat und Glaubensgemeinschaft im Islam, Bd. 1. Zürich/München: Artemis.

Nagel, Tilman (1981b): Staat und Glaubensgemeinschaft im Islam, Bd. 2. Zürich/München: Artemis.

Nagel, Tilman (1981c): „Gab es in der islamischen Geschichte Ansätze einer Säkularisierung“. In: Hans R. Roemer/Albrecht Noth (Hg.), Studien zur Geschichte und Kultur des vorderen Orients : Festschrift für Bertold Spuler zum siebzigsten Geburtstag. Leiden: E.J. Brill, S. 275-288.

Nagel, Tilman (1990): „Theologie und Ideologie im modernen Islam“. In: Munir D. Ahmed u.a., Islamische Kultur - Zeitgenössische Strömungen - Volksfrömmigkeit. Der Islam Bd. III. Stuttgart [u.a.]: Verlag W. Kohlhammer, S. 1-59.

Nancy, Jean-Luc (1988): Die undarstellbare Gemeinschaft. Stuttgart: Edition Patricia Schwarz.

Narlı, Nilüfer (1993): Islamcı Gençlik, Ergebnisse teilweise abgedruckt in: Nokta vom 22-28. August, 35, S. 14-22.

Nökel, Sigrid, 2002: Die Töchter der Gastarbeiter und der Islam. Zur Soziologie alltagsweltlicher Anerkennungspolitiken. Eine Fallstudie. Bielefeld: Transcript.

Ortaylı, İlber (1979): Türkiye İdare Tarihi, Ankara: TODAİE.

Ortaylı, İlber (1983): Osmanlı İmparatorluğun'da Alman Nüfuzu, Istanbul: İletişim.

Ortaylı, İlber (1994): Hukuk ve İdare Adamı Olarak Osmanlı Devletinde Kadı, Ankara: Turhan Kitabevi. 
Öğün, Süleyman Seyfi (1995): Modernleşme, Milliyetçilik ve Türkiye. Istanbul: Bağlam.

Öz, Baki (1996): Alevilik Nedir?, Istanbul: Der.

Özel, İsmet (1998 [1978]): Üç Mesele. Teknik, Medeniyet, Yabancılaşma, Istanbul: Şule.

Öztürk, Yaşar Nuri u.a. (1995) (Hg.): İslam Gerçeği, Ankara: Ankara Üniversitesi İlahiyat Fakültesi.

Öztürk, Yaşar Nuri (1997): Yeniden yapılanmak, Istanbul: Yeni Boyut.

Parla, Taha (1989): Ziya Gökalp, Kemalizm ve Türkiye'de Korporatizm, Istanbul: İletişim. [zuerst erschienen: The Social and Political Thought of Ziya Gökalp, Leiden 1985: E. J. Brill.]

Parsons, Talcott (1969): Gesellschaften. Evolutionäre und komparative Perspektiven, Frankfurt/M: Suhrkamp.

Paşa, Said Halim (1991[1913-1919]): Buhranlarımız ve son eserleri, Istanbul: İz.

Rahman, Fazlur (1966): „The Impact of Modernity on Islam“. In: Islamic Studies V, 113-128.

Rahman, Fazlur (1967): „Some Reflections on the Reconstruction of the Muslim Society in Pakistan“. In: Islamic Studies VI, S. 103120.

Rahman, Fazlur (1970): „Islamic Modernism: Its Scope, Method and Alternatives“. In: International Journal of Middle East Studies 1, S.317-333.

Rahman, Fazlur (1979): Islam, Chicago: The University of Chicago Press.

Rahman, Fazlur (1982): Islam \& Modernity. Transformation of an Intellectual Tradition, Chicago: The University of Chicago Press.

Riesebrodt, Martin (1990): Fundamentalismus als patriarchalische Protestbewegung. Amerikanische Protestanten (1910-1928) und iranische Schiiten (1961-1979) im Vergleich, Tübingen: Mohr.

Salvatore, Armando (1998): „Staging Virtue: The Disembodiment of Self-Correctness and the Making of Islam as Public Norm". In: Georg Stauth (Hg.), Islam - Motor or Challenge of Modernity, Yearbook of Sociology 1. Münster: Lit, S. 87-120.

Sancar, Mithat (1997): „Devlet Aklı, Hukuk Devleti ve,Devlet Çetesi“. In: Birikim 93/93, S. 80-90.

Sarıbay, Ali Yaşar (1993): „İslami popülizm ve sivil toplum arayışı“. In: Birikim 47, S. 14-20.

Sayyid, Boby (1994): „Sign O’ Times: Kaffirs and Infidels Fighting the Ninth Crusade“. In: Ernesto Laclau (Hg.), The Making of Political Identities, London/New York: Verso, S. 264-286. 
Schacht, Joseph (1935): „Zur soziologischen Betrachtung des islamischen Rechts“. In: Der Islam, Zeitschrift für Geschichte und Kultur des islamischen Orients 22, S. 207-238.

Schacht, Joseph (1965): „Fikh“, in: The Encyclopaedia of Islam, Vol. II, Leiden/London: E. J. Brill/Luzac \& Co, S. 887-891.

Scharia'ti, Ali (1979): On the Sociology of Islam. Berkeley: Mizan Press.

Schluchter, Wolfgang (1976): „Die Paradoxie der Rationalisierung. Zum Verhältnis von ,Ethik' und ,Welt' bei Max Weber“. In: Zeitschrift für Soziologie 5, S. 256-284.

Seufert, Günter (1997a): Café Istanbul. Alltag, Religion und Politik in der modernen Türkei, München: Beck.

Seufert, Günter (1997b): Islamismus als symbolische Repräsentation einer sich modernisierenden muslimischen Gesellschaft, Istanbul: In Kommission bei Franz Steiner Verlag Stuttgart.

Seufert, Günter (1999): „Die türkisch-islamische Union (DITIB). Zwischen Integration und Isolation". In: Günter Seufert/Jacques Waardenburg, Istanbul: In Kommission bei Franz Steiner Verlag Stuttgart, S. 261-293.

Sever, Metin/Cem Dizdar (1993): 2. Cumhuriyet Tartışmaları, Ankara: Başak.

Sırma, İ. Süreyya (1994): „Medine Vesikasının Mevsukiyeti ile İlgili Bazı Veriler“. In: Bilgi ve Hikmet 5, S. 46-54.

Sloterdijk, Peter (1989): Der Eurotaoismus, Frankfurt/M: Suhrkamp.

Sprenger, Aloys (1865): Das Leben und die Lehre des Mohammad, Bd. 3, Berlin: Nicolaische Verlagsbuchhandlung.

Stauth, Georg (1993): Islam und westlicher Rationalismus, Frankfurt/New York: Campus.

Stauth, Georg (1995): „Globalisierung, Modernität, nicht-westliche Zivilisationen“. In: Joseph Langer (Hg.), Kleine Staaten in großer Gesellschaft, Eisenstadt: Verlag für Soziologie u. Humanethologie, S. 89-107.

Stauth, Georg (1996): „Islam als Selbstbegriff nichtwestlicher Rationalität". In: Helmut Bucholt/Erhard U. Heidt/Georg Stauth (Hg.), Modernität zwischen Differenzierung und Globalisierung: Kulturelle, wirtschaftliche und politische Transformationsprozesse in der sich globalisierenden Moderne, Münster: Lit Verlag, S. 17-42.

Stauth, Georg (1999): Authentizität, Bielefeld: transcript.

Stauth, Georg (2000): „Religiöser Fundamentalismus zwischen Orient und Okzident: Religiöse Identitätspolitik und ihr Verhältnis zur Demokratie“. In: Dietmar Loch/Wilhelm Heitmeyer (Hg.), Die Schattenseiten der Globalisierung, Frankfurt/M.: Suhrkamp, S. 140-164. 
Stauth, Georg (2001): „Skizzen zur materiellen Kultur des religiösen Ortes (Islam) - Kulturelle Immanenz". In: Heiko Schrader/Markus Kaiser/Rüdiger Korff (Hg.), Markt, Kultur und Gesellschaft. Zur Aktualität von 25 Jahren Entwicklungsforschung, Münster [u.a.]: Lit, S. 149-165.

Tapper, Richard (1993): Çağdaş Türkiye'de İslam, Istanbul 1993: Sarmal Yayınevi.

Tarhanlı, İştar B. (1993): Müslüman Toplum, „Laik Devlet“, Istanbul: Afa.

Taubes, Jacob (1947): Abendländische Eschatologie, Bern : Francke.

TBMM Tutanak Dergisi (Bulleten des türkischen Parlaments): 31. Sitzung, 19.12.1997.

Tekeli, İlhan/İlkin, Selim (1990): „Mustafa Celaleddin Bey'in Mükaleme Adlı Risalesi“. In: Toplum ve Bilim 51/52, S. 171-178.

Tezcan, Levent (1997): „Kemalizmi Düşünmenin Sorunları“. In: Toplum ve Bilim 74, S. 194-208.

Tezcan, Levent (2000): „Kulturelle Identität und Konflikt. Zur Rolle politischer und religiöser Gruppen der türkischen Minderheit". In: Wilhelm Heitmeyer/Raimund Anhut, Bedrohte Stadtgesellschaft. Soziale Desintegrationsprozesse und ethnisch-kulturelle Konfliktkonstellationen, Weinheim/München: Juventa Verlag, S. 401-448.

Tibi, Bassam (1993) Islamischer Fundamentalismus, moderne Wissenschaft und Technologie, Frankfurt/M.: Suhrkamp.

Taylor, Charles (1997): „Die Politik der Anerkennung“. In: Amy Gutmann, Multikulturalismus und die Politik der Anerkennung. Frankfurt/M: Fischer, S. 13-78.

Türköne, Mümtazer (1991): Siyasi İdeoloji Olarak İslamcılığın Doğuşu, Istanbul: İletişim.

Türköne, Mümtazer (1992): „Müslümanlar ve Çoğulcu Bir Toplum Tasarımı“. In: Birikim 43, S. 22-25.

Turner, Bryan S. (1994): Orientalism, Postmodernism and Globalism, London [u.a.]: Routledge.

Uluçay, Ömer (1998): Diyanet. Tartışmalı kurum, Adana: Gözde Yayinevi.

Ülken, Hilmi Ziya (1998 [1966]): Türkiye'de Çağdaş Düşünce Tarihi. Istanbul: Ülken .

Van Bruinessen, Martin (1996): „Aslını inkar eden haramzadedir!“. In: Birikim 88, S. 38-51.

Von Grunebaum, Gustave E. (1960): „Von Begriff und Bedeutung eines Kulturklassizismus“. In: Gustav E. v. Grunebaum/Willy Hartner (Hg.), Klassizismus und Kulturverfall, Frankfurt a.M.: Vittorio Klostermann, S. 5-38.

Von Grunebaum, Gustave E. (1963): Der Islam im Mittelalter, Zürich: Artemis Verlag. 
Von Grunebaum, Gustave E. (1969): Studien zum Kulturbild und Selbstverständnis des Islam, Zürich/Stuttgart: Artemis Verlag.

Wagner, Peter (1995): Soziologie der Moderne, Frankfurt/M. u. New York 1995: Campus.

Watt, Montgomery (1968): Islamic Political Thought. The Basic Concepts, Edinburg: University Press.

Watt, Montgomery/Alford T. Welch (1980): Mohammed und die Frühzeit. Der Islam Bd. 1., Berlin: Kohlhammer.

Weber, Max (1967 [1917/1919]): Wissenschaft als Beruf, Berlin: Duncker \& Humblodt.

Weber, Max (1972 [1922]): Wirtschaft und Gesellschaft. Grundriß der verstehenden Soziologie, hrsg. von Johannes Winckelmann, Tübingen: J.C.B. Mohr (Paul Siebeck).

Weber, Max (1975 [1920]): Die protestantische Ethik I, hrsg. von Johannes Winckelmann. Hamburg: Siebenstern.

Wellhausen, Julius (1889): Skizzen und Vorarbeiten, Bd. 4, Berlin: Verlag von Georg Reimer (Photomech. Nachdruck: Walter de Gruyter, Berlin/New York 1985).

Werner, Karin (1999): „Vom wilden Teenager zur Bürgerin. Der Islamismus als neue Form der Vergesellschaftung junger Frauen in Ägypten“. In: ders. u.a. (Hg.), Der neue Islam der Frauen, Bielefeld: Transcript, S. 249-276.

Wielandt, Rotraud (1971): Offenbarung und Geschichte im Islam, Wiesbaden: Steiner.

Wimmer, Andreas (1995): „Interethnische Konflikte. Ein Beitrag zur Integration aktueller Forschungsansätze“. In: Kölner Zeitschrift für Soziologie und Sozialpsychologie 47, S. 464-493. 